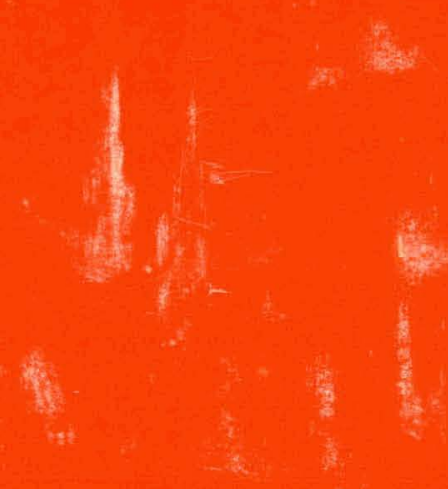

\title{
Simulations and Economic Analyses of Desiccant Cooling Systems
}

Benjamin C. Shelpuk Douglas W. Hooker

Gary J. Jorgensen Carl E. Bingham
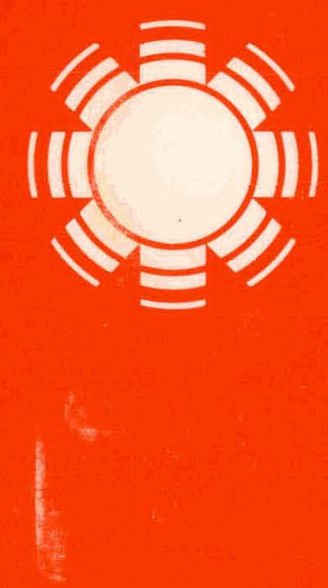

at.

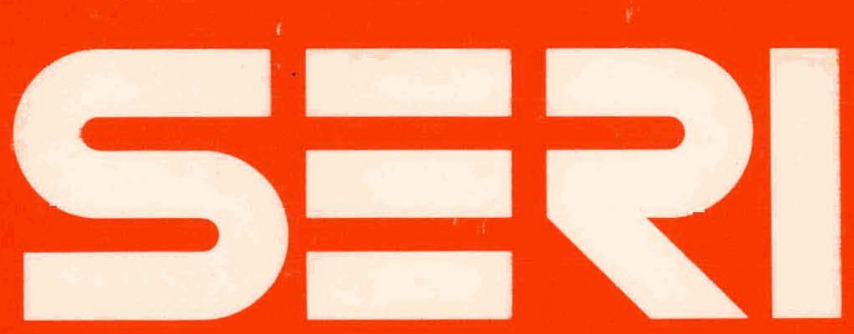

Solar Energy Research Institute A Division of Midwest Research Institute

1536 Cole Boulevard

Golden, Colorado 80401

Operated for the U.S. Department of Ehergy under Contract No. EG-77-C-01-4042 


\section{DISCLAIMER}

This report was prepared as an account of work sponsored by an agency of the United States Government. Neither the United States Government nor any agency Thereof, nor any of their employees, makes any warranty, express or implied, or assumes any legal liability or responsibility for the accuracy, completeness, or usefulness of any information, apparatus, product, or process disclosed, or represents that its use would not infringe privately owned rights. Reference herein to any specific commercial product, process, or service by trade name, trademark, manufacturer, or otherwise does not necessarily constitute or imply its endorsement, recommendation, or favoring by the United States Government or any agency thereof. The views and opinions of authors expressed herein do not necessarily state or reflect those of the United States Government or any agency thereof. 


\section{DISCLAIMER}

Portions of this document may be illegible in electronic image products. Images are produced from the best available original document. 
Printed in the United States of America Available from:

National Technical Information Service

U.S. Department of Commerce

5285 Port Royal Road

Springfield, VA 22161

Price:

Microfiche $\$ 3.00$

Frinted Copy $\$ 9.00$

\section{NOTICE}

This report was prepared as an account of work sponsored by the United States Government. Neither the United States nor the United States Department of Energy, nor any of their employees, nor any of their contractors, subcontractors, or their employees, makes any warranty, express or implied, or assumes any legal liability or responsibility for the accuracy, completeness or usefulness of any information, apparatus, product or process disclosed, or represents that its use would not infringe privately owned rights. 
SER I /TR-34-090

UC CATEGORY: UC-59C

SIMULATIONS AND ECONOMIC

ANALYSES OF DESICCANT

COOLING SYSTEMS

BENJAMIN C. SHELPUK

DOUGLAS $W$. HOOKER.

GARY J. JORGENSEN

CARL E. BINGHAM

JUNE 1979

$r$

This report was prepared as an account of wusk sponsored by the United Sintes Govemmenti Neither the United Suies nor the United States Depertment of Energ nor any of their employees, nor any of thein Energ. nor any or their employees, nor any or their contractors, subcontors, any wartanty, expres or implied, or assues,

liability or responstoily for the accuracy. comple thess

or use fulness of any information, apparatus, product or

process disclosed, or represents that its use would not infringe privately owned rights.

PREPARED UNDER TASK NO. 3134.90

\section{Solar Energy Research Institute}

1536 Cole Boulevard

Golden, Colorado 80401

A Division of Midwest Research Institute

Prepared for the

U.S. Department of Energy

Contract No. EG.77. C $01 \cdot 4042$

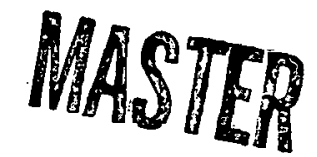


THIS PAGE

WAS INTENTIONALLY

LEFT BLANK 
SEPI率

TR -090

FOREWORD

This report was prepared in compliance with Contract No. EG-77-C01-4042 for the U.S. Department of Energy. It documents a portion of the research output of Task 31.34 .90 in the. Thermal Conversion Branch of the Research Division. The authors would like to recognize the contribution by John Mitchell, a consultant from the University of Wisconsin at Madison, who assisted in the preparations for the computer simulations of solar heating and desiccant cooling systems.

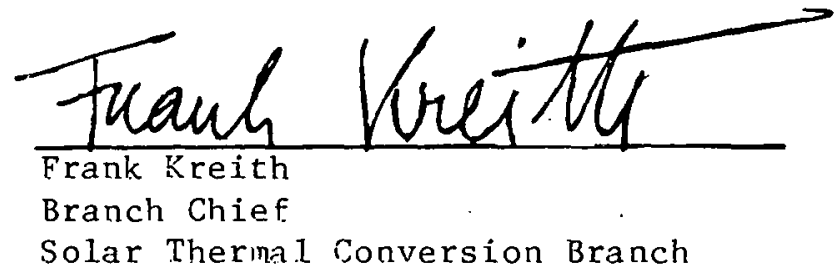

Approved for:

SOLAR ENERGY RESEARCH INSTITUTE

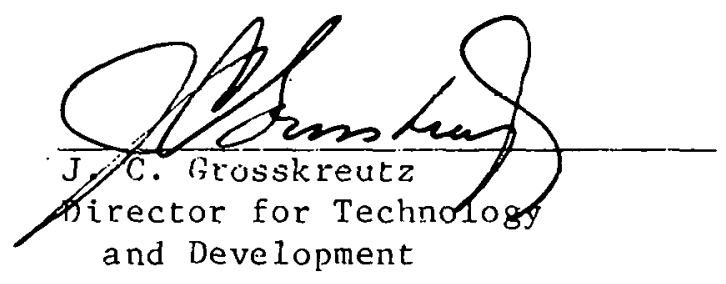

iii 


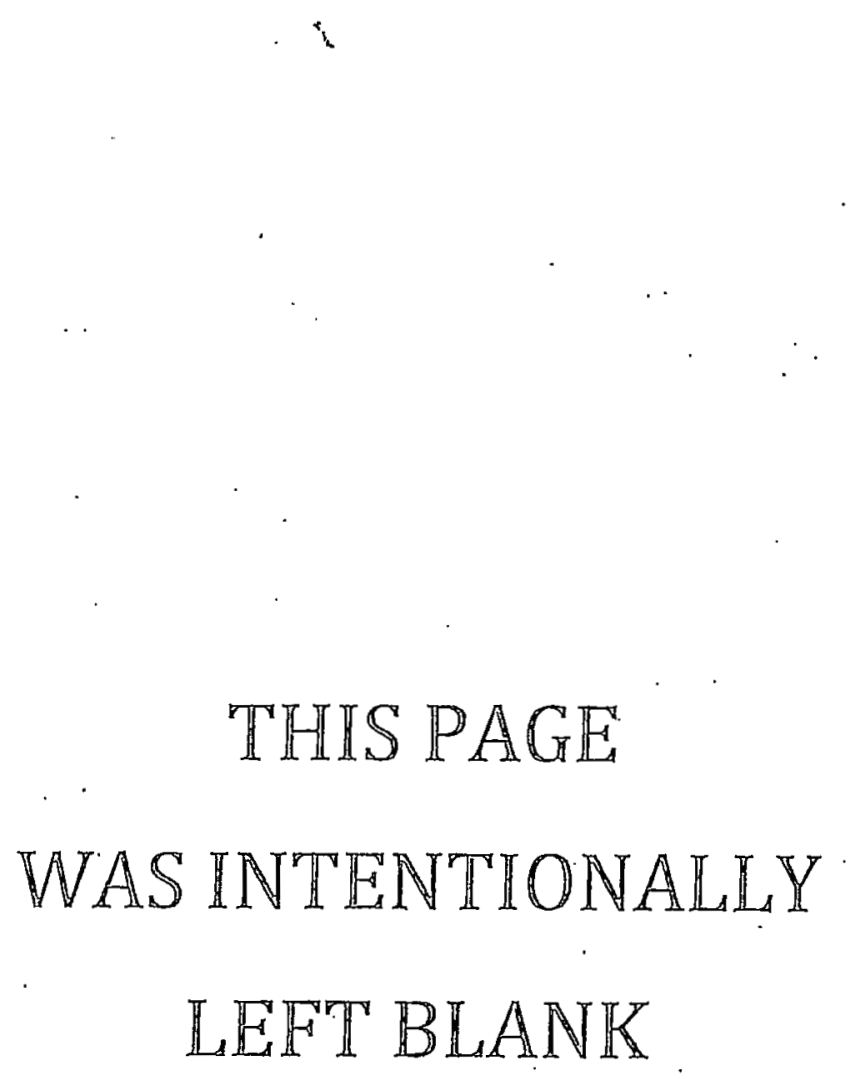




\section{SEMMARY}

This report documents the progress to date in the development and analysis of computer simulations of solar-powered desiccant cooling using an axial-flow disc-type dehumidifier wheel, solar-powered space heating, and electrically driven, standard vapor-compression air-conditioning systems for residential use. Computer simulations for both solar and conventional heating and cooling systems were performed for 12 -month heating and cooling seasons. Annual thermal performance and the resulting life cycle costs for both types of systems were analyzed and compared.

The heating/cooling season simulations were run for five U.S. cities representing a wide range of climatic conditions and insolation. With the information resulting from these simulations, the optimum air-conditioning system was chosen to maximize the conservation of fossil fuels and minimize operating costs. Because of the increasing use of residential air conditioning employing el.ectrically driven vapor-compression coolers, the five locations were studied to determine if it would be beneficial (in terms of both economics and fossil fuel displacement) to displace fossi1-fuel-powered vapor-compression coolers and natural gas sipace heaters with solar-powered heating and desiccant cooling systems.

The overall conclusions include the following:

- solar heating and desiccant cooling systems operate best in climates with nearly balanced heating and cooling loads (Section 3.7.3);

- solar desiccant coolers operate preferentially as dehumidifiers (Sections 3.6.2 and 3.7.3);

- the optimum desiccant cooler size for Washington, D.C., with auxiliary cooling and Lodge City, Kans., without auxiliary cooling is $4.5 \mathrm{~kW}$ with $35-\mathrm{m}^{2}$ collector area (Sections 3.7 .3 and 5.3 );

- under the cost assumptions of Section 5.2, the life-cycle cost for a 20-year solar heating/desiccant cooling system is nearly cost competitive with conventional residential heating and cooling (Section 5.3); and

- adding a desiccant cooler (with or without auxiliary cooling) to a solar heating system can increase fossil fuel displacement (Section 5.3 ) by a factor greater than 2, depending on the location. 
THIS PAGE

\section{WAS INTENTIONALLY LEFT BLANK}


TABLE OF CONTENTS

$\underline{\text { Page }}$

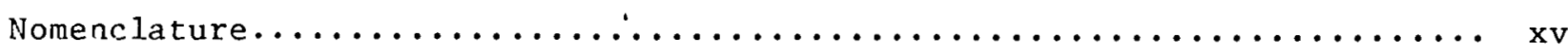

1.0 Introduction $\ldots \ldots \ldots \ldots \ldots \ldots \ldots \ldots \ldots \ldots \ldots \ldots \ldots \ldots \ldots \ldots \ldots \ldots$

1.1 Use of Residential Air Conditioning in the United States...... 2

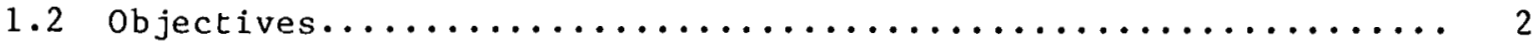

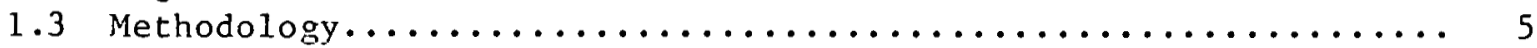

2.0 Desiccant Cooler System Characteristics.................... 9

2.1 Desiccant Cooler Systems........................ 9

2.2 Choice of System for Study $\ldots \ldots \ldots \ldots \ldots \ldots \ldots \ldots \ldots \ldots \ldots \ldots \ldots$

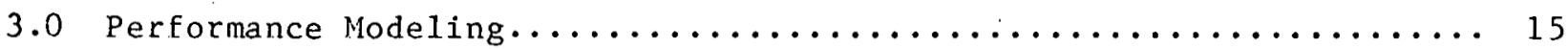

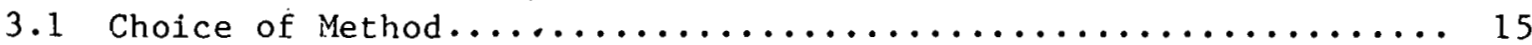

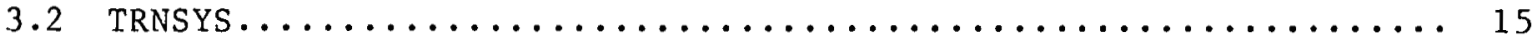

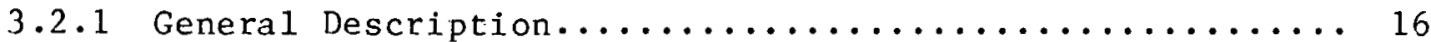

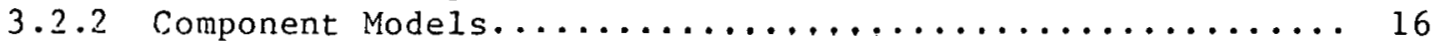

3.2 .3 House Load Mode1.......................... 27

3.3 Desiccant Cooler System Sizing..................... 31

3.4 Definition of House Comfort Conditions.................. 35

3.5 Cooling System Operational Characteristics.............. 37

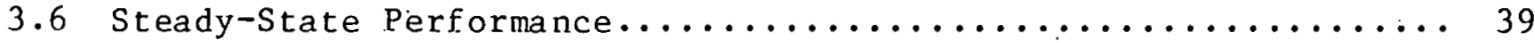

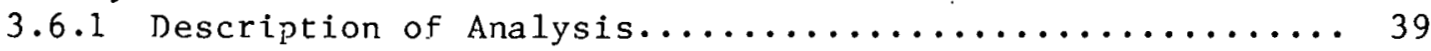

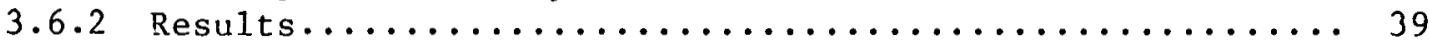

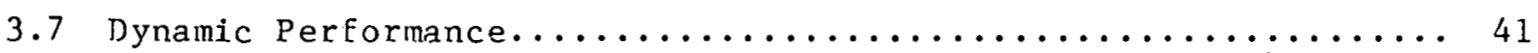

3.7 .1 General Description............................ 41

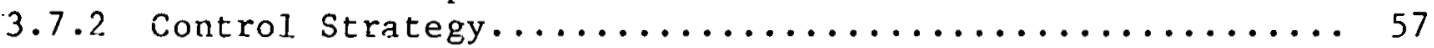

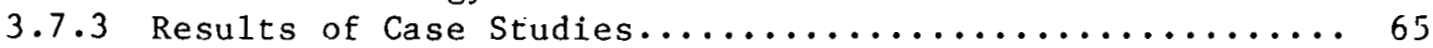

4.0 Standard Vapor-Compression Air-Conditioning Simulation.......... 93

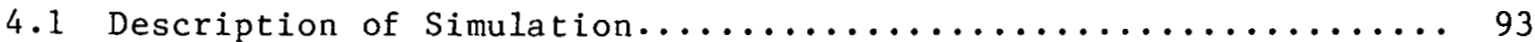

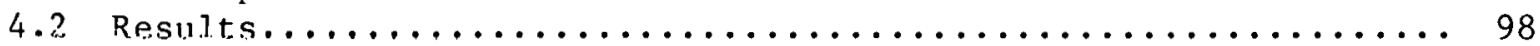

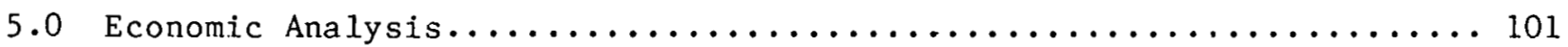

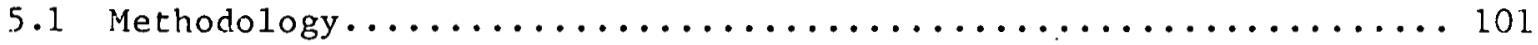

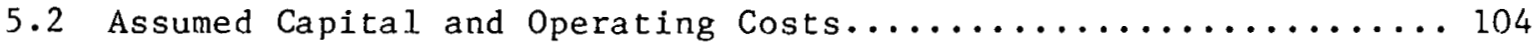

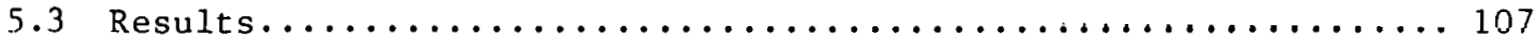

6.0 Conclusions and Recommendations......................... 131

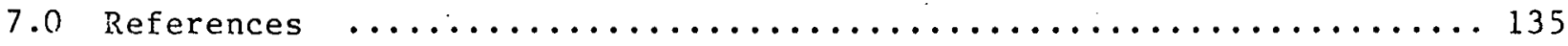


TABLE OF CONTENTS (Conclinded)

Page

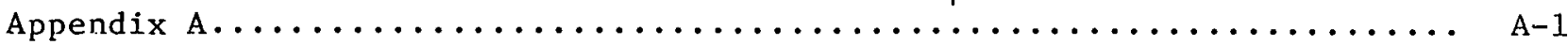

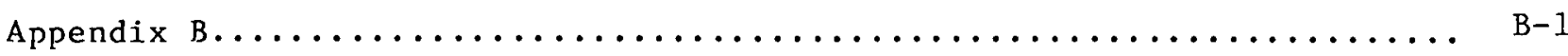

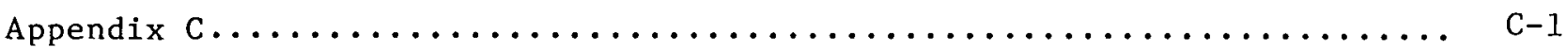

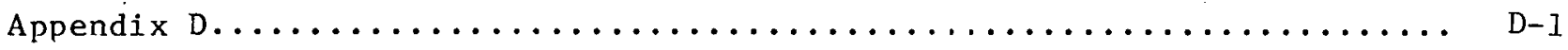




\section{LIST OF FIGURES}

1-1 FEA-Projected Growth in Residential Energy Demand (1970-1990)

by End Use................................... 4

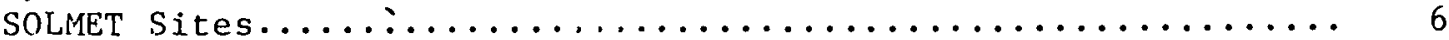

Average Annual Direct Insolation...................... 7

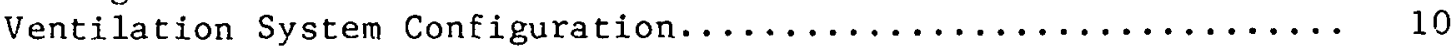

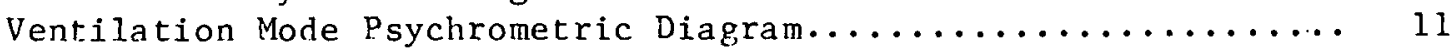

Recirculation System Configuration..................... 12

Recirculaliü Mode Peychrometric Diagram..................13

Desiccant Cooler Component Configuration................. 17

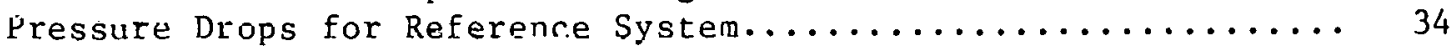

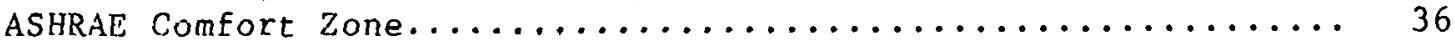

Comfort Zone Used in Computer Simulations................. 38

Configuration of Desiccant System Components Used To Generate

Steady-State Performance Maps......................... 40

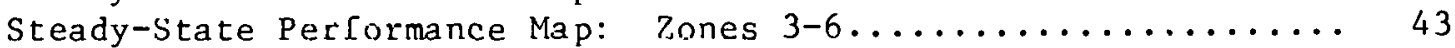

Steady-State Performance Map: Zones $4-6 \ldots \ldots \ldots \ldots \ldots \ldots$

Steady-State Performance Map: Zones $5-6 \ldots \ldots \ldots \ldots \ldots 4$

Steady-State Performance Map: Zones 2-6................ 46

Steady-State Performance Map: Zones $3-4 \ldots \ldots \ldots \ldots 7$

Steady-State Performance Map: Severe Ambient Temperature...... 48

Steady-State Performance Map: Severe Ambient Temperature and dumidity...................................49

Steady-State Performance Map: Mild Ambient Conditions........ 50

Steady-State Sensitivity to Ambient Temperature............. 51

Steady-State Sensitivity to Ambient Humidity............... 52

Steady-State Sensitivity to Room Temperature............... 53

Steady-State Sensitivity to Room Humidity................. 54

Steady-State Sensitivity to Regeneration Temperature.......... 55

Desiccant System Component Configuration for Dynamic

Simulations................................. 56

Diurnal Variation of Ilouse Internal Water Vapor Generation..... 59

Couliol Zonce Based on House Comfort Conditions............ 61

Illustration of Failure to Restore Corfort by

Dehumidification Alone............................. 63

Solar Collector/Storage System Configuration During Heating Season........................................ 69

Performance of Solar System During Heating Season........... 70

Simulated Annual Performances of Solar Desiccant Coolers with Senstble dint Latont Auxi.1iary Coolers in Washington, D.C...... Effect of Design-Point Relative Humidity on (a) CUr and (b) ERR--4.5-kW Cooler with 35-m $\mathrm{m}^{2}$ Collector, with and without Auxiliary Cooling...............................

Effect of Design-Point Relative Humidity on Comfort--4.5-kW

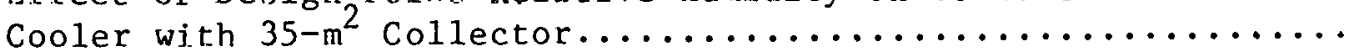

Percentage of Latent Cooling Load Provided by Solar Energy vs. Percentage of Total Cooling Load That Is Latent--4.5-kW Cooler

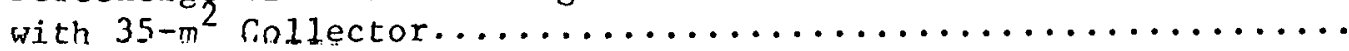
Percentage of Time System Cannot jrovide Cüling Because nf Insufficient Regeneration Temperature $\overline{\mathrm{T}}_{\text {OUT }}$ (Washington, D.C.)... 


\section{LIST OF FIGURES (Continued)}

3-30 Percentage of Time Collector Flowrate $\dot{\mathrm{m}}_{\mathrm{C}}$ Exceeds Desiccant

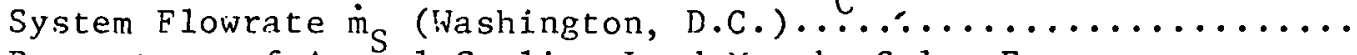

3-31 Percentage of Annual Cooling Load let by Solar Energy (Washington, D.C.; Auxiliary Cooling Supplied).............

3-32 Annual Cooling Supplied by Solar Desiccant Cooler (Washington, D.C.; Auxiliary Cooling Supplied): (a) Sensible Cooling and

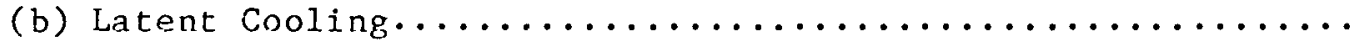

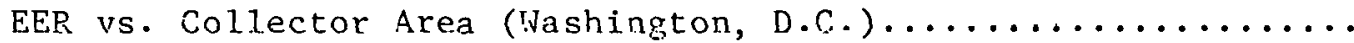

COP vs. Regeneration Temperature $\overline{\mathrm{T}}_{\mathrm{OUT}}$ (Washington, D.C.)......

EER vs. Regencration Temperature $\bar{T}_{\text {OUT }}$ (Washington, D.C.).......

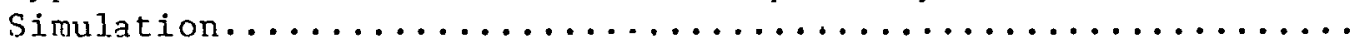

5-7 Fossil Fuel Energy Displaced vs. Collector Area-Dodge City, rans., without Auxiliary Cooling............... Cost/Benefit vs. Collector Area of a 9.0-kW Cooler with Auxiliary in Washington, D.C. (1985 Base Year).............. Cost/Benefit vs. Collector Area of a 4.5-kW Cooler with Auxiliary in Washington, D.C. (1985 Base Year).............. Cost/Benefit vs. Collector Area of a 2.3-kW Cooler with Auxiljary in Washington, D.C. (1985 Base Year).............

5-13 Cost/Benefit vs. Fossil Fuel Energy Displaced by a 2.3-ki Cooler with Auxiliary at Various Collector Areas and Costs in

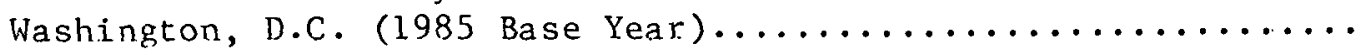




\section{LIST OF PIGURES (Concluded)}

Page

5-14 Cost/Benefit vs. Collector Area of a 9.0-kW Cooler without Auxiliary in Dodge City (1985 Base Year)................ 122

5-15 Cost Benefit vs. Collector Area of a 4.5-kW Cooler without Auxiliary in Dodge City (1985 Base Year)............... 123

5-16 Cost/Benefit vs. Collector Area of a 2.3-kW Cooler without Auxiliary in Dodge City (1985 Base Year)................. 124

5-17 Cost/Benefit vs. Collector Area of Heating and Cooling Systems of Various Sizes and Costs in Dodge Cily (1985 Base Year; Washington, D.C., Energy Costs)............ 125

5-18 Cost/Benefit vs. Fossil Fuel Energy Displaced by a 9.0-kw Cooler without Auxiliary at Various Collector Areas and Costs

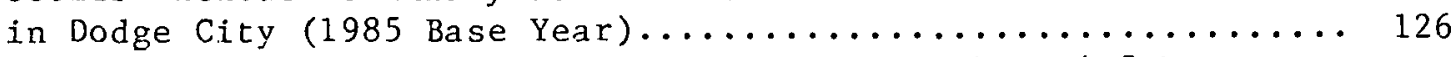

5-19 Cost/Benefit vs. Fossil Fuel Energy Displaced by a 4.5-kW Cooler without Auxiliary at Various Collector Areas and Costs

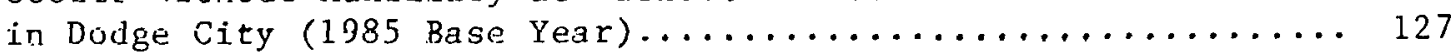

5-20 Cost/Benefit vs. Fossil Fuel Energy Displaced by a 2.3-ki Cooler without Auxiliary at Various Collector Areas and Costs

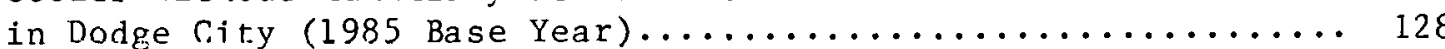


THIS PAGE

\section{WAS INTENTIONALLY LEFT BLANK}




\section{LIST OF TABLES}

Page

1-1 Potential Air-Conditioning Processes..................... 1

1-2 Residential Consumption of Natural Gas and Electricity by End Use... 3

1-3 Climatic Design Conditions.......................... 5

3-1 Parameters and Inputs for Air Collector/Storage System............ 19

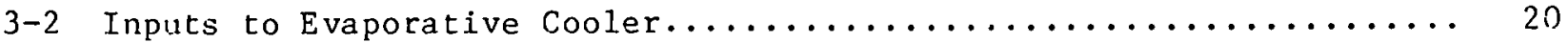

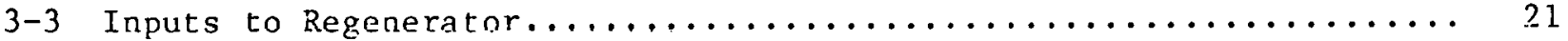

3-4 Parameters and Inpuls for Dehumidifier.................... 23

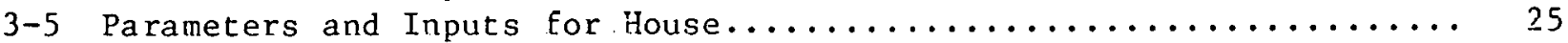

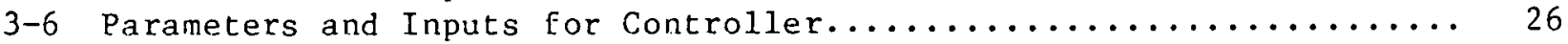

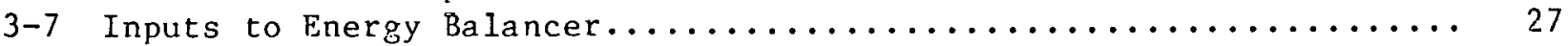

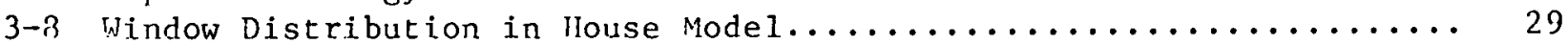

3-9 Seasonal Load Assumptions.......................... 30

3-10 Collector/Storage Size Combinations..................... 31

3-11 Cooler-Size/Air-F lowrate Combinations................... 32

3-12 Desiccant-Cooler-Size/wheel-Diameter Combinations............. 35

3-13 Performance Map Parameter Summary..................... 42

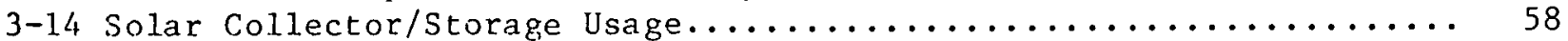

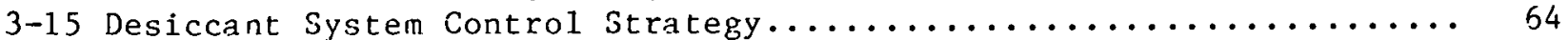

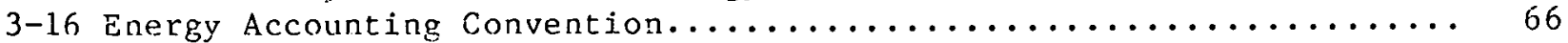

3-17 Parameters Used in Desiccant Cooler Simulations............... 68

3-18 Percentage of Heating Load Supplied by Solar Energy........... 71

3-19 Annual Desiccant System Performance................... 72

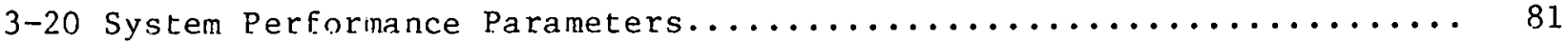

4-1 Summary of Input Parameters for Vapor-Compression

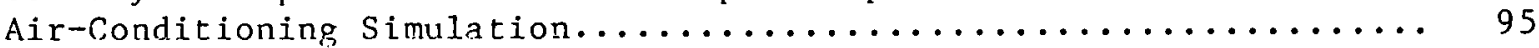

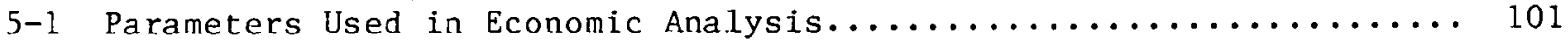

5-2 Equipment-Related Costs Used in Economic Analysis for

Determination of Life-Cycle Present Worth and Cost/Benefit

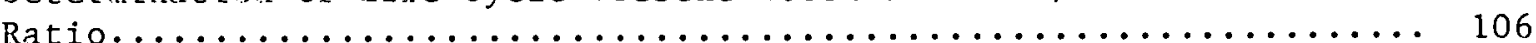

5-3 Electricity and Natural Gas Rates for Residential Buildings....... 106 


\section{THIS PAGE}

\section{WAS INTENTIONALLY LEFT BLANK}




\section{NOMENCLATURE}

A

Dutside wall area of house

$A_{c}$

Ceiling area of house

$A_{W}$

Window a rea of house

ASHRAE

American Society of Heating, Refrigerating, and Air Conditioning Engineers

AUX Auxiliary cooling

$b_{n}$

Transfer function coefficient for temperature terms, house load mode 1

CAP Thermal house capacitance

CFM Fan air flowrate

COP Coefficient of performance

Cpa

G pw

$d_{n}$

DT

$\varepsilon$

Specific heat of dry air

Specific heat of water

Transfer function coefficient for heat flux terms, house load model

Temperature dead band for collector

Evaporative cooler effectiveness

$\varepsilon_{\text {i. }}$

$\varepsilon_{0}$

E

EER

Inlet evaporative cooler effectiveness

Outlet evaporative cooler effectiveness

Fan efficiency

FRACT

Energy efficiency ratio

$\mathrm{F}_{\mathrm{S}}$

Mass fraction of airflow that is dry

$\mathrm{H}_{\mathrm{fg}}$

Shading fraction

$\mathrm{H}_{\mathrm{T}}$

Heat of vaporization of water

$\mathrm{H}_{\mathrm{TW}}$

Solar radiation

i

Solar radiation on windows

INF

Discount rate

LAT

House air infiltration rate

$\dot{\mathrm{m}}_{\mathrm{C}}$

Latent house load

Collector system air flowrate

$\dot{\mathrm{m}}_{\mathrm{L}}$

Desiccant cooler system air flowrate

$\dot{\mathrm{m}}_{\mathrm{S}}$

Desiccant cooler system design atr flowrate

$\mathrm{m}_{\mathrm{T}}$

Total mass of dry air and water vapor in house

MODEH

Heating/cooling molecindicator 


\section{NOMENCLATURE (Continued)}

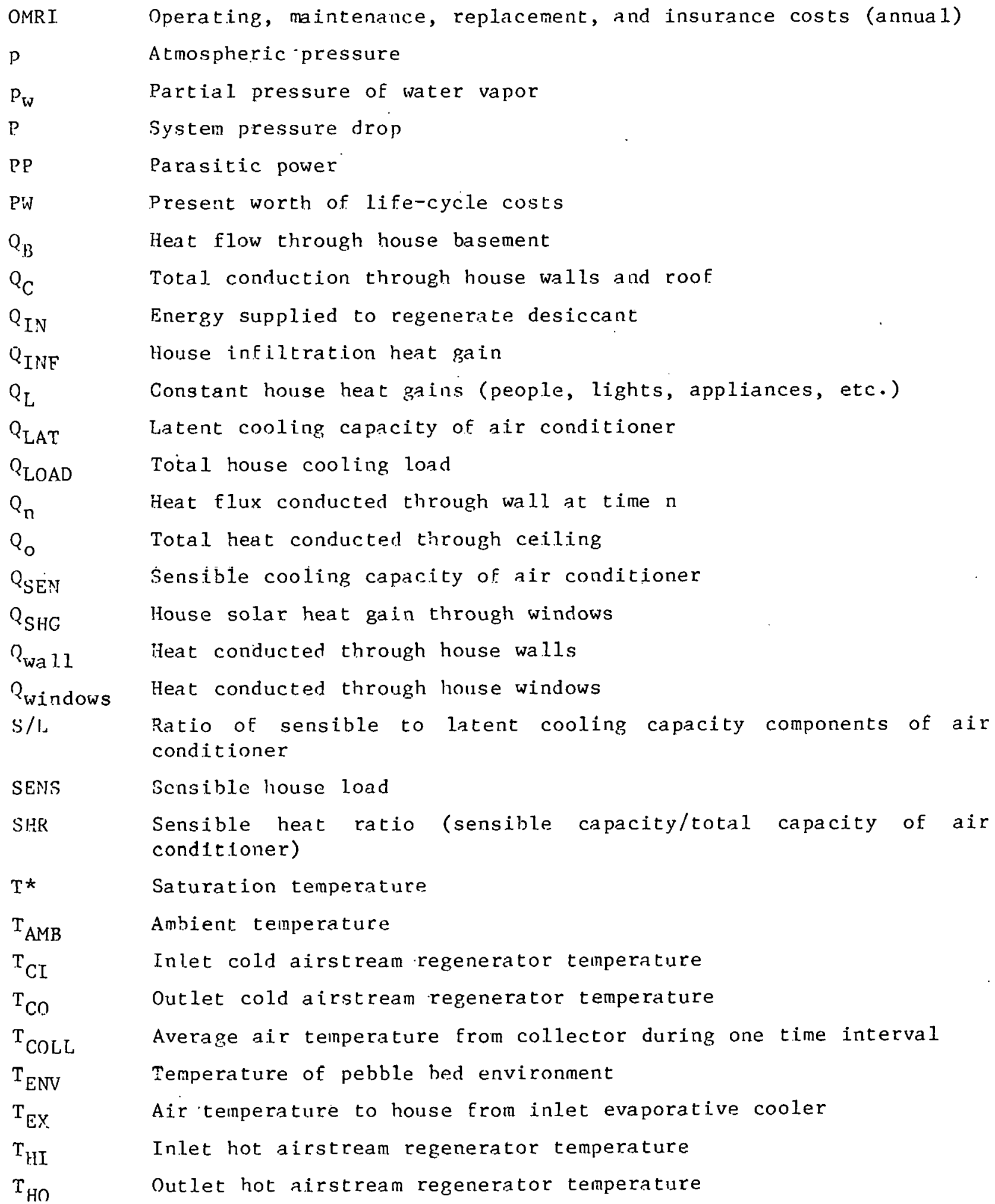




\section{NOMENCLATURE (Concluded)}

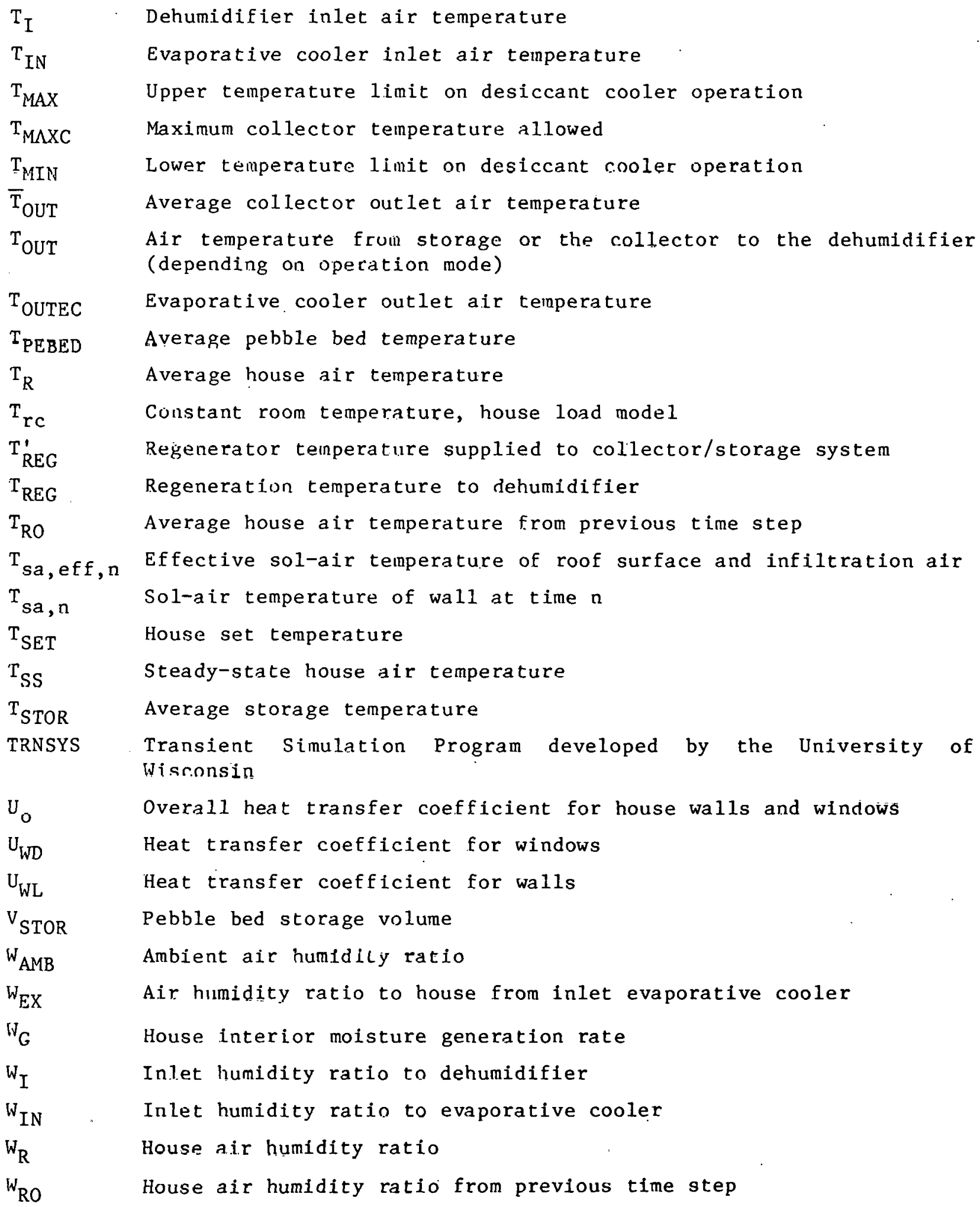


SECTION $\mathbb{1} .0$

INTRODUCTION

This study evaluated residential solar desiccant cooling potential in order to identify optimum system configurations, climatic conditions, and economic parameters. In addition, since the U.S. Department of Energy (DOE) has given SERI the responsibility for managing the national solar cooling programs using desiccant processes, the system simulation techniques and analysis methods will be useful in evaluating other DOE contractor desiccant cooling systems.

Several air-conditioning configurations involving different physical, chemfcal, and electrical processes can be utilized to produce cooling effects that are adequate for residential bulldings. These processes are summarized in Table 1-1.

Table 1-1. POTENTLAL AIR-CONDITIONING PROCESSES

\begin{tabular}{|c|c|c|}
\hline Process & Open Cycle & Closed Cycle \\
\hline Mechanical compression & Air cycle & $\begin{array}{l}\text { Rankine cycle } \\
\text { Brayton } \\
\text { Stirling }\end{array}$ \\
\hline Absorption & Desiccant & Absorption \\
\hline Adsorption & Desiccant & Adsorption \\
\hline Electronic transport & $\begin{array}{r}\text { Thermionic } \\
\text { emission }\end{array}$ & Peltier effect \\
\hline
\end{tabular}

The processes can be implemented in open or closed cycles. The closed cycle involves two separate process loops coupled by heat exchangers, with one loop for the refrigeration process and the other for the transfer of heat from the 1nad. The open-cycle implementation eliminates the need for an interfacing heat exchanger by combining the refrigeration and heat transfer loops.

The open-cycle adsorption desiccant process represents an attractive alternative to conventional air-conditioning systems when coupled with a solar energy supply system. Most existing refrigeration and a1r-conditioning equipment operates on a closed mechanical compression cycle, spectfically the Rankine vapor-compression cycle. There are several major advantages of a solar desiccant cooler based on a recyclable air desiccation process:

- It uses inexpensive materials and has potential to be manufactured at Low cost.

- It uses air and inert inorganic materials and thus will not present corrosion or environmental problems.

- It can tolerate air leakage and be easily serviced, thus making its maintainability and rellability ateractive.

- It can tolerate a wide range in solar input and st111 generate a usable output. 
The potential for residential use of a solar desiccant cooler (using a silica gel desiccant) instead of an electrically driven, Rankine vapor-compression cycle unit was investigated in this study.

\section{1 .1 USE OF RESIDENTIAL AIR CONDITIONING IN THE UNITED STATES}

According l:n the Federa]. Energy Administration (FEA) "Project Independence Report", residential buildings used approximately $70 \%$ of the 18.1 quads of energy consumed in the Household and Commercial Sector in 1972 (as defined by FEA, this sector accounts for $32 \%$ of all energy used in the United States) [1]. Of the roughly 12.7 quads used in residential buildings, about $72 \%(9.0$ quads) was used for heating, cooling, and ventilation. Tabie 1-2 shows the growth in residential consumption of natural gas and electricity by end use For the period 1960-1968 [2].

Figure 1-1 illustrates FEA projections for growth in energy demand in the residential sector through 1990 by the major end uses. Although space heating, dominates the energy used in residential huildings, air conditioning is projected to increase in energy use at an annual. compound growth rate larger than for any other use. It is projected that by 1990 residential space heating and air conditioning will consume over 11 quads of energy, most of which will be obtained from fossil fuels. FEA stated that energy conservation measures to inprove the thermal efficiency of both new and existing housing will be required to reduce residential energy demand [1]. The use of solar. energy in residential space heating and air conditioning could have a significant impact on the displacement of fossil fuel in residential use.

\subsection{OBJECTIVES}

This study was initiated to evaluate the potential for solar desiccant air conditioning in terms of system performance and potential fossil fuel displacement. Although some work in the development of desiccant cooling has been performed, the interaction of the system components and their seasonal operation still require study, particularly when additional system operating complexities are introduced with solar power.

The portion of the task that is covered by this report involved the examination of one particular solar desiccant system configuration (see Section 2.2) in several different geographical. locations. The overall objectives were:

- to determine the optimum use of solar desiccant coolers for particular climates (i.e., optimum cooler size, collector area, etc.);

- to determine the optimum size combination of a solar desiccant cooler and auxiliary vapor-compression cooler;

- to determine the total cost of a solar desiccant cooler versus a vapor-compression cooler; 
Table 1-2. RESIDENTIAL CONSUMPTION OF NATURAL GAS AND ELECTRICITY BY END USE (Trillions of Btu) 1960-196\& 【2】

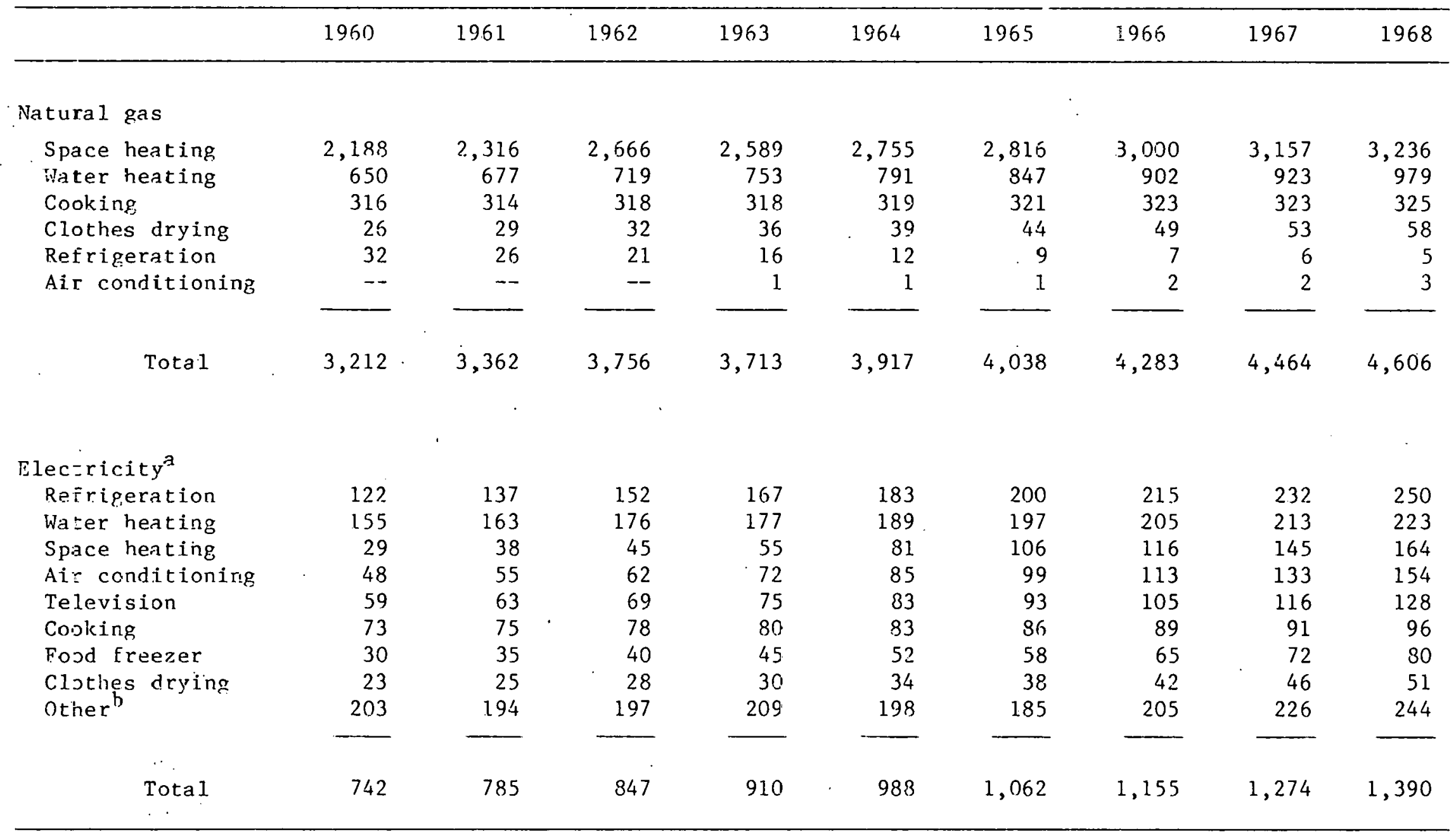

at 3,413 Btu/kinh

bish'vashers, wasting machines, miscellaneous small appliances, and lighting 


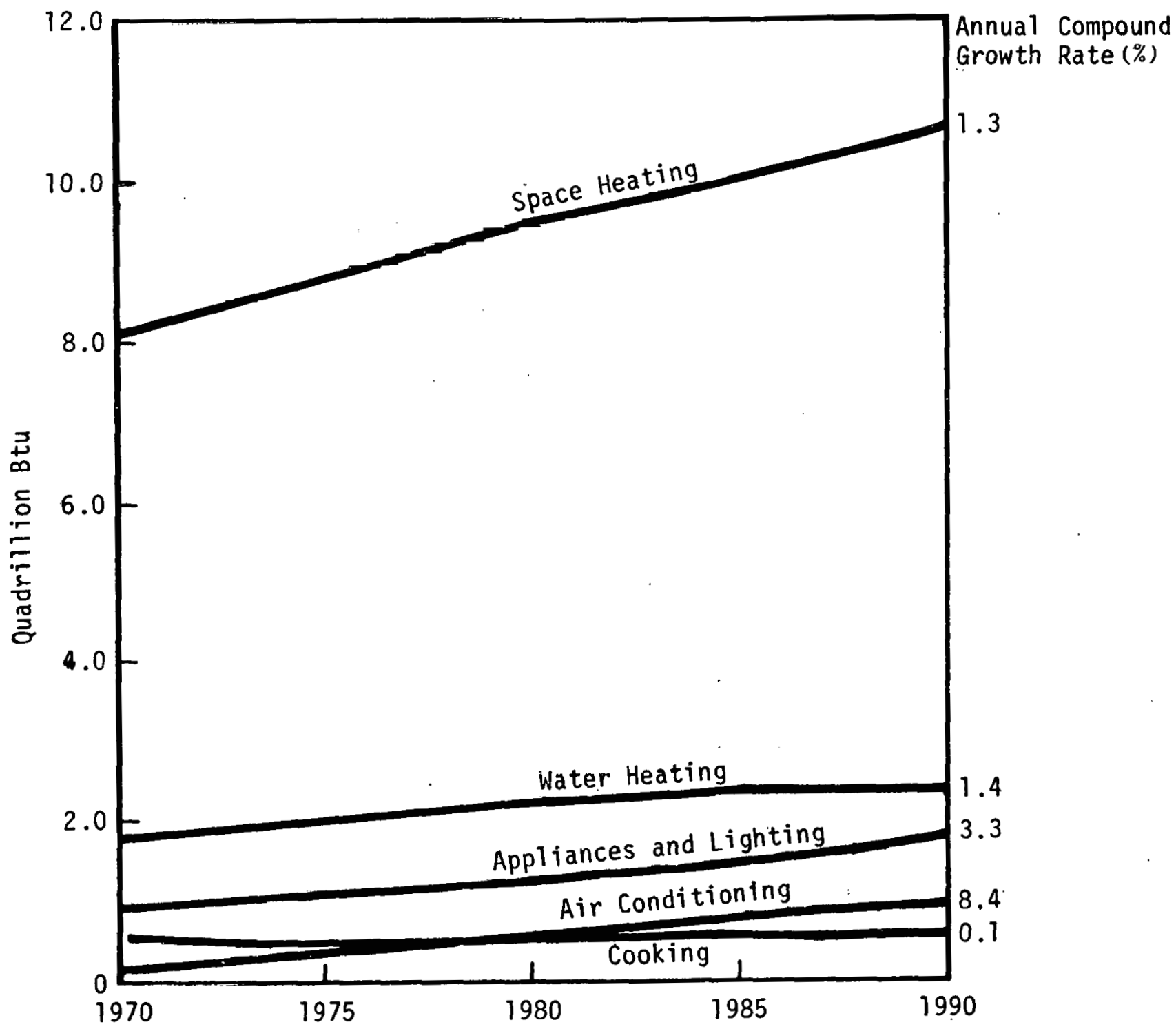

Figure 1-1. FEA-PROJECTED GROWTH IN RESIDENTIAL ENERGY DEMAND (1970-1990) .BY END USE [1] (Note: Electricity measured at point-of-entry) 
- to determine the potential for displacement of fossil fuel energy with a solar heating and desiccant cooling system; and

- to compare the cost and fossil fuel displacement of solar heating systems versus combined solar-heating/dessiccant-cooling systems.

In addition, DOE has given SERI the program managenent responsibilities for national solar cooling programs using desiccant processes. The techniques developed in this task will be useful in evaluating and comparing solar desiccant cooling systeins developed by other DOE contractors.

\subsection{METHODOLOGY}

In order to achieve the stated objectives, the primary need was for computer models to simulate the annual operating performance of solar desiccant and vapor-compression coolers. A computer program to perform the economic analysis based on the results of the seasonal simulations was also required.

For the solar desiccant cooler simulation, it was decided to utilize TRNSYS, a transient simulation computer program developed by the University of Wisconsin at Madison [3]. The standard TRNSYS routines in conjunction with several special routines developed for desiccant cooler components [4] enabled seasonal simulations to be performed. For this study, certain TRNSYS routines were modified as described in Section 3.2 .

To perform the vapor-compression cooler seasonal simulation and the economic analyses for both types of coolers, some additional computer programs (separate from TRNSYS) were developed specifically for this study.

Finally, appropriate sites had to be chosen for the simulations. SOLMET cities were chosen for study because of the availability of hourly meteorological data for use in the computer models. From the sites shown in Figure 1-2, the following five cities were chosen: Charleston, S. C.; Dodge City, Kans.; Ft. Worth, Tex.; Phoenix, Ariz.; and Washington, D.C. These five cities represent a large variation in insolation and climatic conditions. The annual insolation for the sites is shown in Figure 1-3, with climat1c design conditions shown in Table 1-3.

Table 1-3. CLIMATIC DESIGN CONDITIONS

Normal Annual Degree Days [5]

$18.3^{\circ} \mathrm{C}$ Base

\begin{tabular}{|c|c|c|c|c|}
\hline Location & Heating & Cooling & $\begin{array}{l}\text { Dry-bulb } \\
\text { Temp. }\left({ }^{\circ} \mathrm{C}\right)\end{array}$ & $\begin{array}{l}\text { Wet-buib } \\
\text { Temp. }\left({ }^{\circ} \mathrm{C}\right)\end{array}$ \\
\hline Charleston, S.C. & 2146 & 2078 & 34.4 & 27.2 \\
\hline Dodge City, Kans. & 5046 & 1411 & 37.8 & 23.3 \\
\hline Ft. Worth, Tex. & 2382 & 2587 & 38.3 & 25.6 \\
\hline Phoenix, Ariz. & 1552 & 3508 & 42.8 & $24.4^{\circ}$ \\
\hline Washington, D.C. & 4211 & 1415 & 33.9 & 25.6 \\
\hline
\end{tabular}




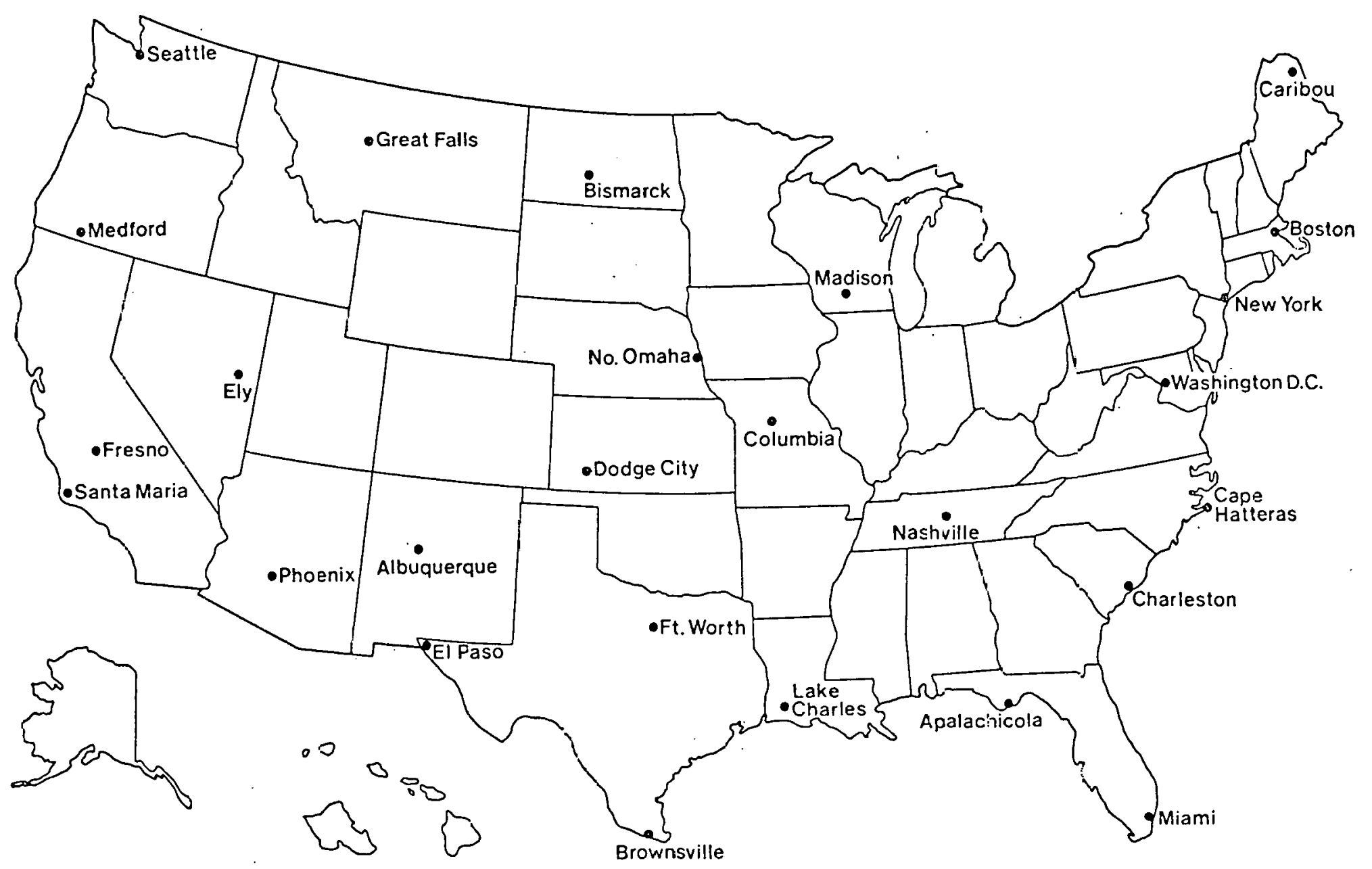

Figure 1-2。 SOLMET SITES 


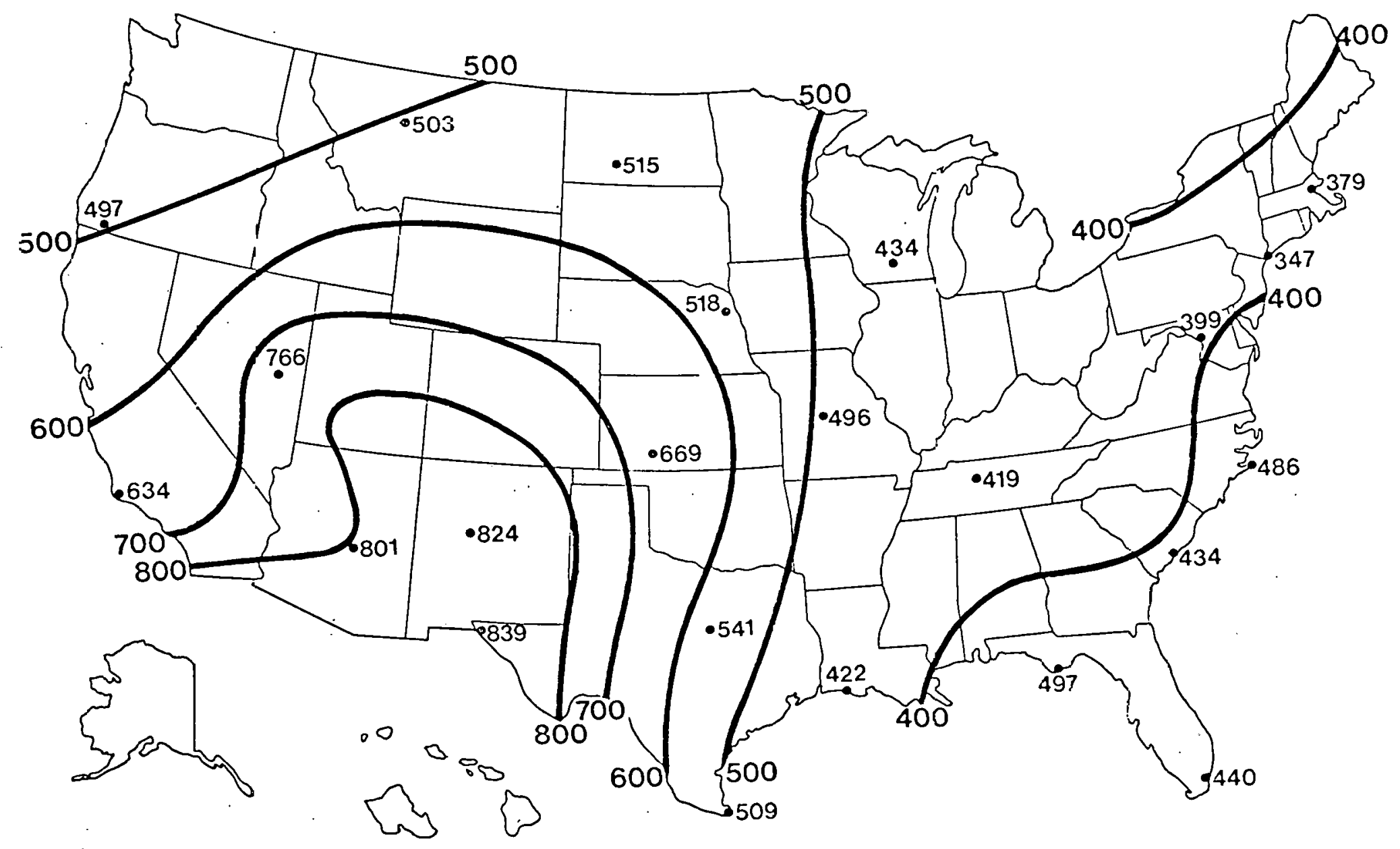

Figure 1-3. AVERAGE ANNUAL DIRECT INSOLATION (In Thousands of Btu/Ft² $\mathrm{Yr}$ ) [7] 
SEP1 
SECTION 2.0

\section{DESICCANT COOLER SYSTEM CHARACTERISTICS}

Several desiccant cooler system configurations have been proposed by various organizations. These system concepts utilize different airflow configurations, dehumidifier designs, desiccant materials, and regenerative heat exchangers. Only desiccant cooler systems that could be simulated with existing TRNSYS routines were considered in this initial study. This section describes two open-cycle desiccant cooler configurations that could be modeled using existing TRNSYS routines and then discusses the choice for this study.

\subsection{DESICCANT COOLER SYSTEMS}

Most of the research and development for application of the adsorption process to solar cooling has been with the open desiccant cycle. The early work was done in Australia [Commonwealth Scientific and Industrial Research Organization (CSIRO)] and the United States [Institute of Gas Technology (IGT)]. The systems used two open process airstreams which were thermally coupled through rotary regenerators. The building airstream was dried in a desiccant bed, cooled in a regenerative heat exchanger, and refrigerated by evaporative cooling. The air drier was reactivated by an outside airstream that was solar heated to supply the desorption energy. The IGT approach, called Solar-MEC, required a gas-fired boost to achieve the requiren levels of desorption. In both systems, the desiccant bed operated as an adiabatic process.

The two system configurations used for this study operate in the ventilation and recirculation modes. The ventilation mode introduces ambient air into the conditioned space, while the recirculation mode recirculates air from the conditioned space. Both systems use the same components; the only differences are in the ducting and airflow paths.

The ventilation system configuration is shown in Figure 2-1. In the supply stream, ambient air is dehumidified, sensibly cooled, evaporalively cooled, and then introduced into the conditioned space. Air removed from the conditioned space is used in the regenerating stream, where it is first evaporatively cooled, then heated as it cools the supply stream, heated again by solar energy, cooled and humidified by the dehumidifier, and finally exhausted to the ambient air. This process is illustrated on the psychromeliic diagram of Figure 2-2. (The numbers correspond to the bulk airstream conditions at the numbered system locations shown in F1gure 2-1,)

For the recirculation system configuration, illustrated in Figure 2-3, the supply and regenerating airflow streams are separate. The supply streain air is removed from the conditioned space, dehumidified, sensibly cooled, evaporatively cooled, and then reintroduced into the conditioned space. In the regenerating stream, ambient air is evaporatively cooled, then heated as it cools the supply stream, heated again by solar energy, humidified and cooled as it regenerates the dehumidifier, and exhausted to the ambient air. This process is shown on a psychrometric plot in Figure 2-4; again, the 


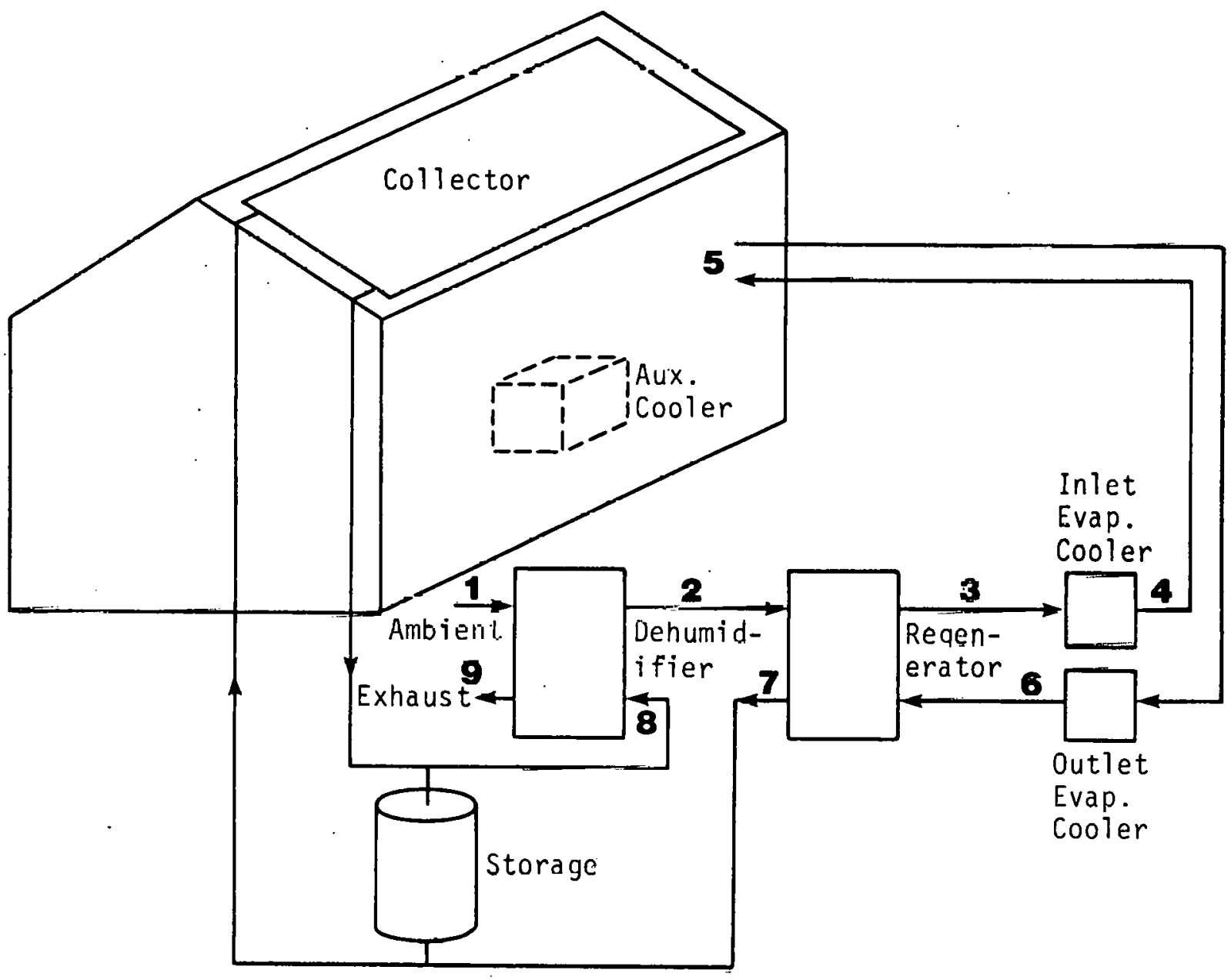

Figure 2-1. VENTILATION SYSTEM CONFIGURATION 


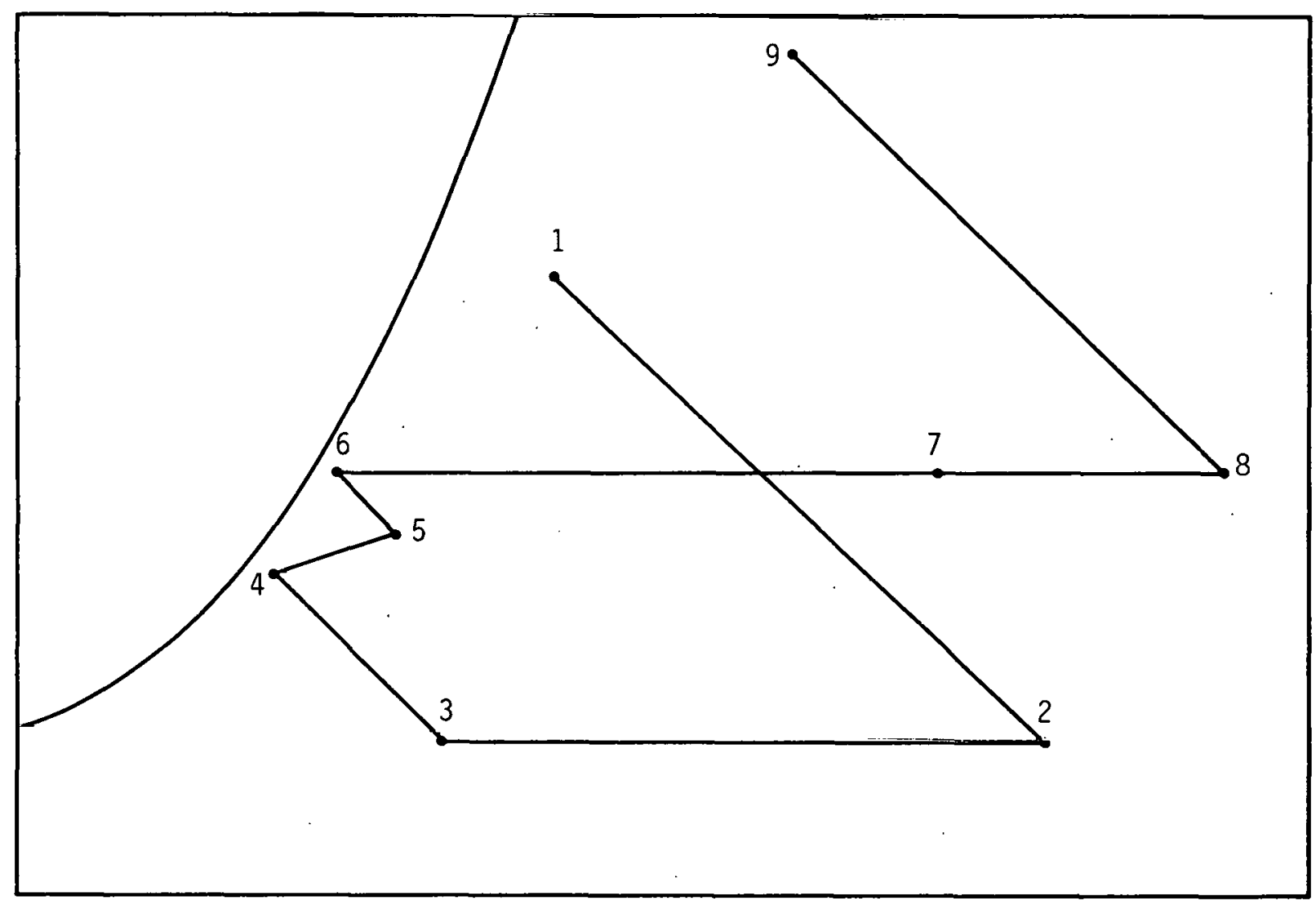

Absolute

Humidity

Dry Bulb Temperature

Figure 2-2. VENTILATION MODE PSYCHROMETRIC DIAGRAM 


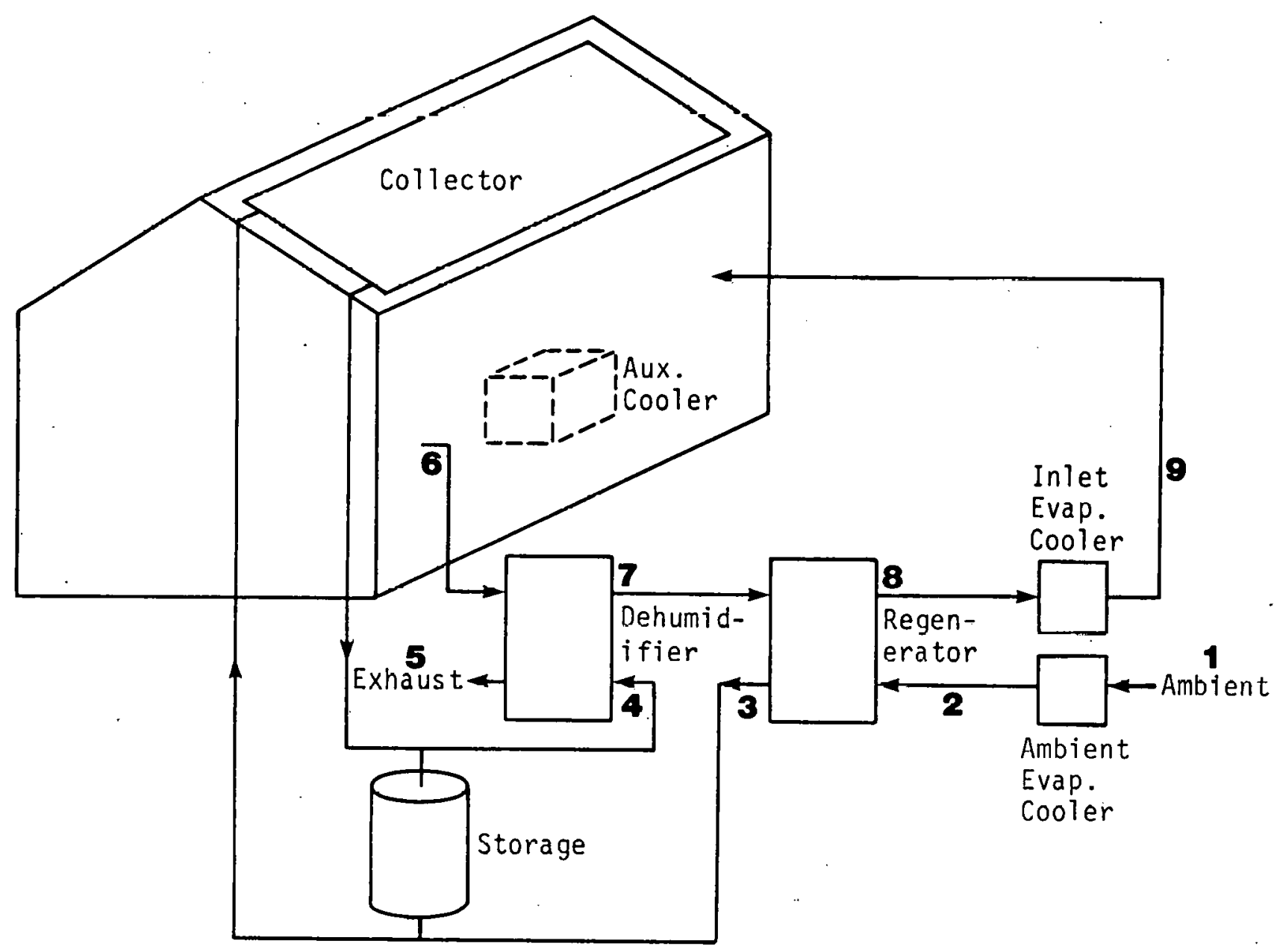

Figure 2-3. RECIRCULATION SYSTEM CONFIGURATION 


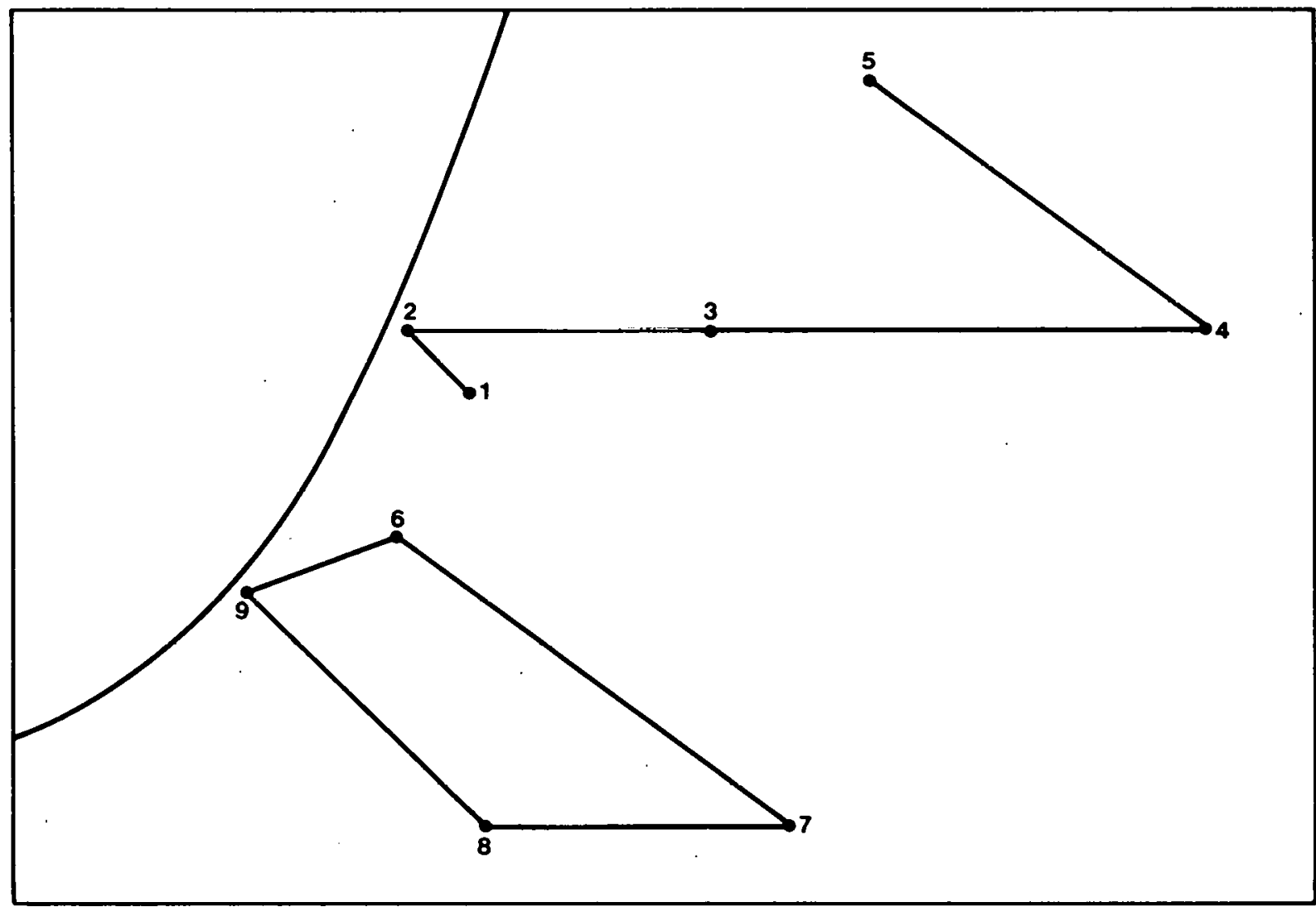

Absolute

Humi dity

Dry Bulb Temperature

Figure 2-4. RECIRULATION MODE PSYCHROMETRIC DIAGRAM 
numbers correspond to the bulk air properties at the system locations shown in Figure 2-3.

\subsection{CHOICE OF SYSTEM FOR STUDY}

Both the ventilation and recirculation modes were examined in previous studies $[4,9]$. It was found that the ventilation mode generally required less thermal energy input per unit of cooling output than the recirculation mode. However, it was also found that the recirculation mode was able to use thermal energy at a lower cemperature than the ventilation mode. The lower operating temperature resulted in less electrical energy input for auxiliary cooling because solar desiccant cooling could be used more often.

Since a major objective of this study was to determine the potential for fossil fuel conservation, the recirculation mode was chosen for further examination. It is possible that, depending on local climate and energy costs, the ventilation mode could be superior to the recirculation mode in a particular location. For this initial study, however, no comparisons were made between these two modes. Thus, Figures 2-3 and 2-4 describe the basic desiccant cooling system used in this study. 


\section{SECTION 3.0}

\section{PERPORMANCE MODELING}

\subsection{CHOICE OF METHOD}

Evaluation of desiccant system performance necessitates a study of the transient response of the house air state driven by external weather conditions, solar insolation, and machine operation. A steady-state analysis is inadequate because insufficient information is avallable that relates dynamic interaction of the desiccant cooling system with varying solar collector/storage energy output and ambient conditions. The effect of varying solar output, which would not be detected in a limited number of steady-state analyses, is discussed in Section 3.7.3.

Although several desiccant units presently exist or are under development [10-1.2]; it was deemed beneficial to provide an indication of system feasibility using computer simulations. Precise modeling required detailed mathematical descriptions of all elements of the system and the capability of accurately predicting the dynamic behavior of component interaction. Yearly simulations were chosen to determine the annual performance of a solarheating/desiccant-cooling system and compare it with the annual performance of a conventional heating and vapor-compression cooling system.

Computer programs that model desiccant coolers were developed previously. Airesearch, for example, uses a finite difference regression analysis of observed data to predict the system response to various sets of ambient and controlled space conditions. Average system performance can then be determined for the cooling season. This model does not meet the requirement of predicting dynamic behavior. Another model, written by the Institute of Gas Technology, is extremely detailed but runs in real time and is thus not appropriate for seasonal simulations.

The only simulation program avallable at the time this study began that modeled desiccant systems in the desired manner was software developed by the University of Wisconsin which was compatible with TRNSYS [3]. TRNSYS provided a framework for long term simulations run at short time step increments. An interface with meteorological data was provided, and the investigation of transient response was facilitated because TRNSYS was designed for the transient case. Furthermore, published results of previous desiccant system simulations using the TRNSYS software are avallable for comparison [4, 9]. Incorporation of other dehumidifier models with TRNSYS are possible and thereby allow direct comparisons of various desiccant dehumidifier units.

\subsection{TRISYS}

The remainder of Section 3.0 (other than 3.6.2 and 3.7.3) provides an in-depth discussion of the various components of the computer model used in this study. A detailed understanding of this information is not required to interpret the results of the simulations. Complete treatments of these results are presented in Sections 3.6 .2 and 3.7.3. 


\subsubsection{Genera1 Description}

The TRNSYS program consists of several subroutines, each describing components of a solar energy system (e.g., collectors, pumps, storage). The program is driven by hourly meteorological data. An executive routine calls the component subroutines as necessary to simulate the transient conditions of the solar energy system. This modular approach reduces the complexity of modeling but increases the cost of computation, especially for long term simulations. Due to these high costs, TRNSYS is not useful as a design tool.

TRNSYS is quite useful, however, as a research tool when studying the transients involved in a particular design, as in the present case for a desiccant cooling system. Because the standard TRNSYS library does not Include many of the components in a destccant cooling system, these subroutines had to be developed. The basis desiccant component subroutines were developed by John S. Nelson [4]. Modifications were made to the routines as required for this study. The control strategy was overhauled and is discussed in detail in Section 3.7.2.

\subsubsection{Component Mode1s}

The following subroutines were developed or modified to simulate the desiccant system:

- air collector/storage system,

- humidity converter,

- evaporative cooler,

- regenerator,

- dehumidifier,

- house,

- controller, and

- energy balancer.

The components were interconnected as shown in Figure 3-1.

\subsubsection{Air Collector/Storage System}

This model was developed by SERI from the original TRNSYS Type-22 air collector/storage routine. The modeled system consists of:

- flat-plate solar air collector,

- domestic hot water crossflow heat exchanger (not used),

- pebble bed storage unit,

- blower with differential temperature controller, and

- dampers to control flow stream. 


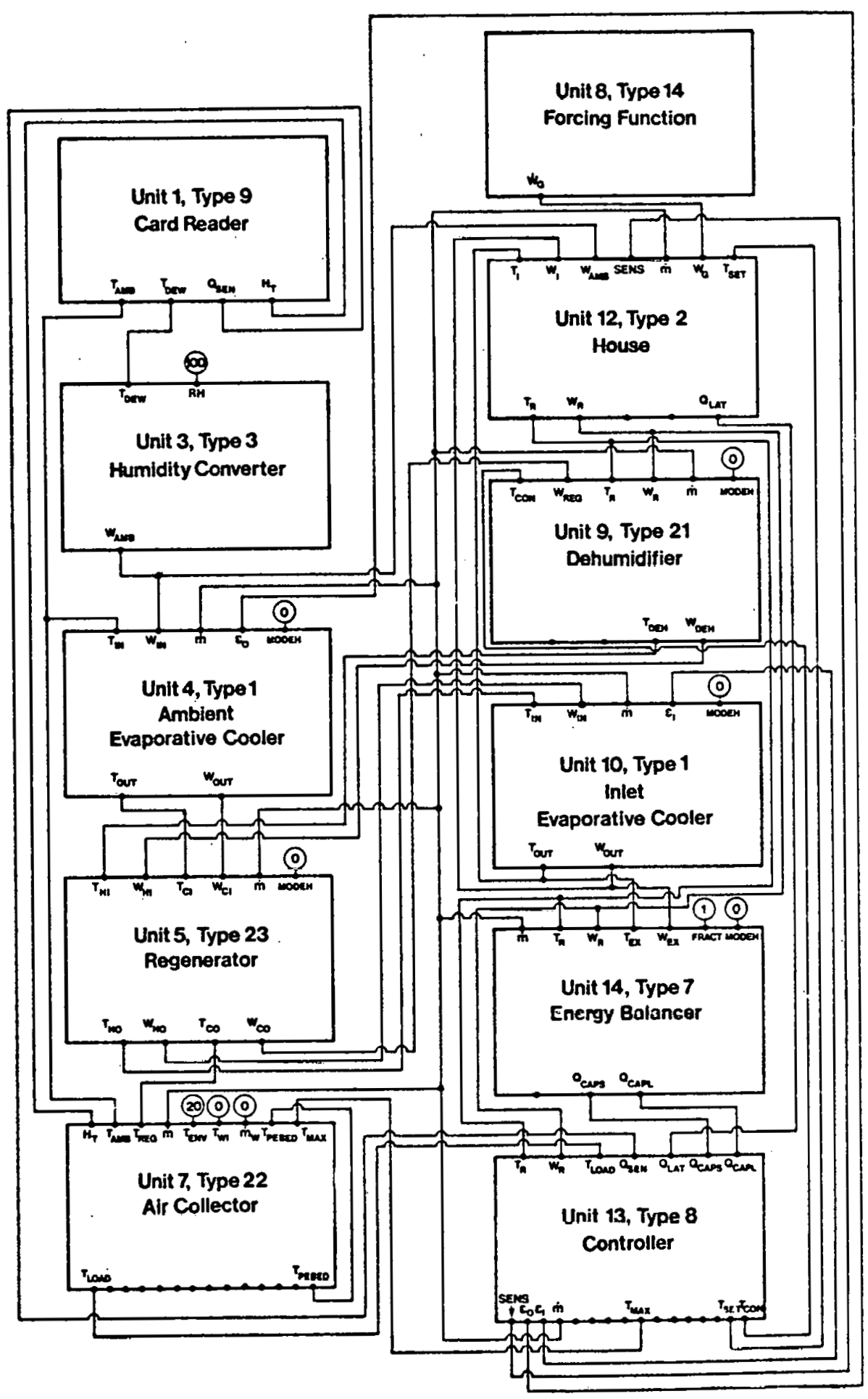

Figure 3-1. DESICCANT COOLER COMPONENT CONFIGIIRATION 
The main difference between the standard TRNSYS routine and the one used in the desiccant simulation was the use of a variable flowrate through the collector to maintain a maximum desiccant regeneration temperature of $85^{\circ} \mathrm{C}$ whenever possible.

The collector fan was controlled as follows:

- The collector fan was turned off if:

-- collector outlet temperature was within $5^{\circ} \mathrm{C}$ of the collector inlet temperature, or

-- collector outlet temperature was less than the average storage temperature and the desiccant cooler was off.

- The collector fan provided a flowrate equal to that of the desiccant system if the collector outlet temperature was $5^{\circ} \mathrm{C}$ or more above the collector inlet temperature and less than $85^{\circ} \mathrm{C}$ (upper operation control temperature).

- The collector fan was on at a flowrate greater than the desiccant system (with excess flow to storage) so that the outlet temperature of the collector was $85^{\circ} \mathrm{C}$ if sufficient solar energy was available.

The energy flowed as follows:

- If there was no load (i.e. the desiccant cooler was not operating), collected energy was delivered to storage at a temperature less than $85^{\circ} \mathrm{C}$ but greater than the average storage temperature.

- If there was a load:

-- the load was met from storage if no solar energy was available;

-... the load was met from collected solar energy if possible, with excess sular energy being deposited into storage; or

-- the difference was made up from storage if collected energy was insufficient to meet the load.

Table 3-1 lists the values used for the parameters and inputs of the air collector/storage system.

\subsubsection{Hnmidity Converter}

l'he humidity converter routine was designed to take dew point temperatures and convert them to humidity ratios. The dew point temperature was inserted into the Keenan-Keyes formula to calculate the partial pressure of water vapor, $p_{w}$ [6]. The humidity ratio of the ambient air $W_{A M B}$ was calculated from the partial pressure of water vapor and the ratio of molecular weights:

$$
\mathrm{W}_{\mathrm{AMB}}=\frac{\text { molecular weight water }}{\text { molecular weight air }} \times \frac{\mathrm{p}_{\mathrm{w}}}{\mathrm{p}^{-} \mathrm{p}_{\mathrm{w}}},
$$


Table 3- $\mathbb{1}$. PARAMETERS \& INPUTS FOR AIR COLLECTOR/STORAGE SYSTEM

\section{PARAMETERS}

Collector area $\left(\mathrm{m}^{2}\right)$

Flowrate $(\mathrm{kg} / \mathrm{s})$

Specific heat of air $\left(\mathrm{J} / \mathrm{kg}^{\circ} \mathrm{C}\right)$

Efficiency factor

Transmittance-absorptance product

Collector loss coeffecient $\left(\mathrm{J} /{ }^{\circ} \mathrm{C} \mathrm{m}{ }^{2} \mathrm{~s}\right)$

Controller $\Delta \mathrm{T}$ for hlower $\left({ }^{\circ} \mathrm{C}\right)$

Voluine of pebble bed ${ }^{a}\left(\mathrm{~m}^{3}\right)$

Effective pebble bed density $\left(\mathrm{kg} / \mathrm{m}^{2}\right)$

Specific heat of pebbles $\left(\mathrm{J} /{ }^{\circ} \mathrm{C} \mathrm{kg}\right.$ )

Pebble bed loss coefficient $\left(\mathrm{J} /{ }^{\circ} \mathrm{C} \mathrm{m}{ }^{2} \mathrm{~s}\right)$

Surface area of pebble bed $\left(\mathrm{m}^{2}\right)$

Air viscosity $(\mathrm{kg} / \mathrm{m} \mathrm{s})$

Air density $\left(\mathrm{kg} / \mathrm{m}^{3}\right)$

Average pebble diameter ( $m$ )

Void fraction in storage

Pressure drop through air ducts $\left(\mathrm{N} / \mathrm{m}^{2}\right)$
10 to 50

Variable

1005

0.78

0.77

4.8

5

3.9 to $19.5^{a}$

1533

880

0.4772

13.7 to 40.1

0.002

0.987

0.0191

0.33

50.0

\section{INPUTS}

Solar radiation, $\mathrm{H}_{\mathrm{T}}$...

Ambient temperacure, $\mathrm{T}_{\mathrm{AMB}}$

Inlet Temperature, $\mathrm{T}_{\mathrm{HO}}$

Inlet flowrate, $\dot{\mathrm{m}}$

Temperature of pebble bed environment $=20^{\circ} \mathrm{C}, \mathrm{T}_{\mathrm{ENV}}$

Temperature of liquid in hot water heat exchanger (not used), $\mathrm{T}_{W I}$

Flowrate of liquid in hot water heat exchanger (not used), $\dot{\mathrm{m}}_{\mathrm{W}}$

Average pebble bed Leniperaturc, $\mathrm{T}_{\mathrm{PEBED}}$

Maximum collector temperature (constant $85^{\circ} \mathrm{C}$ ), $\mathrm{T}_{\mathrm{MAX}}$

${ }^{a}$ Varied as a function of collector area 
where

$$
\mathrm{p}=\text { atmospheric pressure. }
$$

The humidity ratio specified the mass of water in the air to be removed by the desiccant system and was defined as the mass of water vapor per mass of dry air.

\subsubsection{Evaporative Cooler}

The simulation of the evaporative cooler was based on equations given by Hollands [13]. The following assumptions were made for the evaporative cooler [4]:

- a Lewis number of unity,

- a rate at which water was supplied to the pad equal, to the pad convective mass transfer rate,

- a temperature of the pad supply water equal to the thermodynamic wet bulb temperature of the incoming airstream, and

- a closely adiabatic saturation process.

The model calculated the saturacion temperature and enthalpy of the incoming air. The outlet temperature $\mathrm{T}_{\text {OUT }}$ was calculated as a function of the inlet temperature $T_{I N}$, the saturation temperature $T^{*}$, and the given saturation effectiveness $E$ (i.e., the degree to which the outlet temperature approaches the saturation temperature):

$$
\mathrm{T}_{\text {OUT }}=\left(\mathrm{T}^{*}-\mathrm{T}_{\mathrm{IN}}\right) \times \varepsilon+\mathrm{T}_{\mathrm{IN}}
$$

The outlet absolute humidity was calculated by oquating the inlet und outlet enthalpies. Table 3-2 describes the inputs to the evaporative cooler.

\section{Table 3-2. INPUTS TO EVAPORATIVE COOLER}

$$
\begin{aligned}
& \text { Inlet temperature, }{ }^{T}{ }_{I N} \\
& \text { Inlet humidity ratio, }{ }^{W_{I N}} \\
& \text { Flowrate of system, } \dot{\mathrm{n}} \\
& \text { Effectiveness of cooler, } \varepsilon_{I}
\end{aligned}
$$

\subsubsection{Regenerator}

The regenerator model was based on work done by Kays and London [21]. Assumptions were made for the regenerator as follows [4]:

- The effect of energy carry-over from one stream to another could be neglected. 
- The effects of leakage and water vapor carryover could be neglected.

- The radial temperature distribution in the airstream impinging on the face of the regenerator could be neglected.

- The regenerator was balanced and symmetrical (i.e., equal areas exposed to flow in both flow streams).

- The heat exchanger operated at $90 \%$ effectiveness.

The out let temperatures were calculated as a function of effectiveness and inlet temperatures of the two flow streams:

$$
\begin{aligned}
& \mathrm{T}_{\mathrm{HO}}=0.9\left(\mathrm{~T}_{\mathrm{HI}}-\mathrm{T}_{\mathrm{CI}}\right)+\mathrm{T}_{\mathrm{HI}}, \\
& \mathrm{T}_{\mathrm{CO}}=0.9\left(\mathrm{~T}_{\mathrm{HI}}-\mathrm{T}_{\mathrm{CI}}\right)+\mathrm{T}_{\mathrm{CI}},
\end{aligned}
$$

where

$$
\begin{aligned}
& \mathrm{T}_{\mathrm{HO}}=\text { uullel temperature of hot airetream, } \\
& \mathrm{T}_{\mathrm{HI}}=\text { inlet temperature of hot airstream, } \\
& \mathrm{T}_{\mathrm{CO}}=\text { outlet temperature of cold airstream, and } \\
& \mathrm{T}_{\mathrm{CI}}=\text { inlet temperature of cold airstream. }
\end{aligned}
$$

The specific humidity did not change from inlet to outlet. The inputs to the regenerator are described in Table 3-3.

Table 3-3. INPUTS TO REGENERATOR

Temperature of hot airflow stream, $\mathrm{T}_{\mathrm{HI}}$
Humidity ratio of hot airflow stream, $\mathrm{W}_{\mathrm{HI}}$
Temperature of cold airflow stream, ${ }_{\mathrm{CI}}$
Humidity ratio of cold airflow stream, ${ }_{\mathrm{W}} \mathrm{CI}$
Flowrate of airstream, $\dot{\mathrm{m}}$
Heating/cooling mode indicator, MODEH

\subsubsection{Dehumidifier}

The equations used in the axial-flow disc-type dehumidifer model were developed from the work of I. L. Maclaine-Cross and F. J. Banks [14]. The assumptions used were as follows [4]:

- desiccant (silica ge1) packed as a porous medium, the interstices of which were channels through which an air/water vapor mixture flowed;

- constant dry air density;

- constant dry silica gel density; 
- constant interstitlal fluid velocity;

- airstream flow and silica gel bed properties varying only in the direction of flow;

- moist silica gel and air/vapor mixture in thermal and sorption equilibrium at all locations along the flow path; and

- reversible sorption process (1.e., no hysteresis).

The model essentially used a graphical method of analysis developed by BanksClose-Maclaine-Cross [15]. Silica gel data for the dehumidifier was developed from the work of P. J. Banks and D. J. Close [16]. The parameters and inputs for the dehumidifier are described in Table 3-4.

\subsubsection{House}

The house model, modified by SERI to include an option for auxiliary cooling, was connected to the desiccant system in order to ascertain the room conditions (the room temperature and humidity) on a dynamic basis.

The humidity in the room was calculated from a steady-state humidity $\mathrm{W}_{S S}$ defined as follows:

$$
\mathrm{W}_{\mathrm{SS}}=\frac{\dot{\mathrm{m}} \times \mathrm{W}_{\mathrm{EX}}+\mathrm{INF} \times \mathrm{W}_{\mathrm{AMB}}+\mathrm{W}_{\mathrm{G}}}{\dot{\text { ill }}+\mathrm{INF}},
$$

where

$$
\begin{aligned}
\dot{\mathrm{m}} & =\text { system flowrate, } \\
\mathrm{W}_{\mathrm{EX}} & =\text { humidity from inlet evaporative cooler, } \\
\mathrm{INF} & =\text { infiltration rate, } \\
\mathrm{W}_{\mathrm{AMB}} & =\text { ambient humidity, and } \\
\mathrm{W}_{\mathrm{G}} & =\text { interior molsture generation. }
\end{aligned}
$$

The room humidity ratio $W_{R}$ was then determined:

$$
W_{R}=W_{E E}-\left(W_{S S}-W_{R O}\right)-[1-\exp (E X W)] / F X W \text {, }
$$

where

$$
\begin{aligned}
& W_{\mathrm{RO}}=\text { room humidity last time step, and } \\
& \mathrm{EXW}=(\dot{\mathrm{m}} \times \mathrm{INF}) / \mathrm{m}_{\mathrm{T}}, \text { where } \mathrm{m}_{\mathrm{T}}=\text { total mass of dry air and water vapor. }
\end{aligned}
$$

The temperature in the room was similarly computed from a steady-state temperature $\mathrm{T}_{\mathrm{SS}}$ defined as follows:

$$
\mathrm{T}_{\mathrm{SS}}=\mathrm{T}_{\mathrm{EX}}+\operatorname{SENS} /\left(\dot{\mathrm{m}} \times \mathrm{C}_{\mathrm{p}_{\mathrm{a}}}\right) \text {, }
$$




\section{PARAMETERS}

Internal surface area per volume of packing $\left(\mathrm{m}^{2} / \mathrm{m}^{3}\right) \quad 1573$

Length in flow direction (m)

0.0275

Frontal area exposed to flow $\left(\mathrm{m}^{2}\right)$

0.74

Void fraction of packing

0.4

Rulational speed of matrix ( $r / s)$

0.00153

Density of airstream $\left(\mathrm{kg} / \mathrm{m}^{3}\right)$

1.2

Effective conductance between packing and airstream $\left(\mathrm{J} / \mathrm{m}^{2}{ }^{\circ} \mathrm{C} \mathrm{s}\right)$

58

Packing characteristic dimension ( $m$ )

Friction factor

1.2

Fluid viscosity $(\mathrm{kg} / \mathrm{m} \mathrm{s})$

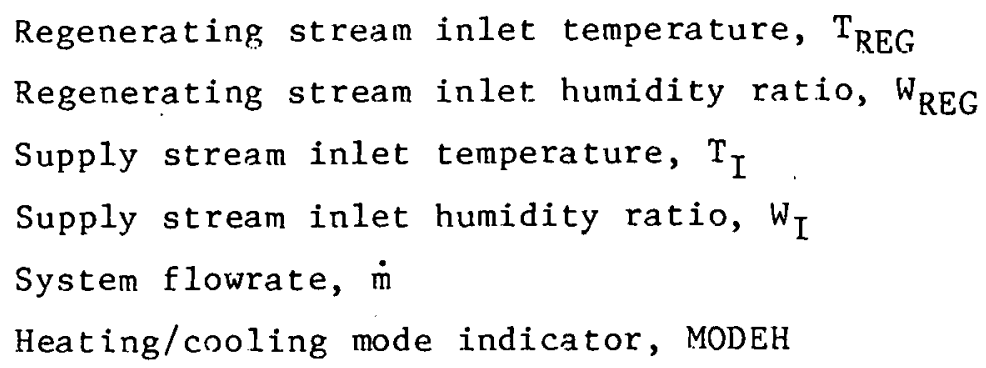


where

$$
\begin{aligned}
\mathrm{T}_{E X} & =\text { temperature from inlet evaporative cooler, } \\
\text { SENS } & =\text { sensible load, and } \\
\mathrm{C}_{\mathrm{P}_{\mathrm{a}}} & =\text { specific heat of dry air. }
\end{aligned}
$$

The room temperature was then determined from the steady-state temperature:

$$
\mathrm{T}_{\mathrm{R}}=\mathrm{T}_{\mathrm{SS}}-\left(\mathrm{T}_{\mathrm{SS}}-\mathrm{T}_{\mathrm{RO}}\right) \times \exp (\mathrm{EXT})
$$

where

$$
\begin{aligned}
& \mathrm{T}_{\mathrm{RO}}=\text { room temperature last time step, and } \\
& \mathrm{EXT}=\dot{\mathrm{m}} \mathrm{C}_{\mathrm{P}_{\mathrm{a}}} / \mathrm{CAP} \text {, where } \mathrm{CAP}=\text { thermal capacitance of house. }
\end{aligned}
$$

The room conditions, as calculated above, are subject to change if an auxiliary backup vapor-compression system is used. The operation of the auxiliary cooling system is discussed in Section 3.7 .

The parameters and inputs for the house model are described in Table 3-5.

\subsubsection{Controller}

The controller was designed by SERI so that, for given room conditions, the desiccant system would operate in a manner which would not only return the room to conditions of specified comfort but also minimize both energy consumption and system operation time. The controller determined the following parameters:

- effectiveness of inlet evaporative cooler,

- effectiveness of outlet evaporative cooler,

- temperature of regeneration stream, and

- flowrate (on/off) of system.

The details of the control strategy are contained in Section 3.7.2. The parameters and inputs for the controller are described in Table 3-6.

\subsubsection{Energy Balancer}

The purpose of the energy balancer was to compute the sensible and latent capacities $\left(Q_{S E N}\right.$ and $\left.Q_{L A T}\right)$ of the desiccant cooler. These values were calculated as follows:

$$
\begin{aligned}
& \mathrm{Q}_{\mathrm{SEN}}=\dot{\mathrm{m}} \times\left[\mathrm{C}_{\mathrm{p}_{\mathrm{a}}}\left(\mathrm{T}_{\mathrm{R}}-\mathrm{T}_{\mathrm{EX}}\right)+\mathrm{C}_{\mathrm{p}_{\mathrm{w}}}\left(\mathrm{W}_{\mathrm{R}} \times \mathrm{T}_{\mathrm{R}}-\mathrm{W}_{E X} \times \mathrm{T}_{E X}\right)\right], \\
& \mathrm{Q}_{\mathrm{LAT}}=\dot{\mathrm{m}}\left(\mathrm{W}_{\mathrm{AMB}}-\mathrm{W}_{E X}\right)+\mathrm{H}_{\mathrm{fg}},
\end{aligned}
$$


Table 3-5. PARAMETERS AND INPUTS FOR HOUSE

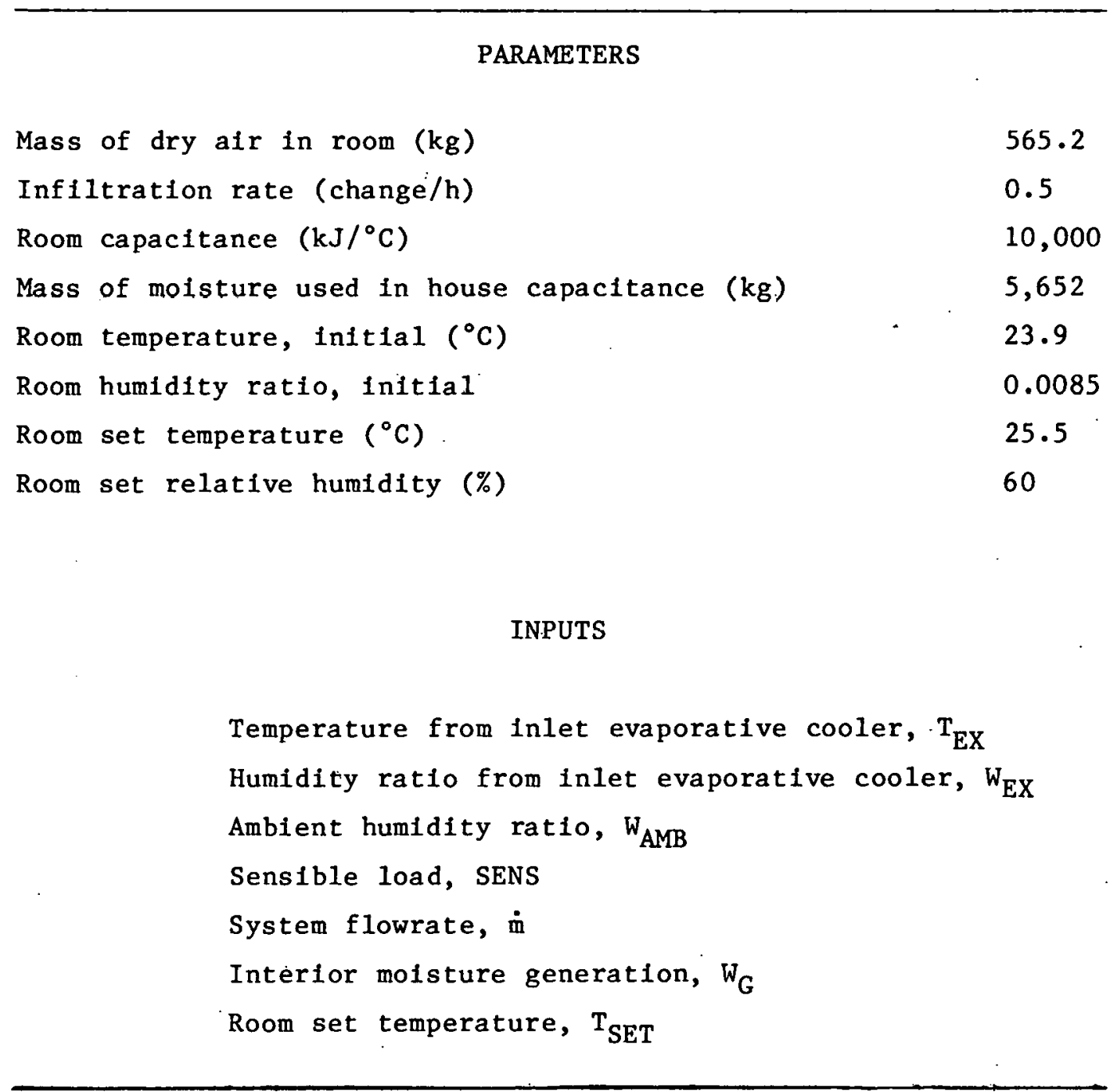

where

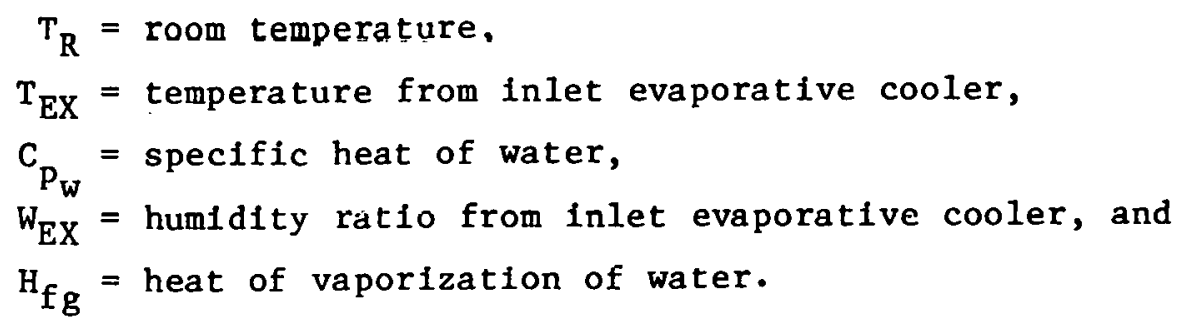

Table 3-7 1ists the inputs to the energy balancer. 


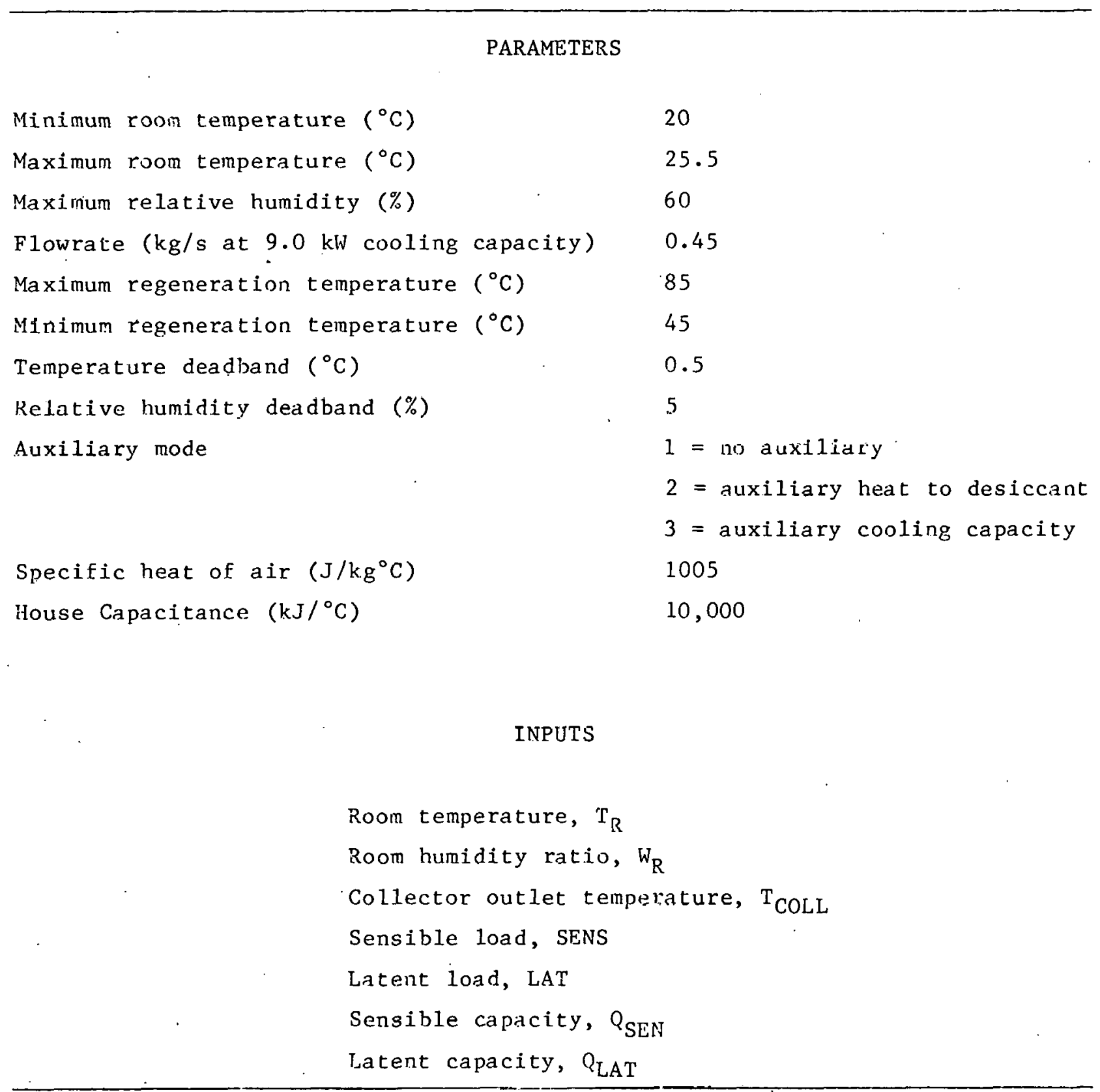


Table 3-7. INPUTS TO ENERGY BALANCER

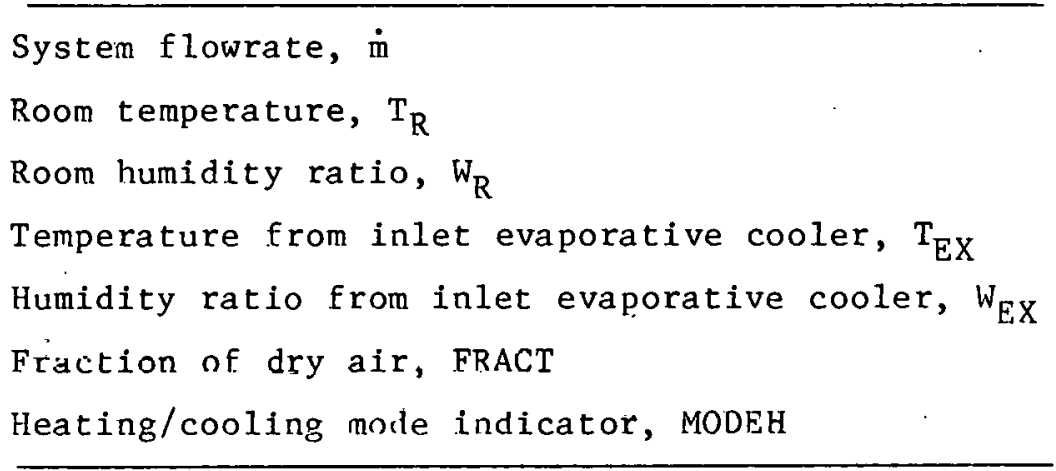

\subsubsection{House Load Model}

\subsubsection{Tramsfer Function Approach}

The standard TRNSYS transfer-function load model developed by M. J. Pawelski was used in this study [17]. The transfer function approach uses past heat flows and temperatures to predict future heat flow at any time. The driving force of the model is the sol-air temperature, which includes solar, convection, and radiation effects at the exterior boundary. Transfer function coefficients from the 1977 ASHRAE Handbook of Fundamentals [6] were used in the model to depict the type of wall used. Each wall may be modeled separately or, assuming similar construction, together using a weighted solair temperature. The house used in the present simulations was a two-story house with $167.3 \mathrm{~m}^{2}$ of floor space and $178.4 \mathrm{~m}^{2}$ of exterior wall space. The ASHRAE 90-75 standard was used in specifying the thermal design. The house was oriented north-south with a roof pitch equal to the latitude of the location. The building is characterized further in the following sections.

\subsubsection{Ha11s}

The heat transfer rates for the walls were calculated using the standard TRNSYS Type-17 wall model. The rates were calculated as follows:

- Heat conducted through walls, $Q_{w a 11}$ :

$$
Q_{\text {wa } 11}=A\left(\sum_{n=0} b_{n}\left(T_{s a, n}-T_{r c}\right)-\sum_{n=1} d_{n} Q_{n}\right)
$$

where

$$
\begin{aligned}
A & =\text { area of wall, } \\
\mathrm{b}_{\mathrm{n}} & =\text { transfer function coefficients of temperature terms, } \\
\mathrm{T}_{\mathrm{sa}, \mathrm{n}} & =\text { sol-air temperature of wall surface at } c \text { llue } \mathrm{a},
\end{aligned}
$$




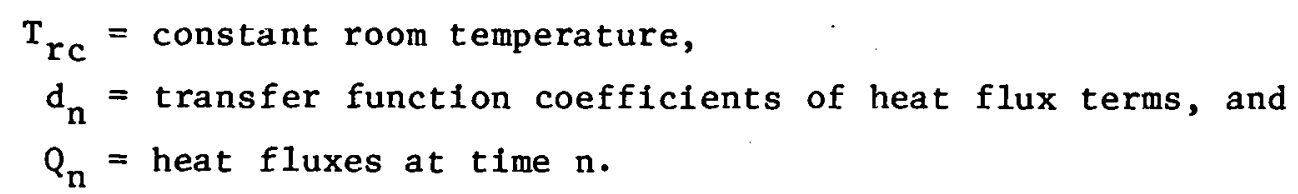

Heat conducted through windows, $Q_{\text {windows }}$ :

$$
Q_{\text {windows }}=U_{W D} \times A_{W}\left(T_{A M B}-T_{R}\right) \text {, }
$$

where

$$
\begin{aligned}
\mathrm{U}_{\mathrm{WD}} & =\text { window heat transfer coefficient, } \\
\mathrm{A}_{\mathrm{W}} & =\text { window area, and } \\
\mathrm{T}_{\mathrm{AMB}} & =\text { ambient temperature. }
\end{aligned}
$$

- Solar heat gain from windows, $Q_{\mathrm{SHG}}$ :

$$
\mathrm{Q}_{\mathrm{SHG}}=\mathrm{A}_{\mathrm{w}}\left(1-\mathrm{F}_{\mathrm{S}}\right) \tau_{\mathrm{T}},
$$

where

$$
\begin{aligned}
\mathrm{F}_{\mathrm{S}} & =\text { shading fraction, } \\
\tau & =\text { transmissivity, and } \\
\mathrm{H}_{\mathrm{T}} & =\text { total solar radiation incident on window. }
\end{aligned}
$$

The total rate of heat gain through the walls was determined by summing $Q_{w a 11}$, $\mathrm{Q}_{\text {windows, }}$ and $\mathrm{Q}_{\mathrm{SHG}}$.

Wall construction was chosen to be frame with 1-in. insulation (ASHRAE wall \#38) with surface absorptance of $50 \%$ and infrared surface emittance of $80 \%$.

An overall heat loss coefficlent of $U_{O}=1.60 \mathrm{~J} / \mathrm{s} \mathrm{m}^{2}{ }^{\circ} \mathrm{C}$ was used for the walls and windows. The allowable window area expressed as a fraction of wall area is:

where

$$
F=\frac{U_{0}-U_{W L}}{U_{W D}-U_{W L}},
$$

$$
\begin{aligned}
& \mathrm{U}_{\mathrm{WL}}=\text { heat transfer coefficient for wall, and } \\
& \mathrm{U}_{\mathrm{WD}}=\text { heat transfer coefficient for window. }
\end{aligned}
$$

Given $U_{W L}=1.012 \mathrm{~J} / \mathrm{s} \mathrm{m}^{2}{ }^{\circ} \mathrm{C}$ and $U_{W D}=3.52 \mathrm{~J} / \mathrm{s} \mathrm{m}^{2 \circ} \mathrm{C}$ and assuming double glazed windows, $12 \%$ of the total wall area should be windows. The window area was then distributed as shown in Table 3-8. 
Table 3-8. HINDOW DISTRIBUTION IN HOUSE MODEL

\begin{tabular}{lcc}
\hline Wall & $\begin{array}{c}\text { Window Area } \\
\left(\mathrm{m}_{2}\right)\end{array}$ & $\begin{array}{c}\% \text { of } \\
\text { Wall Area }\end{array}$ \\
\hline North & 2.23 & 5 \\
East & 4.01 & 9 \\
West & 4.01 & 9 \\
South & 11.15 & 2.5 \\
\hline
\end{tabular}

Window shading factors were also used to express the amount of solar gain lost to shading effects. Shading factors of $20 \%$ in the winter months and $60 \%$ in the summer months were used.

\subsubsection{Roof}

The heat flux calculations for the roof were similiar to those described for the wall in the previous section. Generally, the total rate of heat conducted through the ceiling, $Q_{0}$, is

$$
Q_{0}=A_{c}\left(\sum_{n=1} b_{n}\left(T_{s a, e f f, n}-T_{r c}\right)-\sum_{n=1} d_{n} Q_{n}\right) \text {, }
$$

where

$$
\begin{aligned}
A_{c}= & \text { area of ceiling, and } \\
T_{\text {sa, eff, } n}= & \text { effective solar air temperature of roof surfaces } \\
& \text { and infiltration air. }
\end{aligned}
$$

The $U$ value of the roof was chosen as $0.28 \mathrm{~J} / \mathrm{s} \mathrm{m}{ }^{2}{ }^{\circ} \mathrm{C}$, which represents 6 in. of insulation. The surface emittance and absorptance were the same as for the walls, $80 \%$ and $50 \%$ respectively.

\subsubsection{Room and Basement}

Heat transfer into the room was determined from the input of the walls and roof as described in the previous sections. In addition, other heat gains (or losses) were taken into account, such as heat generated by people, lights, and other appliances. The model also considered heat flows through the basement aud Inflitration losses.

The single-node room temperature was allowed to vary between upper and lower set temperatures. When the house was in comfort, that is, within this specified temperature range, the sensible load was zero. If the room temperature was out of this range, the heating load and minimum (for heating) or maximum (for cooling) temperature was julpul. The cotal load was calculated using a time-dependent transfer function of each component as a function of both current and previous loads. The components were as follows: 


$$
Q_{\text {load }}=Q_{S H G}+Q_{C}+Q_{L}+Q_{I N F}+Q_{B} \text {, }
$$

where

$$
\begin{aligned}
Q_{C} & =\text { conduction gains from walls and roof, } \\
Q_{L} & =\text { constant heat gains (people, lights, appliances, etc.), } \\
Q_{\text {INF }} & =\text { infiltration gains, and } \\
Q_{B} & =\text { heat flow through basement. }
\end{aligned}
$$

Using a room capacitance of $10,000 \mathrm{~kJ} /{ }^{\circ} \mathrm{C}$ and a building conductance (UA) of $1350 \mathrm{~kJ} / \mathrm{h}{ }^{\circ} \mathrm{C}$, the heat inputs from the walls, windows, and roof were applied to the conditions of the room. Thermostat settings were $20.0^{\circ}$ to $25.5^{\circ} \mathrm{C}$ with air infiltration of a half-house volume of air per hour.

Interior sensible heat generation was assumed to be $1260 \mathrm{~kJ} / \mathrm{h}$ from lights and appliances and $1188 \mathrm{~kJ} / \mathrm{h}$ from people. Moisture generation (i.e., latent load) was $0.26 \mathrm{~kg} / \mathrm{h}$ from appliances and $0.24 \mathrm{~kg} / \mathrm{h}$ from people.

The basement was assumed to be a crawl space $1.53 \mathrm{~m}$ deep. Ground-water temperature, used for calculating heat loss to the ground from the basement, was assumed to be a constant $10^{\circ} \mathrm{C}$.

\subsubsection{Determination of Cooling Season}

The cooling season was determined from a full-year heating and cooling load calculation with the following assumptions:

$$
\begin{array}{ll}
\text { Minimum room temperature: } & 18.8^{\circ} \mathrm{C} . \\
\text { Maximum room temperature: } & 25.5^{\circ} \mathrm{C} . \\
\text { Window shading factor: } & 0.4 .
\end{array}
$$

The cooling season was chosen such/that it would include less than $5 \%$ of the heating load. 'lhe season was rounded to the nearest half-month.

The preliminary detcrmination of the cooling season was necessary bccause different assumptions were used in calculating the heating and cooling loads, as shown in Table 3-9.

Table 3-9. SEASONAL LOAD ASSURPTIONS

\begin{tabular}{lccc}
\hline & Heating Season & Cooling Season \\
\hline Minimum room temperature $\left({ }^{\circ} \mathrm{C}\right)$ & 20 & 25.49 \\
Maximum room temperature $\left({ }^{\circ} \mathrm{C}\right)$ & 25.5 & 25.51 \\
Window shading factor & 0.2 & 0.6 \\
\hline
\end{tabular}




\subsection{DESICCANT COOLER SYSTEM SIZING}

In order to simulate the annual operation of a desiccant cooling system, the proper size relationships among the system components had to be determined. This included both the desiccant cooler components and the collector/storage system. The component sizes were dictated by:

- thermal performance requirements;

- economic requirements, including capital and operating costs; and

- physical size restrictions appropriate for residential heating/cooling systems.

The component configurations and required parameters for the computer simulation are discussed in Sections 2.2 and 3.2.2. This section discusses the component sizes used in the computer simulations.

Several different collector and storage size combinations were used with the desiccant systems to determine optimum desiccant thermal performance and economic trends. As previously discussed, the collector model included a pebble-bed storage tank. A general criterion for sizing collector/pebble-bed systems is to include 0.153 to $0.229 \mathrm{~m}^{3}$ of pebbles per square meter of collector area when considering space heating only [18]. In this study, the proportion of pebble-bed volume to collector area was modified because of the addition of the solar desiccant air conditioner. An increased pebble-bed volume of $0.4 \mathrm{~m}^{3}$ of pebbles per square meter of collector area was chosen, based on the results of initial desiccant cooler simulations. The resulting collector/storage sizes used in this study are shown in Table 3-10.

Table 3-10. COLLECTOR/STORAGE SIZE COMBINATIONS

\begin{tabular}{cc}
\hline Collector Area $\left(\mathrm{m}^{2}\right)$ & Pebble Bed Storage Size $\left(\mathrm{m}^{3}\right)$ \\
\hline 10.0 & 3.9 \\
20.0 & 7.8 \\
35.0 & 13.1 \\
42.0 & 16.5 \\
50.0 & 19.6
\end{tabular}

As discussed in Section 3.2.2, the collector/storage system included a variable air mass flnwrate capability in order to control the maximum collector output temperature. The pressure drops through these components were calculated during each time increment to determine the parasitic power for the collector system fan motor. Based on flat-plate collector test data [23], correlations were developed for collector pressure drop as a function of air flowrate, including an allowance for entrance and exit effects plus duct losses, and these correlations were included in the computer program. To determine the pebble-bed storage system pressure drop, the Ergun Equation, which describes the pressure drop across packed columns, was used in the computer simulation [24]. 
Since the desiccant cooler was to be designed for residential use, the nominal cooling capacities chosen for study were in the range of 2.3 to $9.0 \mathrm{~kW}$, with a few simulations run for a $13.5-\mathrm{kW}$ cooler. The chosen reference design was $9.0-\mathrm{kW}$ cooling capacity with an air mass flowrate of $0.45 \mathrm{~kg} / \mathrm{s}$ (corresponding to an average flow of $0.38 \mathrm{~m}^{3} / \mathrm{s}$ ). The cooler size and air flowrate combinations used in this study are shown in Table 3-11.

Table 3-11. COOLER-SIZE/AIR-FLOWRATE COMBINATIONS

\begin{tabular}{rc}
\hline Desiccant Cooler Size $(\mathrm{kW})$ & Air Flowrate $(\mathrm{kg} / \mathrm{s})$ \\
\hline 2.3 & 0.113 \\
4.5 & 0.225 \\
9.0 (reference) & 0.450 \\
13.5 & 0.675 \\
\hline
\end{tabular}

The desiccant system components were sized in accordance with thermal, economic, and physical size requirements. Once the cooler size and corresponding air flowrates of Table 3-11 were established, the flow areas and flow lengths of the dehumidifier, regenerator, and evaporative coolers could be determined by specifying allowable pressure drops. The pressure drops should be as low as possible to minimize the electrical power required to drive the air fans.

An allowable pressure drop of $125.0 \mathrm{~N} / \mathrm{m}^{2}$ across the wheel for each flow (supply and regeneration) was selected for the reference design of the dehumidifier. A dchumidifier wheel diameter of $1.37 \mathrm{~m}$ was also specified. For the packed-bed silica-gel dehumidifier model used in this study, the resulting flow length (packed-bed depth) was $0.0275 \mathrm{~m}$ with a wheel rotation speed of $0.00153 \mathrm{r} / \mathrm{s}$ [19].

The regenerator and evaporative coolers were sized to be physically compatible with the dehumidifier. In this manner, the airflow path through the cooler has as few contractions and expansions as possible in order to minimize the system pressure drop. Reference 20 dcacribes a solar desiccant air conditioner with the same basic airflow path, although the parasitic power experienced in that study was higher than predicted here due to design and operational problems.

The rotary regenerator was assumed to be a parallel passage type with a wheel diameter equal to that of the dehumidifier $(1.37 \mathrm{~m})$. Studies at the University of Wisconsin showed that the desiccant cooler performance was optimized as regenerator effectiveness increased [4]. For this study, a constant regenerator effectiveness of 0.90 was assumed. For a regenerator airflow path length of $0.05 \mathrm{~m}$, a pressure drop of $25.0 \mathrm{~N} / \mathrm{m}^{2}$ was calculated for each flow direction [21].

The evaporative cooler flow area was assumed equal to $0.74 \mathrm{~m}^{2}$, or half the frontal flow area of the dehumidifier and regenerator wheels. Identical 
evaporative coolers were present in both the supply and regeneration streams. The effectiveness for each cooler was assumed to be capable of varying between 0.0 and 0.9 . The effectiveness of the inlet evaporative cooler and that of the ambient evaporative cooler were important parameters in controlling the desiccant cooler performance and will be discussed in Section 3.7.2. For each evaporative cooler, the pressure drop was determined to be $50.0 \mathrm{~N} / \mathrm{m}^{2}$ for the reference design [21].

In addition to pressure drops through the individual system components, pressure drops were associated with other parts of the desiccant cooler system, including ducts and air filters. For each airflow stream, an additional pressure drop of $50 \mathrm{~N} / \mathrm{m}^{2}$ was included to account for duct losses $\left(25 \mathrm{~N} / \mathrm{m}^{2}\right)$ and an air filter $\left(25 \mathrm{~N} / \mathrm{m}^{2}\right)$. The pressure drops for the reference design system are summarized in Figure 3-2.

To determine electrical power requirements (parasitic power), a fan power equation was used in conjunction with the system pressure drops. Fan power was determined from the following equation [22]:

$$
\text { Fan power in } \mathrm{J} / \mathrm{s}=\frac{\mathrm{CFM}(\triangle \mathrm{P})}{72 \cdot 2 \mathrm{E}} \text {, }
$$

where

$$
\begin{aligned}
\text { CFM } & =\text { air flowrate }\left(\mathrm{m}^{3} / \mathrm{s}\right), \\
P & =\text { system pressure drop }\left(\mathrm{N} / \mathrm{m}^{2}\right), \text { and } \\
E & =\text { fan efficiency. }
\end{aligned}
$$

Fan efficiency typically varies from 0.5 to 0.65 ; an average value of 0.58 was used. The computer simulation determined parasitic energy used by the cooler/collector system at each time increment.

Three fans were included in the system, one for each airflow stream (collector/storage, supply, and regeneration). For the reference design, the fan motors were sized as follows:

$\begin{array}{ll}\text { Supply stream: } & 246.1 \mathrm{~J} / \mathrm{s} . \\ \text { Regeneration stream: } & 372.9 \mathrm{~J} / \mathrm{s} .\end{array}$

Collector stream: variable speed (due to variable afrflow as described in Section 3.2.2) with a minimum rating of $186.4 \mathrm{~J} / \mathrm{s}$.

An additional motor was included to drive the dehumidifier and regenerator wheels. This motor was sized at $186.4 \mathrm{~J} / \mathrm{s}$.

Since the desiccant cooler simulation was run at several cooler capacities (as shown in Table 3-11), the parasitic power requirement varied for each size. For each cooler capactty, the desiccant system components were sized so that the pressure drop through each remained the same as that for the reference design. The desiccant wheel flow length was maintained at $0.0275 \mathrm{~m}$ for a11 sizes, with the wheel. dialueter varying as shown in Table 3-12. 


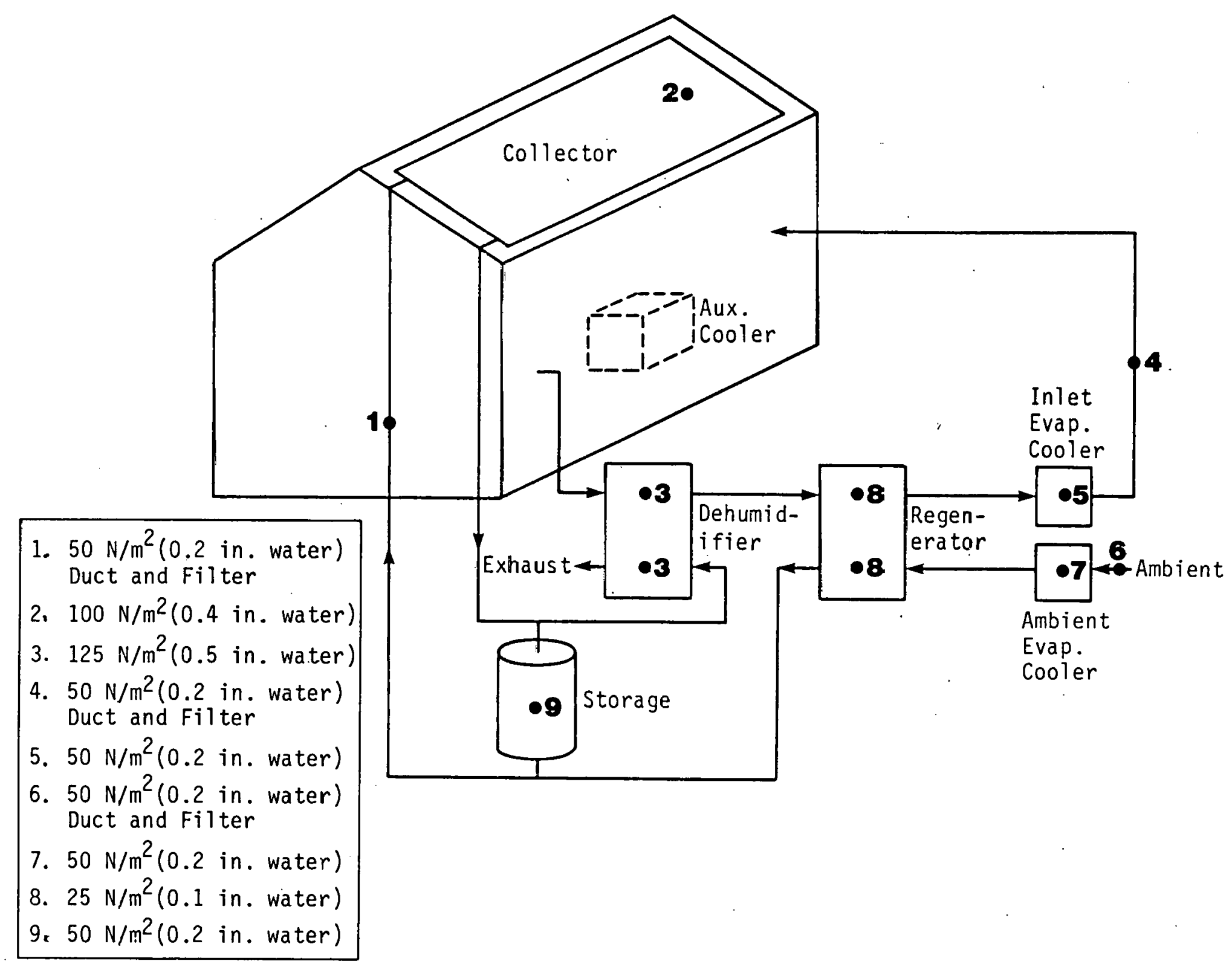

Figure 3-2. PRESSURE DROPS FOR REFERENCE SYSTEM 
Table 3-12. DESICCANT-COOLER-SIZE/WHEELL-DIAMETER COMBINATIONS

\begin{tabular}{cc}
\hline Desiccant Cooler Size $(\mathrm{kW})$ & Desiccant Wheel Diameter $(\mathrm{m})$ \\
\hline 2.3 & 0.68 \\
4.5 & 0.97 \\
9.0 & 1.37 \\
13.5 & 1.68 \\
\hline
\end{tabular}

As a result, the parasitic power for each desiccant system capacity varied with the ratio of the system flowrate to the reference design flowrate. The computer program scaled the parasitic power for each simulation accordingly.

To be certain that the fan motor sizes were never allowed to drop below realistic values, mimimum motor sizes were included in the computer program. The minimum motor sizes were as follows:

$$
\begin{array}{lr}
\text { Supply stream: } & 124.5 \mathrm{~J} / \mathrm{s} . \\
\text { Regeneration stream: } & 186.4 \mathrm{~J} / \mathrm{s} . \\
\text { Collector stream: } & 186.4 \mathrm{~J} / \mathrm{s} .
\end{array}
$$

If the calculated parasitic power requirement exceeded these values, the calculated value was used. However, if the calculated parasitic power was below any of the minimum motor ratings listed above, the minimum motor rating was used to determine parasitic power used by the desiccant cooling system.

\subsection{DEFINITION OF HOUSE COMFORT CONDITIONS}

To properly design heating, ventilating, and air-conditioning systems, an understanding of physiological principles and criteria for comfort is essential. The American Society of Heating, Refrigerating, and AtrConditioning Engineers (ASHRAE) has sponsored research for many years on the prediction of thermal comfort. Primary parameters detérmining thermal comfort include dry-bulb temperature, relative humidity, air movement, and the degree of activity and type of clothing worn by individuals. ASHRAE has developed standards for comfort that serve as guidelines for the design of heating and air-conditioning systems.

Figure 3-3 shows the comfort zone recommended by ASHRAE for a wide range of applications, including homes, schools, and offices. [6]. The comfort zone is applicable to indoor environments ranging in altitude from sea level to $2134 \mathrm{~m}$ at air velocities less than $0.2286 \mathrm{~m} / \mathrm{s}$, and for lightly clothed occupants with sedentary activity. The upper boundaries of the zone are $25.0^{\circ} \mathrm{C}$ dry-bulb temperature and $60 \%$ relative humidity, with the lower. boundaries specified as $22.8^{\circ} \mathrm{C}$ dry-bulb temperature and $20 \%$ relative humidity. 


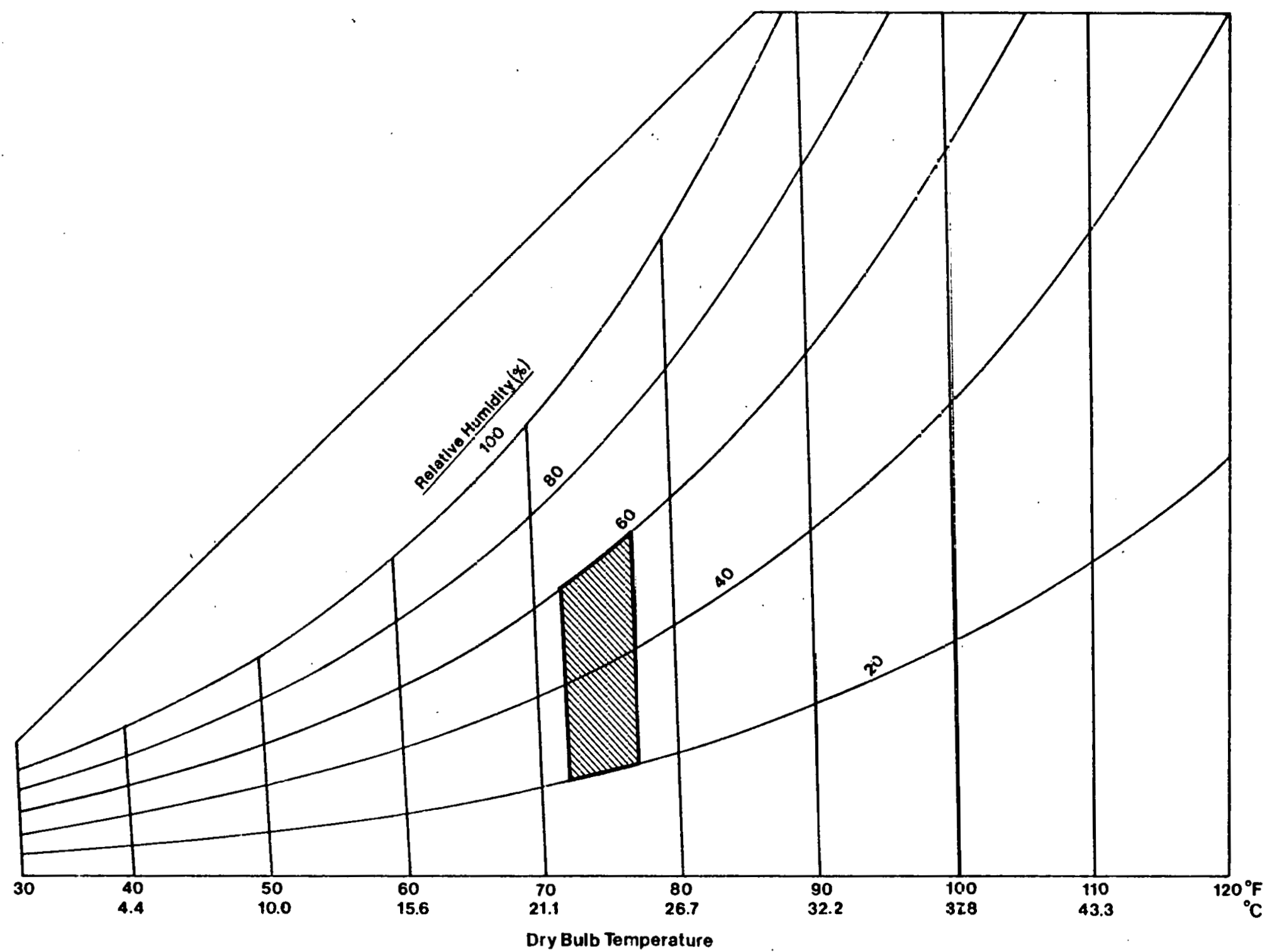

Figure 3-3. ASHRAE COMFORT ZONE (Shaded Area) :6] 
The ASHRAE-recommended comfort zone was modified for the purpose of this study. With the currently increasing need for energy conservation and suggestions by the Federal Government for homeowners to increase thermostat settings in summer and decrease settings in winter, it was decided to increase the ranges of dry-bulb temperature and relative humidity that define the comfort zone. Figure 3-4 depicts the comfort zone used in the study. The upper comfort zone boundary was modified slightly to $25.5^{\circ} \mathrm{C}$ dry-bulb temperature and maintained at $60 \%$ relative humidity. A larger adjustment was made in the lower boundary, with the dry-bulb temperature specified as $20.0^{\circ} \mathrm{C}$ and no lower limit placed on relative. humidity. These revisions to the control zone reduce the amount of energy consumed for maintaining comfort conditions in buildings, particularly during the heating season. Considering the large escalation in fuel costs during recent years and the potential for future fuel shortages, a revised comfort zone intended to conserve energy is appropriate. This comfort zone was used in simulations of both solar desiccant and vapor-compression air conditioners, as described in Sections 3.7 .2 and 4.1 .

\subsection{COOLING SYSTEM OPERATIONAL CHARACTERISTICS}

In describing the annual heating/cooling season simulations of solar desiccant and vapor-compression air conditioners, the remainder of this report employs several parameters commonly used to describe the operating performance of airconditioning equipment. This section of the report briefly summarizes and defines these performance parameters.

The total cooling output of an air conditioner is composed of sensible and latent components which are defined as follows:

- Sensible cooling:

- Latent cooling: cooling capacity associated with heat removal from an airstream, resulting in a drop in air temperature.

cooling capacity associated with moisture removal from an airstream due to a change in the water phase from gas to liquid, resulting in a drop in humidity.

Five other parameters used in this study were the following:

- Parasilic power:

elcctrical input power to the air-conditioning equipment. For a vapor-compression cooler, electrical power drives the compressor and air fan, while a solar desiccant cooler uses electrical power for air fans only (in addition to auxiliary cooling, if any).

- Coefficient of performance (COP):

defined as the ratio of net heat removal (cooling capacity) to the rate of total energy input. For the solar desiccant cooler, only thermal input power (solar energy) was included in the COP calculation. 


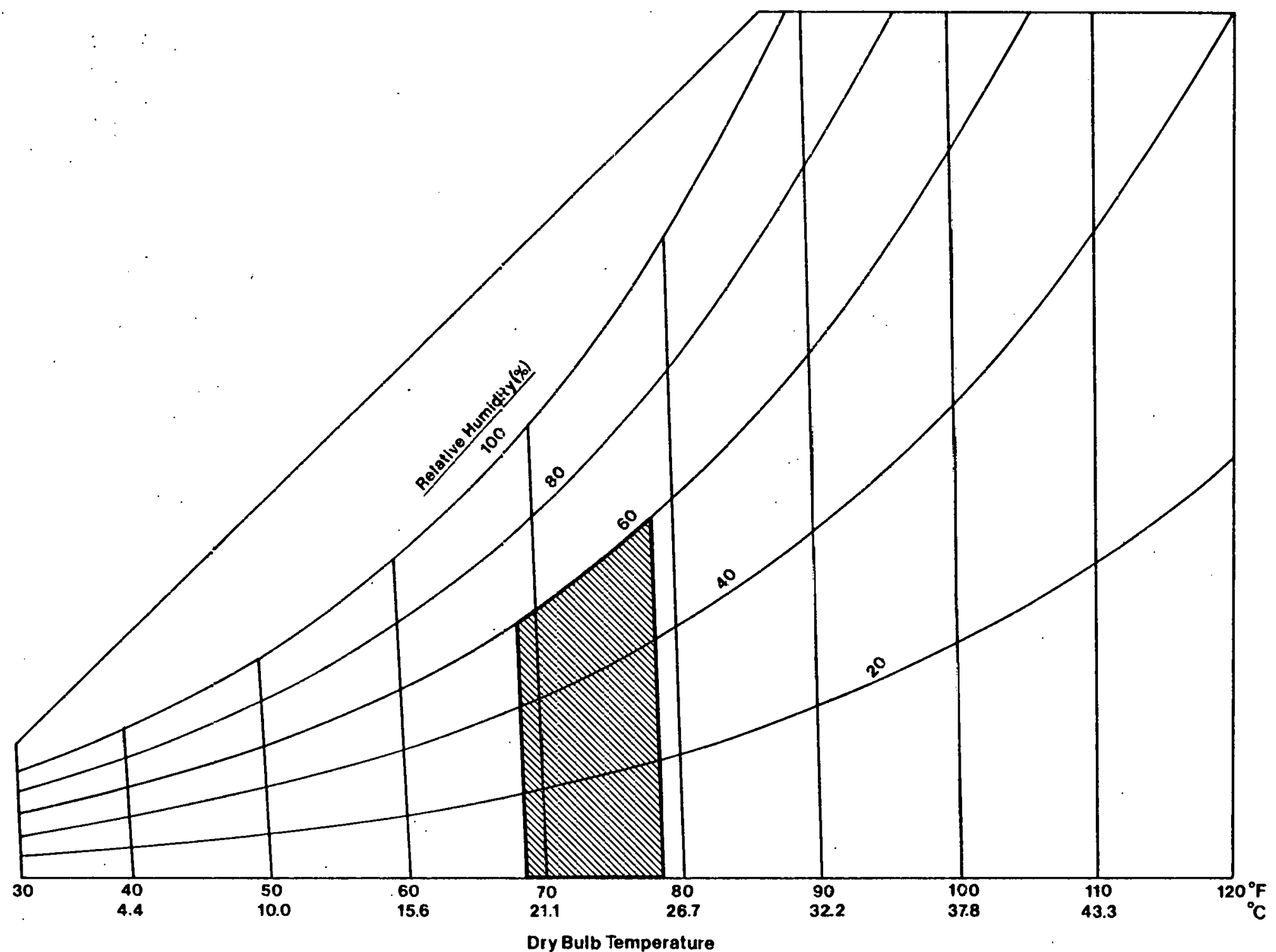

Figure 3-4. COMFORT ZONE USED IN COMPUTER SIMULATIONS (Shaded Area) 
- Energy efficiency ratio (EER):

- Duty cycle:

- Percent in comfort: defined as the ratio of net cooling capacity in $\mathrm{Btu} / \mathrm{hr}$ to the total rate of electrical input in watts. For the solar desiccant cooler, electrical power to the auxiliary vaporcompression cooler (if any) was included in the EER calculation.

fraction of the total time period that the cooler system was in operation.

percentage of the total time period that the average house air conditions fell within the comfort zone (as defined on the psychrometric chart of Figure 3-4).

\subsection{STEADY-STATE PERFORMANCE}

\subsubsection{Description of Analysis}

The purpose of the steady-state analysis was to obtain a general indication of desiccant system performance. Nominal machine characteristics can be ascertalned by examining the sensitivity response of the system to various ambient and indoor environments. Alteration of critical system parameters under steady-state conditions enables the formulation of an operational control strategy for the transient case, as described in Section 3.7.2.

The interaction of system components as shown in Figure 3-5 was studied. Air was circulated from the room into the dehumidifier where drying occurred by absorption of moisture by the desiccant. Heat exchange in the regenerator produced pre-cooling, and final cooling was provided by an inlet evaporative cooler regulated with an effectiveness $\varepsilon_{i}$. Ambient air cooled by another evaporative cooler (of effectiveness $\varepsilon_{0}$ ) was delivered to the regenerator as a heat sink exchange supply. The regeneration temperature $T_{R E G}^{\prime}$, was varied in $10^{\circ} \mathrm{C}$ increments to provide recharging of the moist desiccant gel. The energy needed to boost $T_{\mathrm{REG}}^{\prime}$, the exit temperature from the regenerator, to $T_{\mathrm{REG}}^{\prime}\left(_{\text {IN }}\right.$ in Figure 3-5) was assumed available; this is the energy supplied by snlar storage or an auxiliary source during transient simulations.

\subsubsection{Results}

For a particular assigutent of values to component control parameters ( $\mathrm{REG}_{\mathrm{RE}}$, $\varepsilon_{i}, \varepsilon_{0}$ ), the response of the system, quantified by the inlet temperature and humidity $\left(\mathrm{T}_{\mathrm{I}}\right.$ and $\left.\mathrm{W}_{\mathrm{I}}\right)$, can be investigated as a function of the driving conditions, namely the ambient and room temperatures and humidities (TAMB, $W_{A M B}, T_{R}$, and $W_{R}$ ). Sensible and latent cooling capacities, $Q_{S E N}$ and $Q_{L A T}$ in Figure $3-5$, then depend upon the temperature and humidity differentials that can be generated by the system between the room state and the inlet conditions. Steady-state performance was surveyed using TRNSYS by choosing meaningful sets of $T_{R}, W_{R}, T_{A M B}$, and $W_{A M B}$ and repetitively inputting values for the control parameters until the latent and sensible capacities converged. The primary driving conditions of interest correspond to room 


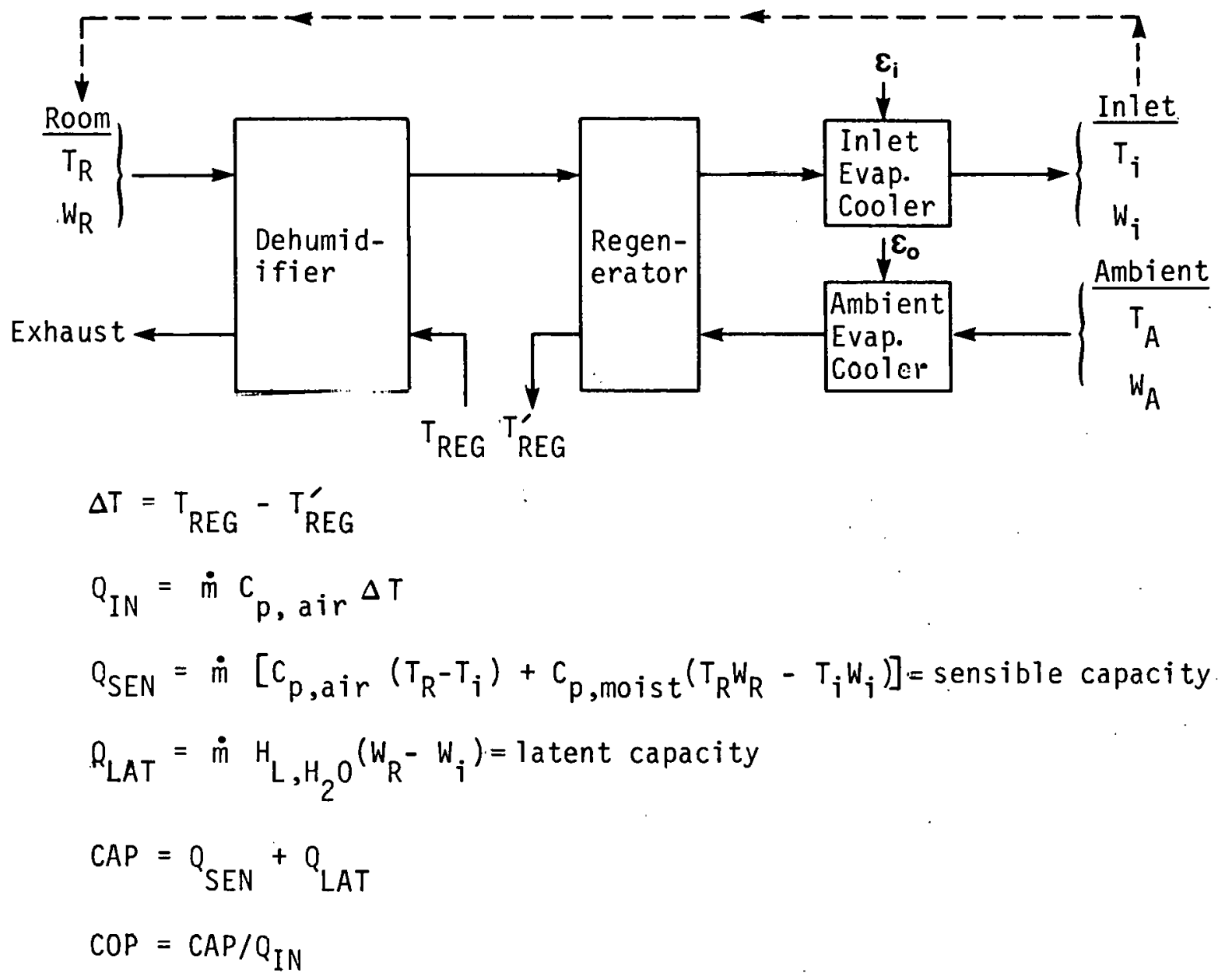

where

$C_{p, a i r}=$ specific heat of dry air $=1005.0 \mathrm{~J} / \mathrm{kg}_{\text {dry }}$ air

$C_{p, \text { moist }}=$ specific heat of moist air $=1884.3 \mathrm{~J} / \mathrm{kg}_{\mathrm{H}_{2} \mathrm{O}}$

$\mathrm{H}_{\mathrm{L}, \mathrm{H}_{2} \mathrm{O}}=$ latent heat of vaporization of water $=2.466 \times 10^{6} \mathrm{~J} / \mathrm{kg}_{\mathrm{H}_{2} \mathrm{O}}$

$\mathrm{T}$ = temperature, ${ }^{\circ} \mathrm{C}$

$W=$ humidity ratio, $\mathrm{kg}_{\mathrm{H}_{2} \mathrm{O}} / \mathrm{kg}$ dry air

F.igure 3-5. CONFIGURATION OF DESICCANT SYSTEM COMPONENTS USED TO GENERATE STEADY-STATE PERFORMANCE MAPS 
states located along the comfort zone borders (Figure 3-21), with the ambient temperature and humidity exceeding those of the room. Results for these cases (Figures 3-6 to 3-9) specify the system capabilities in attempting to restore comfort to each of the particular zones of discomfort.

Figures 3-10 to 3-13 illustrate the system reaction to other climatic circumstances. Machine response to a room state at the maximum comfortable temperature with elevated humidity is given by Figure 3-10. System performance is little affected by raising the outdoor temperature from $29.2^{\circ} \mathrm{C}$ (Figure $3-7$ ) to $35^{\circ} \mathrm{C}$ (Figure 3-11). However, an increase in ambient humidity drastically degrades operation characteristics as seen by comparison of Figures 3-11 and 3-12. Conversely, Figures 3-6 and 3-13 exhibit the enhancement in performance resulting from milder ambient conditions.

To investigate further the sensitivity of performance, a design point (Table 3-13) was defined and the driving conditions and regeneration temperatures were varied. Total and latent system capacity and COP were then plotted (Figures 3-14 through 3-18). Figures 3-14 and 3-16 show relatively flat profiles of performance as functions of outdoor and indoor temperatures, respectively. On the other hand, substantial improvement in latent cooling capacity is attained at higher room humidities (Figure 3-17), and an inverse relationship is evidenced as the ambient humidity rises (Figure 3-15). In each case, system sensible cooling remains essentially constant. Thus, the desiccant machine operates optimally as a latent cooler in climates which are not excessively humid. System performance is seen to peak (Figure 3-18) near $85^{\circ} \mathrm{C}$, in accordance with the choice of $T_{R E G}=85^{\circ} \mathrm{C}$ for design-point operation. 'At lower regeneration temperatures, system capacity is small relative to the energy supplied $\left(Q_{I N}\right)$. At higher temperatures, the large amount of energy supplied causes $Q_{I N}$ to dominate the behavior of the COP.

A summary of the values used to generate a 11 steady-state performance maps is presented in Table 3-13.

\subsection{DYNAMTC PERFORHANCE}

\subsubsection{General Description}

Long-term simulations of the transient behavior of the desiccant cooling system were performed by modifying the steady-state component configuration. The primary changes were the incorporations of a solar energy collector/storage unit, an interactlve house model, and a controller capable of dynamically varying critical system parameters. An interface with hourly meteorological data and sensible load information was also added. The revised system arrangement is presented in Figure 3-19.

Regeneration demanded by the desiccant dehumidifier was provided by a solar collector air system in combination with an external thermal storage tank. A five-layer, thermally stratified pebble bed storage unit was modeled. All simulations assumed isothermal equilibrium at $40^{\circ} \mathrm{C}$ as the initial condition. A cylindrical tank was chosen with a height equal to twice its radius and with a volume $V_{S T O R}$ of $0.40 \mathrm{~m}^{3}$ per $\mathrm{m}^{2}$ of collector area. 
Table 3-13. PERFORMANCE MAP PARAMETER SUMMARY

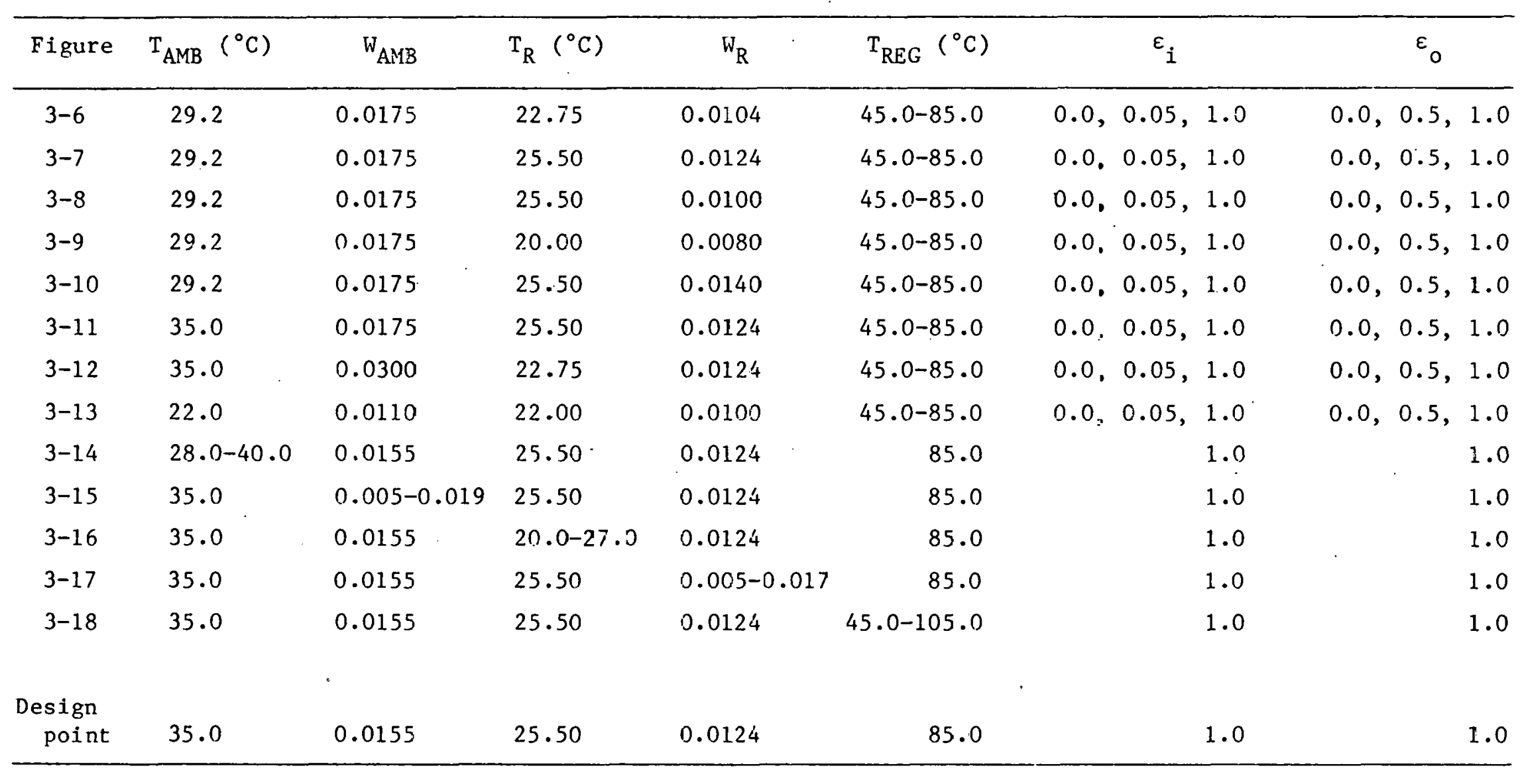




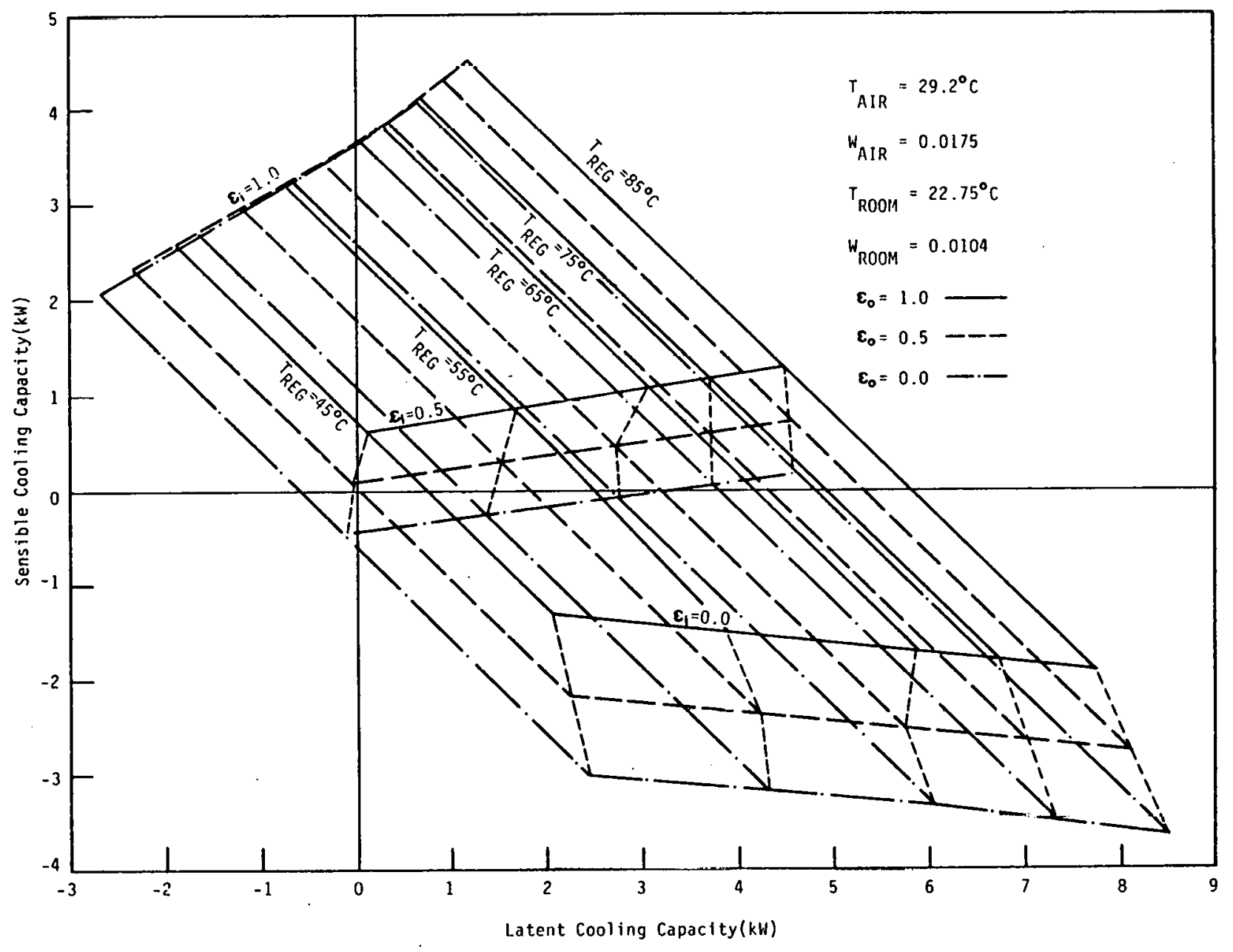

Figure 3-6. STEADY-STATE PERFORMANCE MAP: ZONES 3 - 6 


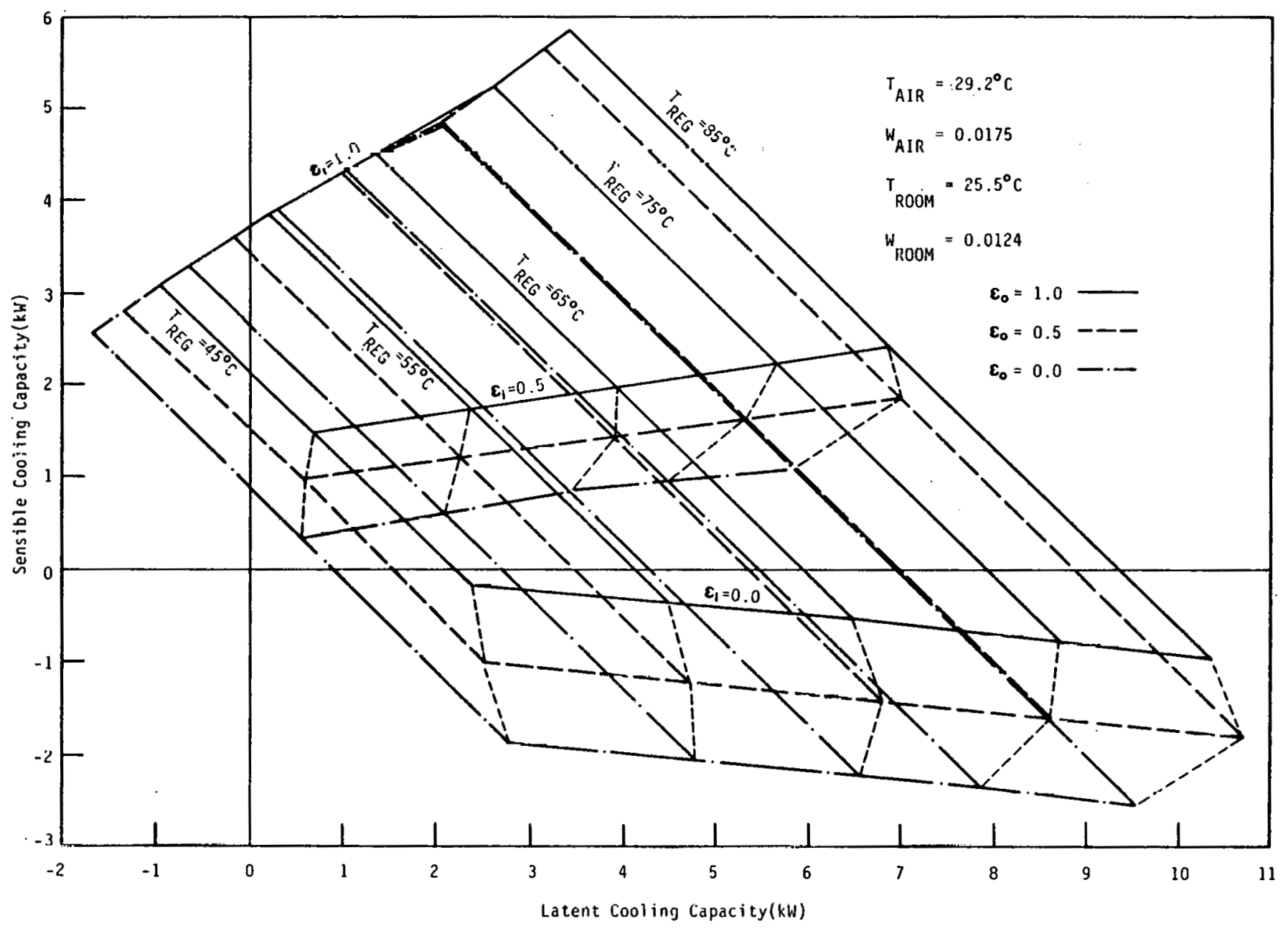

Figure 3-7. STEADY-STATE PERFORMANCE. MAP: ZONES 4 - 6 


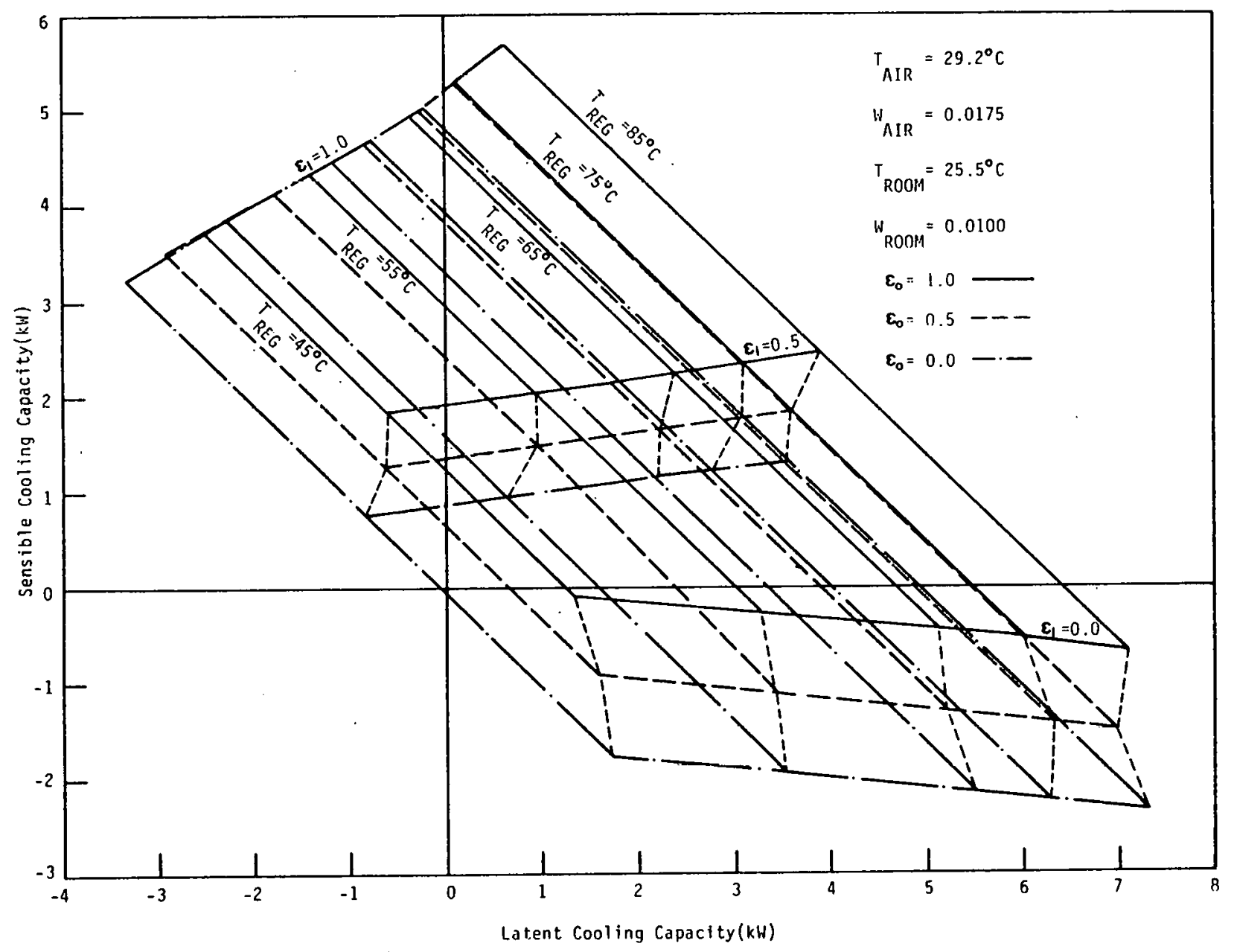

Figure 3-8. STEADY-STATE PERFORMANCE MAP: ZONES $5-6$ 


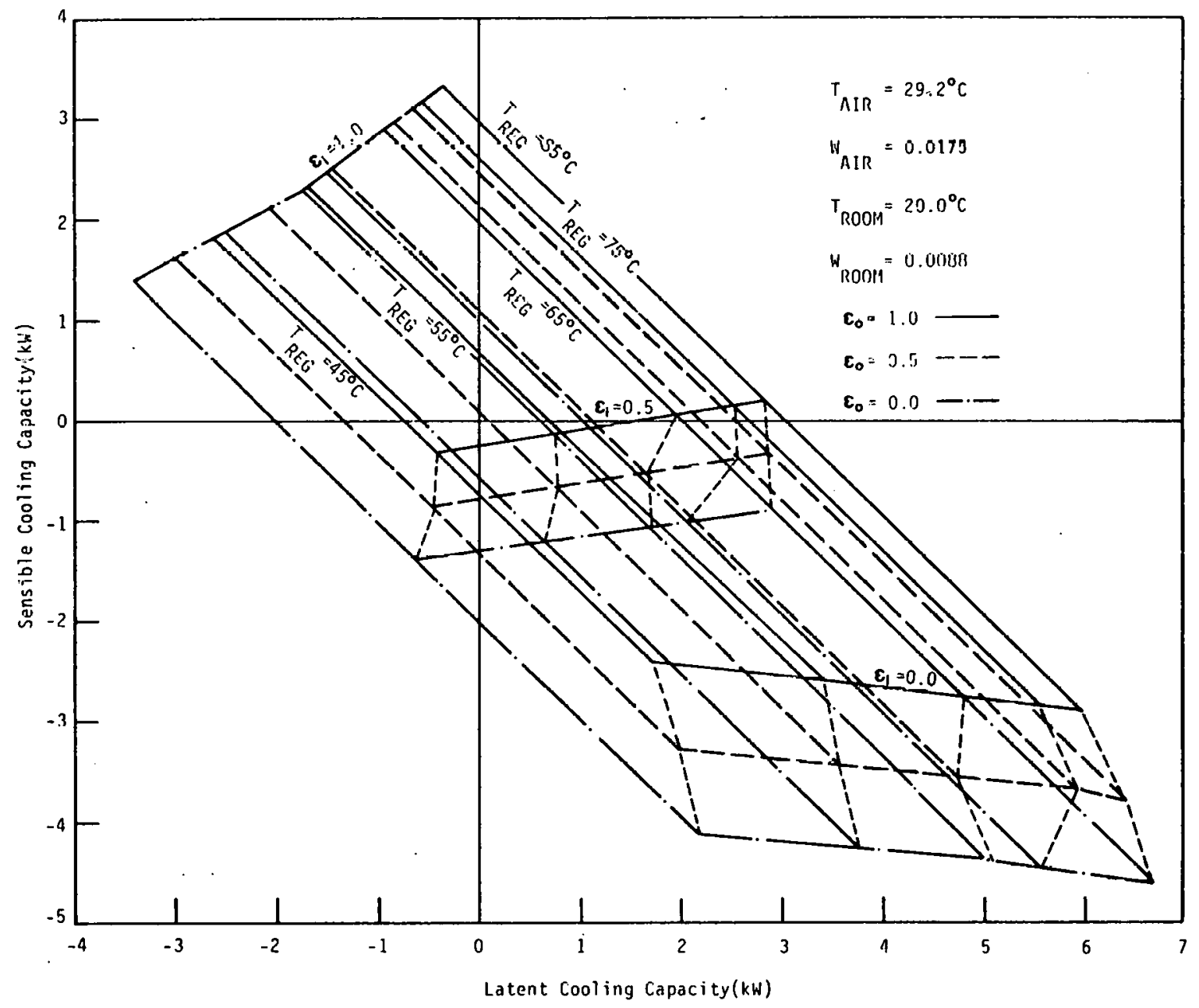

Figure 3-9. STEADY-STATE PERFORMANCE MAP: ZONES 2 - 6 


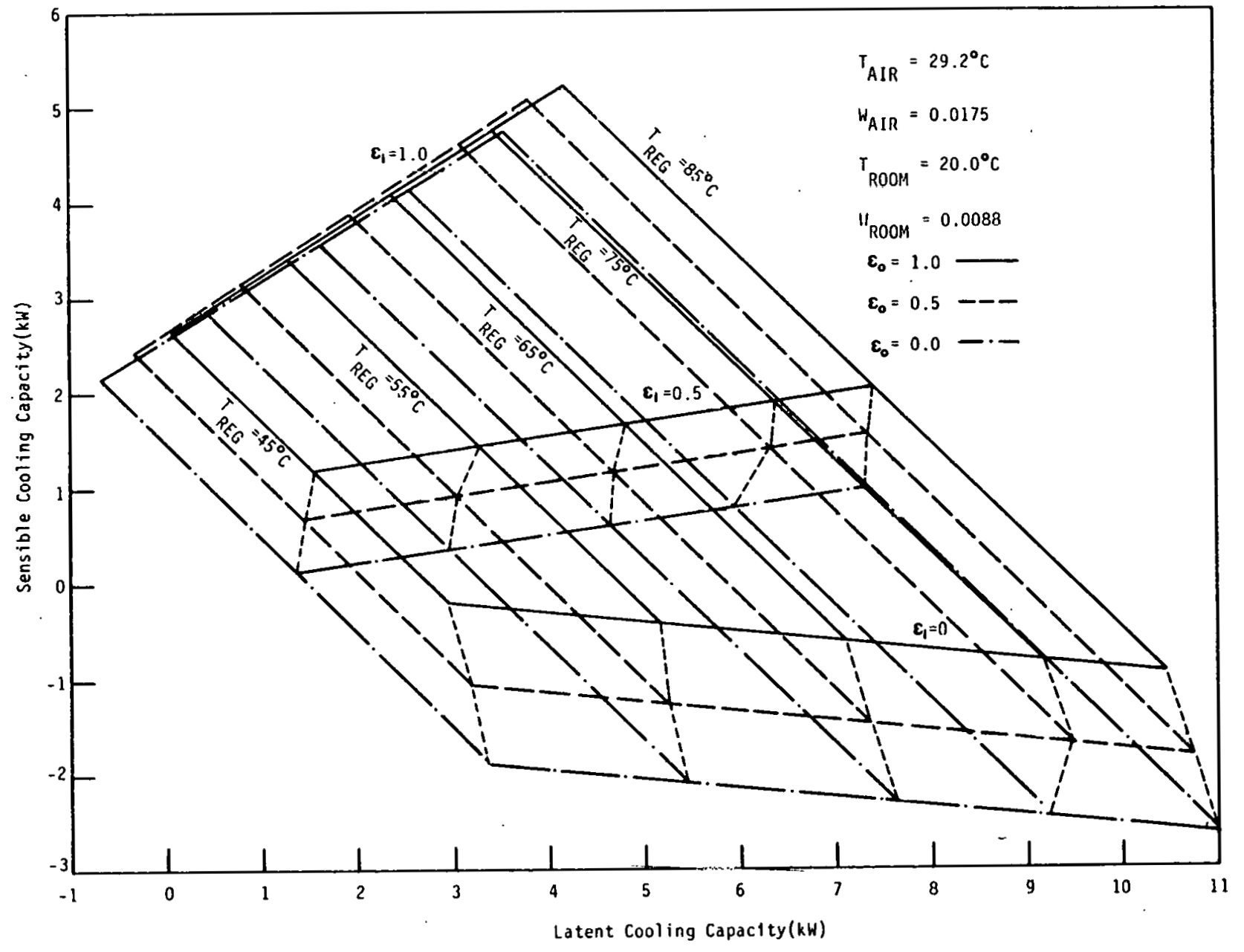

Figure 3-10. STEADY-STATE PERFURMANCE MAP: ZONES 3 - 4 


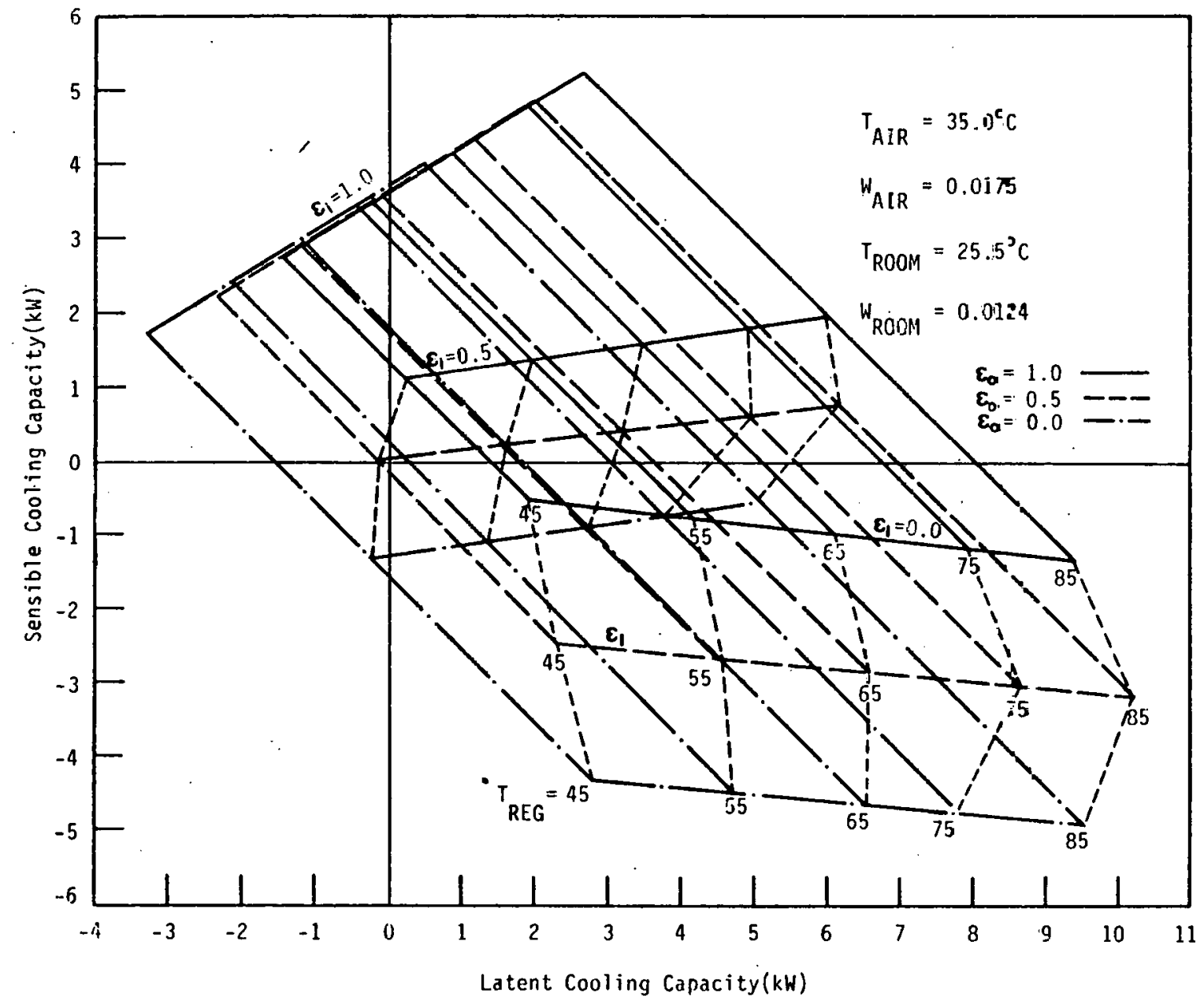

Figure 3-11. STEADY-STATE PERFORMANCE MAP: SEVERE AMBIENT TEMPERATURE 


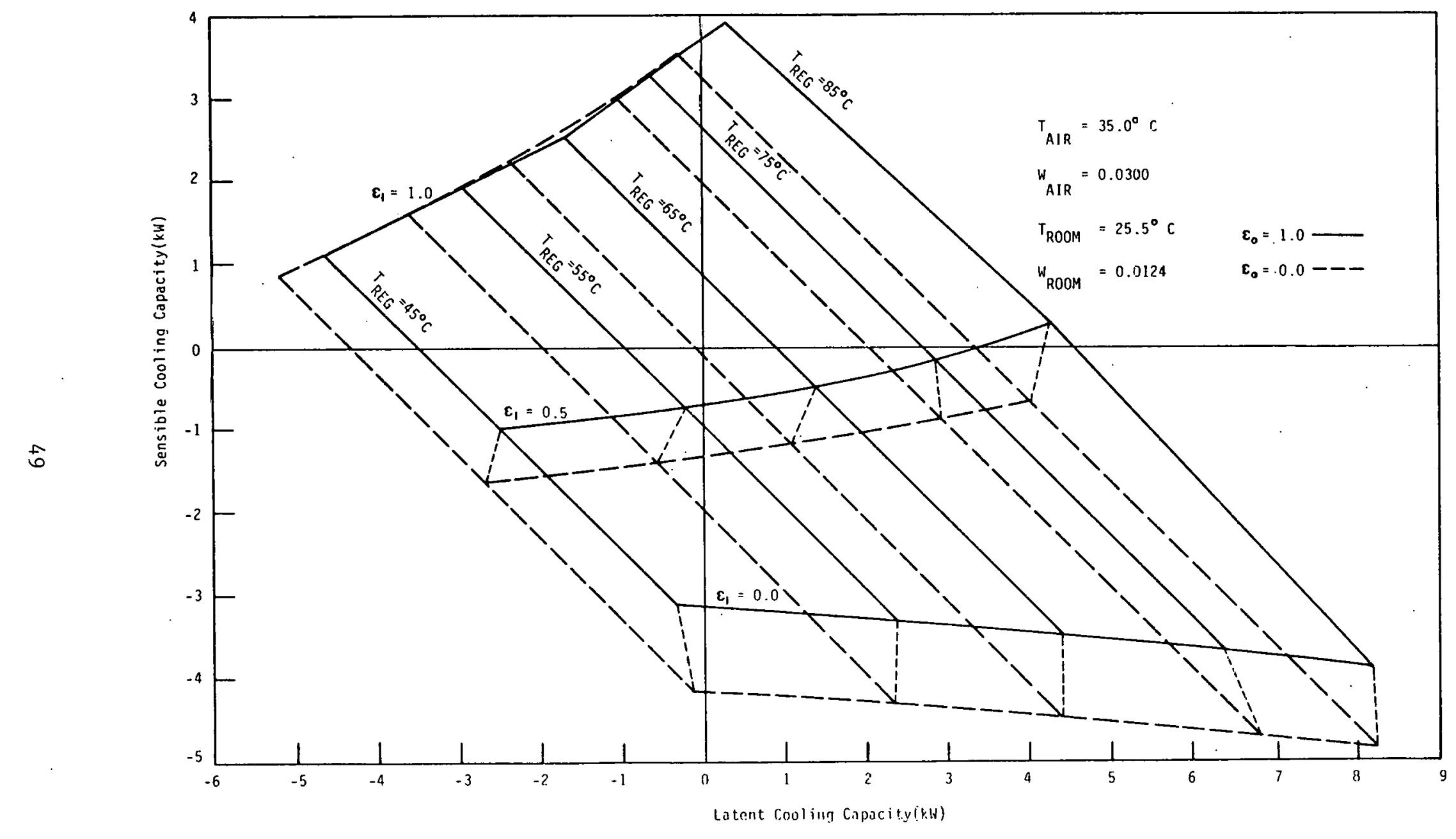

Figure 3-12. STEADY-STATE PERFORNANCE MAP: SEVERE AMBIENT TEMPERATURE AND HUMIDITY 


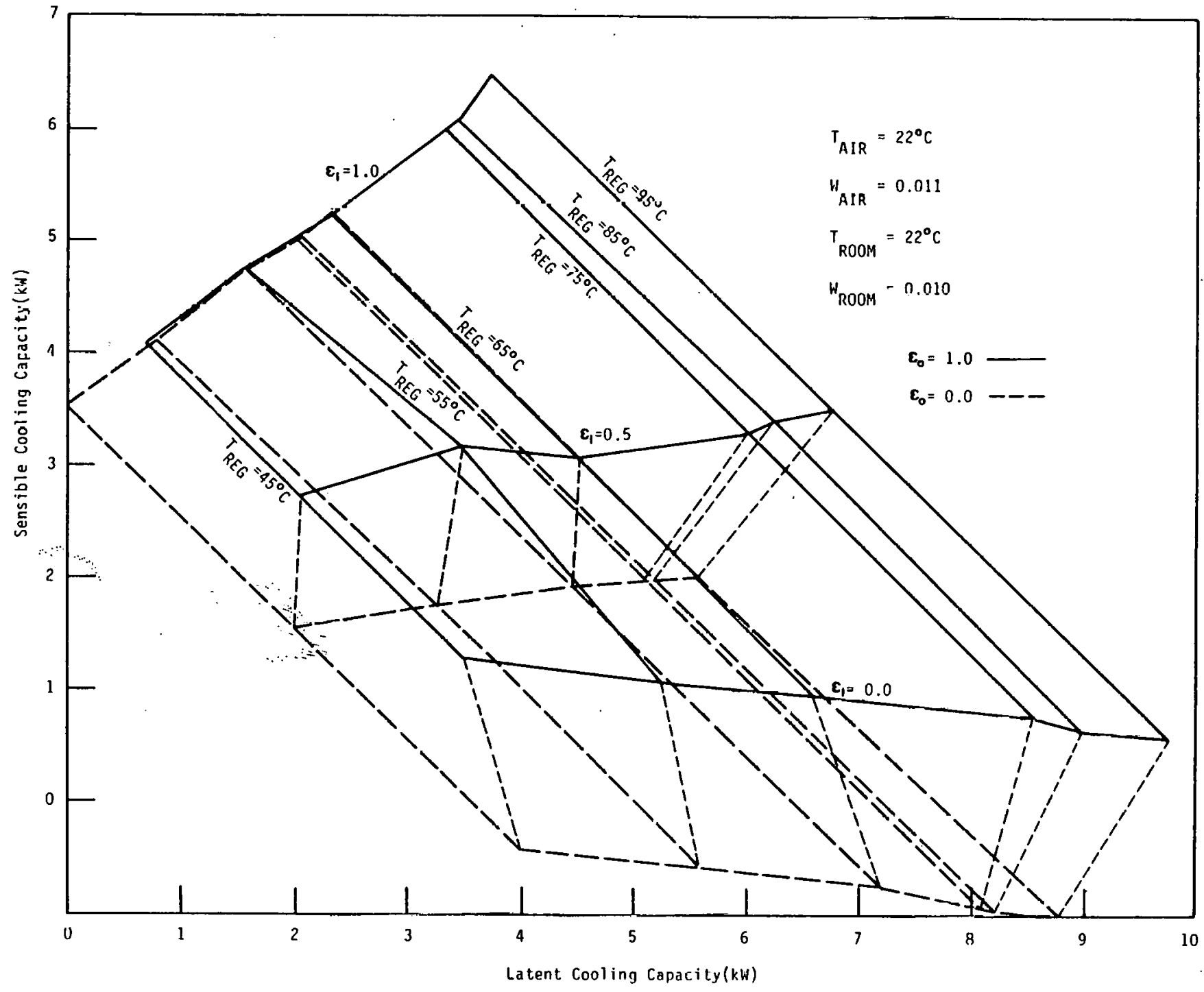

Figure 3-13. STEADY-STATE PERFORMANCE MAP: MILD AMBIENT CONDITIONS 


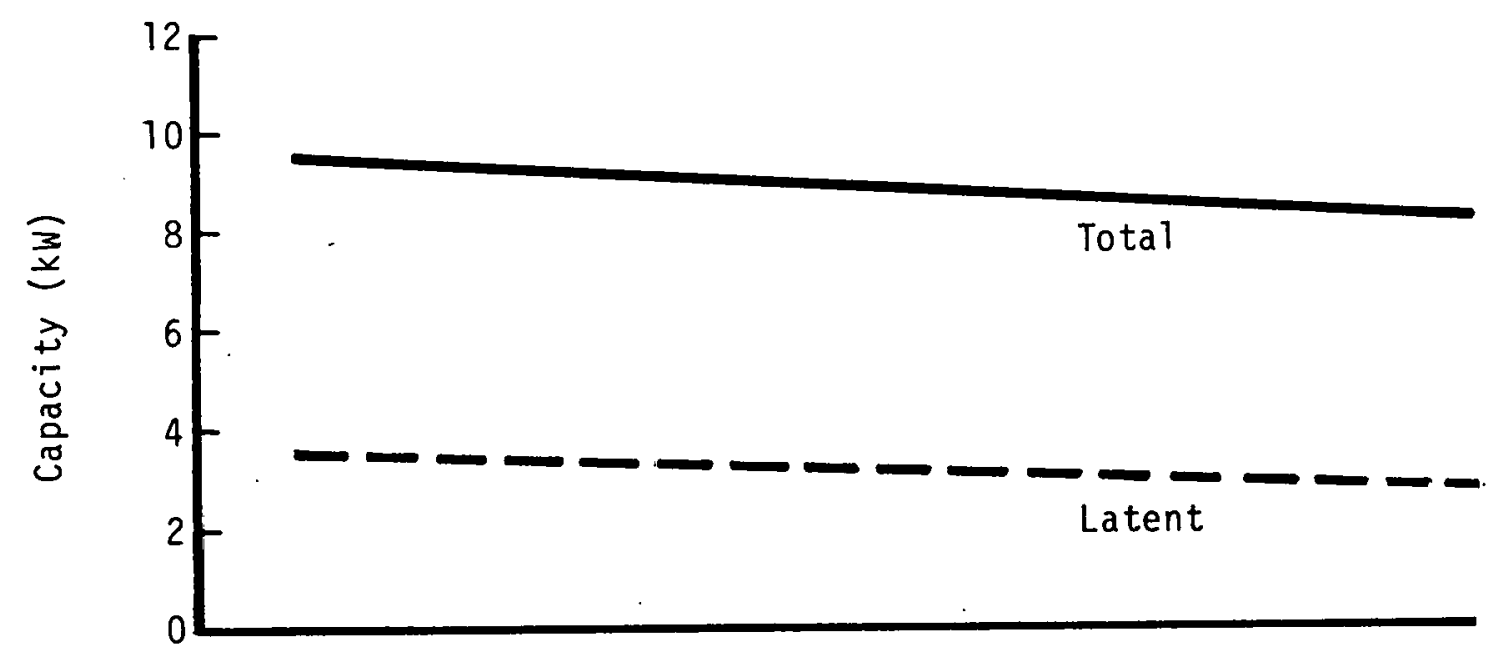

$$
\begin{aligned}
& T_{\text {room }}=25.5^{\circ} \mathrm{C} \\
& W_{\text {room }}=0.0124 \\
& W_{\text {ambient }}=0.0155 \\
& T_{\text {regeneration }}=85^{\circ} \mathrm{C}
\end{aligned}
$$

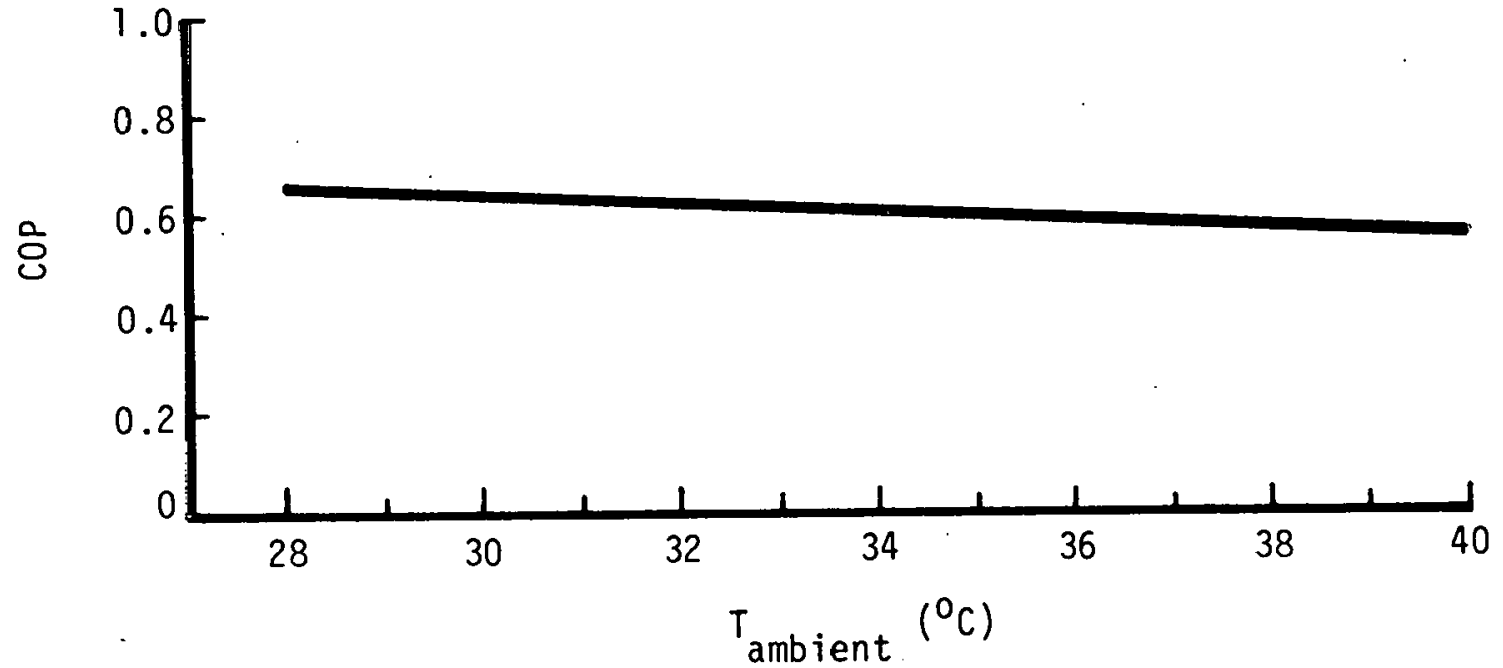

Figure 3-14. STEADY-STATE SENSITIVITY TO AMBIENT TEMPERATURE 


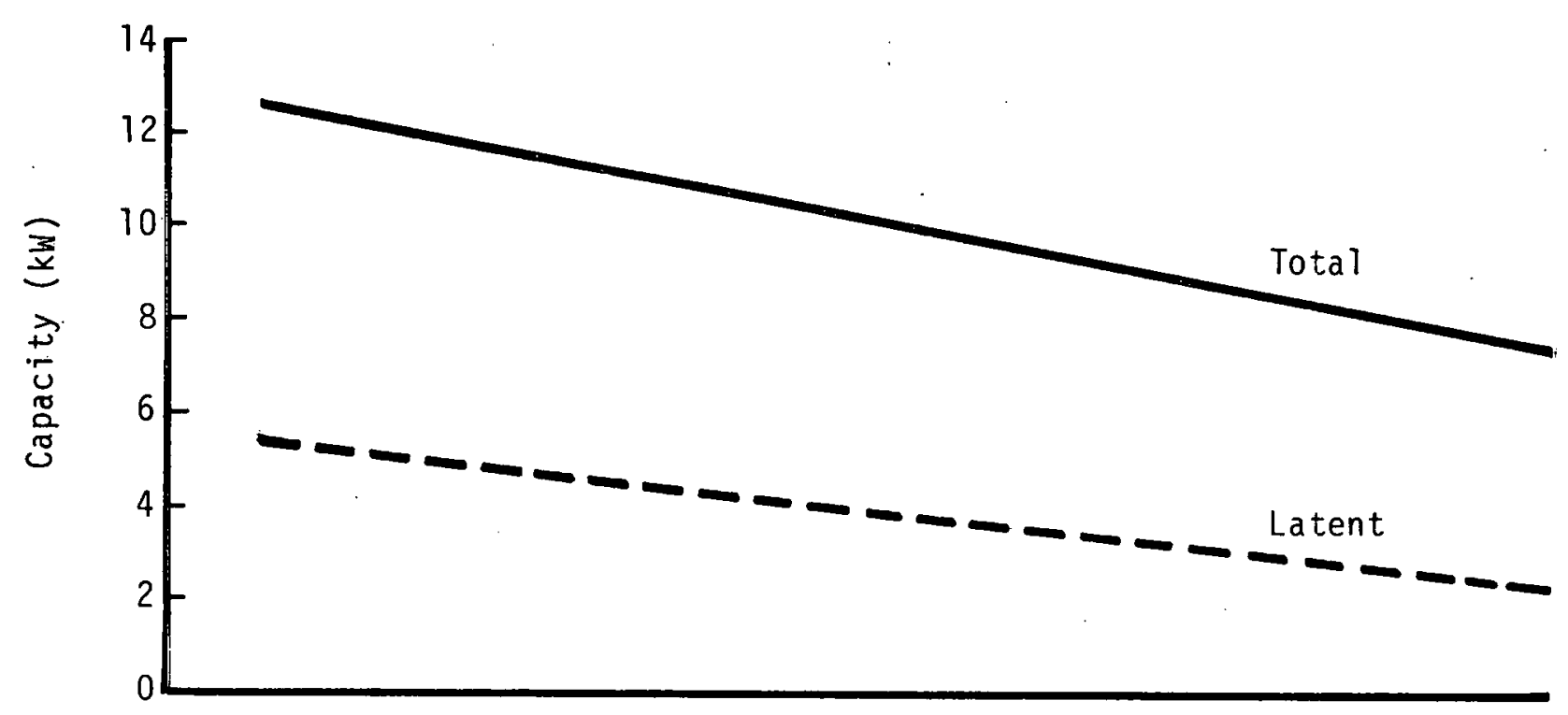

$$
\begin{aligned}
& T_{\text {room }}=25.5^{\circ} \mathrm{C} \\
& W_{\text {room }}=0.0124 \\
& T_{\text {ambient }}=35^{\circ} \mathrm{C} \\
& T_{\text {regeneration }}=85^{\circ} \mathrm{C}
\end{aligned}
$$

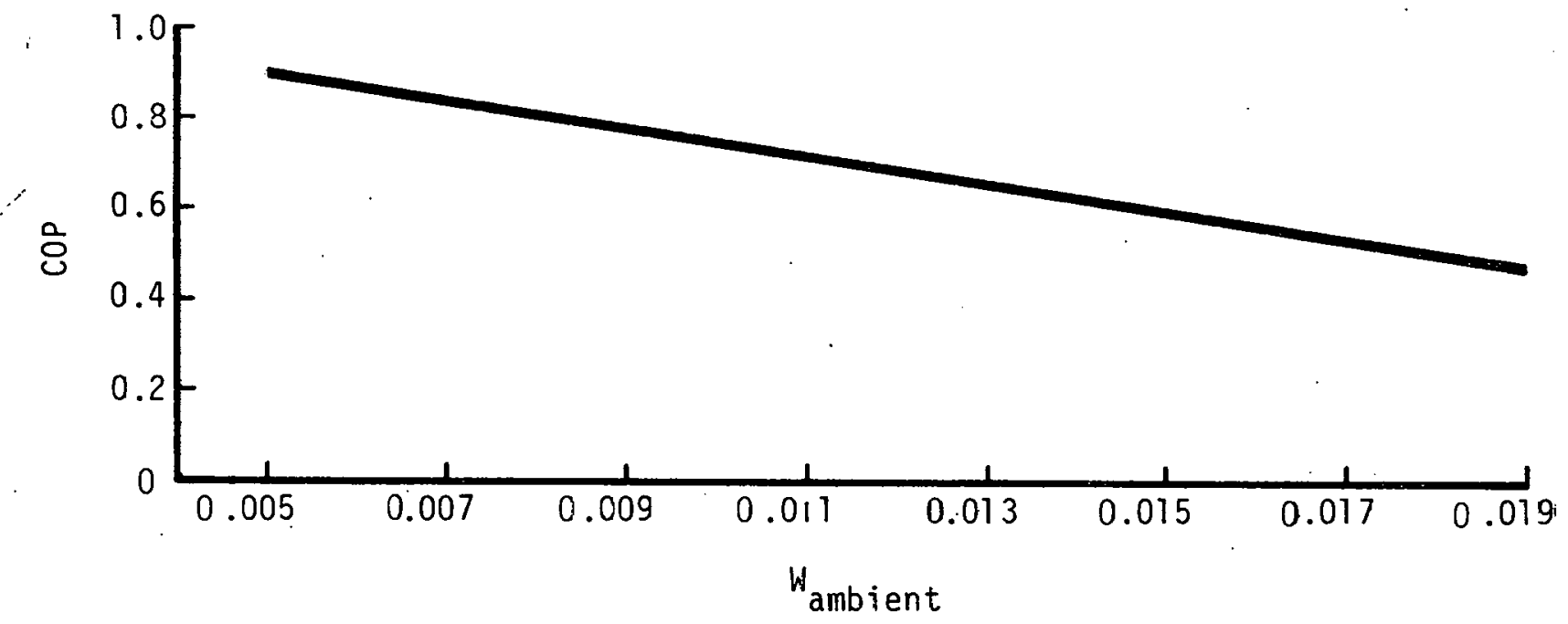

Figure 3-15. STEADY-STATE SENSITIVITY TO AMBIENT HUMIDITY 


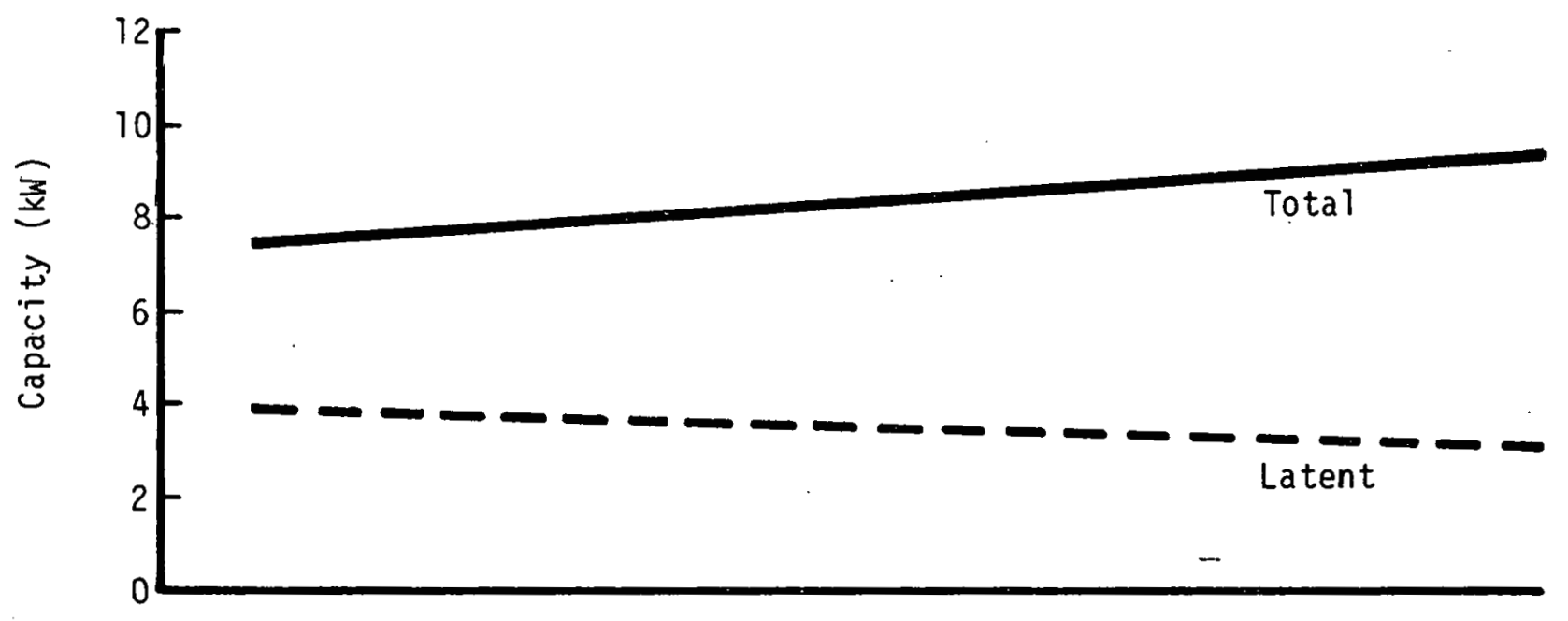

$W_{\text {room }}=0.0124$

$T_{\text {ambient }}=35^{\circ} \mathrm{C}$

$W_{\text {ambient }}=0.0155$

$T_{\text {regeneration }}=85^{\circ} \mathrm{C}$

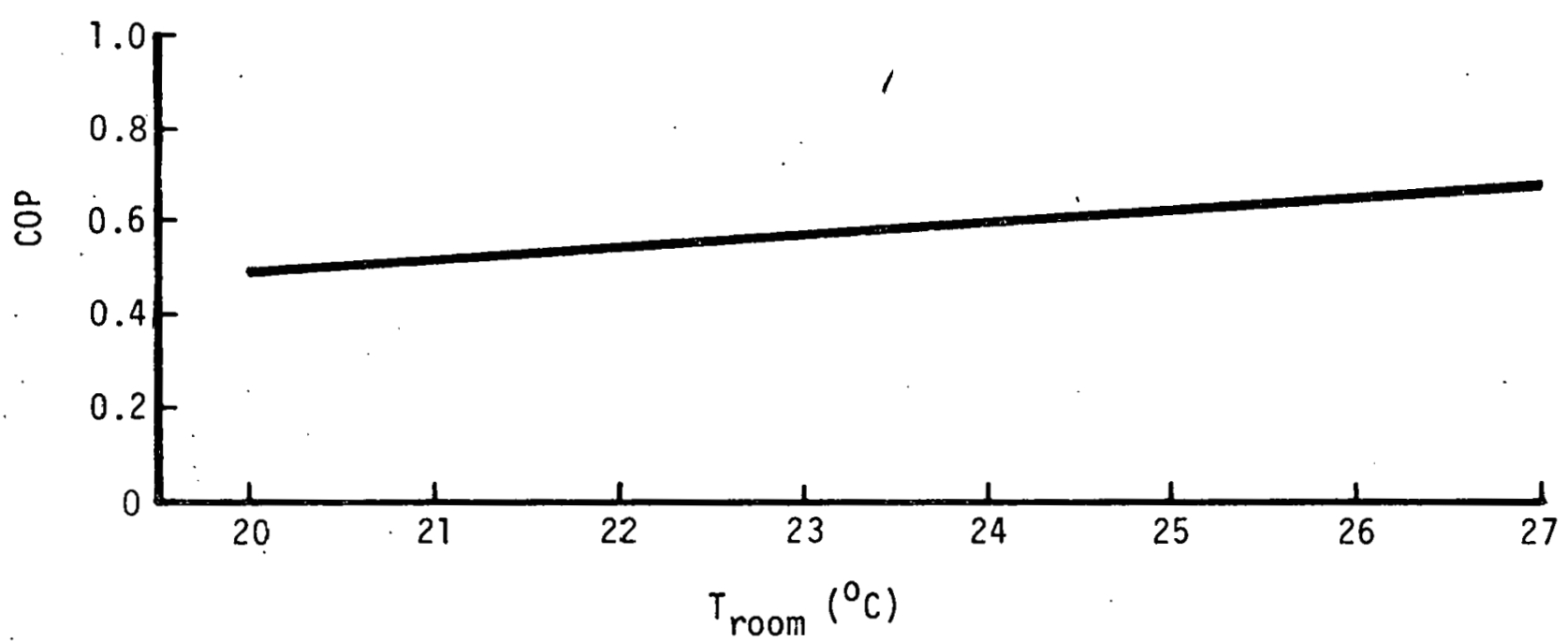

Figure 3-16. STEADY-STATE SENSITIVITY TO ROOM TEMPERATURE 


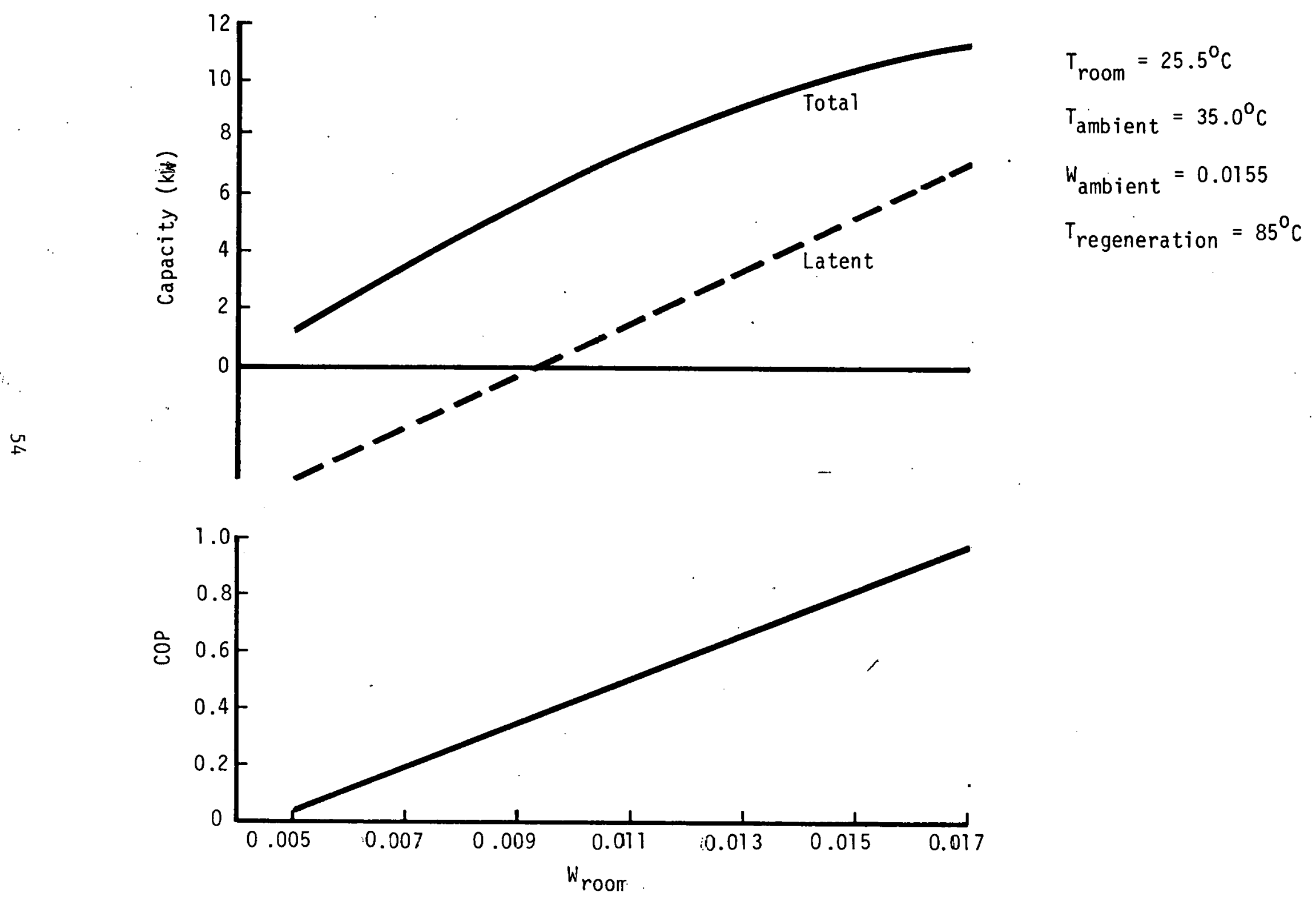

Figure 3-17. STEACY-STATE SENSITIVITY TO ROOM HUMIDITY 


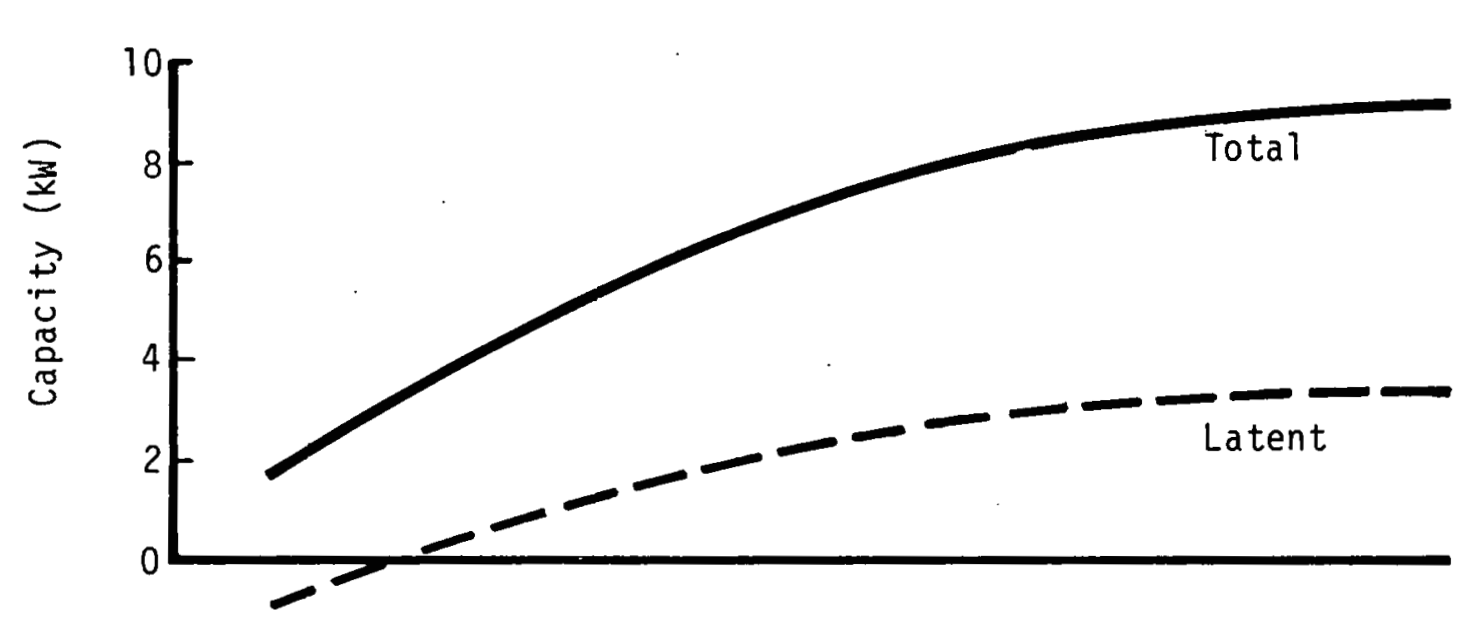

$$
\begin{aligned}
& T_{\text {room }}=25.5^{\circ} \mathrm{C} \\
& W_{\text {room }}=0.0124 \\
& T_{\text {ambient }}=35^{\circ} \mathrm{C} \\
& W_{\text {ambient }}=0.0155
\end{aligned}
$$

Figure 3-18. STEADY-STATE SENSITIVITY TO REGENERATION TEMPERATURE 


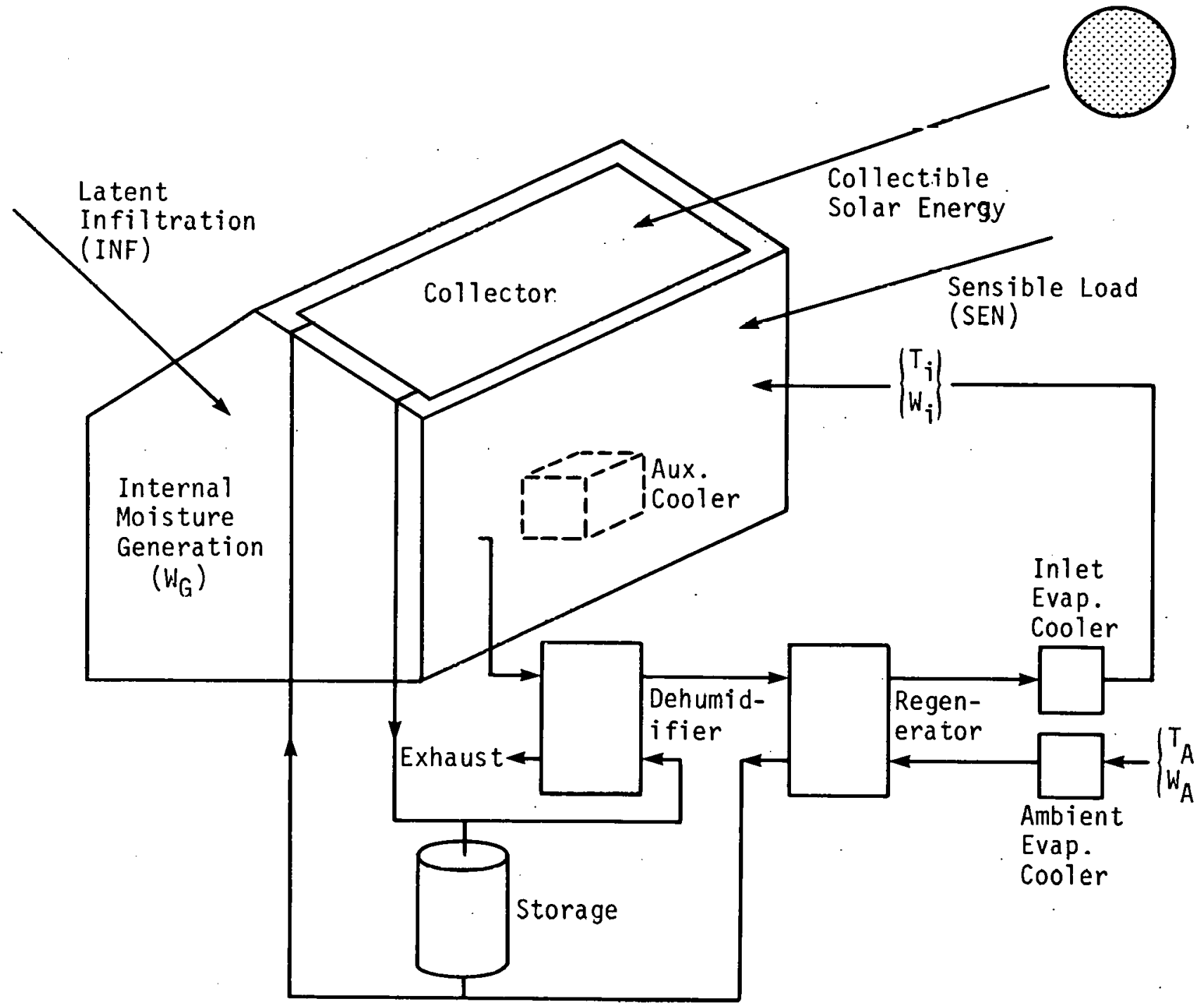

Figure 3-19. DESICCANT SYSTEM COMPONENT CONFIGURATION FOR DYNAMIC SIMULATIONS 
As discussed in Section 3.7.2, upper and lower operation temperature limits ( $\mathrm{T}_{\text {MAX }}$ and $\mathrm{T}_{\mathrm{MIN}}$ ) for the desiccant system were appropriate. Whenever cooling capacity was required and the temperature available from the collector/storage system $\left(T_{R E G}\right)$ was less than $T_{M I N}$, air flow to the dehumidifier was turned off $\left(\dot{\mathrm{m}}_{\mathrm{L}}=0\right)$. To ensure that energy was never used at an outlet temperature exceeding the maximum $\left(\mathrm{T}_{\mathrm{REG}}>\mathrm{T}_{\mathrm{MAX}}\right)$, the flowrate through the collector was increased ( $\dot{\mathrm{m}}_{\mathrm{C}}>\dot{\mathrm{m}}_{\mathrm{L}}$ ) when necessary to regulate the heat delivered either to storage or directly to the drier. The standard TRNSYS collector subsystem was modified to provide collector/storage usage as summarized in Table 3-14.

The transient house model was sensitive to external latent and sensible loads, internal moisture generation, and the cooling capacities of the desiccant machine and an optional auxiliary vapor-compression unit. Calculation of the latent and sensible cooling capacities of the desiccant. system was identical to that for the steady-state case (F1gure 3-5) except that the room conditions were allowed to fluctuate in response to the driving forces. Initial values for the indoor temperature and humidity were selected to be $T_{R}=23.9^{\circ} \mathrm{C}$ and $\mathrm{W}_{R}$ $=0.0085 \mathrm{~kg}_{\mathrm{H}_{2} \mathrm{O}} / \mathrm{kg}_{\mathrm{dry}}$ air, respectively. Thereafter, the room temperature variation was ${ }^{2}$ determined by the sensible machine capacity, if any, and the sensible load was computed as described in section 3.2.3. Similiarly, the room humidity was a function of the desiccant dehumidification capacity and the latent load experienced by the house.

The latent load consisted of two contributions: the transposition of indoor and outdoor moisture due to infiltration, and the formation of water vapor due to internal, water fixtures, household appliances, and residents. A representative daily profile of internal water vapor generation, illustrated in Figure 3-20, was assumed. The instantaneous latent load LAT was then computed:

$$
\mathrm{LAT}=\left[\left(\mathrm{W}_{\mathrm{AMB}}-\overline{\mathrm{W}}_{\mathrm{R}}\right) \mathrm{INF}+\mathrm{W}_{\mathrm{G}}\right] \mathrm{H}_{\mathrm{fg}},
$$

where

$$
\begin{aligned}
& \bar{W}_{\mathrm{R}}=\text { average room humidity }\left(\mathrm{kg}_{\mathrm{H}_{2} \mathrm{O}} / \mathrm{kg} \mathrm{dry} \text { air }\right), \\
& \text { INF }=\text { rate of infiltration }=0.282 \mathrm{~kg}_{\mathrm{dry}} \text { air } / \mathrm{h}, \\
& W_{G}=\text { internal rate of moisture generation, and } \\
& \mathrm{H}_{\mathrm{fg}}=\text { latent heat of vaporization of water }=2.466 \times 10^{6} \mathrm{~J} / \mathrm{kg}_{\mathrm{H}_{2}} \mathrm{O}
\end{aligned}
$$

\subsubsection{Control Strategy}

The primary objective of the control strategy was to maintain the climatic conditions inside the house within the specified comfort limits. During this process, it was desirable to minimize the consumption of energy and the operation time of the machine. This was achieved in the controller by the assignment of values to control parameters. The strategy for choosing these values was based on the results of the steady-state analysis. Implementation of severa l. auxiliary power mode options and accurate bookkeeping of the house loads and system capacities were additional functions performed by the controller. 
Table 3-14. SOLAR COLLECTOR/STORAGE USAGE ${ }^{a}$

\begin{tabular}{|c|c|c|c|c|c|}
\hline Desiccant & System & Flow Logic & & Collector System & Logic \\
\hline Zone & $\mathrm{T}_{\mathrm{REG}}$ & $\dot{\mathrm{m}}_{\mathrm{L}}$ & & $\bar{\Gamma}_{\text {COLL }}$ & $\dot{\mathrm{m}}_{\mathrm{C}}$ \\
\hline $1,2,6$ & & 0 & & $\leq\left(\mathrm{T}^{\prime}{ }_{\mathrm{REG}}+\mathrm{DT}\right)$ & 0 \\
\hline $3,4,5$ & $<\mathrm{T}_{\mathrm{MIN}}$ & 0 & & $<\mathrm{T}_{\mathrm{STOR}}$ & 0 \\
\hline $3,4,5$ & $\geq \mathrm{T}_{\mathrm{MIN}}$ & $\dot{\mathrm{m}}_{\mathrm{S}}$ & $\left(\mathrm{T}_{\mathrm{REG}}+\mathrm{DT}\right)$ & $\begin{array}{l}<\mathrm{T}_{\text {COLL }}<\mathrm{T}_{\mathrm{MAX}} \\
=\mathrm{T}_{\mathrm{MAX}}\end{array}$ & $\begin{aligned} & \dot{\mathrm{m}}_{\mathrm{S}} \\
> & \dot{\mathrm{m}}_{\mathrm{S}}\end{aligned}$ \\
\hline
\end{tabular}

Collector-Desiccant Interaction

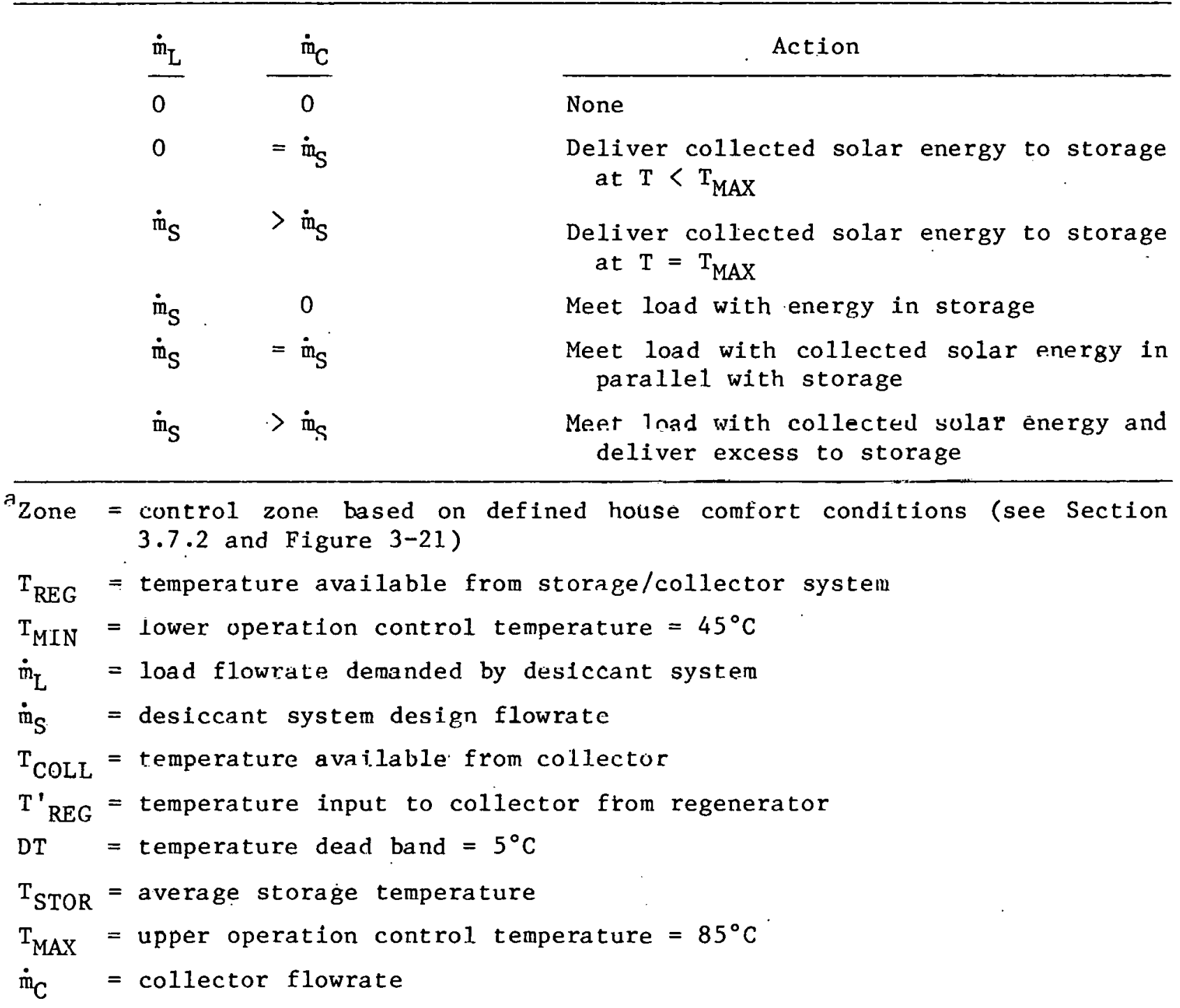




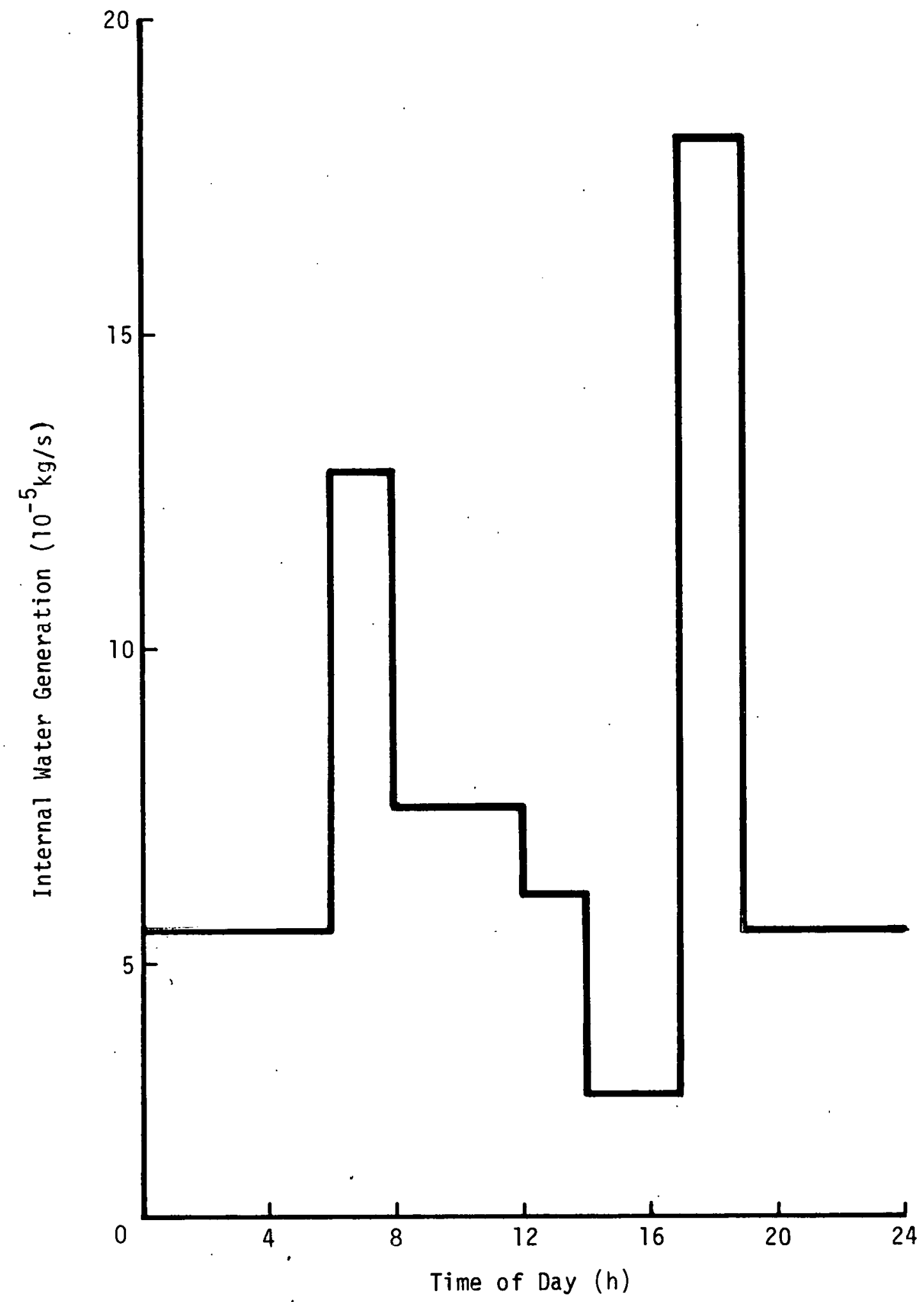

Figure 3-20. DIURNAL VARIATION OF HOUSE INTERNAL WATER VAPOR GENERATION 
Nelson has shown that a set of parameters suitable for characterizing the performance of the desiccant system includes the temperature of the regeneration stream $T_{R E G}$ and the effectiveness of the inlet and outlet evaporative coolers $\left(\varepsilon_{i}\right.$ and $\left.\varepsilon_{0}\right)$ [4]. It can be seen from the steady-state performance maps that $\mathrm{T}_{\mathrm{REG}}$ and, to a lesser extent, $\varepsilon_{\mathrm{o}}$ govern the magnitude of the attainable cooling capacity, whereas $\varepsilon_{i}$ regulates the ratio of the sensible to latent components $(\mathrm{S} / \mathrm{L})$. The strategy was then to vary these control parameters to maximize latent cooling when indoor conditions became too humid, maximize sensible cooling when indoor conditions were too hot, and adjust S/L appropriately when both humidity and temperature exceeded specified thresholds.

Studies by the University of Wisconsin and Solaron Corporation used solar energy supplemented by auxiliary heat to provide the desired regeneratiun temperature at all times $[25,26]$. It was implicitly assumed that all drifting of room conditions were comfort/noncomfort interactions; that is, no passagc from one noncomfort zone to another ever occurred. An incremental control loop was used to approximate a continuous feedback control system. Based upon the room conditions at the start of each time step, the control parameters were adjusted to meet the house loads. Because optimum system performance (COP) is inversely related to the regeneration stream temperature, $\mathrm{T}_{\text {REG }}$ was initialized to a minimum value and then increased with each time step in an effort to enhance system operating efficiency. An upper limit cutoff of $\mathrm{T}_{\text {REG }}(\max )=85^{\circ} \mathrm{C}$ was found to be practical. Wisconsin concluded that further refinements were needed in the control strategy to significantly improve the operation of the desiccant system.

Rather than optimizing the efficient use of solar energy by the desiccant cooler (COP), the emphasis of the control strategy used in this study was to maximize the time spent in comfort (zone 6) and minimize the duty cycle of the desiccant cooler. This should result in the minimum amount of electrical input and thus lower operating costs. The controller was modified to reflect this operating philosophy. Whenever an excursion out of comfort occurred, regeneration of the desiccant material was demanded. A lower cutoff regeneration temperature, required by the dynamic behavior of the gel and evident from the performance maps, was chosen as $T_{R E G}$ (min) $=45^{\circ} \mathrm{C}$. The maximum temperature between $T_{R E G}$ ( $m i n$ ) and $T_{R E G}$ (max) available from storage was then used, resulting, in the generation of the greatest attainable cooling capacity. Obvious trade-offs exist between this method and the attempt to ration the collected solar heat by applying an incremental scheme. By gradually elevating the system capacity until the loads are fust met, system COP is maximized by minimizing solar energy usage. However, deviations from comfort occur with greater frequency because just matching the cooler capacity with the house loads controls along the comfort boundaries. This tends to increase operation time and thereby increase the expenditure of electrical energy. On the other hand, operating at maximum available capacity ensures the highest probability of returning to comfort in the shortest time period, and less electrical energy (fan usage) should be, required. In addition, this strategy allows a deeper penetration into the comfort zone.

Based on the definition of house comfort conditions, six unique control zones can be defined (Figure 3-21). Unlike prior simulations that controlled to a maximum absolute humidity, it was decided to use relative humidity as the 


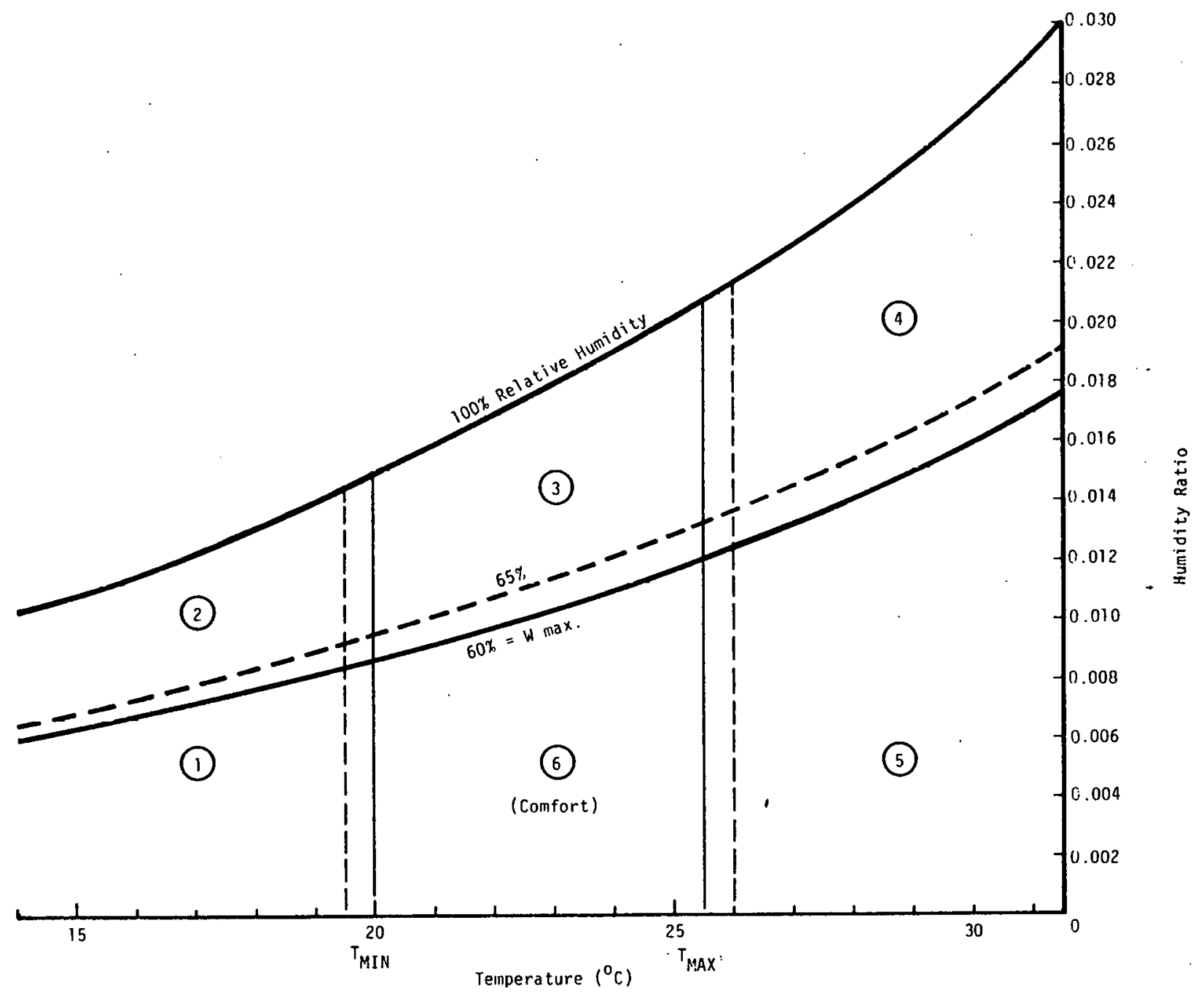

Figure 3-21. CONTROL ZONES BASED ON HOUSE COMFORT CONDITIONS (Dead bands are located between solid and dashed lines) 
control criterion. The reason for adopting this control parameter was the wide variance $(34 \%)$ in humidity ratio at the upper and lower temperature limits ( $\mathrm{T}_{\mathrm{MAX}}$ and $\mathrm{T}_{\mathrm{MIN}}$ ) at $60 \%$ relative humidity. "Dead bands" were employed to suppress the effect of small drifts out of the comfort zone due to fluctuations in room conditions caused by the occasional inability of the machine to meet the total load. Whenever the house resided in a dead band, it was considered to be in comfort but the desiccant cooling system functioned with the appropriate zonal strategy as described in the following paragraphs.

Sensible heating is required to return the zone-1 room state to comfort. The desiccant unit does not operate in this zone. However, the amount of heating needed to return to comfort (zone 6 ) was computed in the model and compared with the external house load due to insolation. If ambient conditions were sufficient to restore comfort within one time increment, then no additional action was taken. Otherwise, the house heating load was met by auxillary heating. Collected/stored solar energy was used for heating during the heating season and strictly for cooling during the rest of the year. Heating loads occurring during the cooling season were always met by auxiliary heating.

Zone-2 strategy dictates that the house be heated and dehumidified. Figure 3-9 presents the performance of the desiccant system at the crossover point between zone 2 and comfort. Operating with $\varepsilon_{i}=\varepsilon_{0}=0$ produces negative sensible (heating) capacity concurrent with positive latent (dehumidification) capacity. However, preliminary simulations showed that zone 2 was reached only occasionally during the transition periods (between heating and cooling seasons). Attempts to. operate the desiccant system as outlined above resulted in an approximately isothermal transition from zone 2 to zone 1 . This was caused by the inability of the desiccant system heating capacity to compensate for the predominantly negative (heating) loads, the net effect of which was dehumidification only. Consequently, it was declded that the optimum approach would be to duplicate the zone-1 control strategy 1 n zone 2, resulting in the transition of room conditlons from zone 2 to zone 3 . The unuesd solar capacity was then used for dehumidification by the zone 3 strategy.

Ideally, only dehumidification is necessary in zone 3 . Nominal system performance for this condition is displayed in Figure 3-6. In this case, it is desirable to operate with zero sensible cooling capacity, a goud approximation to this being $\varepsilon_{0}=0.9$ and $\varepsilon_{i}=0.4$. In practice, the decrease in ambient temperatures each evening results in increased relative humidity and negative sensible house loads. If the humidity drives the indoor state into zone 3 (point $A$ to point $B$ in Figure 3-22), a latent capacity sufficient to bring about a change in humidity ratio $\Delta W=W(B)=W(C)$ Is seyuiled to restore comfort, with the room temperature assumed constant. The accompanying negative evening load, however, lowers the room temperature by an amount $\Delta \mathrm{T}=$ $T(C)-T(D)$. Thus, pure dehumidification of magnitude $\Delta W$, in conjunction with a decrease in room temperature, results in room state $D$ rather than $C$ and comfort is not achieved. For this case, a better strategy is to operate the system with both evaporative coolers turned off $\left(\varepsilon_{0}=\varepsilon_{i}=0\right.$ in Figure 3-6), thereby generating heating capacity to offset the sensible load, and increasing the latent capacity (Table 3-15).

Conditions represented by zone 4 require both latent and sensible cooling to return to comfort. System performance at the 1ntersection of zones 4 and 6 is displayed in Figure 3-7. The ratio of the sensible to latent loads 
Zone 3

is

Zone 6

Temperature $\left({ }^{\circ} \mathrm{C}\right)$

Figure 3-22. ILLUSTRATION OF FAILURE TO RESTORE COMFORT BY OEHUMIDIFICATION ALONE 
Table 3-15. DESICCANT SYSTEM CONTROL STRATEGY ${ }^{a}$

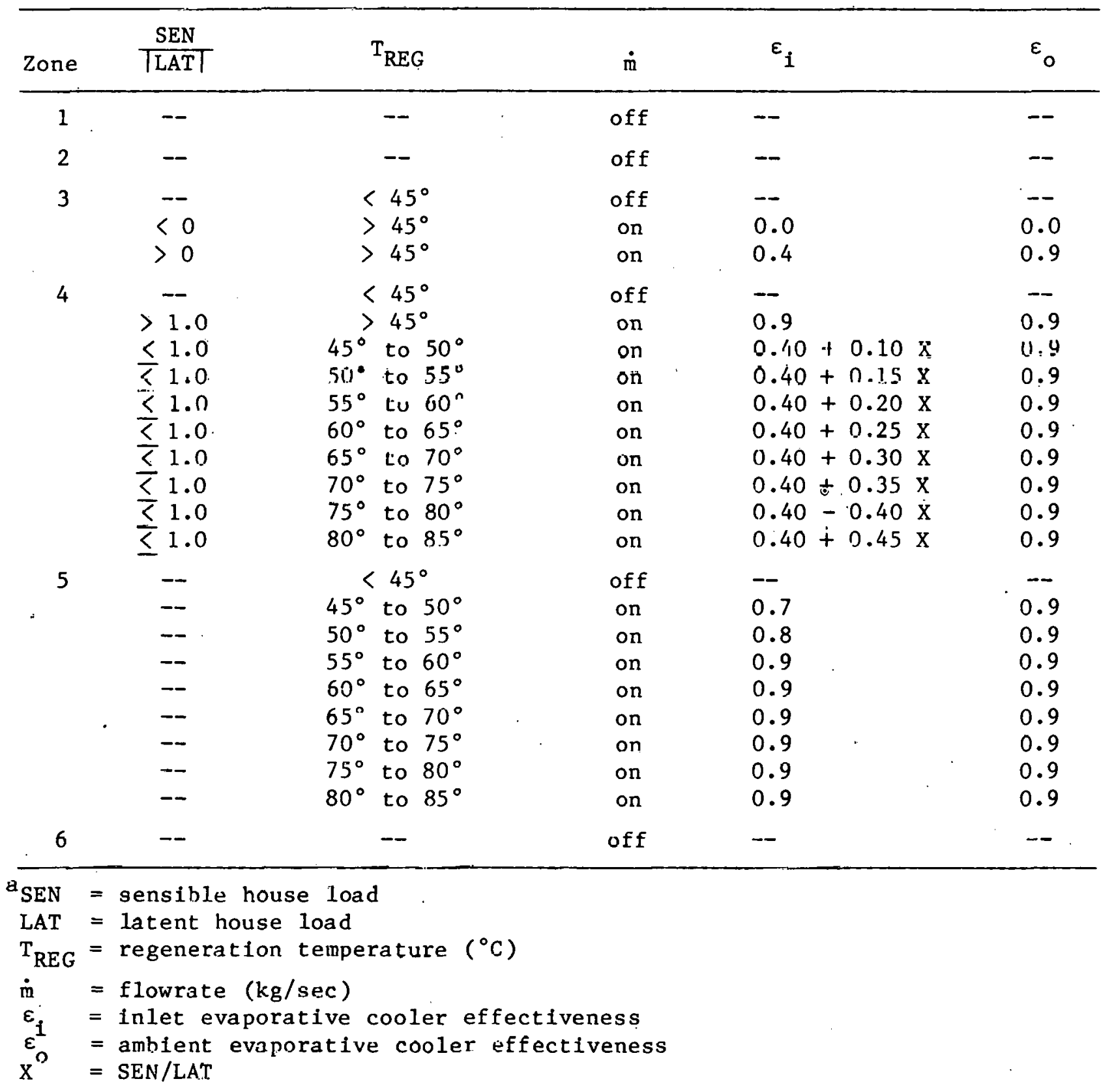


experienced by the house should be reflected in the S/L capacity supplied. When the sensible load exceeded the latent element, the sensible heating ratio SHR (sensible capacity/total capacity) was maximized by operating with $\varepsilon_{i}=\varepsilon_{0}$ $=0.9$. Conversely, when the $\mathrm{S} / \mathrm{L}$ load $\leq 1$, the inlet cooler effectiveness was appropriately proportioned to furnish cooling to counteract both components of the load. Details of this strategy are given in Table 3-15. Implementation of the simulated controller in a practical sense would require monitoring of both indoor and outdoor temperatures and humidities.

Room state 5 demands sensible cooling only for restoration of comfort. This corresponds to operation along the line QLAT $=0$ in Figure 3-8. Achievement of this control was facilitated by optimum outlet cooler effectiveness $\left(\varepsilon_{0}=\right.$ 0.9 ) combined with a scheme parameterizing $\varepsilon_{1}$ as a function of $\mathrm{T}_{\mathrm{REG}}$ (max) as specified in Table 3-15.

Zone 6 represents comfort conditions. No operation of the desiccant system is needed. The action of the control strategy in this case was merely to shut off the machine.

The controller was allowed an auxiliary cooling option to supplement desiccant system performance. In this mode, the portion of the latent and/or sensible load that could not be met by the solar desiccant cooler was provided by an assumed auxiliary vapor-compression unit. This guaranteed an immediate return to comfort whenever the room state entered zones 3, 4, or 5. Several runs for various cities were made in which only the sensible component was supplemented. A second auxiliary alternative, whereby the regeneration stream temperatures could be augmented to $\mathrm{T}_{\mathrm{REG}}=85^{\circ} \mathrm{C}$ at all times, was installed in the controller but not applied in the present study. Frequency of auxiliary usage and fallure of the desiccant system to operate when demanded [due to $\mathrm{T}_{\mathrm{REG}}(\max )<45^{\circ} \mathrm{C}$ ] was recorded.

A convention was established to account for the house loads, desiccant cooler system capacities, auxillary heating, and auxiliary cooling to assure an accurate balance of energy. The possibility of both positive and negative house loads and desiccant cooler system capacities necessitated a spectal energy accounting method. All heating. loads occuring in zones 1 and 2 were assumed to be met by an auxillary heating supply. No cooling loads or capacities were allowed in these zones. In zone 3 , the control strategy permitted a desiccant cooler sensible heating (negative) capacity. Similarily, because zone 5 attempted to operate at zero capacity, ambient and room conditions could precipitate a desiccant cooler latent heating (humidification) capacity. To handle these cases in zones 3 through 6, whenever a desiccant system heating capacity (sensible or latent) was experienced, it was added to the house cooling load. All sensible and latent loads and capacities in these four zones were then algebralcally summed. Table 3-16 gives a summary of this accounting system.

\subsubsection{Results of Case Studies}

The simulations were used to investigate such questions as which climate was most appropriate for desiccant system operation, what system capacity and collector size were optImum, and which auxlliary cooling strategy most enhanced destccant system performance. Five clties were chosen on the basis 
Table 3-16. ENERGY ACCOUNTING CONVENTION

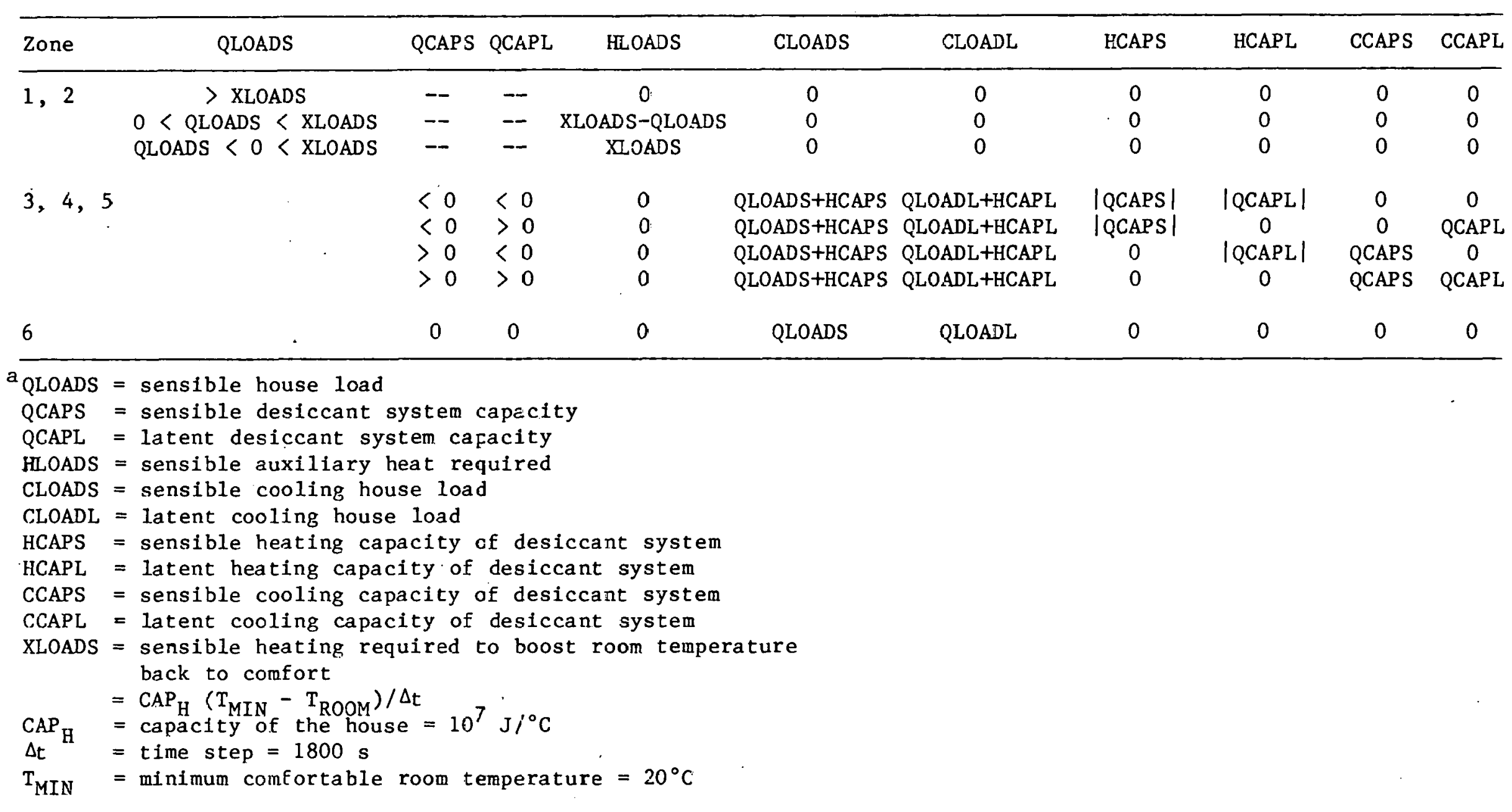


of their diverse climatic characteristics: Phoenix, Arizona (very hot, dry); Dodge City, Kansas (warm, dry); Fort Worth, Texas (hot, humid); Washington, D.C. (warm, humid); and Charleston, South Carolina (warm, very humid). For each city, a series of yearly simulations were made. Results of solar heating during the winter months were incorporated with results of the cooling season to allow annual economic analyses. A range of collector sizes and desiccant system capacities were simulated at each of the geographic locations of interest. The auxiliary strategies were as follows: no auxiliary cooling, auxiliary cooling driven by the sensible load, and auxiliary cooling designed to match both the sensible and latent cooling requirements that could not be met by the desiccant system. A summary is given in Table 3-17 of the simulations.

To determine the relative degree of desirability of solar heating and cooling compared to solar heating only and to permit amortized cost estimates, both the heating and the cooling seasons were simulated. The cooling season was treated as described in Section 3.7.1. A solar space heating unit was modeled for the heating season as shown in Figure 3-23. Solar water heating was not considered.

The objective of the dynamic study was to ascertain the most favorable climate for solar heating and desiccant cooling and the combination of system size and collector area ylelding the best thermal performance. The principal findings can be summarized as follows:

- Climates which experience both high heating loads in the winter and high cooling.loads in the summer are the most suitable candidates for solar heating and desiccant cooling.

- Washington, D.C., is the most promising of the five cities examined for the application of solar heating and desiccant cooling (due to its climatic conditions).

- The desiccant system which was modeled is preferentially a latent rather than sensible cooler.

- Thermal performance is best understood in terms of the dynamic interaction of the desiccant machine with the solar collector/storage system outlet temperature.

- The optimum combinations of system sizes for Washington, D.C.., are $4.5-\mathrm{kW}$ capacity at $35-\mathrm{m}^{2}$ collector area and $9.0-\mathrm{kW}$ capacity at $50-\mathrm{m}^{2}$ collector area.

For the various cities included in this study, Figure 3-24 displays the percentage of the heating load, provided by solar energy as a function of collector size. Geographical optimization of collector areas for solar heating is controlled by economic considerations. Projections based upon a series of F-Chart analyses [27] appear in Table 3-18 with the corresponding heating loads met by solar energy. It can be seen that, with the exception of Phoenix, cost is minimized when $30 \%$ to $50 \%$ of the seasonal heating load is provided by solar energy. The discrepancy of Phoenix is due to the relatively low heating. load and high insolation. Since so little heating 1s needed, a higher percentage must be met by solar energy to allow an appreciable total fuel savings to compensate for collector costs. A more detalled discussion of heating season economics is presented in fection 5.3 . 
Table 3-17. PARAMETERS USED IN DESICCANT COOLER SIMULATIONS

\begin{tabular}{|c|c|c|c|c|c|c|c|}
\hline Run No & Io. & & $\begin{array}{c}\text { Cooler } \\
\text { Size (kW) }\end{array}$ & $\begin{array}{l}\text { Collectgr } \\
\text { Area }\left(\mathrm{m}^{2}\right)\end{array}$ & $\begin{array}{c}\text { Storage } \\
\text { Volume }\left(\mathrm{m}^{2}\right)\end{array}$ & Auxillary & Cooling \\
\hline WASH ${ }^{a}$ & 1 & & 9.0 & 35 & 13.1 & None & \\
\hline WASH & 2 & & 9.0 & 35 & 13.1 & Sensible & \\
\hline WASH & 3 & & 4.5 & 35 & 13.1 & None & \\
\hline WASH & 4 & & 4.5 & 35 & 13.1 & Sens1ble & \\
\hline WASH & 5 & & 2.3 & 35 & 13.1 & None & \\
\hline WA3H & 6 & & 2.3 & 35 & 13.1 & 3eustlle & \\
\hline WASH & $\overline{7}$ & & $\dot{9} .0$ & 50 & 19.6 & None & \\
\hline WAS̄H & 8 & & 9.0 & 50 & 19.6 & Sensible & \\
\hline WASH & 9 & & 4.5 & 50 & 19.6 & None & \\
\hline WASH 1 & 10 & & 4.5 & 50 & 19.6 & Sensible & \\
\hline WASH 1 & 12 & & 2.3 & 50 & 19.6 & Sensible & \\
\hline WASH 1 & 13 & & 9.0 . & 20 & 7.8 & Sensible & . \\
\hline WASH 1 & 14 & & 4.5 & 20 & 7.8 & Senstble & \\
\hline WASH I & 15 & & 2.3 & 20 & 7.8 & Senstble & \\
\hline WASH 1 & 16 & & 9.0 & 42 & 16.5 & Senslble & \\
\hline WASH 1 & 17 & & 4.5 & 42 & 16.5 & Senstble & \\
\hline WASH 1 & 18 & & 2.3 & 42 & 16.5 & Sensible & \\
\hline WASH 1 & 19 & & 9.0 & 42 & 16.5 & Sensible + & + Latent \\
\hline WASH 2 & 20 & & 9.0 & 20 & 7.8 & Sensible + & + Latent \\
\hline WASH 2 & 21 & & 9.0 & 35 & 13.1 & Sensible + & + Latent \\
\hline WASH 2 & 22 & & 9.0 & 50 & $\$ 9.6$ & Sensible + & + Latent \\
\hline WASH 2 & 23 & & 9.0 & 10 & 3.9 & Sensible + & + Latent \\
\hline WASII 2 & 24 & & 4.5 & 10 & 3.9 & Sensible + & + Latent \\
\hline WASH 2 & 25 & & 4.5 & 35 & 13.1 & Sensible + & + Latent \\
\hline WASH 2 & 26 & & 4.5 & 50 & 19.6 & Sensible + & + Latent \\
\hline WASH 2 & 27 & & 2.3 & 10 & 3.9 & Sensible + & + Latent \\
\hline HASH 2 & 28 & & 2.3 & 35 & 13.1 & Sensible + & + Latent \\
\hline WASH 2 & 29 & & 2.3 & 50 & 19.6 & Sensible + & + Latent \\
\hline DODG ${ }^{\mathrm{b}}$ & 1 & & 9.0 & 35 & 13.1 & None & \\
\hline$D \cap D G$ & 2 & & 4.5 & 35 & 13.1 & None & \\
\hline DODC & 3 & & 1.5 & 35 & 13.1 & Senetble & \\
\hline DODG & 4 & & 2.3 & 35 & 13.1 & None & \\
\hline DODG & 5 & & 2.3 & 35 & 13.1 & Sensible & \\
\hline DODG & 6 & & 9.0 & 20 & 7.8 & None & \\
\hline DODG & 7 & & 4.5 & 20 & 7.8 & None & \\
\hline DODG & 8 & & 2.3 & 20 & 7.8 & None & \\
\hline DODG & 9 & & 9.0 & 42 & 16.5 & None & \\
\hline DODG 1 & 10 & & 4.5 & 42 & 16.5 & None & \\
\hline DODC 1 & 11 & & 2.3 & 42 & 16.5 & None & \\
\hline DODG 1 & $1 ?$ & & 4.5 & 35 & 13.1 & Sensible + & + tatent. \\
\hline $\mathrm{CHAR}^{\mathrm{C}}$ & 8 & & 9.0 & 50 & 19.6 & Sensible & \\
\hline CHAR 1 & 10 & & 9.0 & 50 & 19.6 & None & \\
\hline CHAR 1 & 11 & & 4.5 & 35 & 13.1 & Sensible & \\
\hline CHAR 1 & 12 & & 4.5 & 35 & 13.1 & None & \\
\hline CHAR $\cdot 1$ & 13 & & 13.5 & 50 & 19.6 & Sensible & \\
\hline CHAR 1 & 14 & & 4.5 & 35 & 13.1 & Sensible + & + Latent \\
\hline FTWR $^{d}$ & 1 & & 9.0 & 35 & 13.1 & None & \\
\hline FTWR & 2 & & 4.5 & 35 & 13.1 & None & \\
\hline FTVR & 3 & & 4.5 & 35 & 13.1 & Sensible & \\
\hline FTWR & 5 & $\therefore$ & 2.3 & 35 & 13.1 & Sensible & \\
\hline FTWR & 6 & & 4.5 & 35 & 13.1 & Sensible + & + Latent \\
\hline PHNX ${ }^{e}$ & 1 & & 9.0 & 35 & 13.1 & None & \\
\hline PINXX & 2 & & 9.0 & 35 & 13.1 & Sensible & \\
\hline PHNX & 4 & & 4.5 & 35 & 13.1 & Sensible & \\
\hline PHNX & 7 & & 4.5 & 45 & 13.1 & Sensible + & + Latent \\
\hline
\end{tabular}




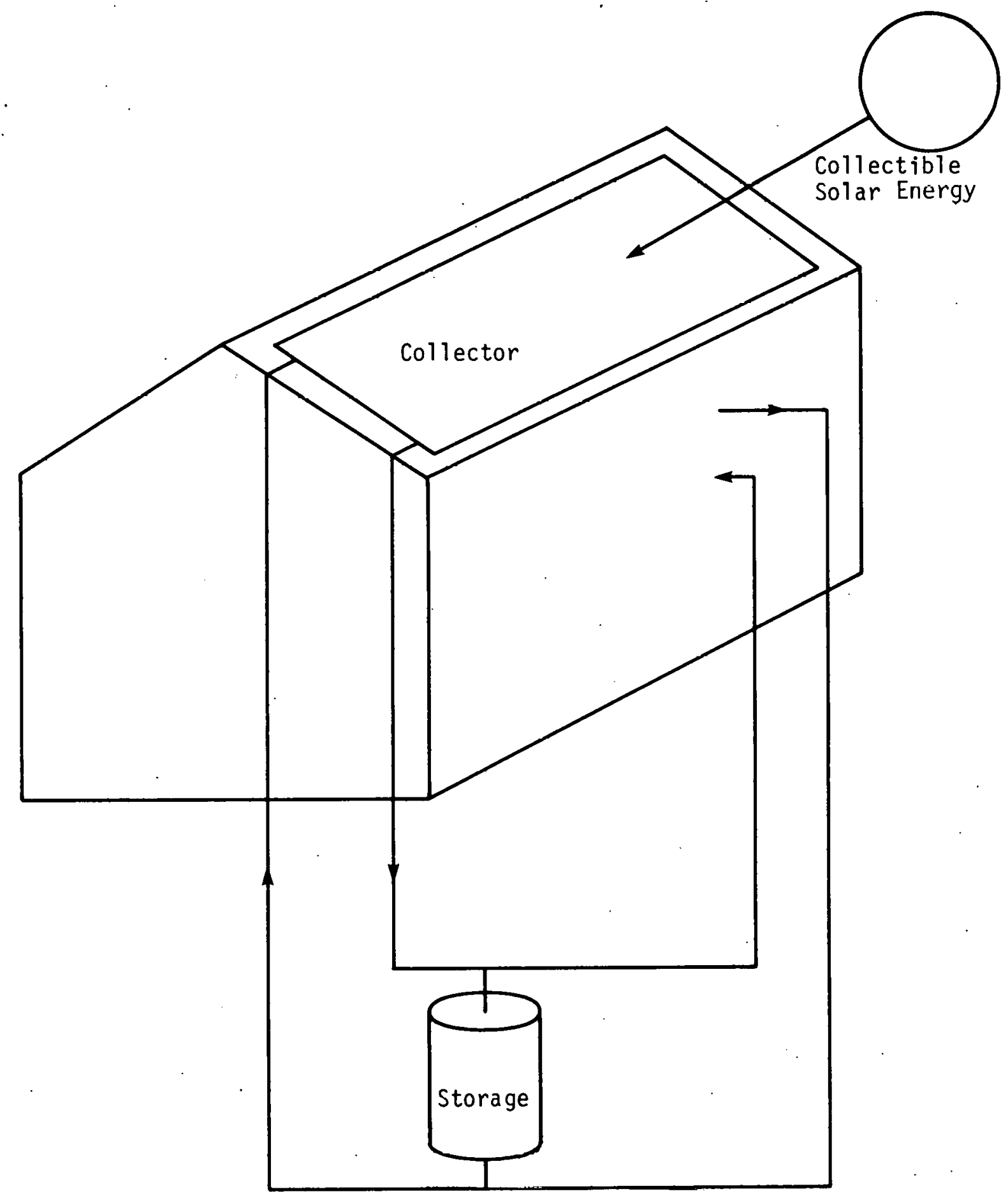

Figure 3-23. SOLAR COLLECTOR/STORAGE SYSTEM CONFIGURATION DURING HEATING SEASON 


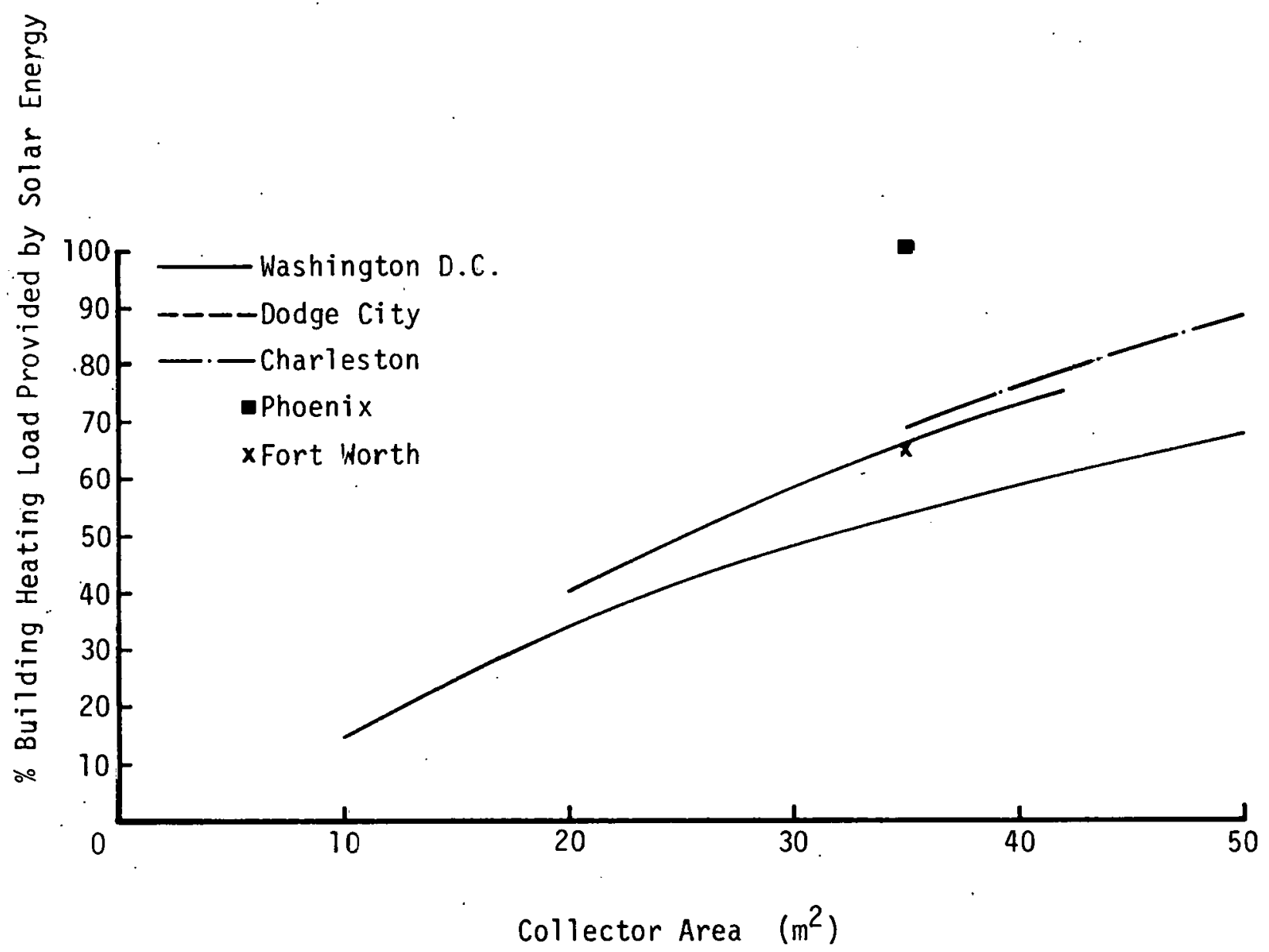

Figure 3-24. PERFORMANCE OF SOLAR SYSTEM DURING HEATINב SEASON 
Areas having mild winter months (lower heating loads) generally experience more severe cooling seasons (higher cooling loads) and vice versa. This makes it unlikely that the optimal. collector sizes for the two seasons will be identical. If the total loads are not significantly high, then the net fuel saved will not offset collector costs. The implication is that the climate most appropriate for both solar heating and cooling is one experiencing high heating and cooling loads.

For each of the runs listed in Table 3-17, monthly and annual summaries of all heating and cooling loads, capacities, and auxiliary requirements were computed, as well as such parameters as COP, EER, and the percentage of time the conditioned space was within the defined comfort zone. Sample reports are included in Appendix $A$ and the annual performance recaps appear in Table 3-19.

Table 3-18. PERCENTAGE OF HEATING LOAD SUPPLIED BY SOLAR ENERGY

\begin{tabular}{|c|c|c|c|c|}
\hline City & $\begin{array}{l}\text { Heating } \\
\text { Load } \\
\left(10^{10} \mathrm{~J}\right)\end{array}$ & $\begin{array}{l}\% \text { of Heating } \\
\text { Load Supp1ied } \\
\text { by Solar Energy } \\
\text { at Collector } \\
\text { Area of } 35 \mathrm{~m}^{2 \mathrm{a}}\end{array}$ & $\begin{array}{c}\text { Optimum } \\
\text { Collector } \\
\text { Area for } \\
\text { Heating }\left(\mathrm{m}^{2}\right)^{b}\end{array}$ & $\begin{array}{l}\% \text { of Heating } \\
\text { Load Supplied } \\
\text { by Solar Energy } \\
\text { at Optimum } \\
\text { Collector Area }\end{array}$ \\
\hline Phoenix, Ariz. & 0.76 & 100 & 14 & $95^{c}$ \\
\hline Charleston, $S_{i} C$ & 2.60 & 69 & 12 & $33^{c}$ \\
\hline Fort Worth, Tex. & 3.24 & 65 & 16 & $45^{c}$ \\
\hline Washington, D.C. & 4.81 & 54 & 18 & $30^{\mathrm{a}}$ \\
\hline Dodge City, Kans. & 5.65 & 66 & 26 & $51^{a}$ \\
\hline
\end{tabular}

See Figure 3-24

$b_{\operatorname{Ref}}$ 27; for an assumed average conventional fuel cost $=\$ 10 / G J$, collector cost $=\$ 110 / \mathrm{m}^{2}$, and annual payback of capital $=0.1$

$c_{F=\text { Chart results }}$

Figures 3-25a, b, and $c$ summarize the effects of desiccant cooler size and collector area on delivered cooling capacity for Washington, D.C. These plots show that the amount of parasitic energy used is relatively unaffected by collector area or desiccant machine size. This is because smaller machines demand less power but operate for longer time periods than larger units.

COP and FF.R were chosen as measures of performance. A benchmark desiccant system was defined to be of a $4.5-\mathrm{kW}$ nominal caparity and $35-\mathrm{m}^{2}$ collector a rea. This configuration was simulated in the cities of interest both with and without auxiliary cooling. The single variable that best characterized climatic conditions was the relative humidity corresponding to the designpoint wet- and dry-bulb temperatures for each city [6]. Plots of COP and EER as functions of this design-point relative humidity (Figures 3-26a and b) indicate that desiccant system performance peaks near $50 \%$ and that, therefore, Washington, D.C., is the optimum climate of the five cities studied. 
TABLE 3-19. ANNUAL DESICCANT STSTIZM PERFORMANCB

(all energy units in joules)

\begin{tabular}{|c|c|c|c|c|c|c|c|c|c|c|c|c|c|c|c|c|c|c|c|c|c|}
\hline \multirow{3}{*}{$\frac{\text { Run }}{\text { WASH }}$} & \multirow{3}{*}{$\frac{\text { No. }}{\text { i } 1}$} & \multicolumn{5}{|c|}{ Butlding Load } & \multicolumn{4}{|c|}{$\begin{array}{c}\text { Cooling } \\
\text { Capacity Supplfed }\end{array}$} & \multicolumn{4}{|c|}{$\begin{array}{l}\text { Auxil1ary } \\
\text { Supplied }\end{array}$} & \multicolumn{2}{|c|}{$\begin{array}{l}\text { \% Bldg. Load } \\
\text { by Solar Energy }\end{array}$} & \multirow[b]{2}{*}{$\begin{array}{l}\text { Parasitic } \\
\text { Energy }\end{array}$} & \multirow{3}{*}{$\frac{\operatorname{COP}}{0.71}$} & \multirow{3}{*}{$\frac{\text { EER }}{22.07}$} & \multirow{3}{*}{$\frac{\begin{array}{c}\text { Duty } \\
\text { Cycle }\end{array}}{0.19}$} & \multirow{3}{*}{$\frac{\begin{array}{c}\% \text { in } \\
\text { Comfort }\end{array}}{59}$} \\
\hline & & \multirow{2}{*}{\multicolumn{2}{|c|}{$\frac{\begin{array}{l}\text { Sensible } \\
\text { Cooling }\end{array}}{1.28 \text { E10 }}$}} & \multicolumn{2}{|c|}{$\begin{array}{l}\text { Latent } \\
\text { Cooling }\end{array}$} & Heat & \multicolumn{2}{|c|}{ Sensible } & \multicolumn{2}{|c|}{ Latent } & \multicolumn{2}{|c|}{ Heat } & \multicolumn{2}{|c|}{ Cooling } & \multirow{2}{*}{$\frac{\text { Heat }}{54}$} & \multirow{2}{*}{$\frac{\text { Cool1ng }}{--}$} & & & & & \\
\hline & & & & 6.74 & E9 & $4.81 \mathrm{E} 10$ & 1.32 & E10 & 6.54 & E9 & 2.19 & E10 & -- & & & & $3.05 \quad 89$ & & & & \\
\hline & 2 & 1.29 & Elo & 7.56 & E9 & 4.81 E10 & 7.91 & E9 & 7.33 & B9 & 2.19 & E10 & 5.39 & E9 & 54 & 74 & $2.99 \mathrm{E9}$ & 0.57 & 13.68 & 0.19 & 81 \\
\hline & 3 & 1.29 & E10 & 6.84 & E9 & $4.81 \quad E 10$ & 1.34 & E10 & 6.81 & E9 & 2.19 & E10 & -- & & 54 & -- & 3.44 E9 & 0.77 & 20.07 & 0.34 & 57 \\
\hline & 4 & 1.29 & E10 & 7.94 & E9 & $4.81 \quad E 10$ & 6.17 & E9 & 7.90 & E9 & 2.19 & $\mathrm{E} 10$ & 7.23 & E9 & 54 & 66 & $2.84 \mathrm{Eg}$ & 0.61 & 12.69 & 0.27 & 88 \\
\hline & 5 & 1.29 & E10 & 6.63 & E9 & 4.81 E10 & 1.34 & E10 & 6.64 & E9 & 2.19 & E10 & -- & & 54 & - & 5.27 E9 & $C .89$ & 12.99 & 0.56 & 49 \\
\hline & 6 & 1.29 & Elo & 7.85 & E9 & 4.81 E1O & 4.04 & E9 & 7.84 & E9 & 2.19 & E10 & 9.39 & E9 & 54 & 56 & $4.05 \mathrm{E9}$ & C.62 & 9.30 & 0.42 & 91 \\
\hline & 7 & 1.29 & E10 & 8.34 & E9 & $4.81 \quad$ E10 & 1.33 & E10 & 8.15 & E9 & 1.56 & E10 & - & & 68 & -- & $3.48 \mathrm{E} 9$ & 0.59 & 21.08 & 0.22 & 72 \\
\hline & 8 & 1.29 & E10 & 8.80 & E9 & $4.81 \quad E 10$ & 9.77 & E9 & 8.61 & E9 & 1.56 & E10 & 3.57 & E9 & 68 & 84 & $3.30 \mathrm{E} 9$ & a. 54 & 15.87 & 0.21 & 91 \\
\hline & 9 & 1.29 & E10 & 8.46 & E9 & 4.81 E10 & 1.35 & $E 10$ & 8.50 & E9 & 1.56 & E10 & -- & & 68 & - & $3.86 \mathrm{E} 9$ & 0.66 & 19.45 & 0.39 & 70 \\
\hline & 10 & 1.29 & E10 & 8.81 & E9 & $4.81 \mathrm{E} 10$ & 6.90 & E9 & 8.82 & E9 & 1.56 & E10 & 6.52 & E9 & 68 & 71 & $3.01 \mathrm{E9}$ & 0.58 & 13.53 & 0.30 & 96 \\
\hline & 12 & 1.29 & E10 & 8.43 & E9 & $4.81 E 10$ & 4.26 & E9 & 8.45 & Eg & 1.56 & E10 & 9.17 & E9 & 68 & 58 & 4.02 E9 & 0.60 & 9.71 & 0.42 & 98 \\
\hline & 13 & 1.29 & E10 & 5.32 & E9 & $4.81 \quad E 10$ & 4.48 & E9 & 5.14 & E9 & 3.17 & E10 & 8.80 & E9 & 34 & 52 & 2.27 E9 & 0.62 & 10.87 & 0.14 & 65 \\
\hline & 14 & 1.29 & E10 & 6.12 & E9 & $4.81 \mathrm{E} 10$ & 4.17 & E9 & 6.05 & E9 & 3.17 & E10 & 9.15 & E9 & 34 & 53 & 2.37 E9 & 0.64 & 10.98 & 0.21 & 72 \\
\hline & 15 & 1.29 & El0 & 6.33 & $E 9$ & $4.80 \quad E 10$ & 3.17 & E9 & 6.29 & E9 & 3.17 & E10 & 1.02 & E10 & 34 & 48 & $3.53 \mathrm{E} 9$ & 0.66 & 8.82 & 0.35 & 76 \\
\hline & 16 & 1.30 & E10 & 8.25 & E9 & 4.81 E10 & 8.98 & 89 & 8.01 & E9 & 1.88 & E10 & 4.34 & E9 & 61 & 80 & $3.18 \mathrm{E9}$ & 0.56 & 14.82 & 0.20 & 86 \\
\hline & 17 & 1.29 & E10 & 8.41 & E9 & 4.81 E10 & 6.57 & E9 & 8.41 & E9 & 1.88 & E10 & 6.83 & E9 & 61 & 69 & 2.96 E9 & 0.59 & 13.07 & 0.29 & 93 \\
\hline & 18 & 1.29 & E10 & 8.25 & E9 & $4.81 \quad \mathrm{E} 10$ & 4.17 & E9 & 8.26 & E9 & 1.88 & E10 & 9.25 & E9 & 61 & 57 & $4.11 \mathrm{Eg}$ & 0.51 & 9.48 & 0.43 & 96 \\
\hline & 19 & 1.29 & E10 & 9.25 & E9 & $4.81 \quad E 10$ & 9.62 & E9 & 6.58 & E9 & 1.88 & E10 & 6.15 & 89 & 61 & 72 & $3.08 \mathrm{E9}$ & 0.56 & 13.76 & 0.19 & 100 \\
\hline & 20 & 1.28 & ElO & 8.49 & E9 & $4.81 \quad E 10$ & 5.48 & E9 & 2.80 & E9 & 3.17 & E10 & 1.32 & E10 & 34 & 39 & 2.12 E9 & 0.58 & 9.92 & 0.12 & 100 \\
\hline & 21 & 1.29 & E10 & 9.02 & E9 & $4.81 \quad E 10$ & 8.80 & E9 & 5.59 & E9 & 2.19 & E10 & 7.69 & E9 & 55 & 65 & 2.90 E9 & 0.57 & 12.62 & 0.18 & 100 \\
\hline & 22 & 1.29 & E10 & 9.48 & E9 & $4.82 \mathrm{E} 10$ & 1.02 & E10 & 7.57 & E9 & 1.56 & E10 & 4.80 & E9 & 68 & 79 & $3.19 \mathrm{E9}$ & 0.54 & 15.11 & 0.20 & 100 \\
\hline
\end{tabular}


TABLE 3-19. AMTUAL DESICCAITT SYSTEM PERFORMANCE (Continued) (a11 energy units in joules)

\begin{tabular}{|c|c|c|c|c|c|c|c|c|c|c|c|c|c|c|c|c|c|c|c|c|}
\hline \multirow{3}{*}{$\frac{\text { Run }}{\text { WASH }}$} & \multirow{3}{*}{$\frac{40 .}{23}$} & \multirow{2}{*}{\multicolumn{2}{|c|}{$\begin{array}{l}\text { Bu } \\
\begin{array}{l}\text { Sensible } \\
\text { Cooling }\end{array}\end{array}$}} & \multicolumn{3}{|c|}{ lding Load } & \multicolumn{3}{|c|}{$\begin{array}{c}\text { Cooling } \\
\text { Capacity Supplied }\end{array}$} & \multicolumn{3}{|c|}{$\begin{array}{l}\text { Auxillary } \\
\text { Supplied }\end{array}$} & \multicolumn{2}{|c|}{$\begin{array}{l}\text { \% Bldg. Load } \\
\text { by Solar Energy }\end{array}$} & \multirow{2}{*}{\multicolumn{2}{|c|}{$\begin{array}{l}\text { Parasitic } \\
\text { Energy }\end{array}$}} & \multirow{3}{*}{$\frac{\mathrm{COP}}{0.63}$} & \multirow{3}{*}{$\frac{\text { EER }}{8.63}$} & \multirow{3}{*}{$\begin{array}{c}\begin{array}{c}\text { Duty } \\
\text { Cycle }\end{array} \\
0.03\end{array}$} & \multirow{3}{*}{$\frac{\begin{array}{c}\% \text { in } \\
\text { Comfort }\end{array}}{100}$} \\
\hline & & & & $\begin{array}{l}\text { Late } \\
\text { Cool }\end{array}$ & $\begin{array}{l}\text { ent } \\
\text { ling }\end{array}$ & Heat & \multirow{2}{*}{$\frac{\text { Sens }}{1.20}$} & \multirow{2}{*}{$\frac{1 \text { ble }}{\mathrm{Eg}}$} & Latent & \multicolumn{2}{|c|}{ Heat } & Cooling & \multirow{2}{*}{$\frac{\text { Heat }}{14}$} & \multirow{2}{*}{$\frac{\text { Cooling }}{9}$} & & & & & & \\
\hline & & 1.27 & $E 10$ & 7.96 & E9 & $4.81 \mathrm{E} 10$ & & & $6.34 \mathrm{E} 8$ & 4.00 & E10 & 1.91 E10 & & & 6.44 & E8 & & & & \\
\hline & 24 & 1.27 & E10 & 8.13 & E9 & 4.81 Elo & 2.85 & E9 & $1.58 \mathrm{E9}$ & 4.01 & E10 & 1.67 E10 & 14 & 21 & 1.52 & E9 & 0.61 & 8.79 & 0.13 & 100 \\
\hline & 25 & 1.28 & E10 & 8.80 & E9 & $4.81 \quad \mathrm{E} 10$ & 6.53 & E9 & $6.58 \mathrm{Eg}$ & 2.19 & E10 & 8.89 E9 & 55 & 60 & 2.64 & E9 & 0.60 & 12.11 & 0.25 & 100 \\
\hline & 26 & 1.28 & E10 & 8.97 & E9 & 4.81810 & 6.87 & E9 & $7.48 \mathrm{Eg}$ & 1.56 & E10 & 7.52 E9 & 68 & 66 & 2.67 & E9 & 0.58 & 13.37 & 0.26 & 100 \\
\hline & 27 & 1.28 & E10 & 8.14 & E9 & $4.81 \quad E 10$ & 2.66 & E9 & $2.05 \mathrm{Eg}$ & 4.02 & E10 & $1.64 \mathrm{E} 10$ & 14 & 22 & 2.35 & E9 & 0.63 & 8.09 & 0.21 & 100 \\
\hline & 28 & 1.28 & E10 & 8.43 & E9 & $4.81 E 10$ & 3.82 & E9 & 5.24 E9 & 2.19 & E10 & 1.24 E10 & 55 & 42 & 2.97 & E9 & 0.59 & 9.24 & 0.30 & 100 \\
\hline & 29 & 1.28 & E10 & 8.47 & E9 & $4.81 \quad 810$ & 3.89 & 89 & $5.64 . \mathrm{Eg}$ & 1.56 & E10 & $1.20 \mathrm{E} 10$ & 68 & 44 & 2.93 & E9 & 0.57 & 9.51 & 0.30 & 100 \\
\hline DODS & 1 & 1.16 & E10 & 3.33 & E9 & $5.65 \times 10$ & 1.20 & E10 & $3.59 \mathrm{E} 9$ & 1.91 & E10 & - & 66 & - & 3.07 & E9 & 0.56 & 17.38 & 0.18 & 82 \\
\hline & 2 & 1.14 & E10 & 3.46 & E9 & 5.66 E10 & 1.21 & 810 & $3.78 \mathrm{E9}$ & 1.91 & E10 & - & 66 & - & 2.91 & E9 & 0.59 & 18.69 & 0.32 & 76 \\
\hline & 3 & 1.14 & E10 & 3.18 & E9 & 5.66 E10 & 6.01 & E9 & $3.48 \mathrm{E} 9$ & 1.91 & E10 & 6.01 E9 & 66 & 61 & 1.86 & E9 & 0.53 & 12.42 & 0.18 & 99 \\
\hline & 4 & 1.13 & E10 & 3.25 & E9 & $5.66 \mathrm{E} 10$ & 1.19 & E10 & $3.49 \mathrm{E9}$ & 1.91 & E10 & - & 66 & -- & 4.06 & E9 & 0.69 & 12.95 & 0.47 & 61 \\
\hline & 5 & 1.14 & E10 & 2.77 & E9 & 5.66 E10 & 3.40 & E9 & 2.99 E9 & 1.91 & E10 & 8.6089 & 66 & 43 & 2.20 & E9 & 0.52 & 9.08 & 0.23 & 99 \\
\hline & 6 & 1.16 & E10 & 2.27 & E9 & 5.64 E10 & 1.18 & E10 & 2.38 E9 & 3.36 & E10 & -- & 40 & - & 2.26 & E9 & 0.79 & 21.45 & 0.16 & 60 \\
\hline & 7 & 1.14 & E10 & 2.38 & E9 & $5.65 E 10$ & 1.20 & E10 & $2.62 \mathrm{E} 9$ & 3.36 & E10 & - & 40 & -- & 2.32 & E9 & 0.81 & 21.53 & 0.25 & 55 \\
\hline & 8 & 1.13 & E10 & 2.53 & E9 & $5.65 \quad 810$ & 1.19 & E10 & $2.72 \mathrm{E} 9$ & 3.36 & E10 & - & 40 & -- & 3.89 & E9 & 0.88 & 12.83 & 0.48 & 56 \\
\hline & 9 & 1.16 & E10 & 3.55 & E9 & $5.65 \mathrm{E} 10$ & 1.21 & E10 & $3.84 \mathrm{E9}$ & 1.42 & E10 & - & 75 & -- & 2.51 & E9 & 0.52 & 21.66 & 0.18 & 94 \\
\hline & 10 & 1.15 & E10 & 3.60 & E9 & 5.66 E10 & 1.21 & E10 & 3.92 E9 & 1.42 & E10 & - & 75 & -- & 2.63 & E9 & 0.56 & 20.86 & 0.31 & 80 \\
\hline & 11 & 1.13 & E10 & 3.32 & E9 & 5.65 E10 & 1.19 & Elo & $3.57 \mathrm{E} 9$ & 1.42 & ElO & - & 75 & -- & 3.83 & E9 & 0.67 & 13.80 & 0.46 & 61 \\
\hline & 12 & 1.14 & E10 & 3.18 & E9 & $5.66 \mathrm{E} 10$ & 6.00 & E9 & $3.39 \mathrm{E} 9$ & 1.91 & E10 & 6.08 E9 & 66 & 61 & 1.65 & E9 & 0.53 & 12.93 & 0.18 & 99 \\
\hline
\end{tabular}




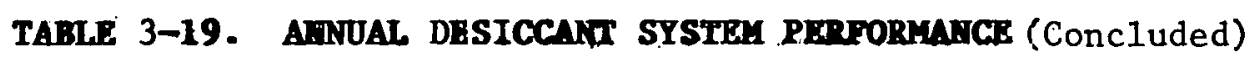
(a11 energy unite in joules)

\begin{tabular}{|c|c|c|c|c|c|c|c|c|c|c|c|c|c|c|c|c|c|c|}
\hline \multirow[b]{2}{*}{ Run } & \multirow[b]{2}{*}{ No. } & \multicolumn{4}{|c|}{ Buflding Load } & \multicolumn{3}{|c|}{$\begin{array}{c}\text { Cooling } \\
\text { Capacity Supplied }\end{array}$} & \multicolumn{3}{|c|}{$\begin{array}{l}\text { Auxillary } \\
\text { Supplied }\end{array}$} & \multicolumn{2}{|c|}{$\begin{array}{l}\text { \% Bldg. Load } \\
\text { by Solar Energy }\end{array}$} & \multirow[b]{2}{*}{$\begin{array}{l}\text { Parasitic } \\
\text { Energy }\end{array}$} & \multirow[b]{2}{*}{$\mathrm{COP}$} & \multirow[b]{2}{*}{ EER } & \multirow[b]{2}{*}{$\begin{array}{l}\text { Duty } \\
\text { Cycle }\end{array}$} & \multirow[b]{2}{*}{$\begin{array}{c}\text { \% In } \\
\text { Comfort }\end{array}$} \\
\hline & & $\begin{array}{l}\text { Sensible } \\
\text { Cooling }\end{array}$ & $\begin{array}{l}\text { Late } \\
\text { Cool }\end{array}$ & $\begin{array}{l}\text { ent } \\
\text { lng }\end{array}$ & Heat & Sens & Ible & Latent & Heat & & Cool1ng & Heat & Cooling & & & & & \\
\hline \multirow[t]{4}{*}{ PHNX } & 1 & $5.13 \mathrm{E} 10$ & 1.39 & E9 & $7.57 \mathrm{E9}$ & 5.15 & E10 & 1.47 E9 & $\mathbf{0}$ & & - & 100 & -- & $6.06 \mathrm{E9}$ & 0.72 & 29.87 & 0.29 & 52 \\
\hline & 2 & $5.13 \mathrm{E} 10$ & 1.94 & E9 & 7.55 E9 & 3.00 & E10 & $1.98 \mathrm{E9}$ & 0 & & 2.12 E10 & 100 & 60 & $5.32 \mathrm{Eg}$ & 0.49 & 13.17 & 0.25 & 99 \\
\hline & 4 & 5.11 E10 & 1.85 & E9 & 7.52 E9 & 1.89 & $\mathbf{R} 10$ & $1.90 \mathrm{E9}$ & $\mathbf{0}$ & & $3.26 \mathrm{E} 10$ & 100 & 39 & $3.89 \mathrm{E9}$ & 0.43 & 10.77 & 0.28 & 99 \\
\hline & 7 & $5.11 \quad E 10$ & 1.89 & E9 & $7.52 \mathrm{E9}$ & 1.89 & E10 & $1.87 \mathrm{E} 9$ & 0 & & 3.27 E10 & 100 & 39 & $3.89 \mathrm{E9}$ & 0.43 & 10.76 & 0.28 & 99 \\
\hline \multirow{6}{*}{ CHAR } & 8 & $1.21 \mathrm{E} 10$ & 1.21 & E10 & 2.60 E10 & 9.45 & E9 & 1.24. E10 & 2.86 & E9 & $3.42 \mathrm{E} 9$ & 89 & 86. & 5.07 E9 & 0.51 & 13.41 & 0.24 & 86 \\
\hline & 10 & $1.20 \mathrm{E} 10$ & 1.15 & E10 & $2.60 \mathrm{E} 10$ & 1.28 & E10 & $1.19 E 10$ & 2.86 & E9 & 一 & 89 & - & $5.20 \mathrm{E} 9$ & 0.54 & 16.20 & 0.25 & 72 \\
\hline & 11 & $1.19 \mathrm{E} 10$ & 1.11 & E10 & $2.60 \quad E 10$ & 5.91 & E9 & $1.15 \mathrm{E} 10$ & 8.10 & E9 & $6.87 \mathrm{E} 9$ & 69 & 72 & 4.10 E9 & 0.57 & 12.09 & 0.33 & 81 \\
\hline & 12 & $1.19 \mathrm{E} 10$ & 9.66 & E9 & $2.59 \mathrm{~B} 10$ & 1.27 & E10 & $1.00 \mathrm{E} 10$ & 8.10 & E9 & - & 69 & -- & 4.54 E9 & 0.73 & 17.08 & 0.37 & 51 \\
\hline & 13 & 1.22 E10 & 1.15 & E10 & $2.60 \mathrm{E} 10$ & 1.01 & E10 & $1.16 \mathrm{ELO}$ & 2.86 & E9 & 2.84 E9 & 89 & 88 & $7.25 \mathrm{E9}$ & 0.47 & 9.99 & 0.19 & 80 \\
\hline & 14 & $1.17 \mathrm{E} 10$ & 1.27 & E10 & $2.61 \mathrm{E} 10$ & 6.38 & 89 & $9.19 \mathrm{E9}$ & 8.10 & E9 & $9.92 \mathrm{E9}$ & 69 & 61 & 3.24 E9 & $0.5 j$ & 12.07 & 0.29 & 100 \\
\hline \multirow[t]{5}{*}{ FTWR } & 1 & $2.39 \mathrm{ElO}$ & 9.39 & E9 & $3.24 \mathrm{~B} 10$ & 2.41 & E10 & 9.27 E9 & 1.13 & ElO & -- & 65 & - & $5.28 \mathrm{E9}$ & 0.71 & 21.57 & 0.25 & 48 \\
\hline & 2 & 2.38810 & 9.72 & E9 & 3.24 E10 & 2.45 & E10 & 9.83 E9 & 1.13 & Ela & -- & 65 & - & $5.88 \mathrm{E} 9$ & 0.7 & 19.90 & 0.49 & 46 \\
\hline & 3 & $2.38 \mathrm{E} 10$ & 1.09 & E10 & 3.24 E10 & 1.07 & E10 & $1.10 \mathrm{E} 10$ & 1.13 & E10 & $1.36 \mathrm{E} 10$ & 65 & 61 & $4.40 \mathrm{E9}$ & 0.55 & 12.25 & 0.35 & 95 \\
\hline & 5 & $2.39 \mathrm{E} 10$ & 1.05 & E10 & 3.24 E.10 & 6.59 & E9 & $1.05 \mathrm{E} 10$ & 1.13 & E10 & $1.78 \mathrm{E} 10$ & 65 & 49 & $5.49 \mathrm{Eg}$ & 0.61 & 9.44 & 0.48 & 98 \\
\hline & 6 & $2.37 E 10$ & 1.11 & E10 & 3.25 E10 & 1.08 & E10 & 9.63 E9 & 1.13 & E10 & 1.49810 & 65 & 58 & 3.73 E9 & 0.59 & 12.45 & 0.31 & 100 \\
\hline
\end{tabular}



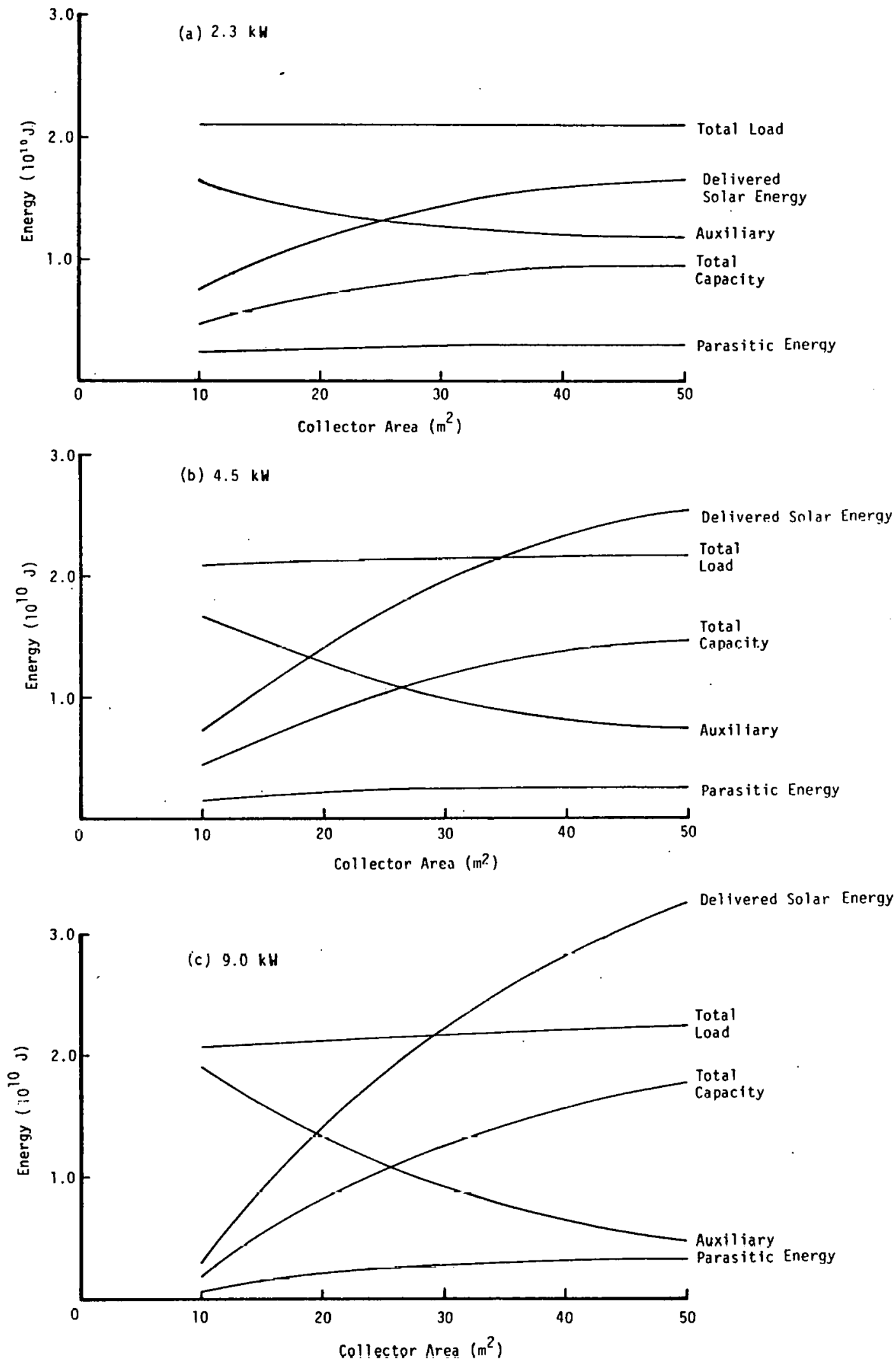

Figure 3-25. SIMULATED ANNUAL PERFORMANCES OF SOLAR DESICCANT COOLERS WITH SENSIBLE AND LATENT AIIXILIARY COOL.ERS IN WASHINGTON, D.C. 

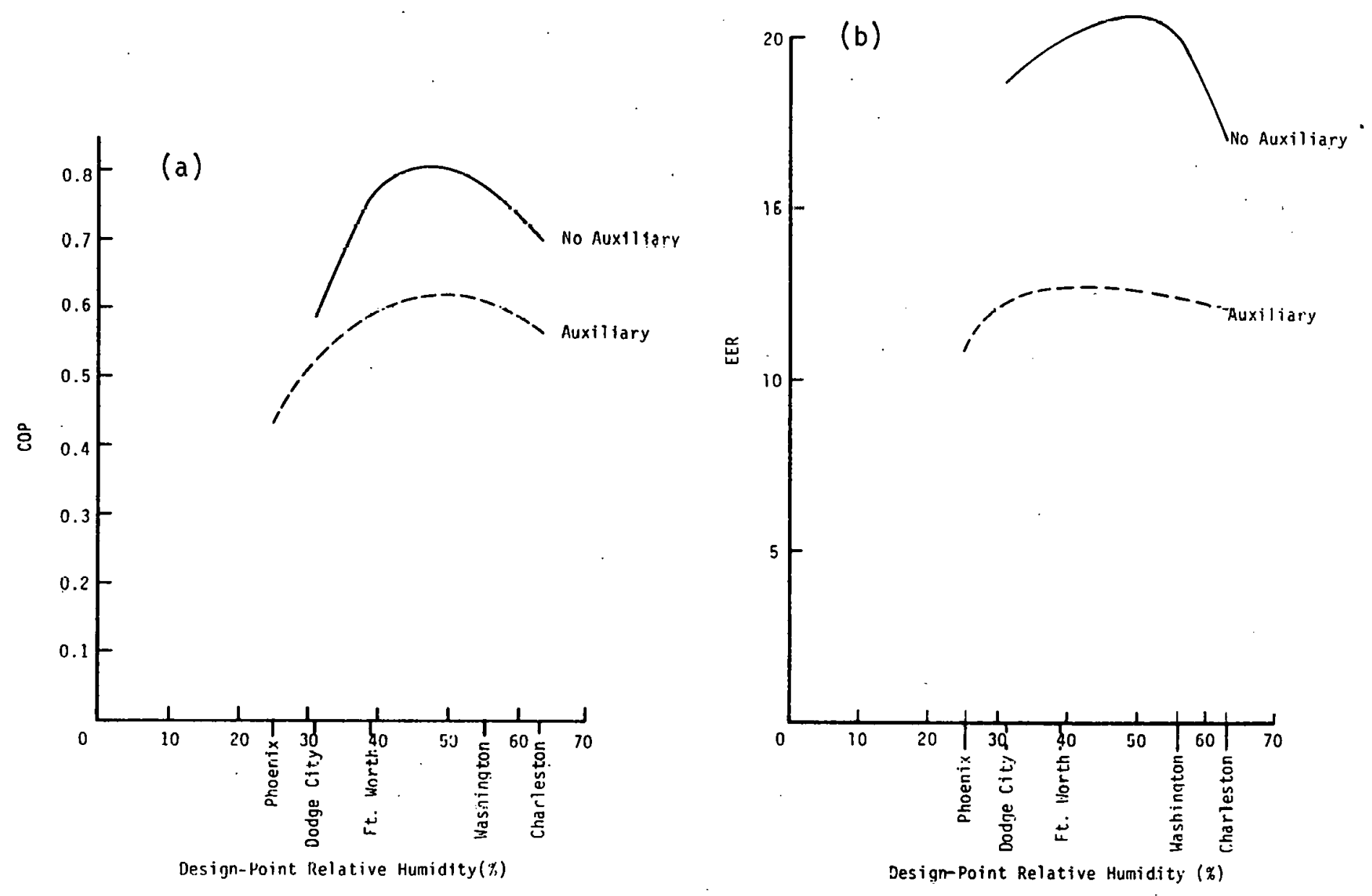

(b)

Figure 3-26. EFFECT OF DESIGN-POINT RELATIVE HUMIDITY ON (a) COP AND (b) EER - 4.5-KW COOLER WITH 35-M2 COLLECTOR, WITH AND WITHOUT AUXILIARY COOLING 
The steady-state analysis (Section 3.6.2) showed that the modeled desiccant system was preferentially a latent rather than sensible cooler. For the dynamic analysis, runs in which auxiliary sensible cooling was provided were chosen to see how well the latent component of the load could be met by the desiccant machine. The percentage of time which the house spent in zone 3 (out of comfort, too humid) in each city was again plotted against designpoint relative humidity (Figure 3-27). General agreement was found with the steady-state sensitivity curve of capacity versus ambient humidity; namely, as outside humidity increased, system performance decreased and a greater amount of time was spent out of comfort.

To further illustrate the effect of climate upon system operation, the variation of the percentage of the latent cooling load that was provided by solar energy, as a function of the percentage of the total latent cooling load, was studied. The percentage of the latent cooling supplied by solar energy was calculated as follows:

$\frac{\text { Latent cooling capacity supplied by solar energy }}{\text { Latent cooling load }} \times 100 \%$

The results are plotted in Figure 3-28 and they agree with the steady-state performance. As the latent load became more appreciable, the cooling capacity dropped and the percentage of the latent load supplied by solar energy decreased. Thus, the response of the modeled desiccant system was more sensitive to latent than sensible conditions.

As explained in Section 3.7.2, whenever the collector/storage system could not deliver $45^{\circ} \mathrm{C}$, the desiccant system did not operate. The percentage of time that cooling capacity was required but could not be provided due to insufficient outlet temperature was recorded for each simulation run (see Table 3-20). Inability to operate was plotted in Figure 3-29 as a function of collector area and system capacity for Washington, D.C., for two auxiliary cooling strategies. Proper matching of collector area with desiccant system size minimized the percentage of time in which the system was unable to operate. Two conclusions can then be made if it is desired that the desiccant system operate $90 \%$ of the time that it is needed. First, a considerable increase in collector area (roughly $15 \mathrm{~m}^{2}$ ) is required to maintain a $90 \%$ avallability ( $10 \%$ downtime) if only sensible auxiliary cooling is provided rather than both sensible and latent auxiliary. This implies, on the basis of minimizing collector area, that the strategy of providing sensible and latent auxiliary cooling is more favorable than supplying sensible auxiliary only. Second, the appropriąte cholce of collector size versus system capacity is $20 \mathrm{~m}^{2}$ at $2.3 \mathrm{~kW}, 35 \mathrm{~m}^{2}$ at $4.5 \mathrm{~kW}$, and $50 \mathrm{~m}^{2}$ at $9.0 \mathrm{~kW}$.

Additional support for the above combinations of collector size and system capacity was obtained from frequency histograms of collector flowrate. As mentioned in Section 3.7.1, if the collectible solar energy resulted in an outlet temperature greater than $85^{\circ} \mathrm{C}$, the collector flowrate $\dot{\mathrm{m}}_{\mathrm{C}}$ was Increased until exactly $85^{\circ} \mathrm{C}$ was available. The percentage of time that ${ }_{\mathrm{C}}$ exceeded the desiccant system flowrate $\dot{\mathrm{m}}_{S}$ was therefore a measure of how oversized the collector area was relative to desiccant capacity. These percentages are presented in Table 3-20 and are displayed as a function of collector area in Figure 3-30. When it is assumed that $30 \%$ represents the maximum percentage of time that collector flowrate should exceed desiccant flowrate, agreement is 


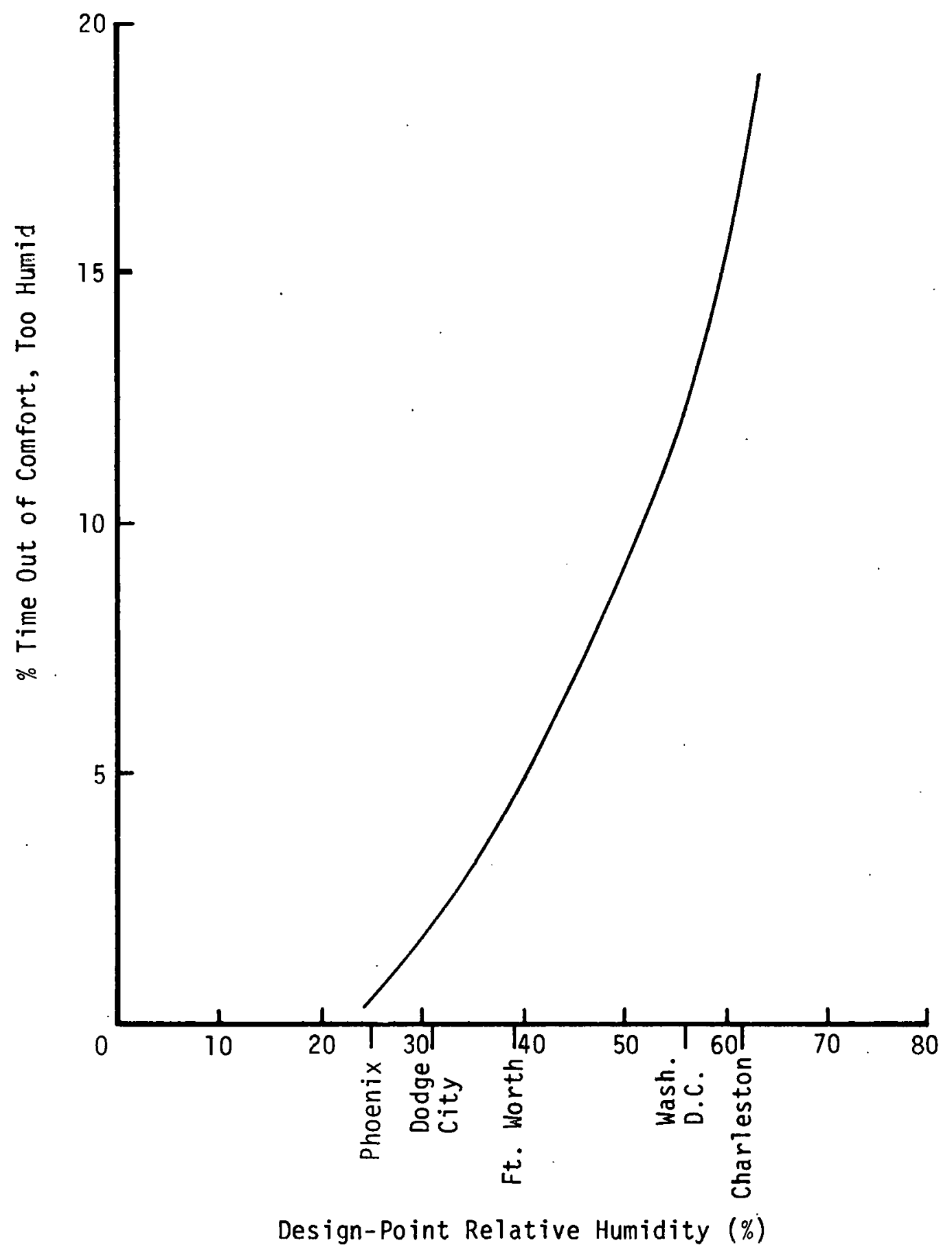

Figure 3-27. EFFECT OF DESIGN-POINT RELATIVE HUMIDITY ON COMFORT - 4.5-KW COOLER WITH
$35-M^{2}$ COLLECTOR 


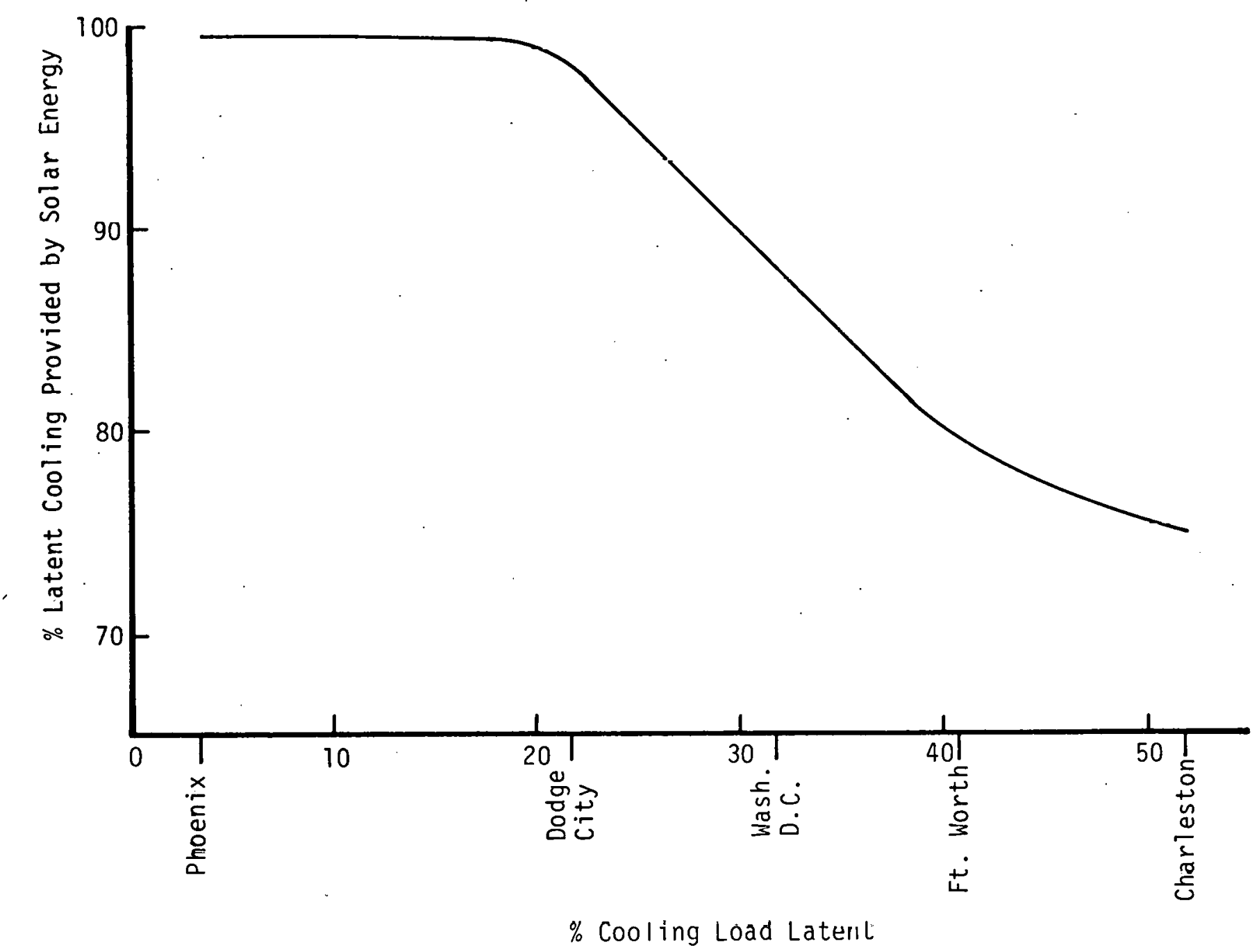

Figure 3-28. PERCENTAGE OF LATENT COOLING LOAD PROVIDED BY SOLAR ENERGY VS. PERCENTAGE OF TOTAL COOLING LOAD THAT IS LATENT - 4.5-KW COOLER WITH 35-M² COLLECTOR 


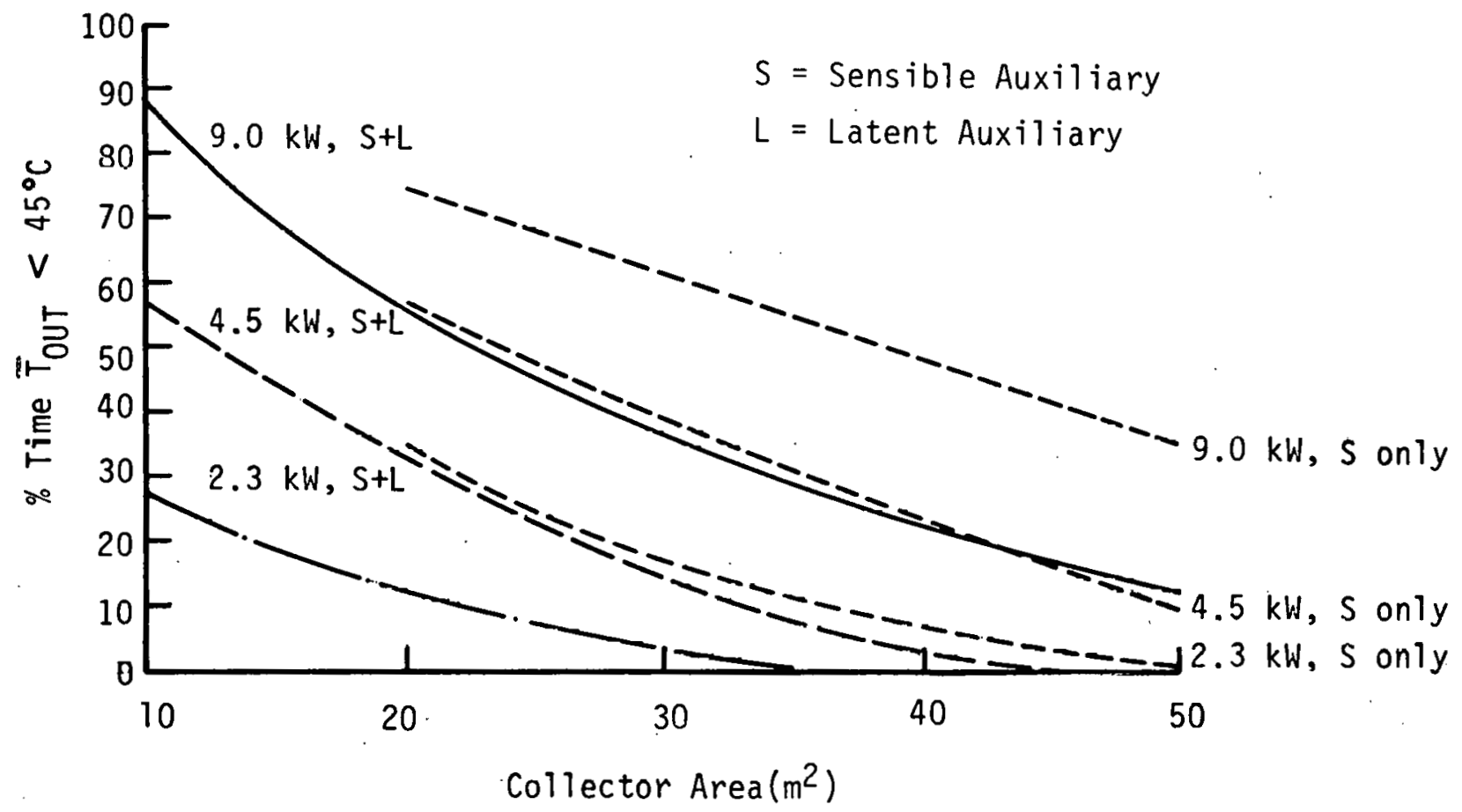

Figure 3-29. PERCENTAGE OF TIME SYSTEM CANNOT PROVIDE COOLING BECAUSE OF INSUFFICIENT REGENERATION TEMPERATURE OUT (WASHINGTON, D.C.) 
Table 3-20. SYSTEM PERPORMANCE PARAMRTERS

\begin{tabular}{|c|c|c|c|c|c|c|}
\hline Run $N$ & No. & $\begin{array}{l}\text { Average Temperature } \\
\text { Ava1lable from } \\
\text { Solar Collector/ } \\
\text { Storage }\left({ }^{\circ} \mathrm{C}\right)\end{array}$ & $\begin{array}{l}\% \text { of Time } C \\
\text { Capacity Re } \\
\text { and } \overline{\mathrm{T}}_{\text {OUT }}{ }^{<} \\
\text {(machine }\end{array}$ & $\begin{array}{l}\text { Oooling } \\
\text { equired } \\
45^{\circ} \mathrm{C} \\
\text { off) }\end{array}$ & $\begin{array}{l}\% \text { of Time } \\
\text { Auxillary } \\
\text { Required }\end{array}$ & $\begin{array}{c}\% \text { of Time } \\
\text { Collector Flow- } \\
\text { rate }>\text { System } \\
\text { Flowrate }\end{array}$ \\
\hline WASH & 1 & 57.0 & 63.0 & & 0.0 & 0.0 \\
\hline WASH & 2 & 58.5 & 54.4 & & 12.4 & 0.0 \\
\hline WASH & 3 & 60.7 & 38.5 & & 0.0 & 37.9 \\
\hline WASH & 4 & 65.1 & 31.2 & & 14.0 & 38.3 \\
\hline WASH & 5 & 67.0 & 9.4 & & 0.0 & 57.9 \\
\hline WASH & 6 & 69.8 & 10.0 & & 15.6 & 59.0 \\
\hline WASH & 7 & 56.7 & 47.3 & & 0.0 & 6.0 \\
\hline WASH & 8 & 64.5 & 35.3 & & 9.6 & 5.8 \\
\hline WASH & 9 & 66.3 & 16.3 & & 0.0 & 55.5 \\
\hline WASH & 10 & 70.6 & 9.7 & & 12.7 & 58.8 \\
\hline WASH & 12 & 74.4 & 1.0 & & 15.3 & 69.7 \\
\hline WASH & 13 & 49.3 & 75.2. & & 15.8 & 0.0 \\
\hline WASH & 14 & 56.7 & 58.7 & & 16.1 & 1.6 \\
\hline WASH & 15 & 61.6 & 35.7 & & 16.7 & 29.4 \\
\hline WASH & 16 & 61.6 & 45.1 & & 10.7 & 0.5 \\
\hline WASH & 17 & 67.9 & 19.4 & & 13.4 & 50.4 \\
\hline WASH & 18 & 72.2 & 3.2 & & 15.4 & 64.2 \\
\hline WASH & 19 & 62.7 & 20.6 & 。 & 24.5 & 0.7 \\
\hline WASH & 20 & 50.5 & 555 & & 28.4 & 0.0 \\
\hline WASH & 21 & 59.7 & 29.0 & & 25.5 & 0.0 \\
\hline WASH & 22 & 65.7 & 12.2 & & 23.0 & 6.1 \\
\hline WASH & 23 & 42.8 & 89.3 & & 30.7 & 0.0 \\
\hline WASH & 24 & 49.3 & 56.9 & & 30.0 & 0.0 \\
\hline WASH & 25 & 67.6 & 6.6 & & 27.3 & 39.0 \\
\hline WASH & 26 & 72.4 & 1.0 & & 26.4 & 60.6 \\
\hline WASH & 27 & 57.6 & 29.3 & & 30.7 & 0.0 \\
\hline WASH & 28 & 74.0 & 0.1 & . & 30.0 & 64.3 \\
\hline WASH & 29 & 76.7 & 0.0 & & 29.9 & 73.6 \\
\hline DODG & 1 & 65.9 & 36.4 & & 0.0 & 0.4 \\
\hline DODG & 2 & 70.1 & 5.9 & & 0.0 & 55.3 \\
\hline DODG & 3 & 75.1 & 0.0 & & 11.1 & 65.2 \\
\hline DODG & 4 & 76.3 & 0.0 & & 0.0 & 73.1 \\
\hline DODG & 5 & 78.4 & 0.0 & & 13.5 & 74.6 \\
\hline DODG & 6 & 54.3 & 65.5 & & 0.0 & 0.0 \\
\hline DODC & 7 & 61.3 & 49.9 & & 0.0 & 15.3 \\
\hline DODG & 8 & 66.9 & 7.2 & & 0.0 & 50.6 \\
\hline DODG & 9 & 69.6 & 7.5 & & 0.0 & 4.4 \\
\hline DODG & 10 & 73.5 & 0.3 & & 0.0 & 66.0 \\
\hline DODG & 11 & 78.0 & 0.0 & & 0.0 & 76.5 \\
\hline DODG & 12 & 75.2 & 0.0 & & 18.1 & 66.0 \\
\hline CHAR & 8 & 62.5 & 38.2 & & 8.7 & 0.0 \\
\hline CHAR & 10 & 60.8 & 44.8 & & 0.0 & 6.6 \\
\hline C.HAR & 11 & 61.9 & 33.9 & . & 12.8 & 38.0 \\
\hline CHAR & 12 & 58.6 & 39.5 & & 0.0 & 38.0 \\
\hline CHAR & 13 & 57.7 & 54.3 & & 7.5 & 0.0 \\
\hline CHAR & 14 & 66.5 & 6.9 & & 31.6 & 40.1 \\
\hline FTWR & 1 & 56.1 & 58.6 & & 0.0 & 0.0 \\
\hline FTWR & 2 & 60.4 & 23.1 & & 0.0 & 49.2 \\
\hline FTWR & 3 & 68.4 & 10.9 & & 19.1 & 52.9 \\
\hline FTWR & 5 & 74.3 & 2.2 & & 22.2 & 69.6 \\
\hline FTWR & 6 & 70.2 & 1.6 & & 32.1 & 56.2 \\
\hline PHNX & 1 & 60.1 & 46.8 & & 0.0 & 0.2 \\
\hline PHNX & 2 & 65.6 & 7.3 & & 20.5 & 0.1 \\
\hline PFNX & 4 & 74.0 & 0.7 & & 24.2 & 67.5 \\
\hline PHNX & 7 & 74.0 & 0.3 & & 28.9 & 67.5 \\
\hline
\end{tabular}




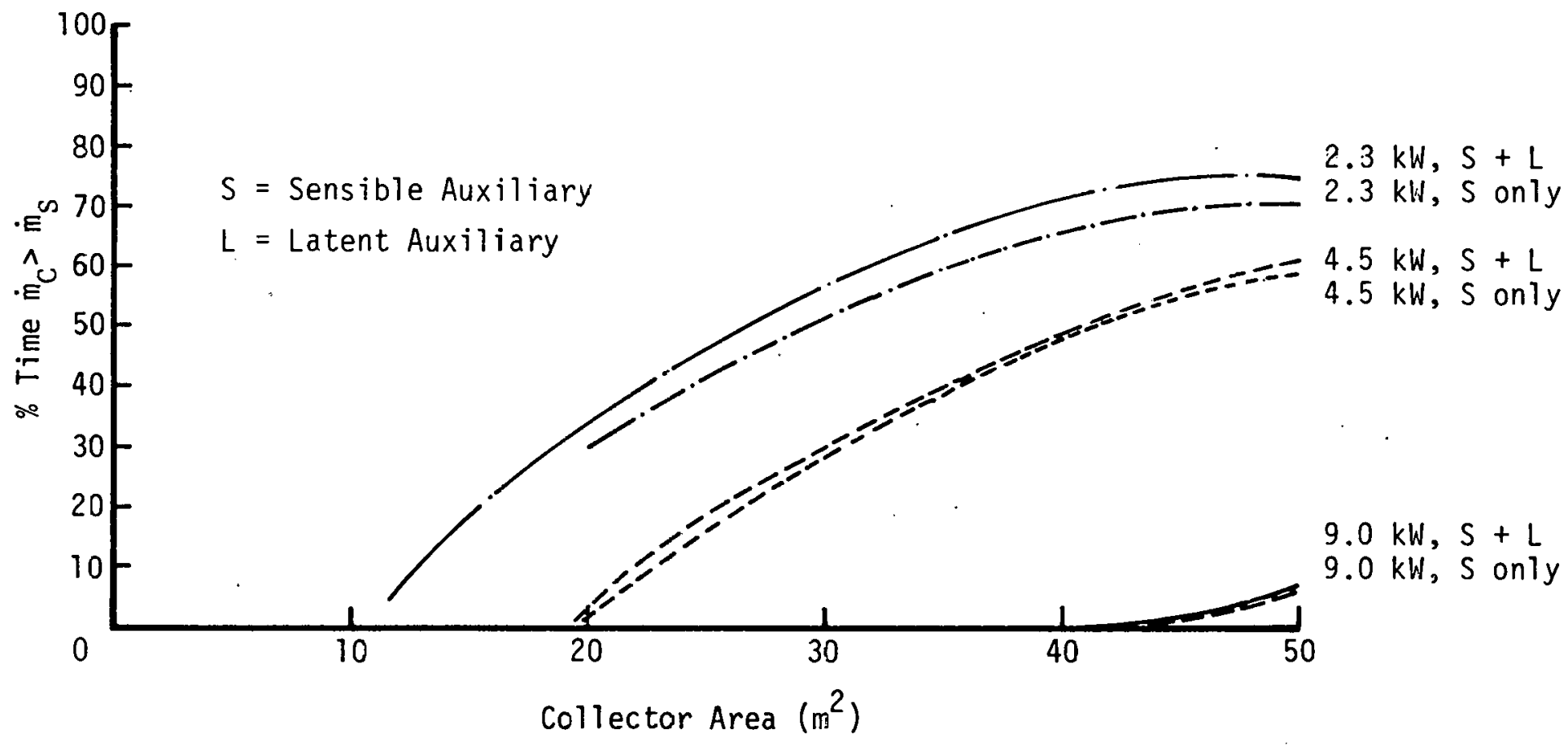

Figure 3-30. PERCENTAGE OF TIME COLLECTOR FLOWRATE $\dot{\mathrm{m}}_{\mathrm{C}}$ EXCEEDS DESICCANT SYSTEM FLOWRATE $\dot{\mathrm{m}}_{\mathrm{S}}$
(WASHINGTON, D.C.) 
found with the matching of $20 \mathrm{~m}^{2}$ with $2.3 \mathrm{~kW}$ and $35 \mathrm{~m}^{2}$ with $4.5 \mathrm{~kW}$. Note that the collector area required by a machine of $9.0-\mathrm{kW}$ capacity is undersized even at $50 \mathrm{~m}^{2}$.

To determine which of the combinations of collector area and system capacity was most desirable for Washington, D.C., the percentage of the total house cooling load supplied by solar energy was plotted against collector area (Figure 3-31). The capacity of the 9.0-kW system was far too great for small collectors. Usable solar energy was rapidly depleted and the system remained off most of the time. Another way of viewing this is that the average temperature from the collector available for regeneration was low and, thus, the corresponding percentage of time that the collector outlet temperature was less than $45^{\circ} \mathrm{C}$ (and, hence, the system inoperative) was high (see Figure 3-29). On the other hand, when sufficient collector area was provided, the 9.0-kW machine capacity could meet a greater percentage of the building load than the smaller systems. The percentages for the three system configurations under consideration were as follows:

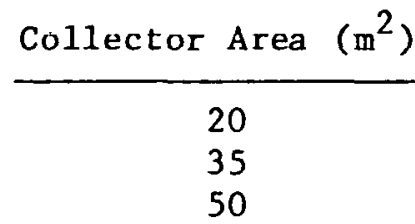

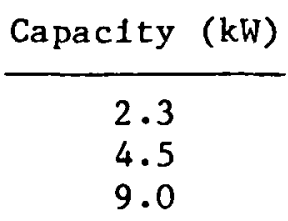

$\%$ of Building

Load Met

\section{2}

60

79

The sensible and latent components of the cooling load exhibited the same general behavior as the total cooling load (see Figures 3-32a and b).

Thus, the larger collector/capacity systems clearly exhibit greatly improved performance over the $20-\mathrm{m}^{2} / 2.3-\mathrm{kW}$ combination. This conclusion is further supported by a similar anlaysis of EER versus collector area (see Figure 3-33). For the sensible and latent auxiliary cooling strategy, the EER at $50-\mathrm{m}^{2}$ collector area and $9.0-\mathrm{kW}$ capacity was 15.11 and at $35 \mathrm{~m}^{2}$ and $4.5 \mathrm{~kW}$ it was 12.11 , whereas at $20 \mathrm{~m}^{2}$ and $2.3 \mathrm{~kW}$ the EER was only 9.51 .

When system sizing is viewed from the standpoint of COP, the importance of the dynamic interaction between the desiccant system and the collector/storage unit becomes evident. Figure 3-34 is a plot of system COP as a function of collector area for the system sizes under consideration. At very low collector areas, the $9.0-\mathrm{kW}$ machine is quite oversized, as discussed previously, and hence the system rarely was capable of operating. When it did operate, it was primarily driven directly by solar energy; that is, storage remained depleted. Thus, while the system operated with a low duty cycle (see Table 3-19), high temperatures were avallable during those times it did operate, resulting in efficient use of supplied energy and a high COP. With large collector areas, more solar energy was collected, some of which could be stored at temperatures above $45^{\circ} \mathrm{C}$ (the lower level temperature control). This storage was depleted a smaller fraction of time than in the case of the smaller collector areas, and the desiccant system could operate at the correspondingly lower temperature range, resulting in a smaller COP. This behavior could not have been predicted from the steady-state analysis; it can only be understood in terms of the dynamic interaction of the desiccant cooler with the solar collector/storage system outlet temperature. 


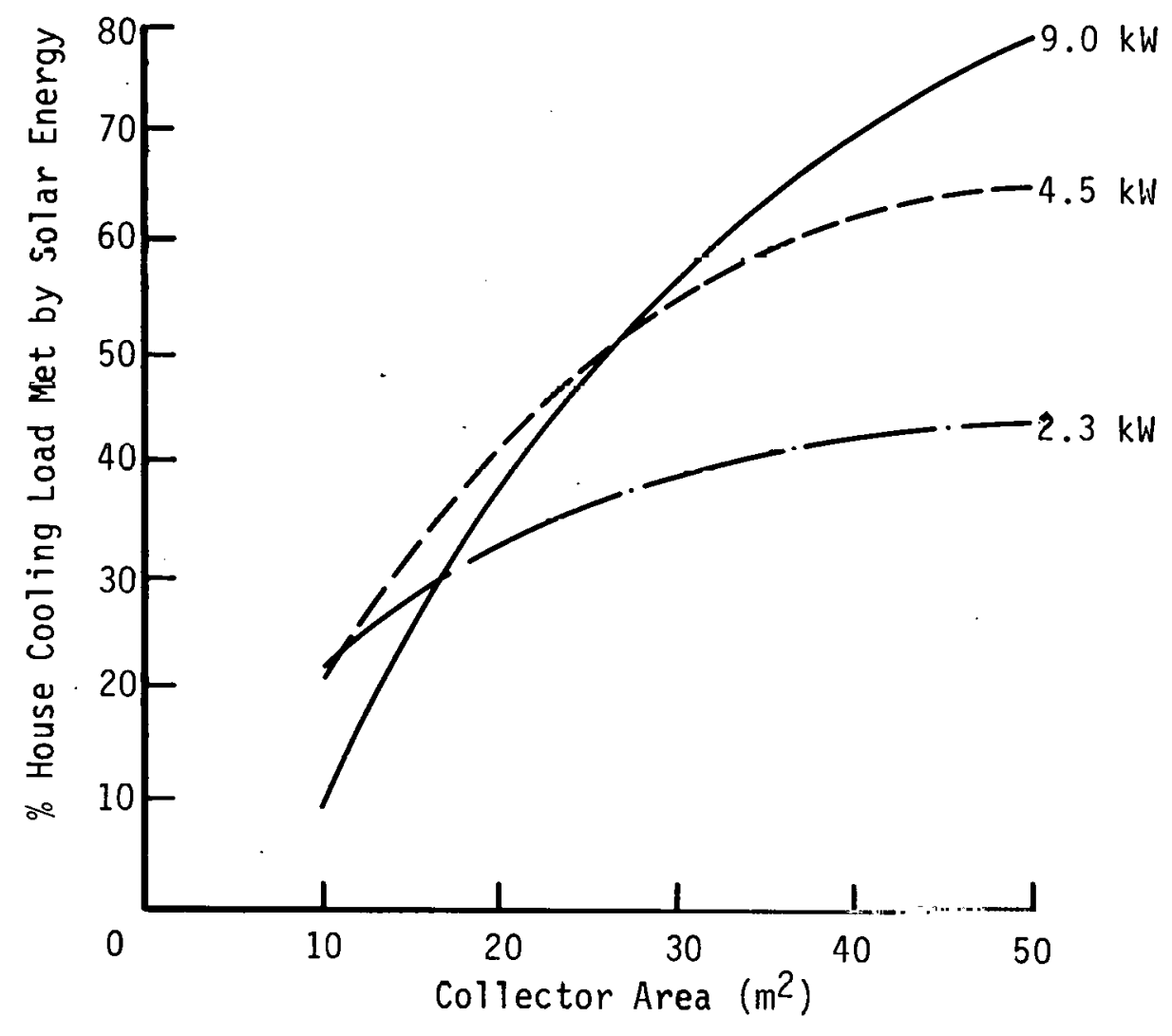

Figure 3-31. PERCENTAGE OF ANNUAL COOL ING LOAD MET BY SOLAR ENERGY (WASHINGTON, D.C.; AUXILIARY COOLING SUPPLIED) 

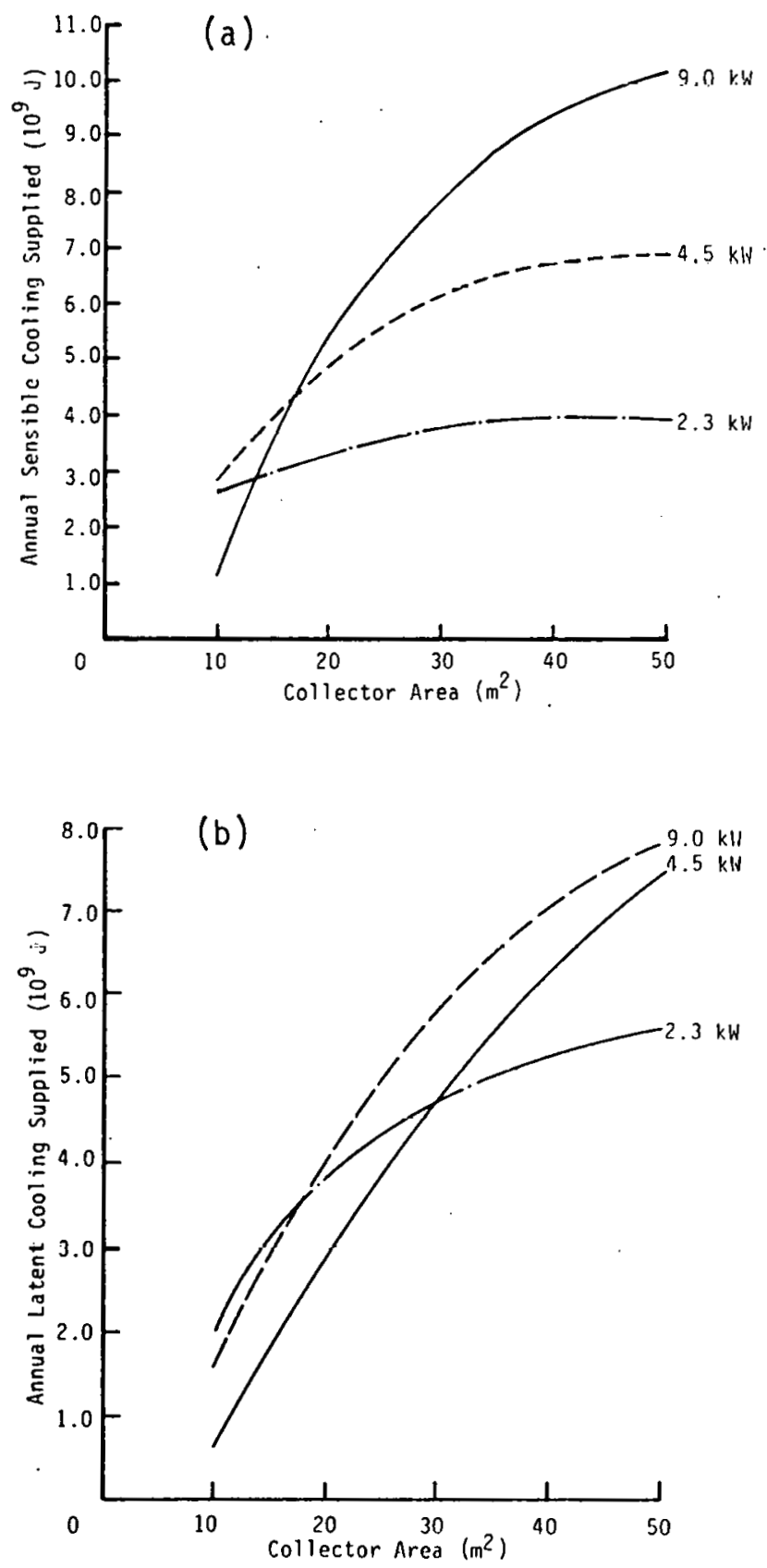

Figure 3-32. ANNUAL COOLING SUPPLIED BY SOLAR DESICCANT COOLER (WASHINGTON, D.C.; AUXILIARY COOLING SUPPLIED): (a) SENSIBLE COOLING AND (b). LATENT COOLING 


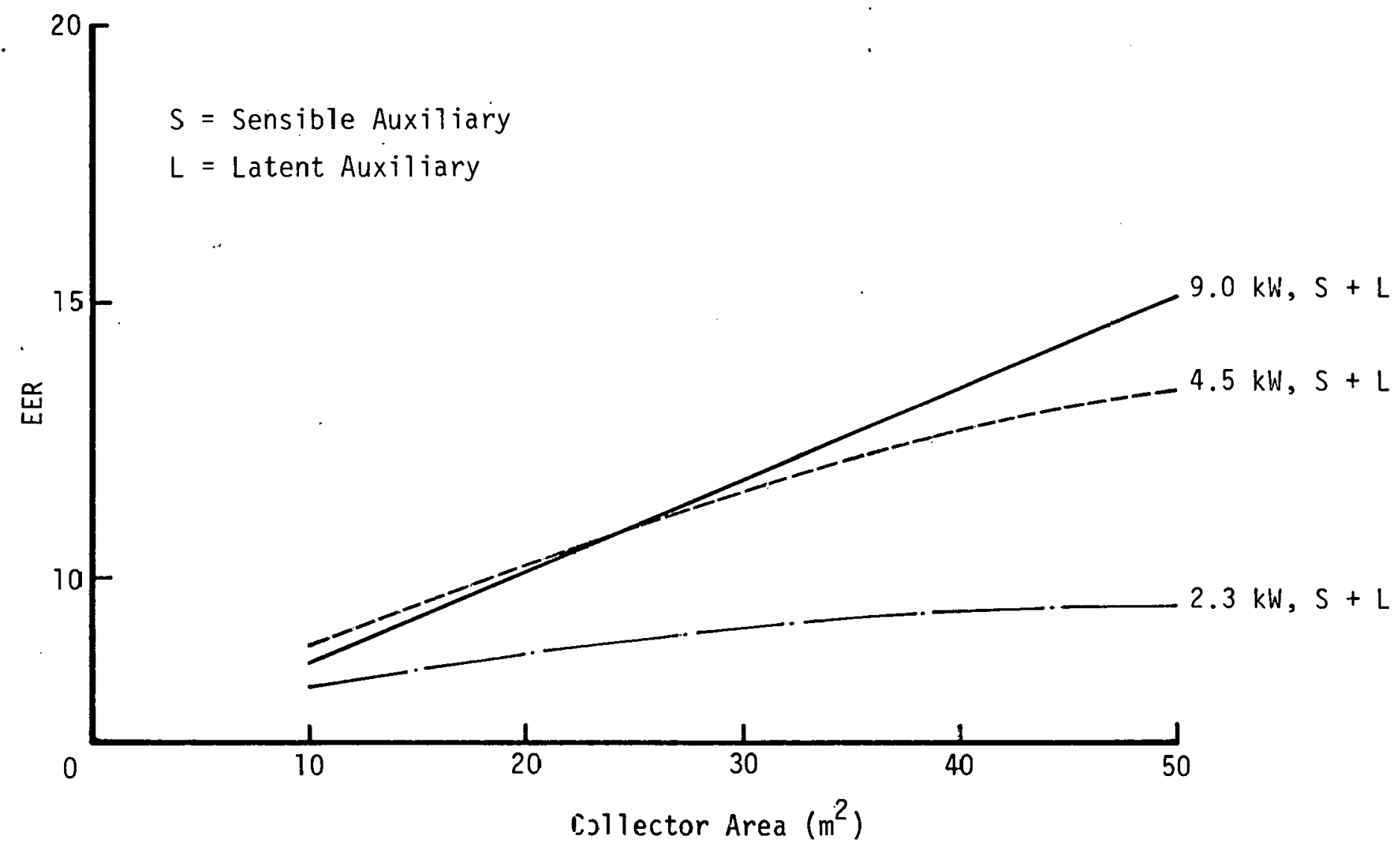

Figure 3-33. EER VS. COLLECTOR AREA (WASHINGTON, D.C.) 


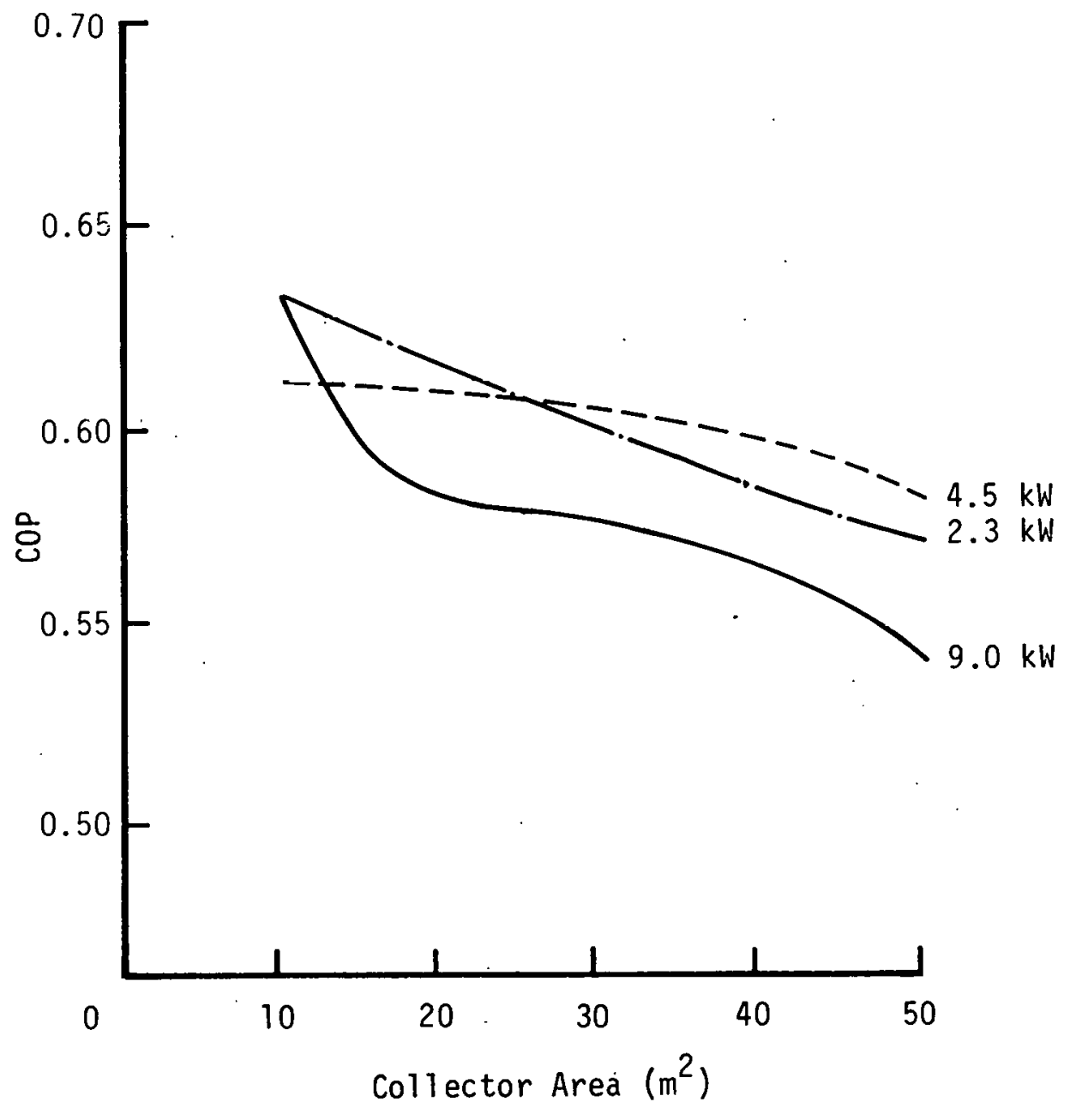

Figure 3-34. COP VS. COLLECTOR AREA (WASHINGTON, D.C.) 
This suggests that a more meaningful characterizing variable for the desiccant cooler (rather than COP or collector area) is the average temperature available from the collector/storage unit (i.e., regeneration temperature). Such information is available from frequency histograms of the outlet temperature from the collector/storage system and is compiled in Table 3-20. The translation from collector area to average outlet temperature $\overline{\mathrm{T}}_{\text {OUT }}$ is depicted in Figure 3-35.

Figure 3-36 shows average outlet temperature plotted versus COP. The reason for the decreasing $C O P$ as $\overline{\mathrm{T}}_{\text {OUT }}$ increases is similar to the argument given in the steady-state analysis. At high regeneration (outlet) temperatures, the supplied energy increases more rapidly than the cooling capacity. This appears to he an inherent characteristic of the desiccant systems.

To further illustrate the effect on system parameters of increasing collector outlet temperatures, a plot of $\overline{\mathrm{T}}_{\mathrm{T}}$ versus EER for Washington, D.C., is presented in Figure 3-37. As discussed earlfer, parasilic power requirements are essentially independent of collector area and machine size. Therefore, since a larger machine provides a larger fraction of the total house cooling load, as shown in Figure 3-38, the cooling capacity supplied per unit of parasitic power (i.e., EER) is greater for the systems of larger size.

The smaller machine with $20-\mathrm{m}^{2}$ collector area and 2.3-kW desiccant cooler had the most favorable COP. (see Figure 3-36), but the objective of the present control strategy was to maximize capacity and machine off-time and not to optimize system COP. For this reason, the resulţs presented in Figures 3-31 and 3-33 support the selection of a $9.0-\mathrm{kW} / 50-\mathrm{m}^{2}$ or a $4.5-\mathrm{kW} / 35-\mathrm{m}^{2}$ system, with both sensible and latent auxiliary cooling supplied, as the most suitable system for Washington, D.C. For the $4.5-\mathrm{kW}$ cooler, a $35-\mathrm{m}^{2}$ collector area is most favorable since the incremental increase in cooling capacity and EER does not justify the increase from $35-$ to $50-\mathrm{m}^{2}$ collector area. As previously discussed, a $50-\mathrm{m}^{2}$ collector area is oversized for a $4.5-\mathrm{kW}$ desiccant cooler. The 9-kW cooler performs best with a $50-\mathrm{m}^{2}$ collector area. 


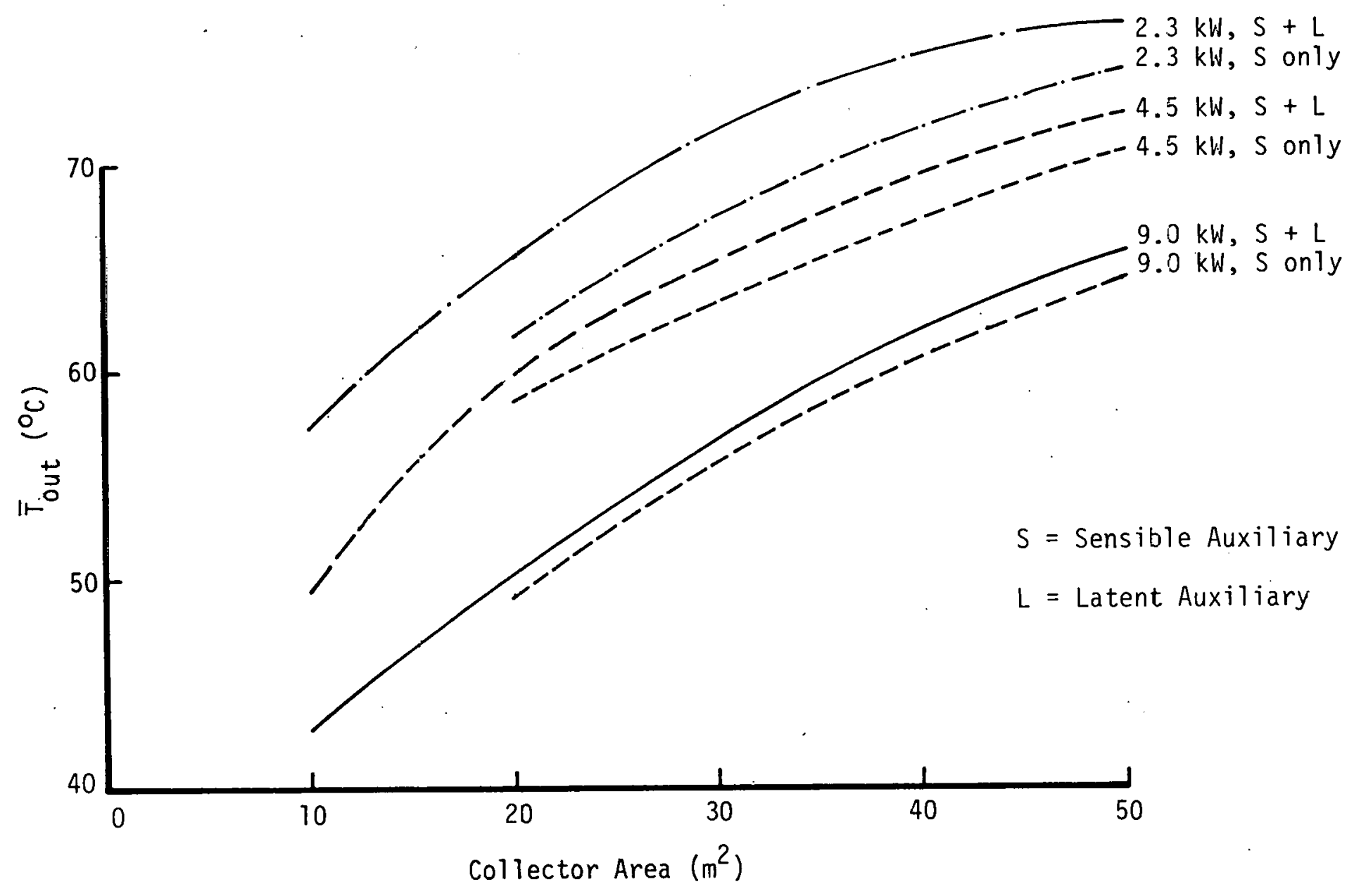

Figure 3-35. REGENERATION TEMPERATURE TOUT VS. COLLECTOR AREA (WASHINGTON, D.C.) 


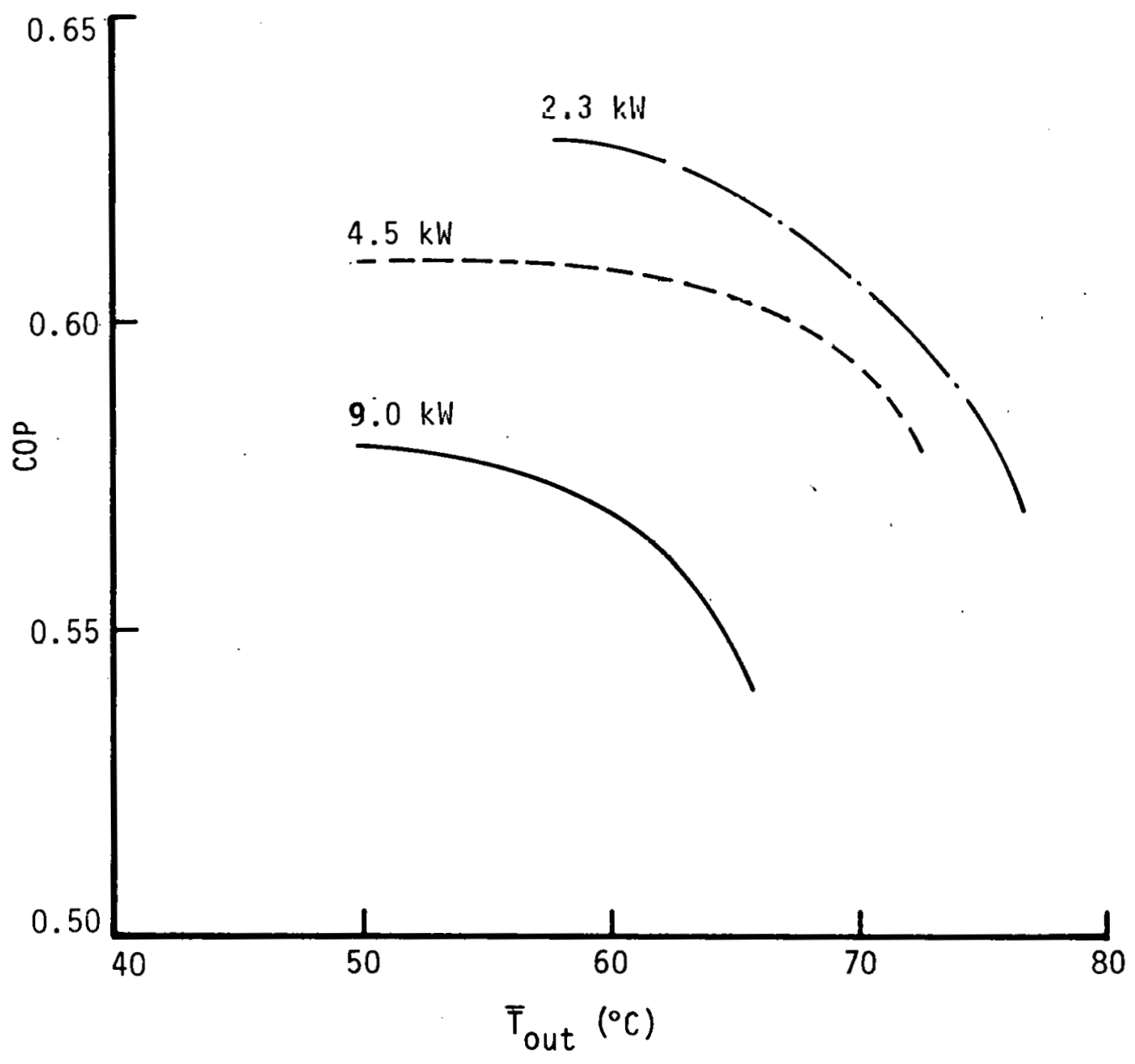

Figure 3-36, COP VS. REGENERATION TEMPERATURE TOUT (WASHINGTON, D.C.) 


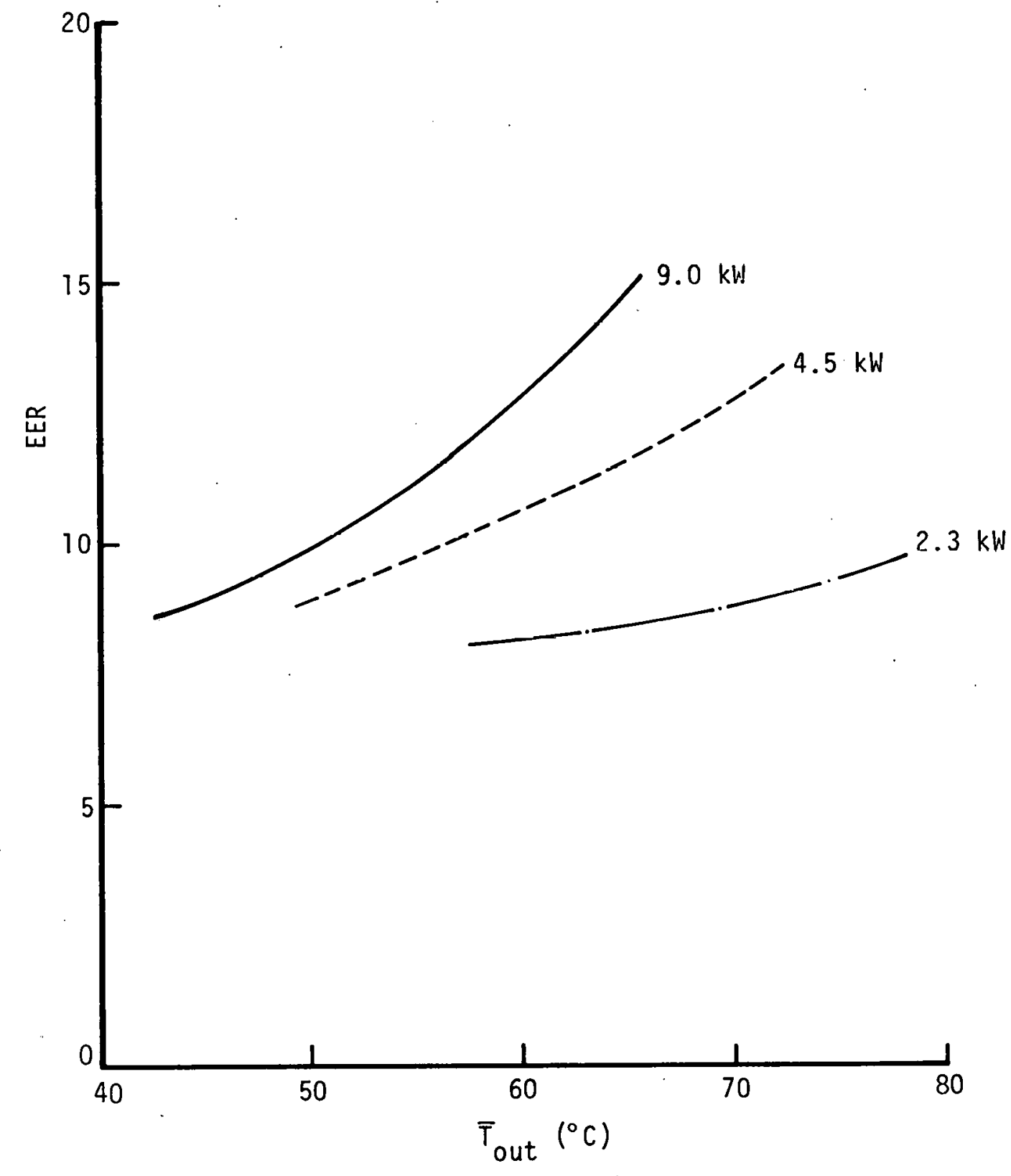

Figure 3-37. EER VS. REgENERATION TEMPERATURE TOUT (WASHINGTON, D.C.) 


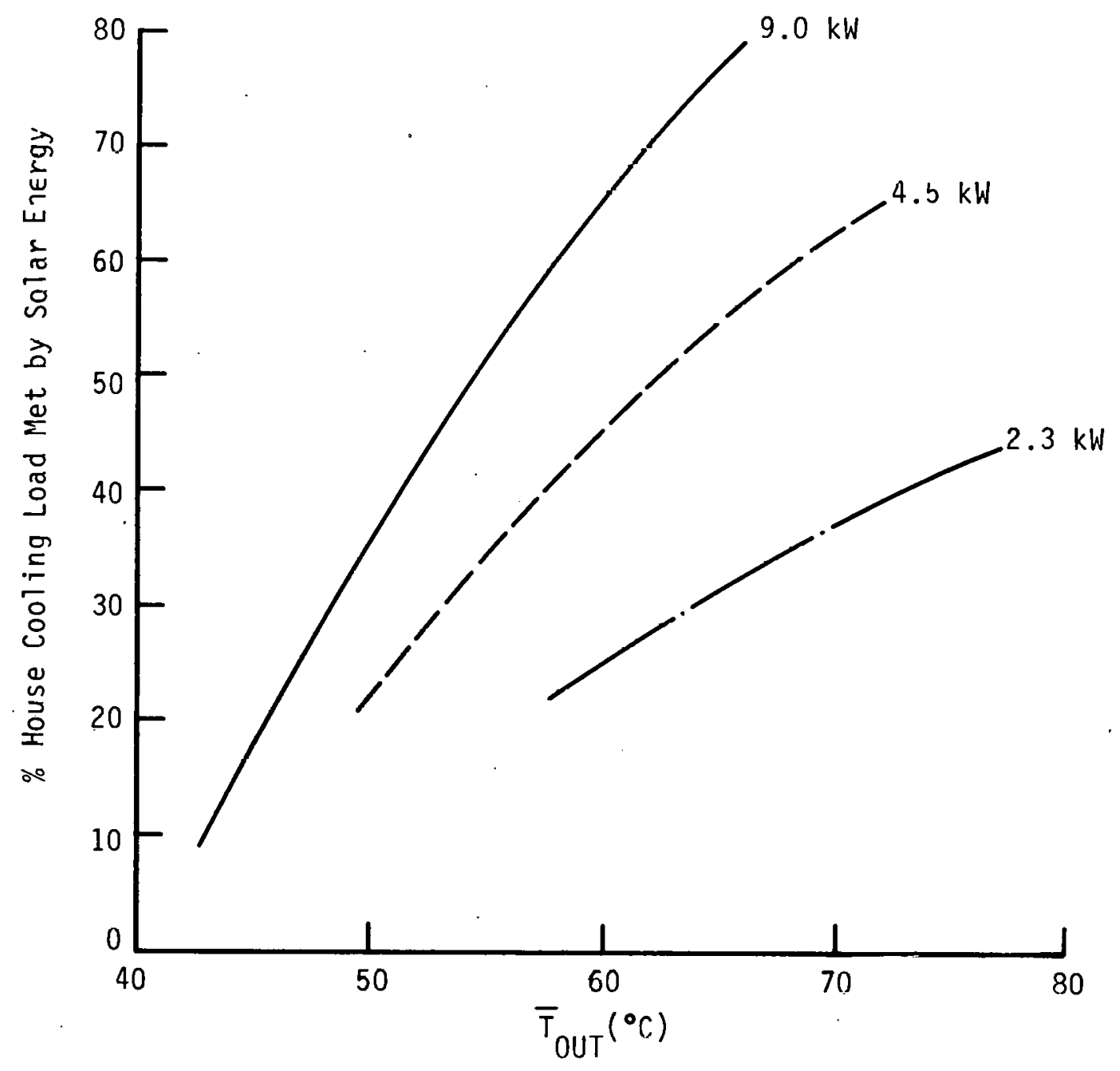

Figure 3-38. P.ERCENTAGE OF ANNUAL COOLING LOAD MET BY SOLAR ENERGY VS. REGENERATION TEMPERATURE TOUT (WASHINGTON, D.C.) 


\section{SECTION 4.0}

\section{STANDARD VAPOR-COMPRESSION AIR-CONDITIONING SIMULATION}

In order to evaluate the performance characteristics and cost of a solar desiccant cooler, an accepted basis of comparison is required. For the purposes of this study, an electrically driven, standard vapor-compression air conditioner, used commonly throughout the United States, was chosen for comparison. As with the desiccant cooler, the vapor-compression cooler simulation was run for a 12-month cooling/heating season. Important parameters required to make a comparison between the two cooler types were calculated, including cooling capacity supplied, heat supplied, electrical energy required, COP, EER, and percentage of time the house was in the comfort zone.

\subsection{DESCRIPTION OF SIMULATION}

The vapor-compression cooler simulations were performed by a computer program entirely separate from TRNSYS. However, the desiccant and vapor-compression simulations shared many features so that direct comparisons of the results could be made. The same basic house model, load calculation model, house comfort zone, SOLMET ambient weather data for each location, and time increment (one-half hour) were used.

Figure 4-1 illustrates the ideal single-stage vapor-compression refrigeration cycle. The energy transfers are given by

$$
\begin{aligned}
& 2^{Q_{3}}=h_{3}-h_{2}, \\
& 3^{W_{4}}=h_{4}-h_{3}, \\
& 4^{Q_{1}}=h_{3}-h_{1}, \text { and } \\
& h_{1}=h_{2},
\end{aligned}
$$

where

$$
\begin{aligned}
& Q=\text { heat transfer }(\mathrm{J} / \mathrm{kg}), \\
& W=\text { work transfer }(\mathrm{J} / \mathrm{kg}), \text { and } \\
& \mathrm{h}=\text { enthalpy }(\mathrm{J} / \mathrm{kg}) .
\end{aligned}
$$

The theoretical coefficient of performance is defined as

$$
\operatorname{cop}=\frac{h_{3}-h_{2}}{h_{4}-h_{3}} .
$$

The vapor-compression simulation was written with two basic assumptions: 


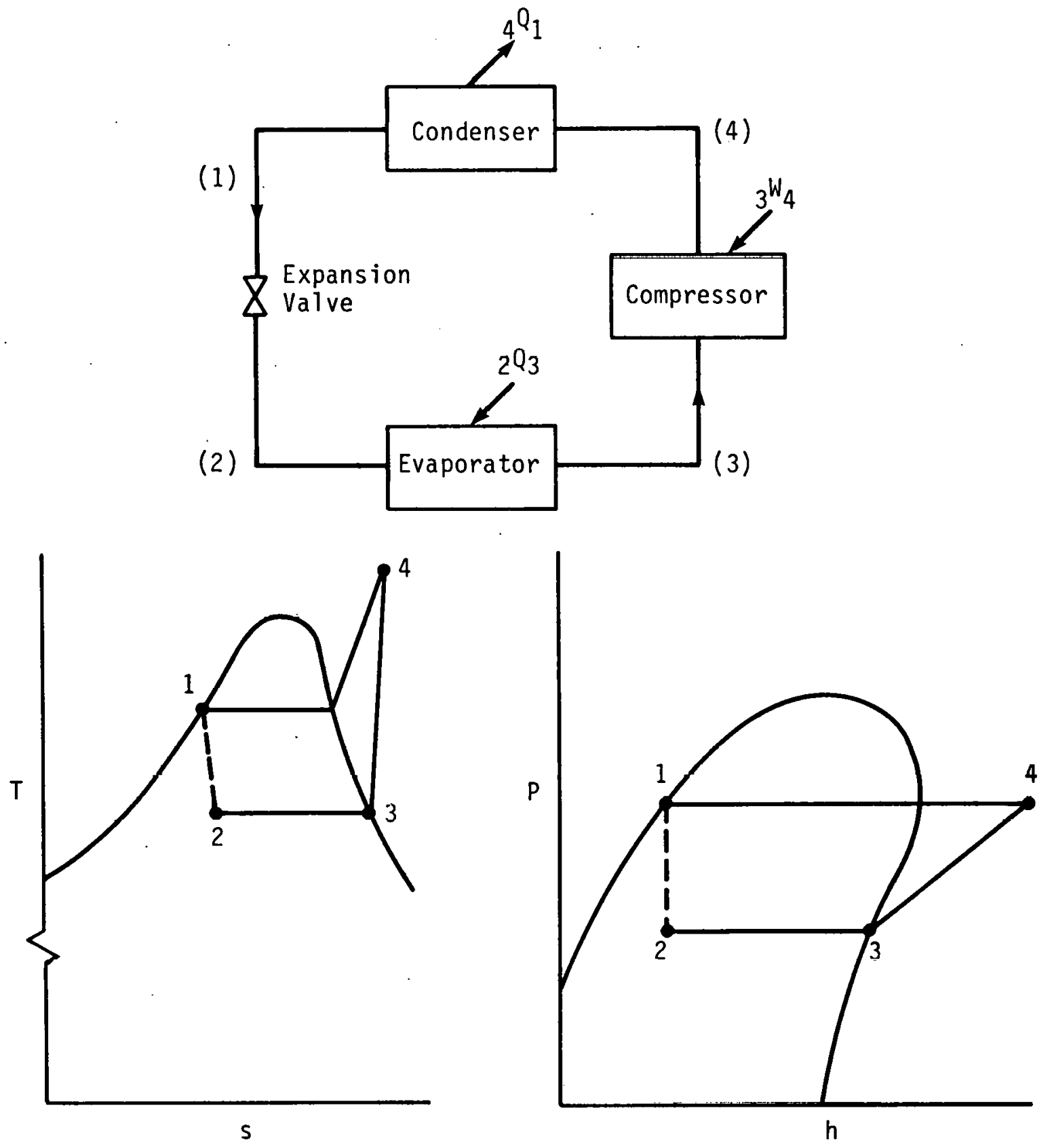

Figure 4-1. THEORETICAL SINGLE-STAGE VAPOR-COMPRESSION REFRIGERATION CYCLE 
- The vapor-compression machine had a constant cooling capacity of 9.0 $\mathrm{kW}$ (sensible + latent).

- The average COP for the cooler was 2.5 .

These and the other basic input parameters of the simulation are summarized in Table 4-1.

Table 4-1. SUMMARY OF INPUT PARAMTTERS FOR VAPORCOAPRESSION AIR-CONDITIONING STMULATION

\begin{tabular}{ll}
\hline $\begin{array}{l}\text { Operating capacity (kW) [tons] } \\
\text { Average vapor-compression COP }\end{array}$ & $9.0[2.5]$ \\
$\quad$ (without reheat) & 2.5 \\
Flowrate $\left(\mathrm{m}^{3} / \mathrm{s}\right)$ & 0.48 \\
Assumed air pressure drops $\left(\mathrm{N} / \mathrm{m}^{2}\right)$ & 125 \\
House comfort zone & Defined in Figure 3-4 \\
House model. & Described In Section 3.2 .2 .6 \\
Holise cooling/heating loads & Described in Section 3.2 .3 \\
SOLMET hourly ambient weather data & \\
$\quad$ Charleston, S.C. & 1963 \\
Dodge City, Kans. & 1955 \\
$\quad$ Ft. Worth, Tex. & 1960 \\
Phoenix, Ariz. & 1962 \\
Washington, D.c. & 1955 \\
Simulation time increment (h) & 0.5 \\
Simulation time period & $12-$ month heating/cooling season
\end{tabular}

The simulated operation of the vapor-compression air conditioner is illustrated in Figure 4-2. Two different room conditions, $25.5^{\circ} \mathrm{C}$ with $60 \%$ relative humidity and $25.5^{\circ} \mathrm{C}$ with $20 \%$ relative humidity, are shown on the psychrometric chart with the corresponding paths for room air passing through the vaporcompression cooler evaporator.

Point 1 on Figure 4-2 represents room air at $25.5^{\circ} \mathrm{C}$ dry-bulb temperature and $60 \%$ relative humidity. As the air passes through the evaporator, it is sensibly cooled along a line of constant humidity ratto $\mathrm{W}$ until it reaches saturation (dew-point temperature) at point 2. From point 2 to point 3 the air undergoes both sensible and latent cooling as its dry-bulb temperature and humidity ratio decrease. The sum of the sensible cooling from points 1 to 2, sensible cooling from points 2 to 3 , and latent cooling from points 2 to 3 equals $9.0 \mathrm{~kW}$.

In the same manner, point 4 represents room air at $25.5^{\circ} \mathrm{C}$ dry-bulb temperature and $20 \%$ relative humidity. As the air passes through the evaporator, it is sensibly cooled to point 5. At this point the cooling capacity of $9.0 \mathrm{~kW}$ has 
\%

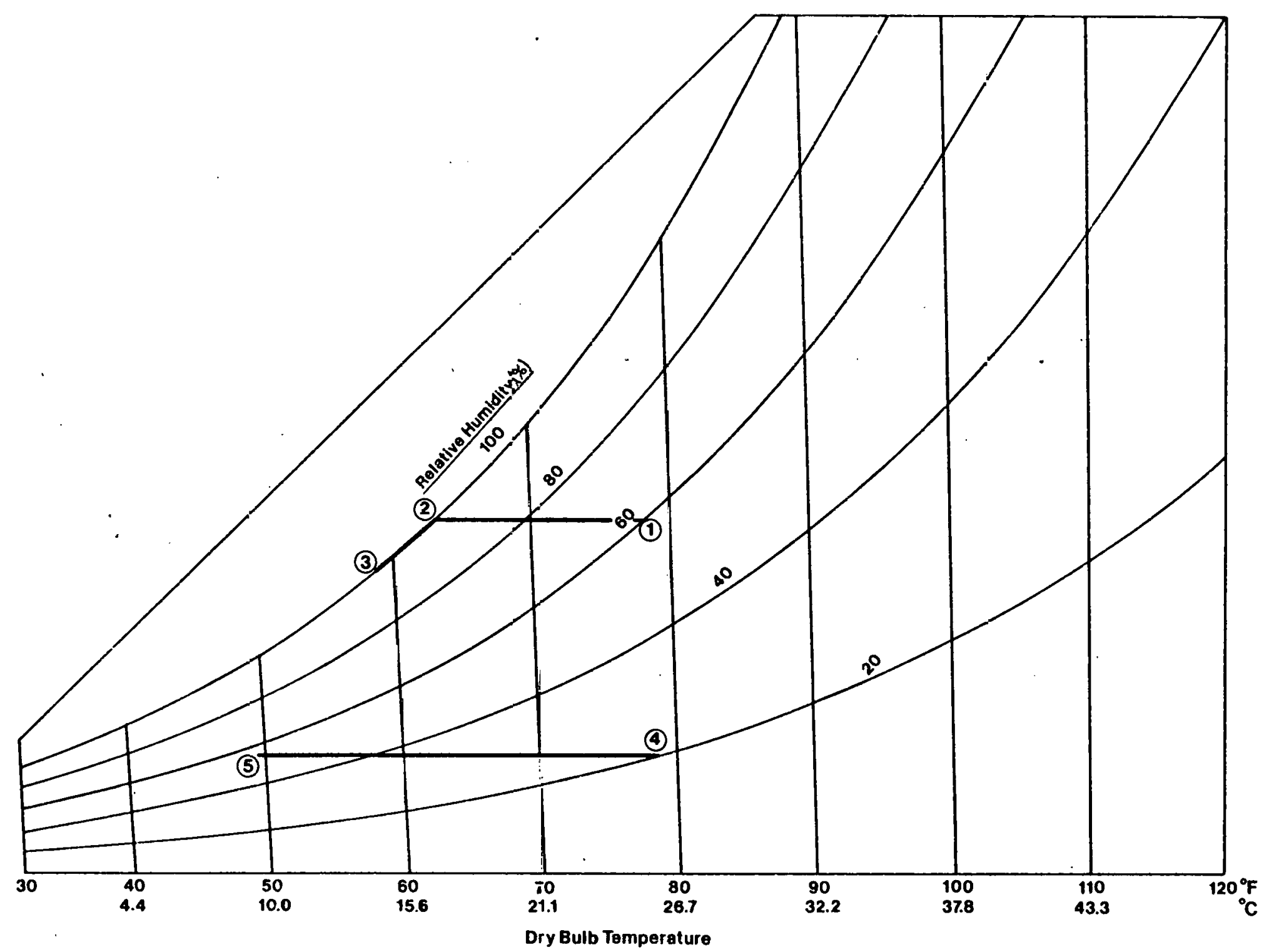

Figure 4-2. TYPICAL AIR STATE TRANSITIONS FOR VAPOR-COMPRESSION COOLER SIMULATION 
been reached and, therefore, no latent cooling is supplied. This condition could occur in very dry climates such as Phoenix, Ariz. Correlations for enthalpy as a function of humidity ratio and specific heat of moist air allow the states indicated in Figure 4-2 to be determined [28].

Two sets of simulations were performed for each of the five cities under study:

- a standard operating mode for a residential vapor-compression cooler, and

- a revised operating mode using reheat for the room air immediately after the air leaves the cooler and before it is reintroduced into the house.

Although commonly used in commercial applications, reheat is not usually employed in residential systems. Reheat was included in one set of simulations in order to match latent house load to cooler latent capacity for the desiccant and vapor-compression systems. The desiccant cooler system can meet latent loads as well as sensible loads and can even supply latent capactity alone if required. However, the vapor-compression cooler must supply enough sensible cooling to bring the room air to saturation before any latent capacity can be supplied. In humid climates such as Charleston, S. C., or Washington, D.C., the vapor-compression cooler might supply too much sensible cooling in meeting the large latent loads. Therefore, when more latent than sensible cooling was required to maintain the house in comfort, reheat was used whereby heat was added to the cooled air leaving the vaporcompression machine in an amount equal to the difference between the sensible cooling supplied and the sensible house load.

The controller required to operate the vapor-compression cooler was simpler than that for the desiccant cooler (see section 3.7.2). When room conditions were above comfort in dry-bulb temperature or relative humidity, the vaporcompression system was simply turned on. The proportions of sensible and latent cooling supplied were determined by the state of the moist air introduced into the evaporator. It would be possible to change the proportions of sensible to latent cooling by varying the rate of airflow through the cooler while maintaining the $9.0-\mathrm{kW}$ total cooling capacity. A variable air mass flow capability was included in the controller for the vapor-compression simulation but the feature was not used in this study.

The computer program written for the vapor-compression machine simulated the conditions for an annual rooling/heating season in essentially the same manner as did the program for the desiccant cooler. Moist air at room conditions entered the conler, $9.0 \mathrm{~kW}$ of cooling capacity was supplied, reheat (if any) was added, and the airstream was reintroduced into the house. The house model determined the resulting house air conditions, and the controller continued cooler operation if the room air was out of comfort in dry-bulb temperature and/or relative humidity; or, if the room was in confort, the controller turned off the cooler. If the room conditions were such that heating was required, the heating load was assumed to be met with an auxiliary heater so that the room dry-bulb temperature never dropped below $20^{\circ} \mathrm{C}$. However, the room conditions could go higher than $25.5^{\circ} \mathrm{C}$ dry-bulb temperature and $60 \%$ 
relative humidity if the vapor-compression cooler could not meet the sensible and latent house loads. Energy accounting for cooler capacity, house loads, etc., was identical to that described for the destccant cooler. Figure 4-3 is a flow diagram showing basic steps in the computer program.

\subsection{RESULTS}

The vapor-compression simulation was run for the five cities used in the desiccant simulation. The results are shown in Appendix B (Tables B-1 through $\mathrm{B}-10)$. The size of the vapor-compression cooler was not varied from $9.0 \mathrm{~kW}$.

The information shown in the tables of Appendix $B$ was defined in the same manner as for the desiccant cooler with the exception of reheat (see Section 4.1) and COP. Although the average COP for the vapor-compression cooler was assumed to be 2.5 , the overall system $C O P$ was calculated as

$$
\text { COP overall }=\frac{\text { Cooling capacity }}{\text { Cooling capacity/2.5 }+ \text { reheat }} \text {. }
$$

The reheat was considered part of the vapor-compression system and, as a heat input, was included in the calculation of cooling COP shown in Tables B-6 to B-10. Tables $B-1$ to $B-5$ are the results of the vapor-compression simulation without reheat.

Investigation of the two sets of results (with and without reheat) indicates that the net energy requirements for each are nearly the same. For all five cities, the results for the standard operating mode without reheat (Tables B-1 to $B-5$ ) show that the heating load increased by an amount approximately equal to the reheat requirements of Tables B-6 to B-10. Thus, in the standard operating mode, the vapor-compression cooler drove the room conditions to the lower comfort boundary in temperature $\left(20^{\circ} \mathrm{C}\right)$ in an effort to meet the latent load and maintain comfort conditions of relative humidity ( $60 \%$ upper limit). The excess sensible cooling capacity of the cooler was offset by the house natural-gas-fired space heater. In the reheat mode, the excess sensible cooling capacity was met by a natural-gas-fired air heater between the cooler and the house. In either case, the annual electrical and natural gas requirements were essentlally the same. If the cooler had been controlled by temperature only, the house relative humidity would have drifted in and out of the comfort zone and no extra energy for reheat or space heating would have been required.

Several items of information from the tables in Appendix $B$ were required for the economic analysis (see section 5.0), including total supplied heat, cooling capacity, reheat, and parasitic energy. 


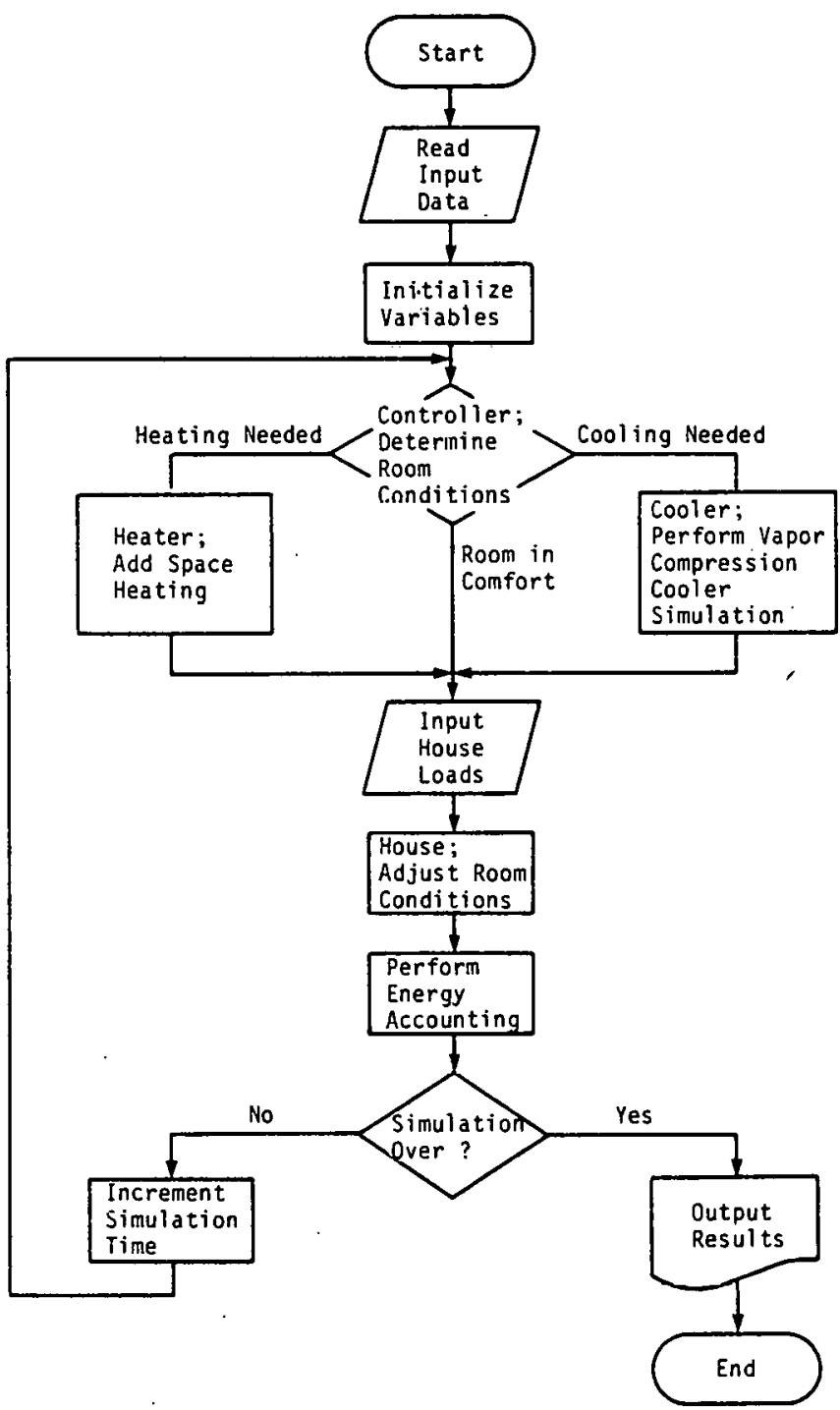

Figure 4-3. VAPOR-COMPRESSION COOLER SIMULATION FLOW DIAGRAM 


\section{SE기눈}




\section{SECTION 5.0}

\section{ECONOMIC ANALYSIS}

The potential for using solar space heating and/or desiccant cooling in residential buildings ultimately depends on the economics of solar heating and cooling systems as compared to conventional systems. Local energy costs (electricity and natural gas) and the amount of conventional energy displaced by solar energy determine if the capital cost of the solar system can be recovered within an acceptable time period through energy cost savings. The previous sections of this report describe simulations of solar and conventional systems for residential space heating and cooling. The results of these simulations, namely, power input required to provide annual heating and cooling, were used in an economic analysis computer program to make direct comparisons between solar and conventional systems. Also considered was the potential for fossil fuel conservation.

\subsection{METHODOLOGY}

The economic analysis program was used to discount life-cycle costs of the solar and conventional systems, resulting in present worths of the costs for each system. The present worth was determined for all annual heating/cooling season simulations of the solar and conventional systems in each of the five cities studied. Cost/benefit ratios for the solar systems were then calculated from the present worth figures.

In order to determine the present worth of life-cycle costs, several parameters were required for the economic analysis. These included interest rates, inflation rates, and energy-cost escalation rates. Since a 20-year economic lifetime was assumed for both the solar and conventional systems, forecasts were made for the economic parameters (assumed as constants) over the lives of the systems. The values used in the analysis (base year of 1978) are shown in Table 5-1.

Table 5-1. PARAMETERS USED IN ECONOMIC ANALYSIS

\begin{tabular}{lc}
\hline System lifetime & 20 years \\
General inflation rate & $6 \%$ \\
Interest rate & $9 \%$ \\
Discount rate & $3 \%$ \\
Natural gas escalation rate & $5 \%$ \\
Electricity escalation rate & $5 \%$ \\
\hline
\end{tabular}

By using these parameters, the annual cash flow (outlay) for each system was discounted to the present by using the following equation [29]: 


$$
P W=A \times \frac{(1+1)^{n}-1}{1(1+1)^{n}} \text {, }
$$

where

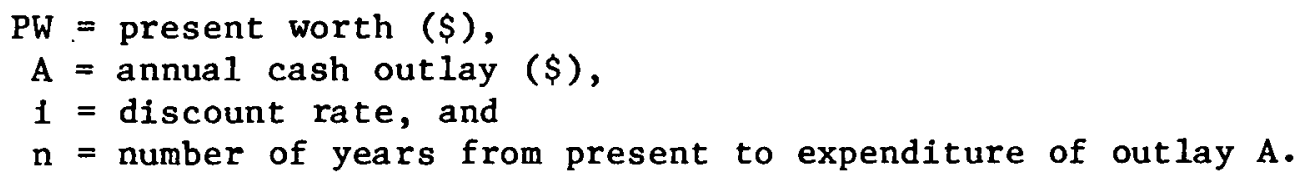

All cash outlays and the present worth were assumed to be in constant dollars. Due to the natural gas and electricity escalation rates (that is, the rate at which the costs of these fuels increase in excess of the general inflation rate), the annual cash outlay increased nver the life of the system.

In addition to the economic parameters of Table 5-1, annual cash nutlays fons solar and conventional systems are influenced by capital equipment costs; installation costs; operation, maintenance, replacement, and insurance (OMRI) costs; and potential government tax credits or subsidies for residential solar installations. The values used in this study are described in Section 5.2. Since the economic parameters and costs used in the. IIfe-cycle analysis can vary widely over a 20-year period, the results are useful only for general comparisons between system types. The analyses may not reflect true costs in the latter years of the system lifetimes.

Once the present worth of the life-cycle costs for solar and conventional systems was calculated, the solar system cost/beneift ratio was determined. For the purposes of this study, "benefit" was defined as the present worth of life-cycle costs to maintain house air conditions within the comfort zone over 20 consecutive 12-month heating/cooling seasons by use of conventional fuels and afr-conditioning methods (that 1s, natural gas heating and plprtriral1y driven, vapor-compression alr conditioning). "Cost" was defined as the present worth of the life-cycle costs to maintain comfort conditions for the same time period using solar energy for heating and desiccant air conditioning, with auxiliary heating and cooling as required. Thus, a cost/benefit ratio equal to 1.0 represents a case where the net solar system costs equal the conventional system costs over 20-year lifetimes. For a cost/benefit ratio less than 1.0 , the solar system results in a net savings over the cost of a conventional system, and for a ratio greater than 1.0 , the conventional system results in a net savings over the cost of the solar system.

Solar systems that supply only space heating also were compared. Cost/benefit ratios were determined for solar space heating systems with natural gas heaters for auxiliary heat and vapor-compression air conditioners for the total cooling loads. With this information, incremental changes in cost/benefit ratios were examined for cases in which combined solar desiccant coolers and solar space heating systems replaced conventional coolers with solar space heating systems. 
An important aspect of the solar heating and cooling systems is the potential for conservation of fossil fuels. As fossil fuels become more scarce, the impetus for their displacement by solar energy for heating and cooling may equal economic incentives. The percentage of fossil fuel displaced by solar energy was determined for each of the annual simulations performed in this study. The fossil fuel displacement was also determined for solar heating systems with vapor-compression air conditioning.

To determine the fossil fuel displaced by solar heating and cooling systems, the power inputs to both the solar and conventional systems were obtained from the computer simulations for annual heating and cooling seasons. To convert electrical power to its equivalent in fossil fuel, an overall conversion and transmission efficiency of $33 \%$ was assumed. The following equations were used to determine fossil fuel displacement:

$$
\text { DISP }=\frac{\text { HEAT DISP } \times \text { HEAT LOAD }+ \text { (BASE THERMAL }- \text { SOLAR THERMAL })}{\text { HEAT LOAD + BASE THERMAL }},
$$

where

$$
\begin{aligned}
\text { DISP }= & \text { fraction of fossil fuel energy displaced by solar } \\
& \text { energy, } \\
= & \text { total annual house heating load, } \\
\text { HEAT LOAD DISP = fraction of HEAT LOAD met by solar energy } & \text { BASE THERMAL = } \\
& \text { fossil fuel energy required for cooling season with } \\
\text { SOLAR THERMAL = } & \text { fossil fuel energy required for cooling season with } \\
& \text { solar desiccant cooler. }
\end{aligned}
$$

BASE THERMAL and SOLAR THERMAL were determined as follows:

$$
\text { BASE THERMAL }=3.0 \times \frac{\text { COOLING }}{\text { COP }}+\mathrm{PP}+\text { REHEAT, }
$$

where

$$
\begin{aligned}
\text { COOLING } & =\text { annual vapor-compression cooling supplied to house, } \\
\text { COP } & \text { vapor-compression cooler coefficient of performance } \\
& \text { (assumed to be } 2.5 \text { ), } \\
= & \text { electrical power to vapor-compression cooler air } \\
& \text { fan, and } \\
= & \text { natural gas reheat (if any); }
\end{aligned}
$$

and

$$
\text { SOLAR THERMAL }=3.0 \times \mathrm{PPS}+\frac{\mathrm{AUX} \text { COOL }}{\mathrm{COP}},
$$

where

PPS = electrical power to desiccant cooler air fans and drive motor. 


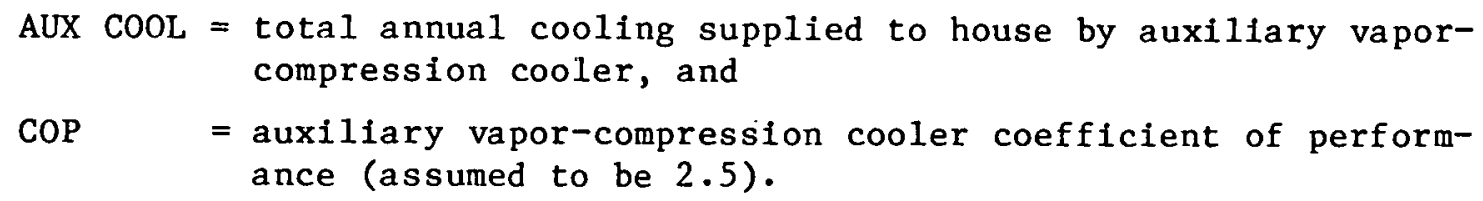

The factor of. 3.0 in the BASE THERMAL and SOLAR THERMAL accounts for the $33 \%$ conversion efficiency from fossil fuels to delivered electrical power. All auxiliary natural gas space heating and reheat values include an assumed heater efficiency of $65 \%$.

For the case in which solar energy was utilized solely for space heating in conjunction with a vapor-compression cooler, the fraction of displaced fossil fuel energy, DISP $\mathrm{H}$, was calculated in a similar manner. The equation was as follows:

$$
\text { DISP } \mathrm{H}=\frac{\text { HEAT DISP } \times \text { HEAT LOAD }}{\text { HEAT LOAD }+ \text { BASE THFRMAT. }}
$$

\subsection{ASSUMED CAPITAL AND OPERATING COSTS}

In order to determine life-cycle costs for the solar and conventional systems, assumptions were made regarding capital equipment costs, installation costs, OMRI costs, and potential government solar tax incentives or subsidies. Due to uncertainty of the values of these costs and incentives, the program was written so that the present worth of life-cycle costs was determined for several increments in collector cost, percentage of initial capital cost for OMRI, and percentage of inital solar equipment cost subsidized by the government. In addition, the complete analysis was performed for five base years (year of system purchase and startup): 1978, 1985, 1990, 1995, and 2000.

Because of the very linited amount of experience with desiccant cooler systems, detailed system cost figures were not available. 'The cost of the installed desiccant cooler was assumed to vary with cooling capacity as follows:

$$
\text { Desiccant Capital Cost }=\$ 500.00+\$ 800.00 / \text { ton cooling capacity. }
$$

The desiccant system cost is plotted as a function of capacity in Figure 5-1a.

The average cost for an installed vapor-compression cooler was estimated from manufacturers' quotations. A cost of $\$ 400.00$ per ton of cooling capacity was used in the economic analysis. This cost is plotted as a tunction of capac1ty in Figure 5-1b.

The collector/storage system cost was a major portion of the total solar heating/cooling system capital cost. Due to differences in collector cost projections, the installed collector/storage system costs were varied from $\$ 108 / \mathrm{m}^{2}$ to $\$ 323 / \mathrm{m}^{2}$ in increments of $\$ 54 / \mathrm{m}^{2}$.

OMRI costs vary widely for different systems. For this study, OMRI costs were taken as constant annual percentages of the initial capital investment. The OMRI percentage was varied from $0.5 \%$ to $5.0 \%$ in increments of $0.5 \%$. 


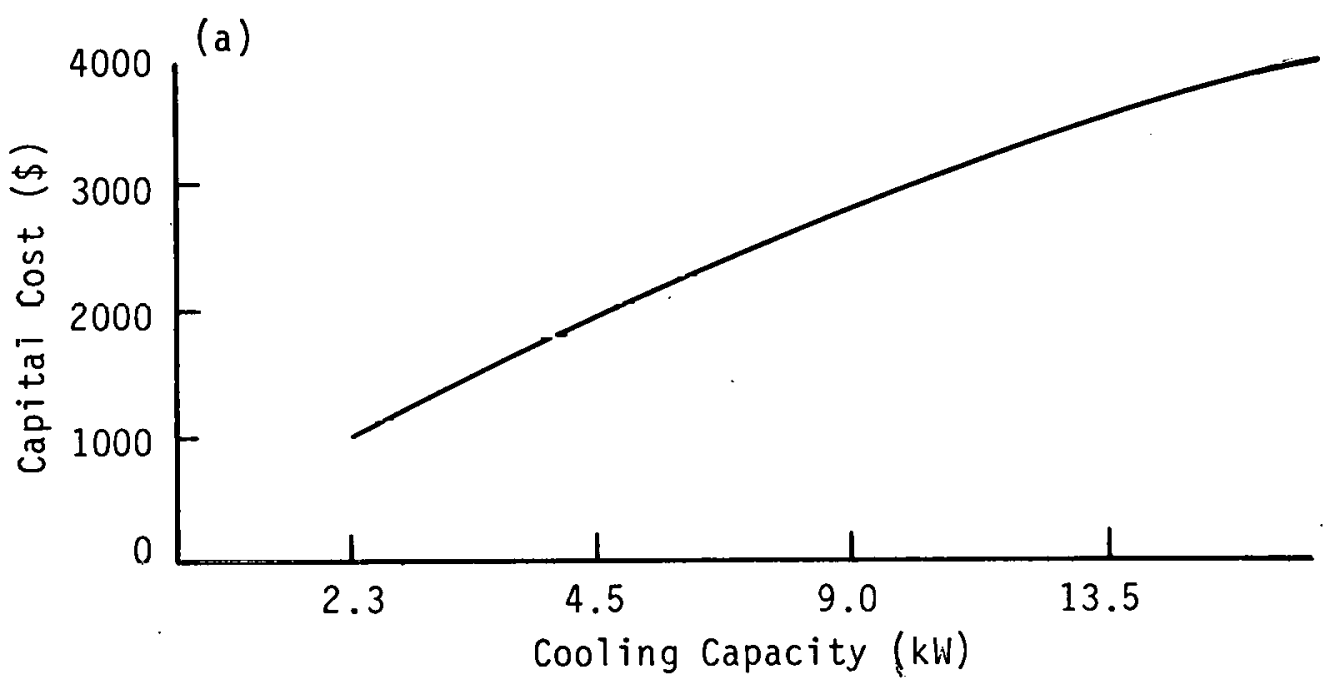

(b)

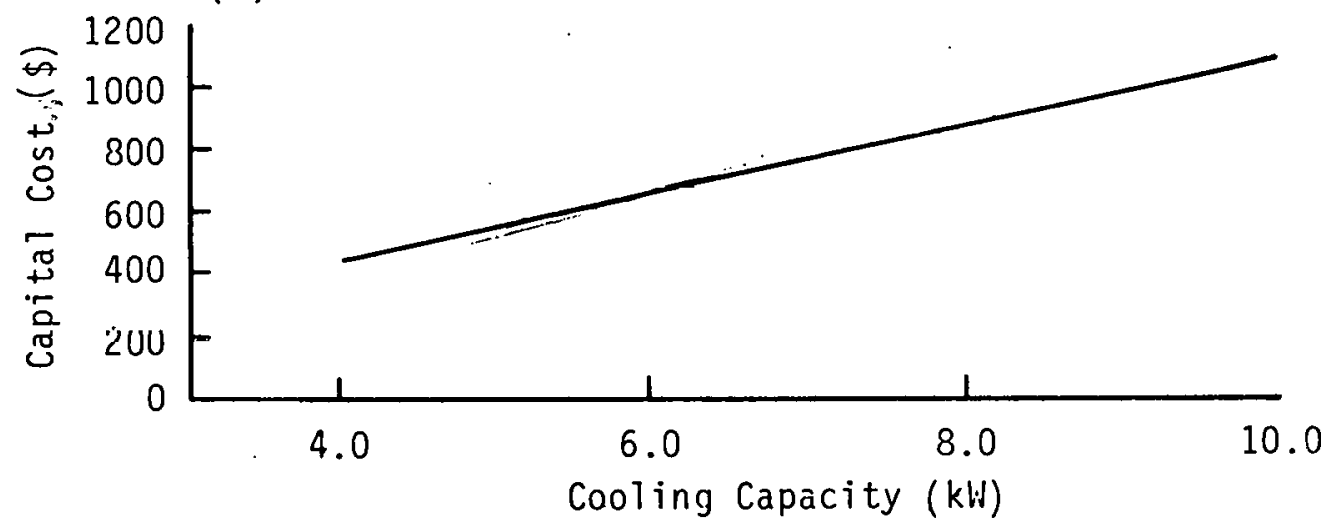

Figure 5-1. CAPITAL COST VS. CAPACITY FOR (a) DESICCANT COOLER AND (b) VAPOR-COMPRESSION COOLER 
Allowances were made in the economics program for potential government subsidies for solar systems. Two cases were studied: subsidies of $0 \%$ and $25 \%$ of the initial capital cost of solar equipment.

Table 5-2 summarizes the ranges of cost figures used in the economic analysis program and the values upon which most of the study conclusions were based.

Table 5-2. EQUIPMENT-RELATED COSTS USED IN ECONOMIC ANALYSIS FOR DETERMINATION OF LIFE-CYCLE PRESENT WORTH AND COST/BENEFIT RATIO

\begin{tabular}{|c|c|c|c|}
\hline $\begin{array}{c}\text { Cost } \\
\text { Parameter }\end{array}$ & $\begin{array}{l}\text { Parameter } \\
\text { Range }\end{array}$ & $\begin{array}{l}\text { Parameter } \\
\text { Increment }\end{array}$ & $\begin{array}{l}\text { Value(s) Used } \\
\text { in Study }\end{array}$ \\
\hline Desiccant cooler capital cost (ș) & --- & ---- & $500+800 /$ con \\
\hline $\begin{array}{l}\text { Vapor-compression cooler capital } \\
\text { cost }(\$)\end{array}$ & --- & --- & $400 /$ ton \\
\hline $\begin{array}{l}\text { Collector/storage system cost } \\
\left(\$ / \mathrm{m}^{2}\right)\end{array}$ & $\begin{array}{l}107.65 \text { to } \\
322.95\end{array}$ & 53.83 & $\begin{array}{l}107.65 \text { and } \\
215.30\end{array}$ \\
\hline OMRI $(\%)$ & 0.5 to 5.0 & 0.5 & 1.0 \\
\hline $\begin{array}{l}\text { Government subsidy of initial } \\
\text { capital cost }(\%)\end{array}$ & 0 to 25.0 & --- & 25.0 \\
\hline
\end{tabular}

The last of the major inputs required for the economic anlysis were electricity and natural gas rates for the five cities. These rates were obtained directly from the utility serving each city, assuming a monthly consumption of $500 \mathrm{kWh}$ of electrical energy and $340 \mathrm{~m}$ of natural gas. The electrical and natural gas rates for each city are shown in Table 5-3.

Table 5-3. ELECTRICITY AND NATURAL GAS RATES FOR RESIDENTIAL BUILDINGS (AUGUST 1978) ${ }^{\mathrm{a}}$

\begin{tabular}{lcc}
\hline \multicolumn{1}{c}{ City } & $\begin{array}{c}\text { Electricity Cost } \\
(\$ / \mathrm{kWh})\end{array}$ & $\begin{array}{c}\text { Natural Gas Cost } \\
(\$ / \mathrm{kWh})\end{array}$ \\
\hline Charleston, S.C. & 0.0526 & 0.0120 \\
Dodge City, Kans. & 0.0499 & 0.0049 \\
Fort Worth, Tex. & 0.0396 & 0.0094 \\
Phoenix, Ariz. & 0.0603 & 0.0090 \\
Washington, D.C. & 0.0410 & 0.0150 \\
\hline
\end{tabular}

$a_{\text {Rates are based on monthly consumption of } 500 \mathrm{kWh} \text { of electrical }}$ energy and $340 \mathrm{~m}^{3}$ of natural gas. 


\subsection{RESULTS}

Utilizing the economics program and cost data described in the previous section, the present worth of 20-year life-cycle costs was determined for each of the annual desiccant simulations described in Section 3.7.3. The resulting cost/benefit ratios for base years 1985 and 1990 are presented in Appendix C. A sample economics computer program output is included in Appendix D.

The general conclusions resulting from the economic analysis with a base year of 1985 include the following:

- Humld climates with high conventional fuel costs such as exist in Washington, D.C., and Charleston, S.C., are economically the preferred conditions for desiccant coolers.

- Based on 1.ife-cycle costs and fossil fuel displacement, a 4.5-kW desiccant cooler system with a $35-\mathrm{m}^{2}$ collector area and auxillary cooling is the preferred configuration for Washington, D.C.; without auxlliary cooling, it is also the preferred configuration for Dodge City.

- The solar heating/desiccant-cooling system approaches cost competitiveness in Washington, D.C.: (including auxiliary cooling) but not in Dodge City (without auxiliary cooling) due to low costs for conventional fossil fuels in Dodge City.

In order to illustrate the effects of climate on the operation of solar heating and desiccant cooling systems, cost/benefit was plotted versus ambient design relative humidity in Figures 5-2 and 5-3 for the five cities. Design relative humidity is a good indication of climate since it is a function of both dry- and wet-bulb temperatures. In Figure 5-2, the cost/benefit ratios were determined using actual 1978 electricity and natural gas prices from Table 5-3 (escalated to base years 1985 and 1990) for each city. Figure 5-3 shows cost/benefit ratios resulting from economic analyses using washington, D.C., 1978 electricity and natural gas prices for all five cities. These figures clearly show that the effect of increasing relative humidity on solar cost-effectiveness is a decreasing cost/benefit ratio. Since a desiccant cooler generally has a larger latent capacity, this ts the expected result. Thus, humid climates such as exist in Washington, D.C., and Charleston, S.C., are economically the preferred climate types for desiccant cooling systems.

The curves in Figure 5-2 do not show a continuous decrease in cost/benefit with increasing design relative humidity because of the varying energy costs in the five cities. Dodge City shows the largest variation because of its high annual heat load and very low natural gas price, a combination that favors conventional systems over solar systems. However, the curves in Figure 5-3 show increasing cost-effectiveness with increasing ambient design relative humidity when uniform energy costs (1978 Washington, D.C., costs) are assumed.

Figures 5-2 and 5-3 are not generic and cannot be used to obtain cost/benefit ratios for cities other than the five studied. Locations with the same design relative humidity can have different heating loads, cooling loads, and annual solar Insolation, all of which are factors that affect the cost/benefit ratio. 


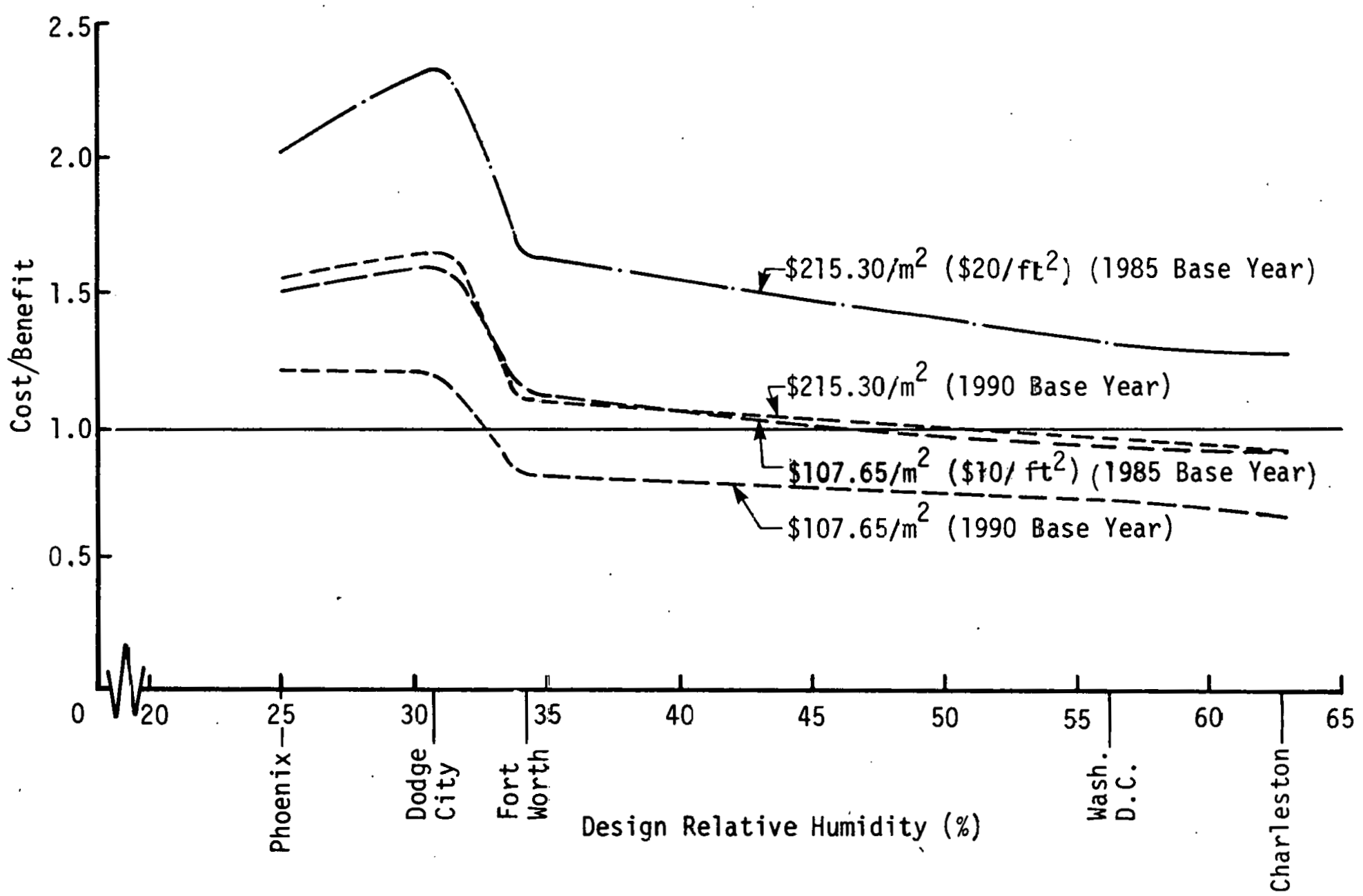

Figure 5-2. COST/BENEFIT VS. DESIGN RELATIVE HUMIDITY (1985 BASE YEAR) 


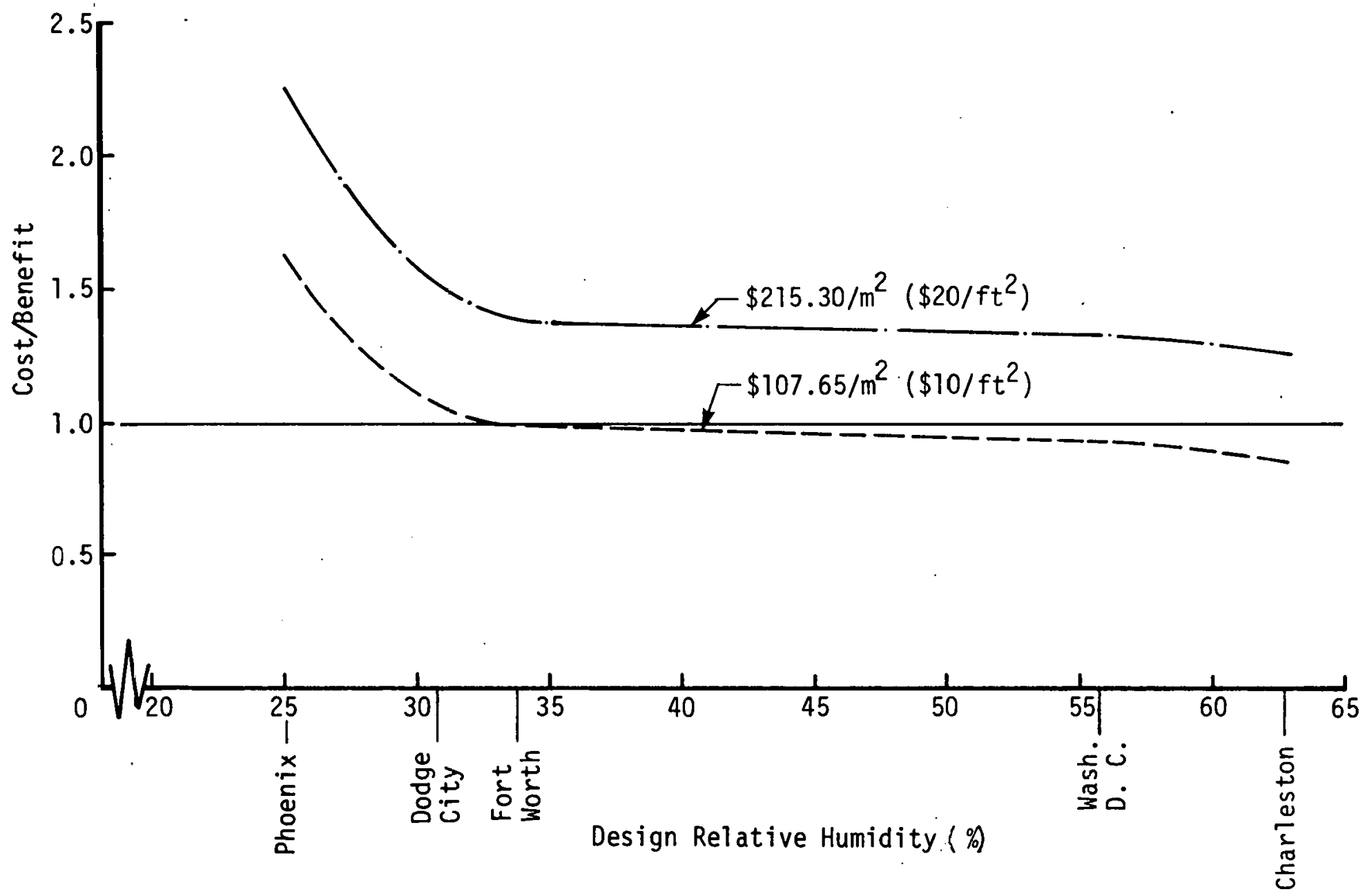

Figure 5-3. COST/BENEFIT VS. DESIGN RELATIVE HUMIDITY USING WASHINGTON, D.C., ENERGY COSTS FOR ALL CITIES (1985 BASE YEAR) 
Figures 5-4 and 5-5 show the effects of the choice of base year (year of system purchase and startup) on the cost/benefit ratio. Under the economic parameter assumptions of Section 5.2, Figure 5-4 shows cost/benefit ratio versus base year for $\$ 108 / \mathrm{m}^{2}$ collectors. Figure $5-5$ shows the same plots for $\$ 215 / \mathrm{m}^{2}$ collectors. Although it is impossible to predict accurately economic trends for the time periods encompassed, the two figures nevertheless illustrate that the cost/benefit ratio should decrease and eventually drop below 1.0 as conventional energy costs increase. As the base year is extended further into the future, collector costs become less important and the cost/benefit ratios for systems with collector costs of either $\$ 108 / \mathrm{m}^{2}$ or $\$ 215 / \mathrm{m}^{2}$ drop below 1.0 .

The remainder of this section of the report deals with Washington, D.C., and Dodge City, Kansas. Washington, D.C., was chosen for further study because of the superior thermal performance of the destccant couler system in that climate and the potential for cost-effectiveness. Dodge City represents a location where the solar heating and desiccant cooling system described in this report could potentially provide comfort in a residential building without an auxillary vapor-compression cooler (see Table 3-19).

An important characteristic to identify is the fraction of fossil fuel energy displaced by the solar energy systems. This is economically important since it determines whether a solar system is cost-effective. The percentage of fossil fuel energy displaced as a function of collector area is shown for Washington, D.C., and Dodge City in Figures 5-6 and 5-7, respectively.

Both figures show that the percentage of fossil fuel energy displaced was not significantly influenced by desiccant cooler capacity; instead, collector area appears to be the dominant influence. Two factors were responsible for this lack of influence by cooler capacity. First, superposition of the solar heating and cooling system performances diluted the impact of small differences in cooling system performance. This occurred in spite of the fact that cooling was responsible for $35 \%$ of the primary energy consumed for environmental control in a Washington, D.C., home and $25 \%$ in a Dodge City home. Second, cooling supplied by solar energy did not translate directly into displaced fossil fuel energy. Substantial parasitic energy was required in the solar desiccant cooling system. Thus, only a portion of the fossil fuel energy associated with providing a given amount of cooling was displaced through the use of the solar desiccant unit.

The analysis indicated that a small desiccant system tended to be more costeffective than a larger system and that larger desiccant systems displaced a greater percentage of fossil fuel, although not by a significant amount. In Section 3.7 .3 it is concluded that either a $4.5-$ or $9.0-\mathrm{kW}$ cooler with a $35-\mathrm{m}^{2}$ collector is generally the optimum combination for Washington, D.C. Thus, the more cost-effective 4.5-kW system, which displaces nearly the same percentage of fossil fuel as a $9.0-\mathrm{kW}$ system, is the preferred system size for Washington, D.C.

Figures 5-8 through 5-13 show the effects of collector area and the percentage of fossil fuel energy displaced on the cost/benefit ratio for solar heating alone and solar heating plus a 9.0-, 4.5-, or 2.3-kW desiccant cooler for Washington, D.C. The base year is 1985, and both sensible and latent 


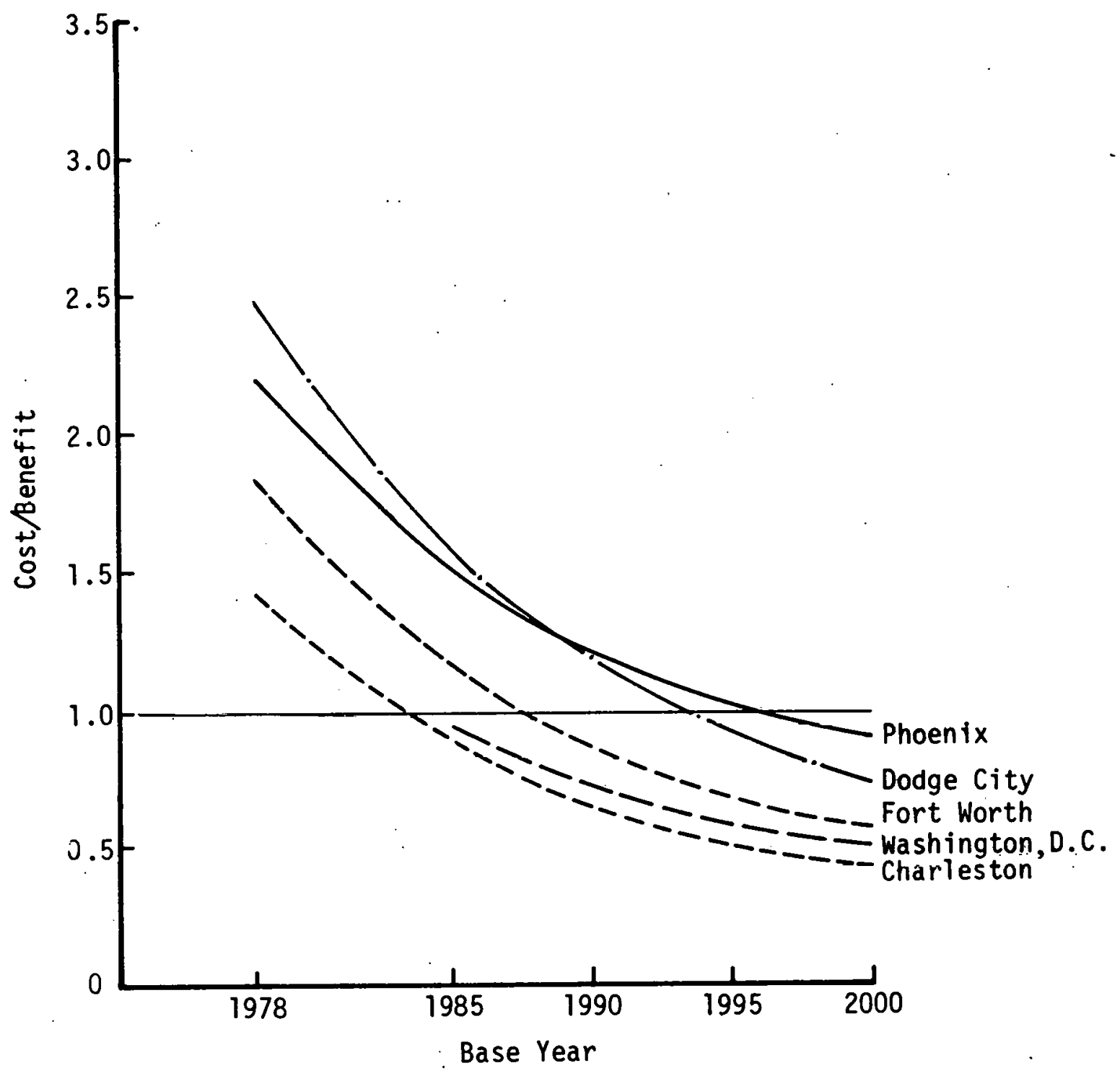

Figure 5-4. COST/BENEFIT VS. BASE YEAR - 35-M $\mathrm{M}^{2}$ COLLECTOR AT $\$ 107.65 / \mathrm{M}^{2}\left(\$ 10 / \mathrm{FT}^{2}\right)$ 


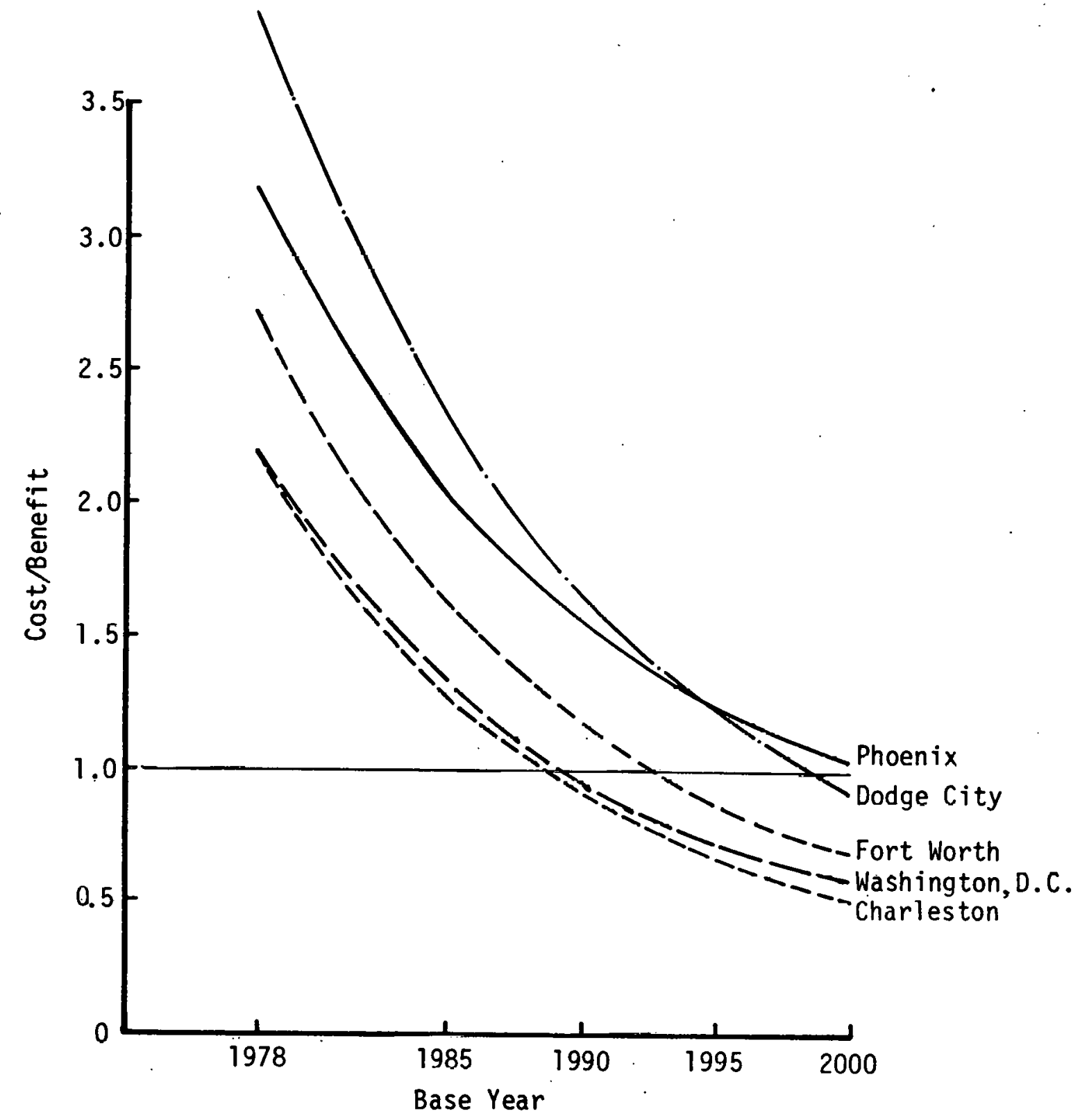

Figure 5-5. COST/BENEFIT VS. BASE YEAR $-35-M^{2}$ COLLECTOR AT $\$ 215.30 / \mathrm{M}^{2}\left(\$ 20 / \mathrm{FT}^{2}\right)$ 


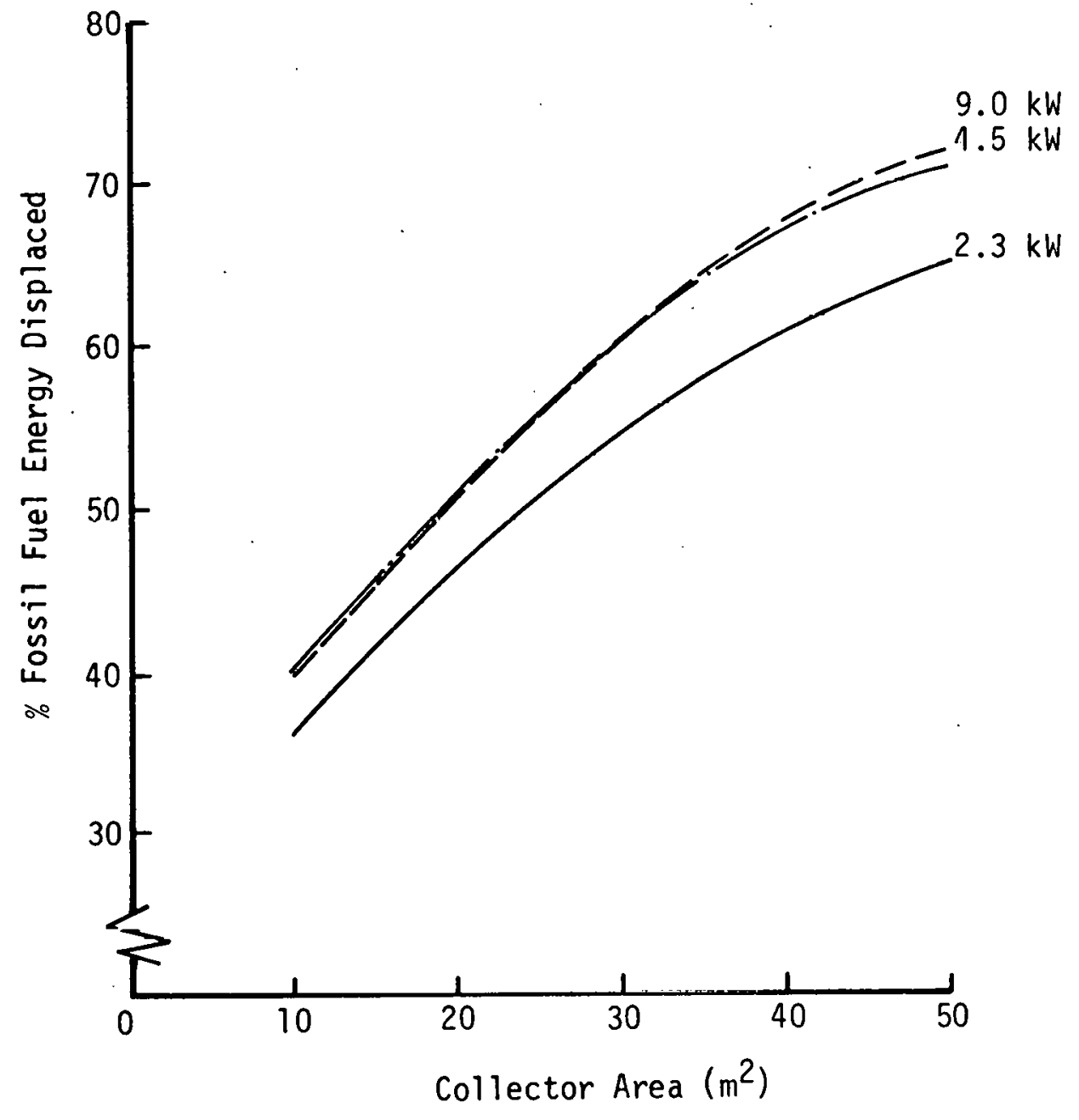

Figure 5-6. FOSSIL FUEL ENERGY DISPLACED VS. COLLECTOR AREA - WASHINGTON, D.C., WITH AUXILIARY COOLING 


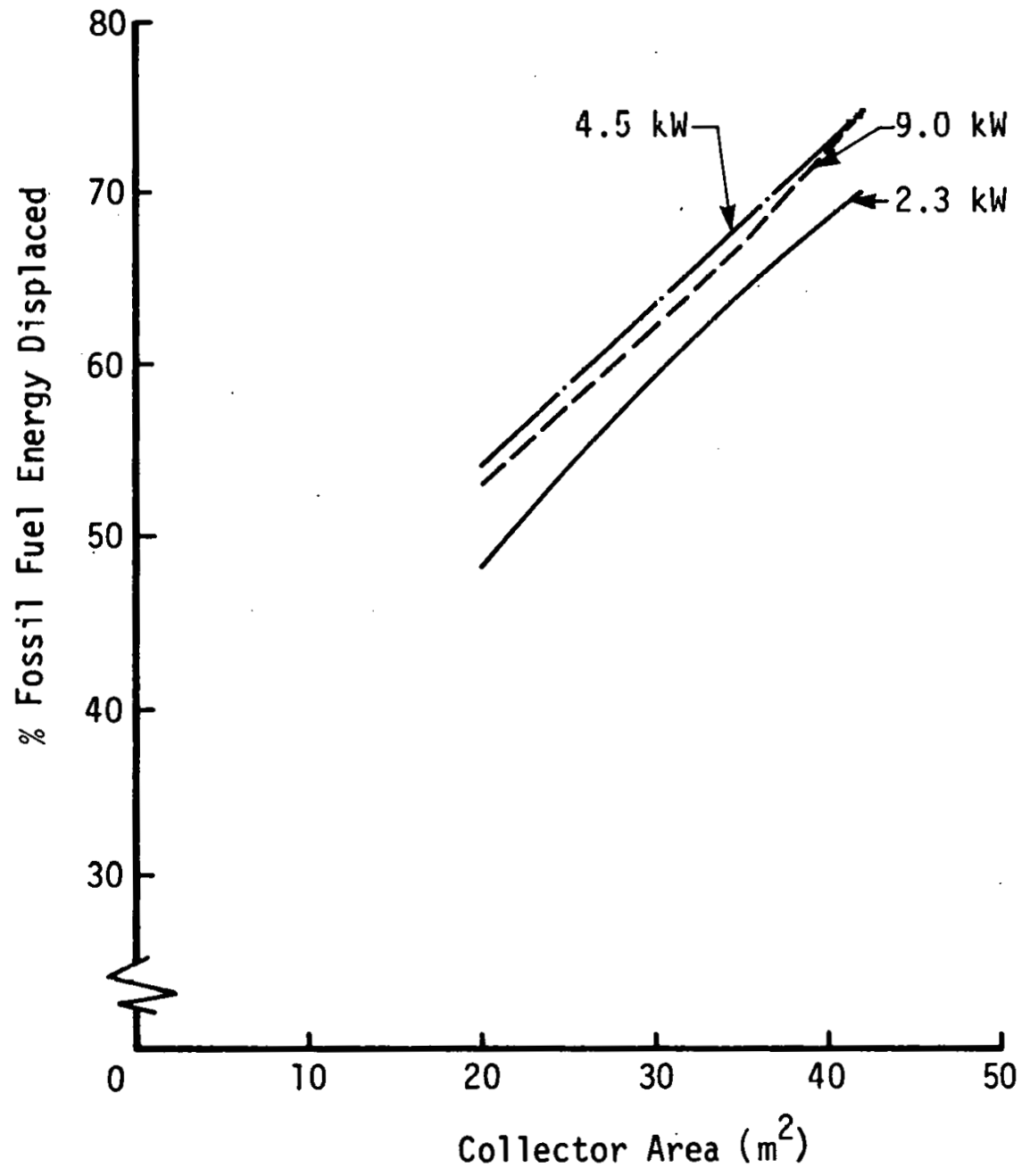

Figure 5-7. FOSSIL FUEL ENERGY DISPLACED VS. COLLECTOR AREA - DODGE CITY, KANS., WITHOUT AUXILIARY COOLING 


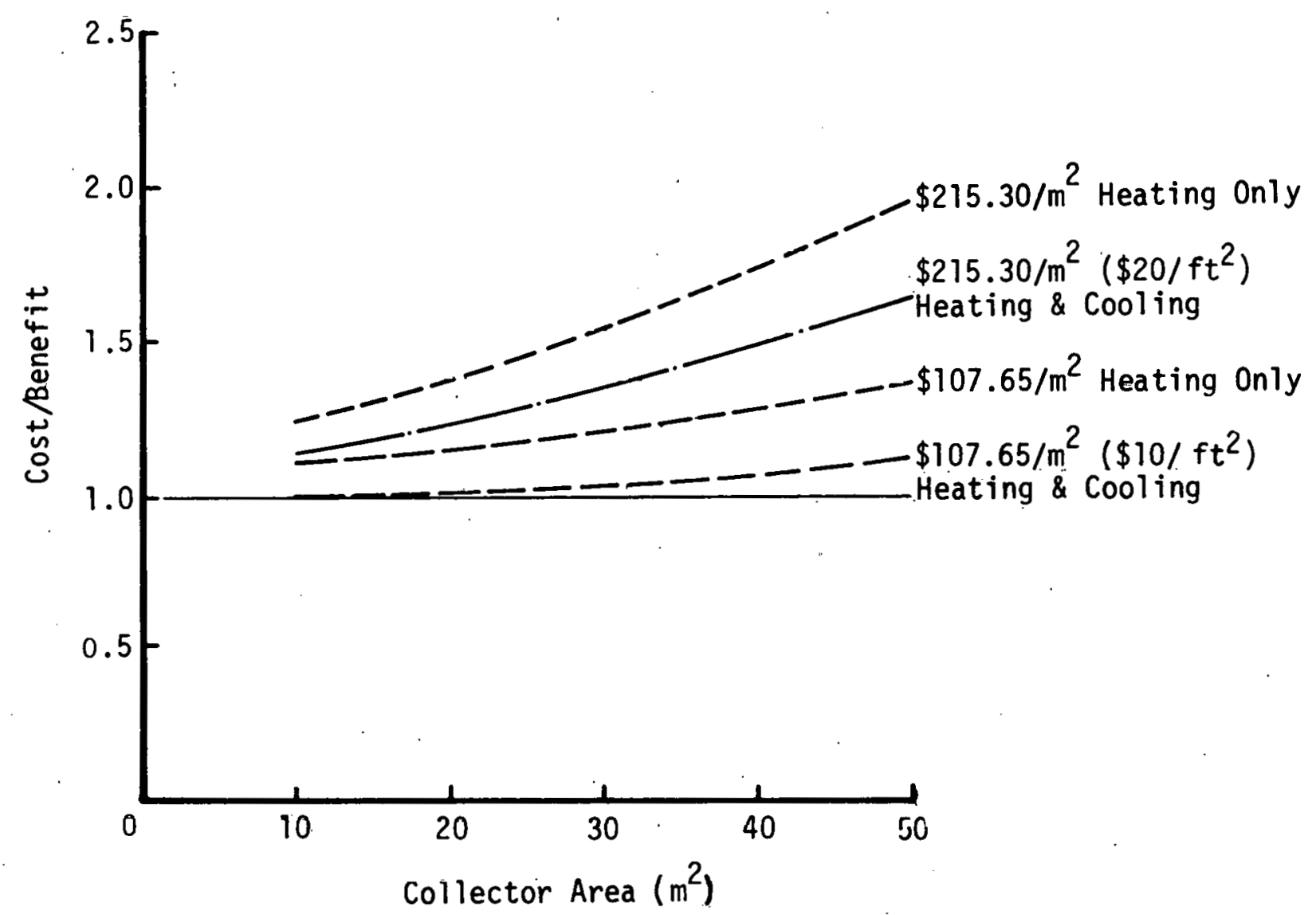

Figure 5-8. COST/BENEFIT VS. COLLECTOR AREA OF A 9.0-KW COOLER WITH AUXILIARY IN WASHINGTON, D.C. (1985 BASE YEAR) 


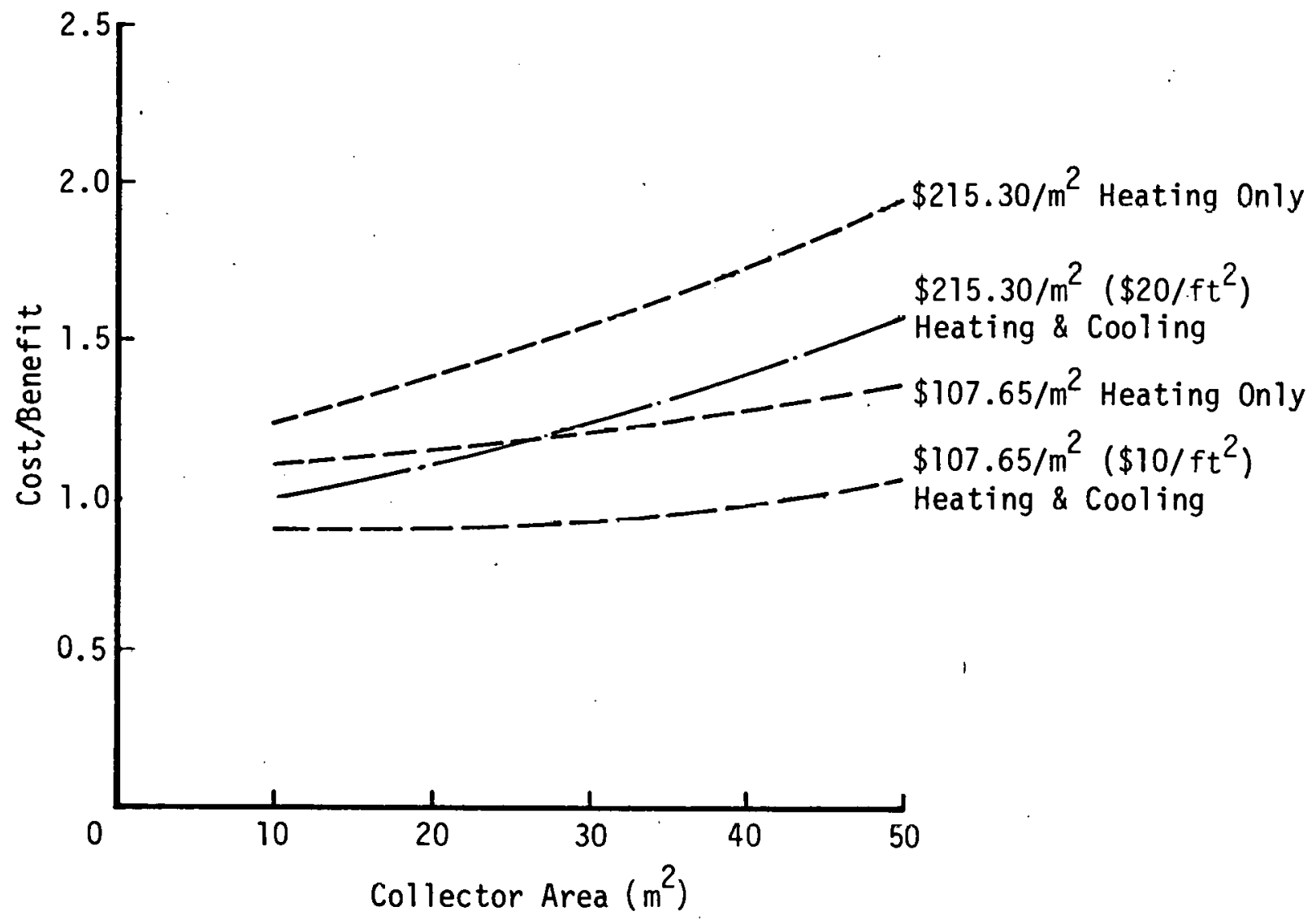

Figure 5-9. COST/BENEFIT VS。 COLLECTOR AREA OF A 4.5-KW COOLER WITH AUXILIARY IN WASHINGTON, D.C. (1985 BASE YEAR) 


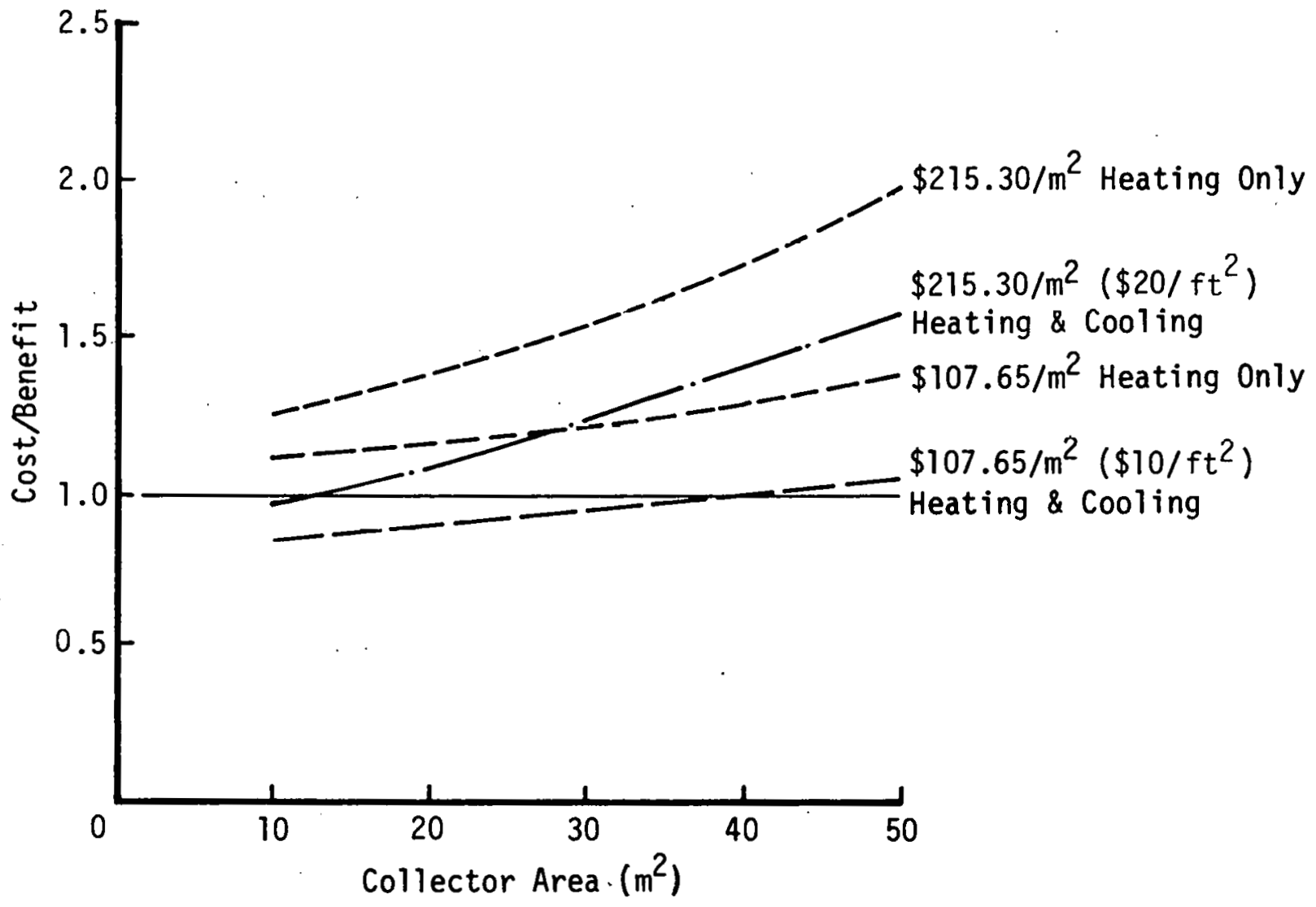

Figure 5-10. COST/BENEFIT VS. COLLECTOR AREA OF A 2.3-KW COOLER WITH AUXILIARY IN WASHINGTON, D.C. (1985 BASE YEAR) 


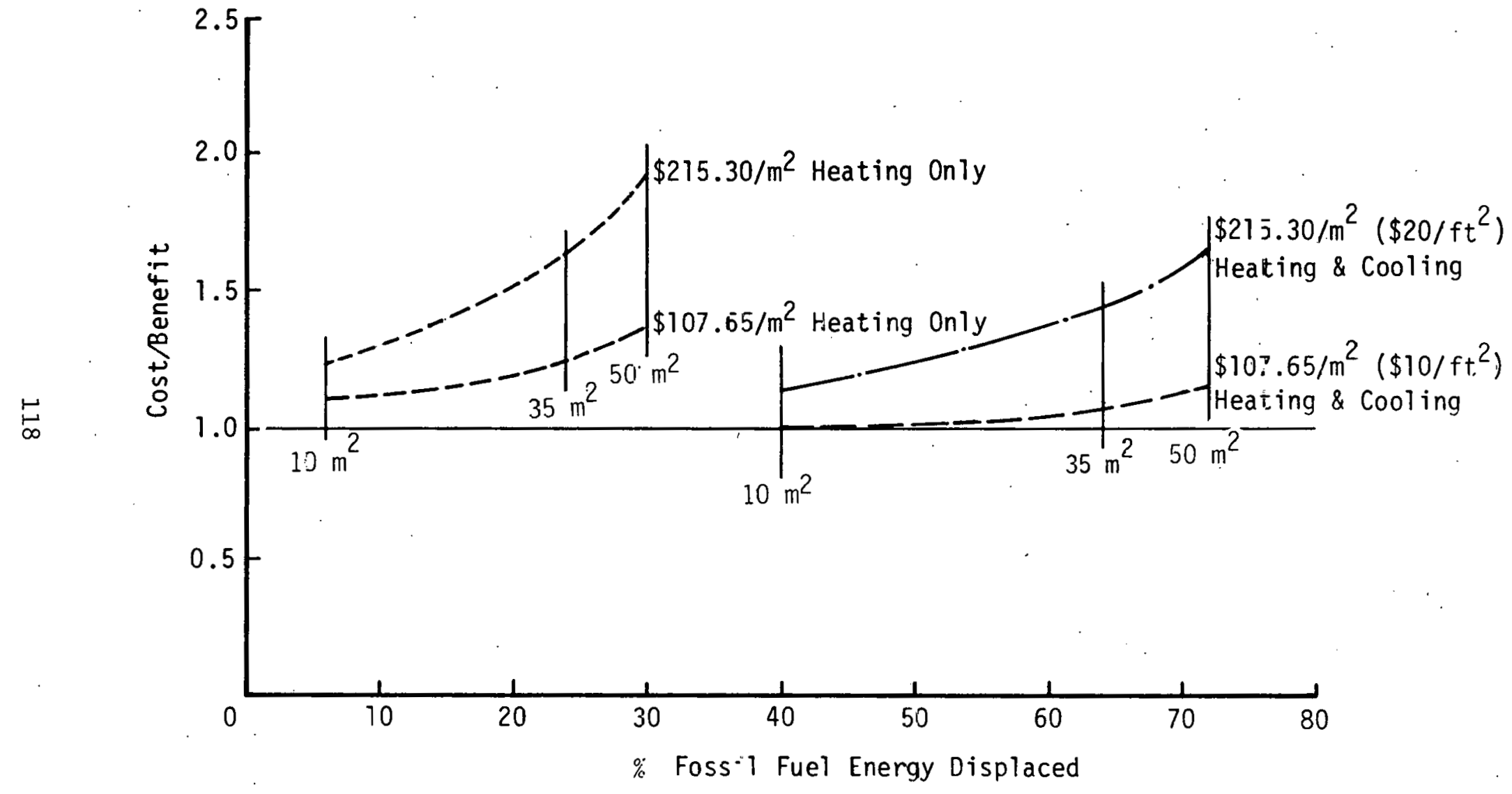

Figure 5-11. COST/BENEFIT VS. FOSSIL FUEL ENERGY DISPLACED BY A 9.0-KW COOLER WITH AUXILIARY AT VARIOLS COLLECTOR AREAS ANO COSTS IN WASHINGTON, D.C. (1985 BASE YEAR) 


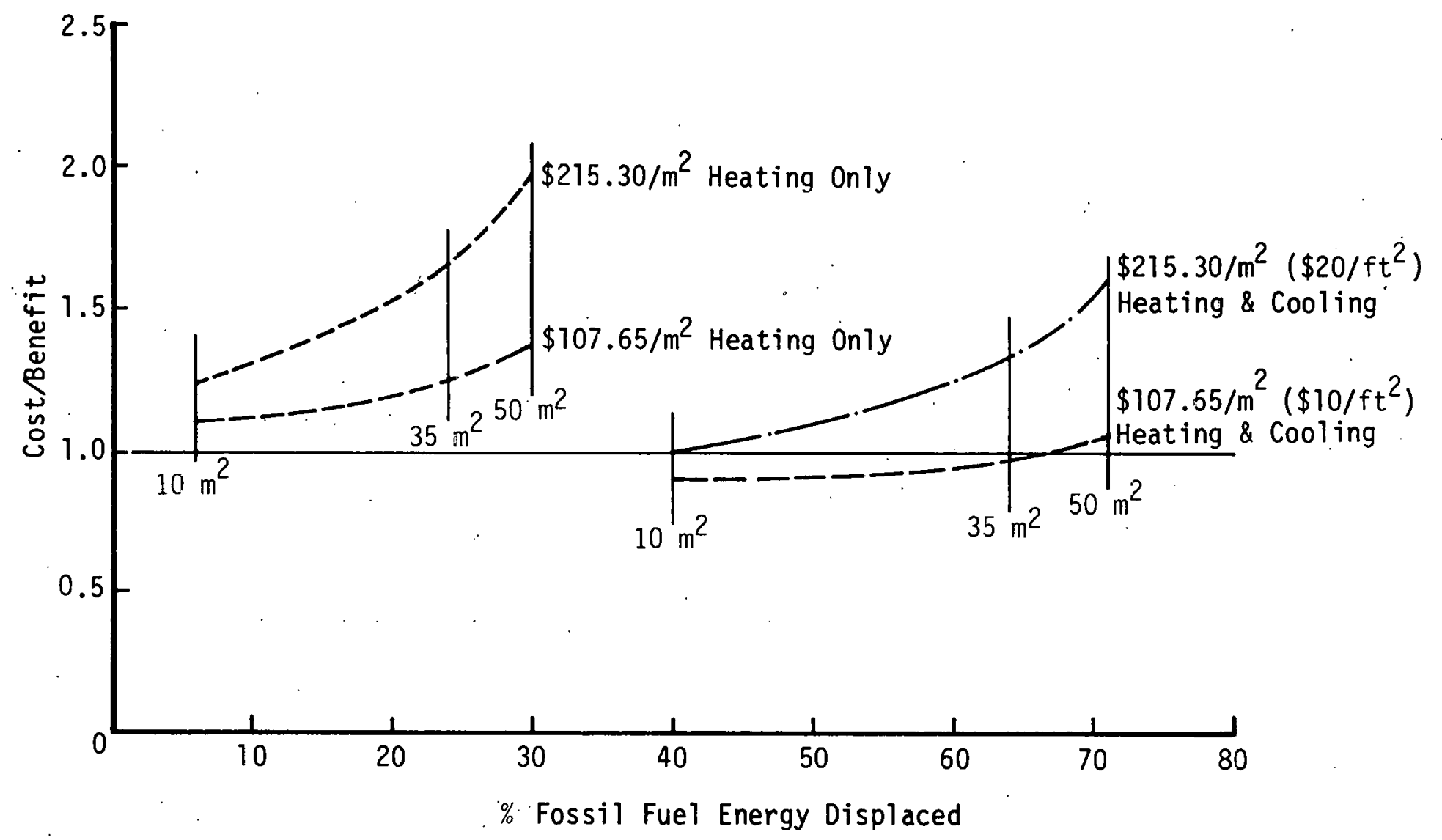

Figure 5-12. COST/BENEFIT VȘ. FOSSIL FUEL ENERGY DISPLACED BY A 4.5-KW COOLER WITH AUXILIARY AT VARIOUS COLLECTOR AREAS AND COSTS IN WASHINGTON, D.C. (1985 BASE YEAR) 


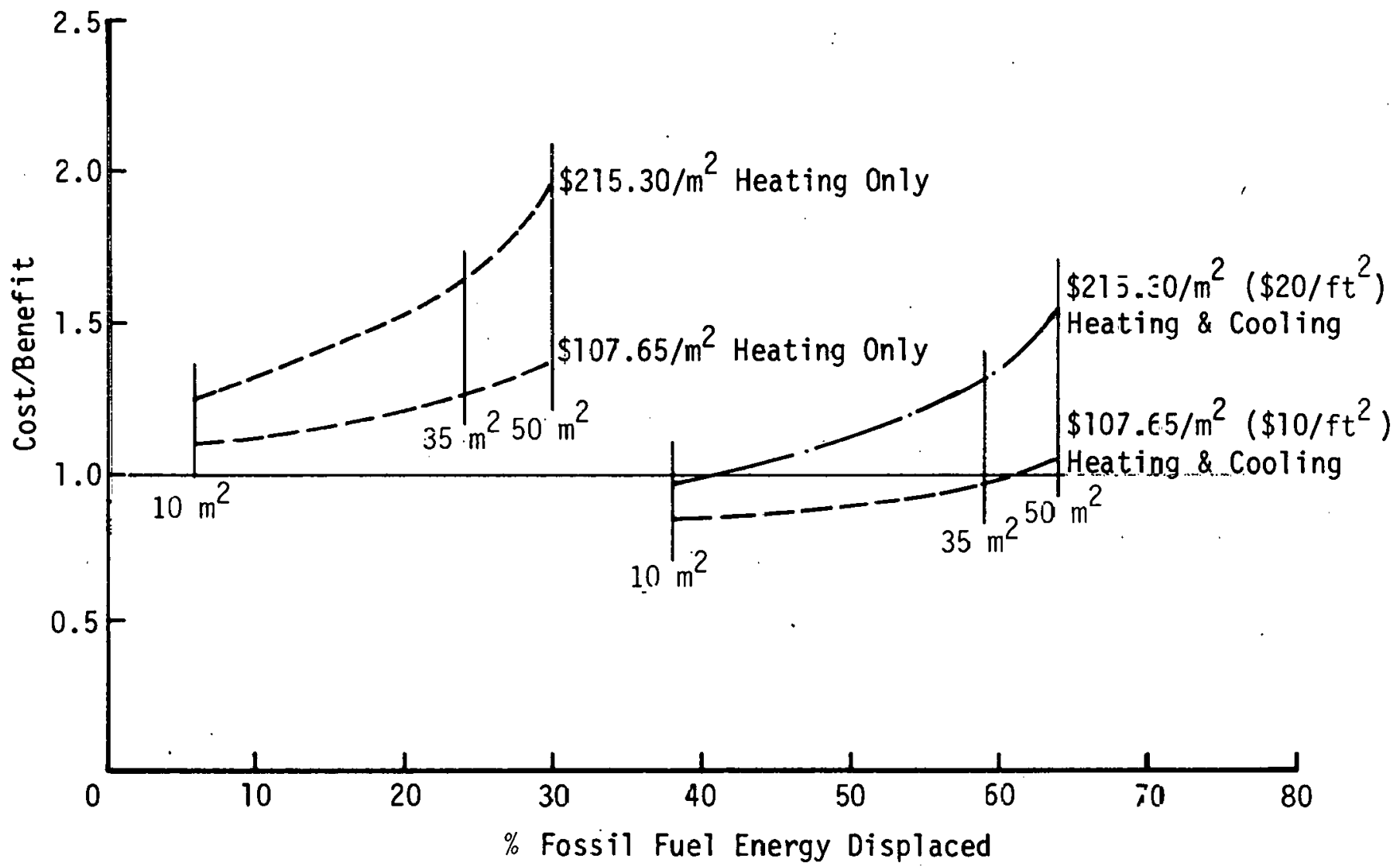

Figure 5-13. COST/BENEFIT VS. FOSSIL FUEL ENERGY DISPLACED BY A 2.3-K'N COOLER WITH AUXILIARY AT VARIOUS COLLECTOR AREAS AND COSTS IN WASH]NITION, D.C. (1985 BASE YEAR) 
auxiliary cooling are provided. Three basic conclusions can be drawn from these six figures:

- Under the economic assumptions of this study (Section 5.2), solar heating in Washington, D.C., is not cost competitive (i.e., the cost/benefit ratio is never less than 1.0 ). Domestic hot water was not included in this analysis. Its inclusion would increase benefits without appreciable increase in cost and, therefore, a cost/benefit ratio higher than 1.0 might warrant installation of such a system if the cost of the collectors were in the $\$ 108$ to $\$ 140 / \mathrm{m}^{2}$ range.

- If a desiccant cooler is added to the solar heating system, the cost/benefit ratio falls below 1.0 for certain cases, indicating cost-effectiveness. For the $4.5-\mathrm{kW}$ cooler with a $35-\mathrm{m}^{2}$ collector array (Figure 5-9), the cost/benefit ratio is 0.94 with $\$ 108 / \mathrm{m}^{2}$ collectors. With solar hot water included, this system should remain cost-effective with collector costs in the $\$ 140$ to $\$ 161 / \mathrm{m}^{2}$ range. For $\$ 108 / \mathrm{m}^{2}$ collector cost, the $9.0-\mathrm{kW}$ system (Figure $5-8$ ) is costeffective only with the lowest collector areas, while the $2.3-\mathrm{kW}$ system (Figure 5-10) is cost-effective with all but the largest collector sizes.

- When a desiccant cooling system is added to a solar heating system, a significant increase in the displaced fossil fuel energy can be achleved. This is the case for the 9.0-, 4.5-, and 2.3-kW cooler sizes (Figures 5-11, 5-12, and 5-13, respectively). As previously discussed, the addition of a desiccant cooler to a solar heating system may result in cost-effectiveness. However, even if the cost/benefit ratio is greater than 1.0 , the addition of a desiccant cooling system results in larger allowable collector area and greater fossil fuel displacement for the same cost/benefit as a heating-only system. For example, in Figure 5-12 a heating system with collector area of $10 \mathrm{~m}^{2}$ has a cost/benefit ratio of 1.23 and a fossil fuel displacement of $6 \%$ at a collector cost of $\$ 215 / \mathrm{m}^{2}$. For the same cost/benefit ratio and collector cost, a solar heating and $4.5-\mathrm{kW}$ desiccant cooling system would have a collector area of approximately $30 \mathrm{~m}^{2}$ and a $59 \%$ fossil fuel displacement. Thus, if solar heating can be justified (either economically or for fossil fuel conservation) for residential use in Washington, D.C., the addition of desiccant cooling will significantly increase the potential fossil fuel displacement at the same cost/benefit ratio.

Figures 5-14 through 5-20 show the same plots for Dodge City. These results are for a solar system with no auxillary cooling, so the house air conditions leave the comfort zone during the times when the desiccant cooler cannot meet the house cooling load.

As in the case of Washington, D.C., solar heating is not cost competitive in Dodge City under the cost assumptions of this study. In addition, solar heating plus desiccant cooling is never cost competitive for 9.0-kW (Figure 514 ) or $4.5-\mathrm{kW}$ (Figure 5-15) desiccant systems. The only cost competitive system is a $2.3-\mathrm{kW}$ desiccant cooler (Figure 5-16) with a 20-m collector area and a collector cost of $\$ 108 / \mathrm{m}^{2}$. The cost/benefit ratios tend to be higher in Dodge City than in Washington, D.C., and rise at much faster rates with increasing collector area. 


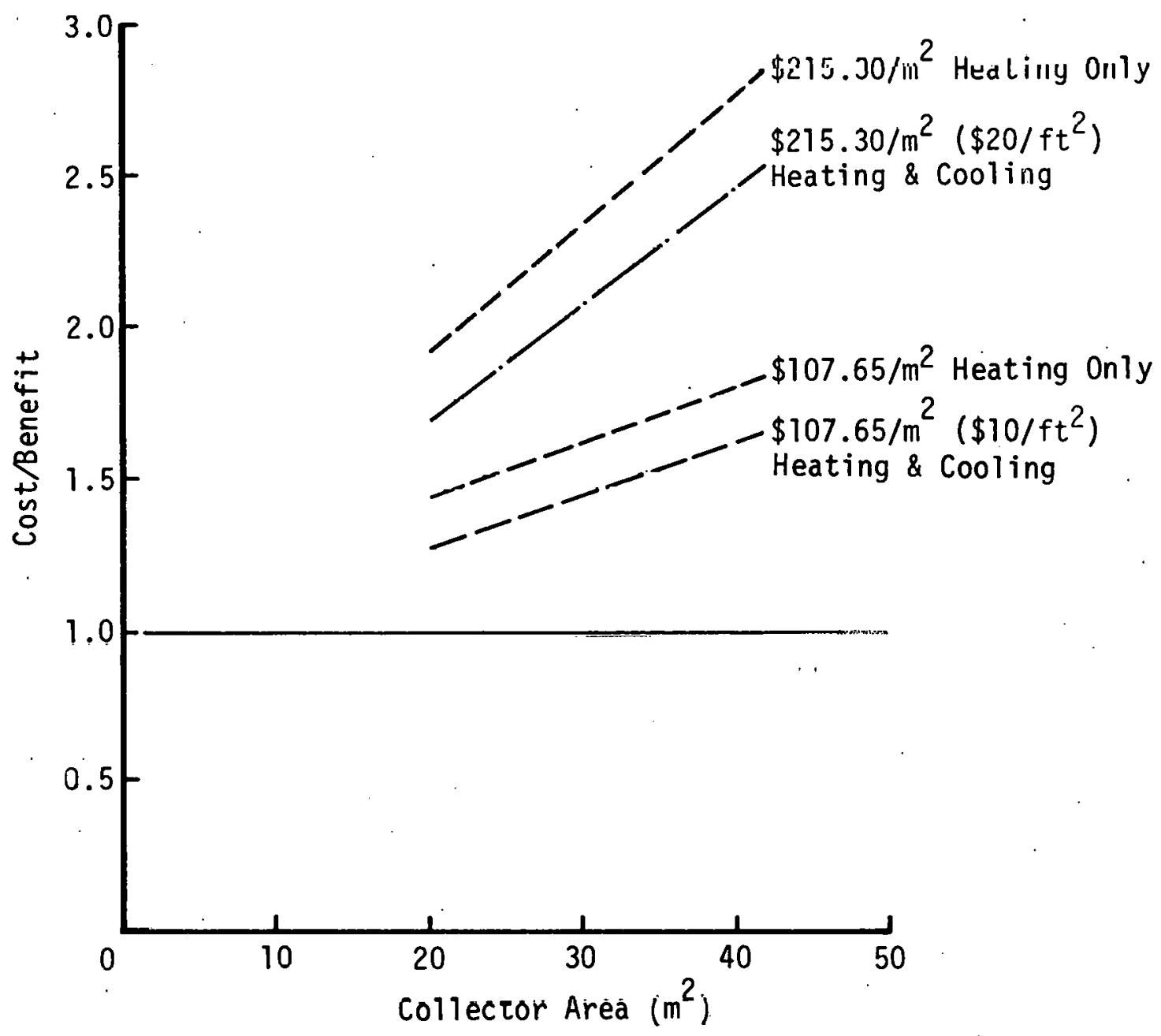

Figure 5-14. COST/BENEFIT VS. COLLECTOR AREA. OF A 9.0-KW COOLER WITHOUT AUXILIARY IN DODGE CITY (1985 BASE YEAR) 


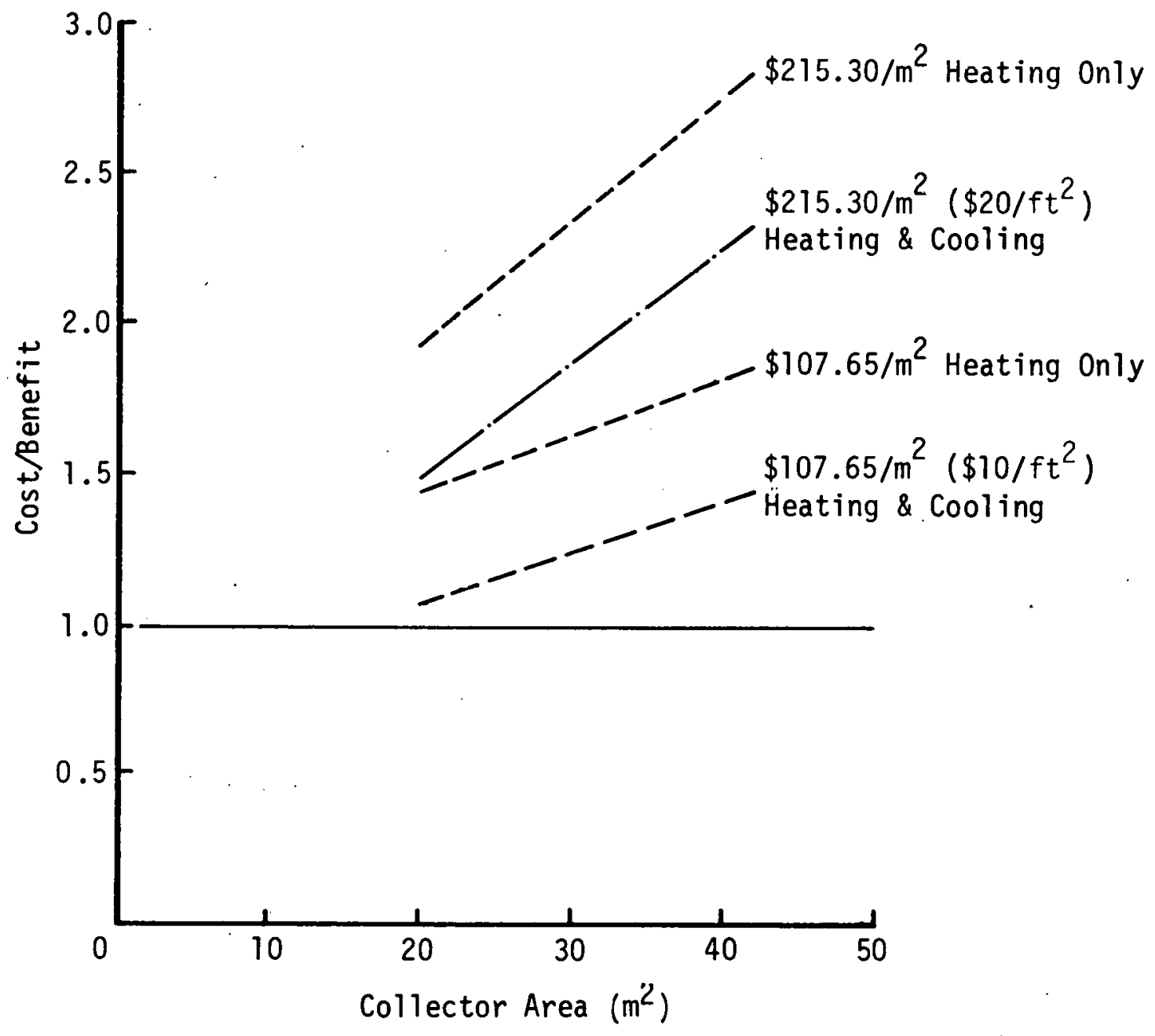

Figure 5-1'5. COST/BENEFIT VS. COLLECTOR AREA OF A 4.5-KW COOLER WITHOUT AUXILIARY IN DODGE CITY (1985 BASE YEAR) 


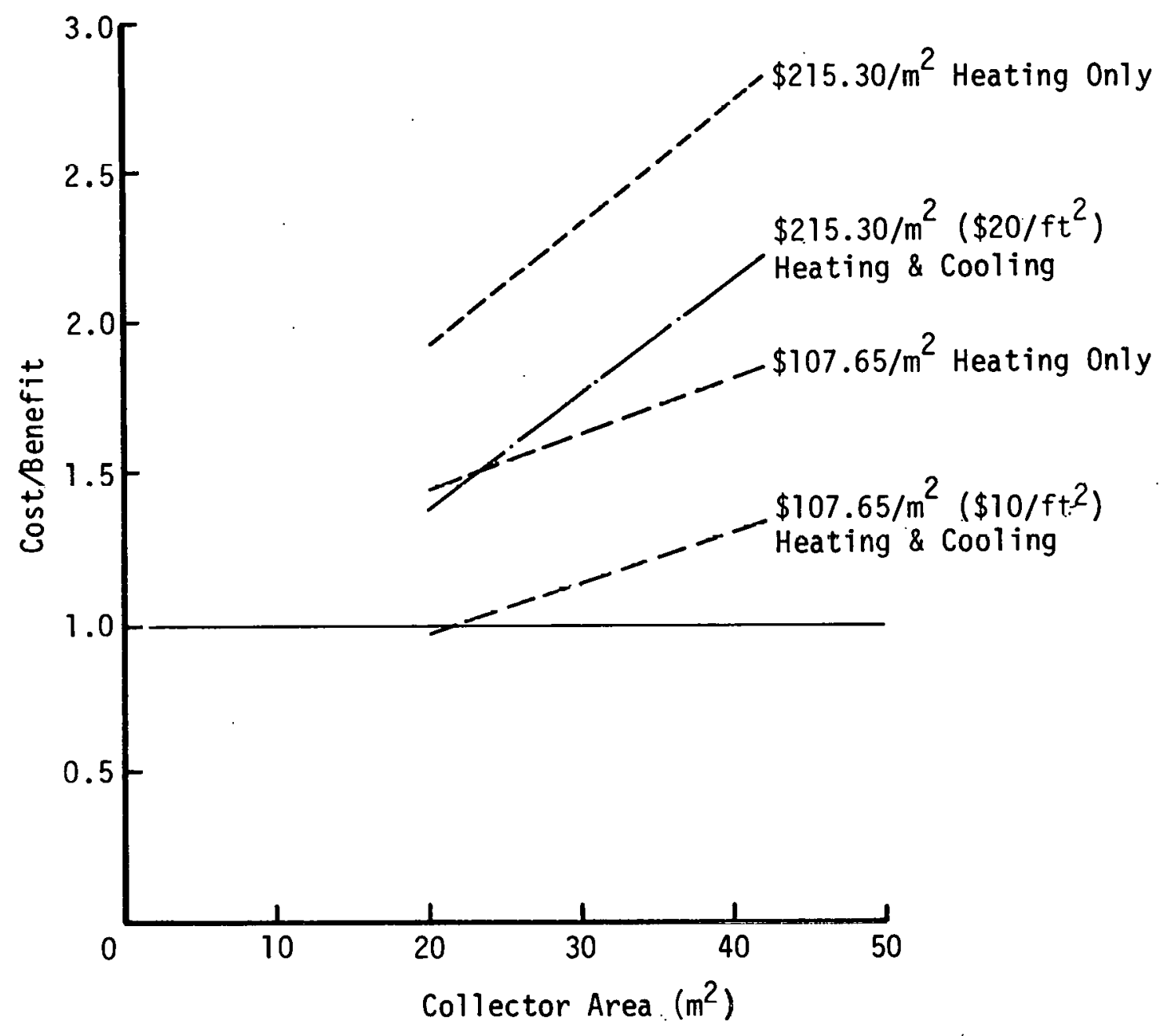

Figure 5-16. COST/BENEFIT VS. COLLECTOR AREA OF A 2.3-KW COOLER WITHOUT AUXILIARY IN DODGE CITY (1985 BASE YEAR) 


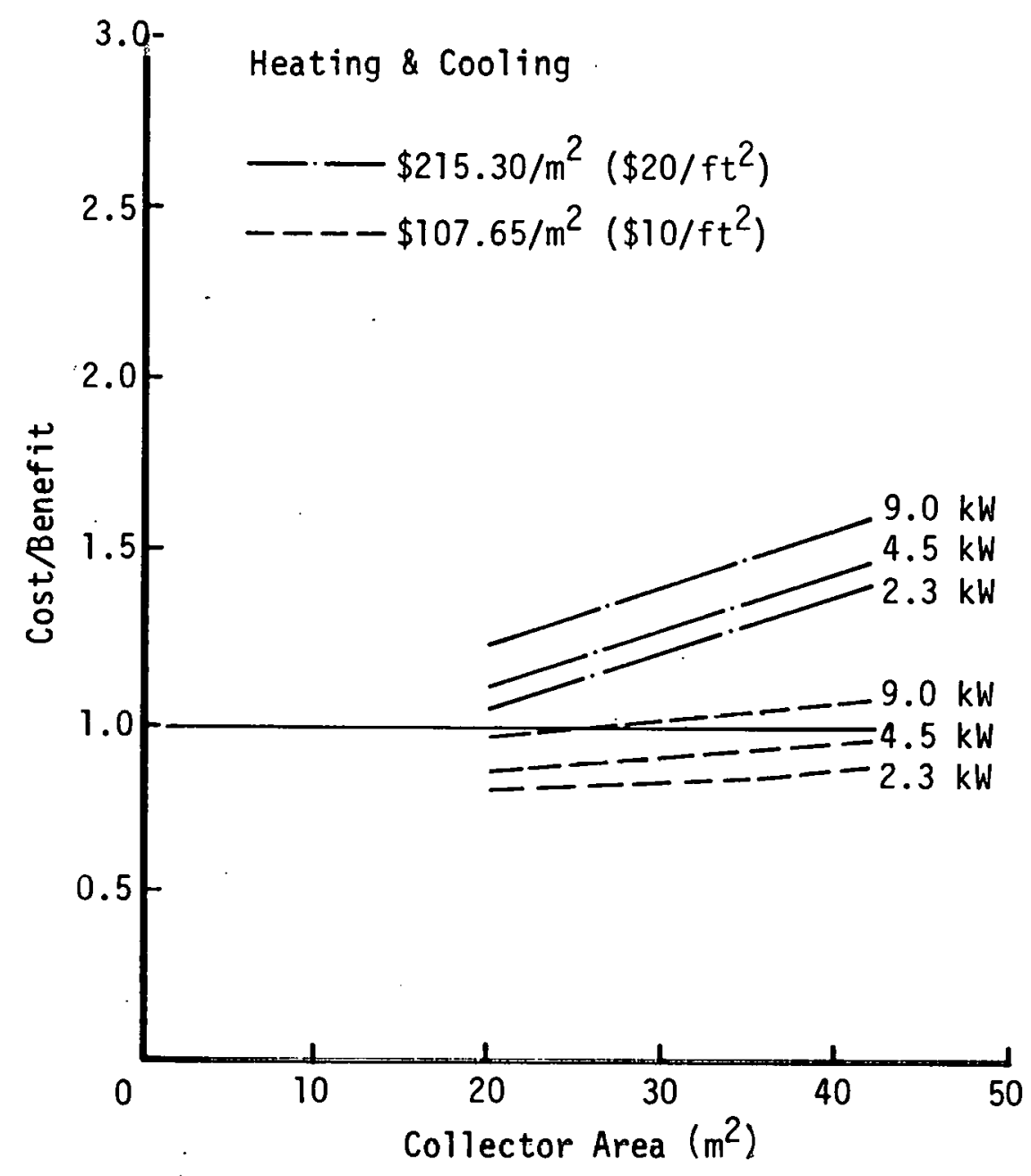

Figure 5-17. COST/BENEFIT VS. COLLECTOR AREA OF HEATING AND COOLING SYSTEMS OF VARIOUS SIZES AND COSTS IN DODGE CITY (1985 BASE YEAR; WASHINGTON, D.C., ENERGY COSTS) 


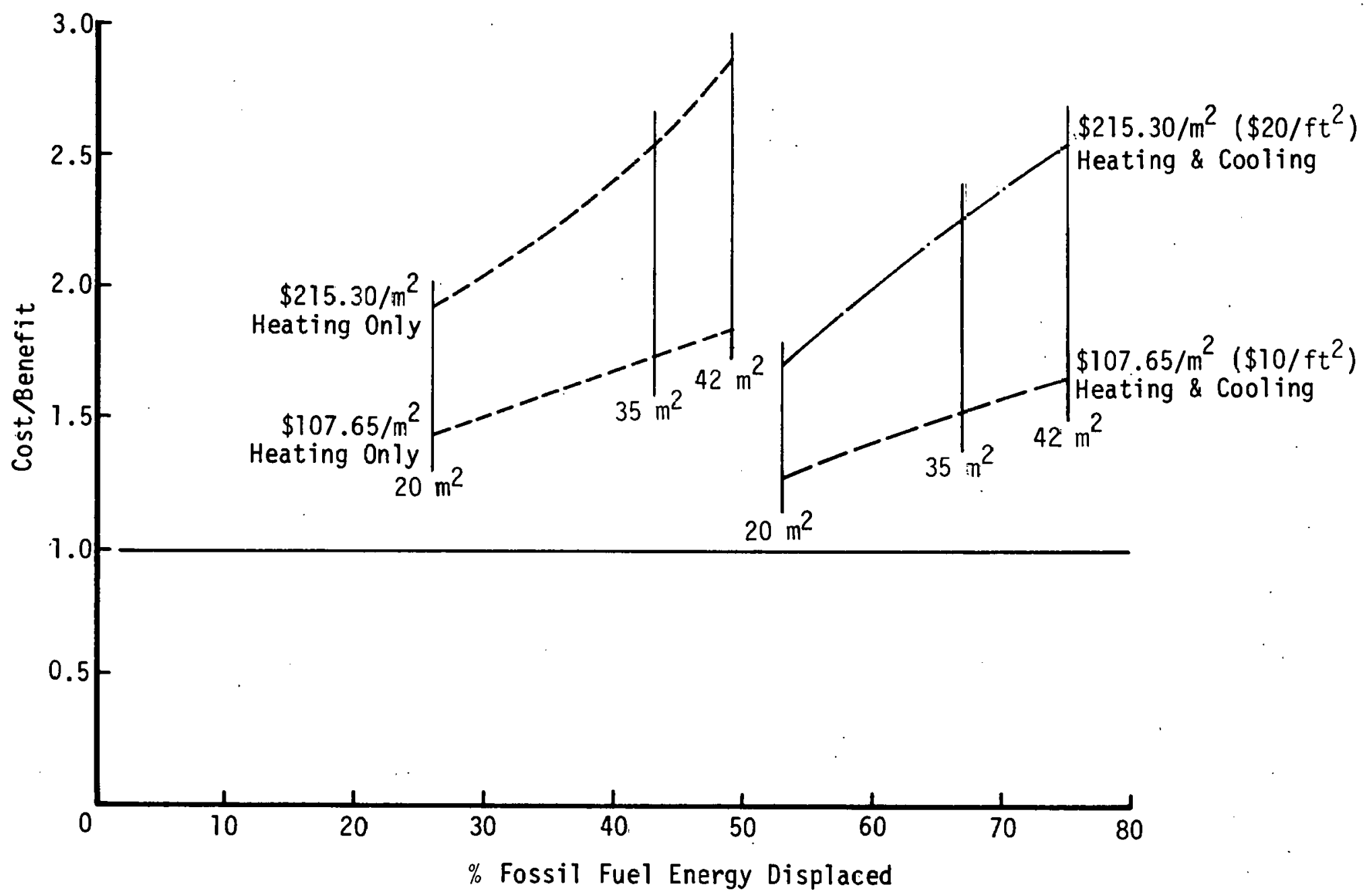

Figure 5-18. COST/BENEFIT VS. FOSSIL FUEL ENERGY DISPLACED BY A 3.0-KW COOLER WITHOUT AUXILIARY AT VARIOUS COLLECTOR AREAS AND COSTS IN DJDGE CITY (1985 BASE YEAR) 


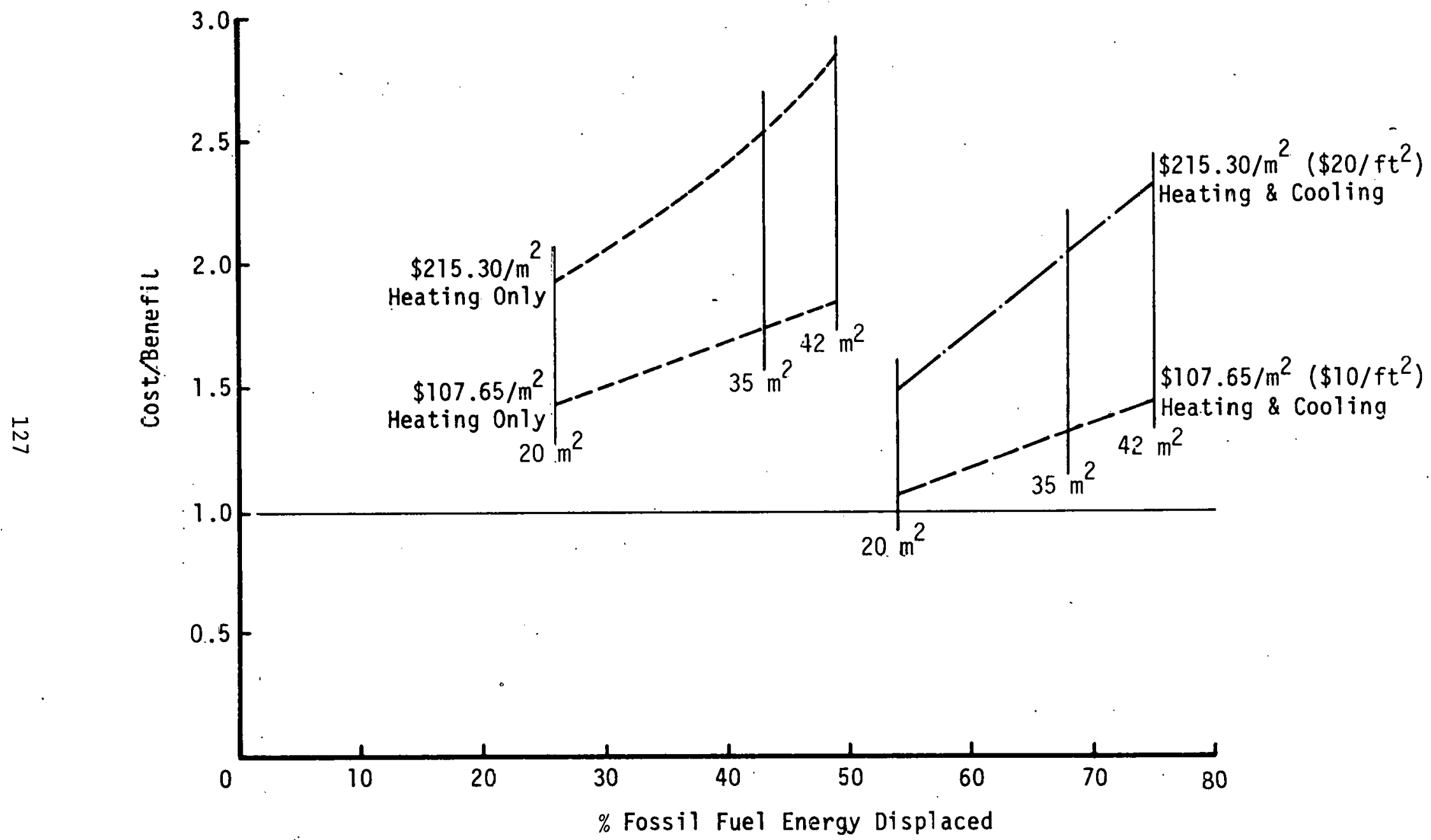

Figure 5-19. COST/BENEFIT VS. FOSSIL FUEL ENERGY DISPLACED BY A 4.5-KW COOLER WITHOUT AUXILIARY AT VARIOUS COLLECTOR AREAS AND COSTS IN DODGE CITY (1985 BASE YEAR) 


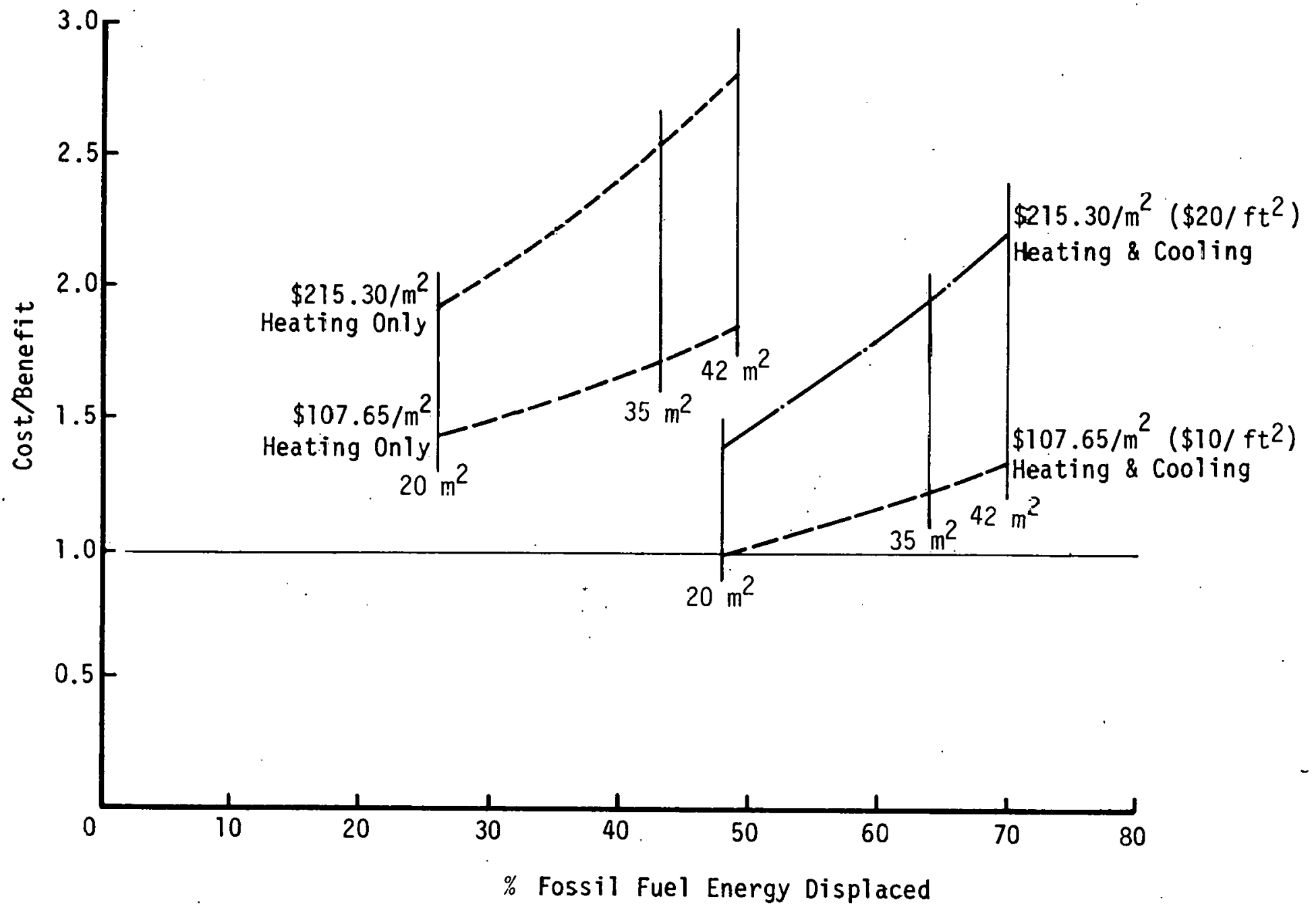

Figure 5-20. COST/BENEFIT VS. FOSSIL FUEL ENERGY DISPLACED BY A 2.3-KW COOLER WITHOUT AUXILIARY AT VARIOUS COLLEOTOR AREAS AND COSTS IN DODGE CITY (1985 BASE YEAR) 
As previously discussed, the high cost/benefit ratios for Dodge City result from the combination of low natural gas rates and a relatively high heating load. To illustrate this point, Figure 5-17 is a plot of cost/benefit ratio versus collector area for Dodge City using Washington, D.C., electricity and natural gas rates. A large decrease in the cost/benefit ratio occurs; the desiccant systems are cost-effective for part or all of the collector sizes from 20 to $42 \mathrm{~m}^{2}$ at $\$ 108 / \mathrm{m}^{2}$. Thus, with sufficiently high-cost conventional energy sources (on the order of Washington, D.C., 1978 prices), solar heating and desiccant coolers in the $2.3-$ to $4.5-\mathrm{kW}$ range, without auxiliary cooling, can be cost-effective in Dodge City at collector costs up to approximately $\$ 161 / \mathrm{m}^{2}$. The addition of solar hot water systems would result in further increases in cost-effectiveness.

Figures 5-18, 5-19, and 5-20 show cost/benefit ratio plotted versus displaced fossil fuel for 9.0-, 4.5-, and $2.3-\mathrm{kW}$ solar heating-only and heating/destccant-cooling systems in Dodge City at collector costs of $\$ 107.65 / \mathrm{m}^{2}$ and $\$ 215.30 / \mathrm{m}^{2}$. The percentage of fossil fuel displaced increases with the addition of desiccant cooling in all cases. As before, desiccant cooling plus heating results in a larger allowable collector area and greater fossil fuel displacement for the same cost/benefit ratio as a heating-only system. A solar heating system with a $20-\mathrm{m}^{2}$ collector area displaces $26 \%$ of the fossil fuel requirement. With $\$ 215 / \mathrm{m}^{2}$ collectors the cost/benefit ratio is 1.92 . The addition of a $4.5-\mathrm{kW}$ desiccant cooler results in approximately a $35-\mathrm{m}^{2}$ collector area and a fossil fuel displacement of $65 \%$ with the same cost/benefit ratio and collector cost (see Figure 5-19). This represents an increase in fossil fuel displacement by a factor greater than two. 


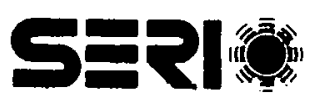

130 


\section{SECTION 6.0}

\section{CONCLUSIONS AND RECOMMENDATIONS}

This report describes the results of the development and analysis of computer simulations of solar space heating, solar desiccant cooling (using an axialflow, disc-type dehumidifier with silica gel), and electrically driven vaporcompression air-conditioning systems for residential heating and cooling. The objective of the study was to evaluate residentlal solar desiccant cooling potential and identify optimum system configurations, climatic conditions, and economic parameters. The system chosen for study was a disc-type desiccant bed configuration in the recirculation mode (Figures 2-3 and 2-4).

The TRNSYS computer program, in conjunction with speclal desiccant cooler routines, proved to be a valuable tool in evaluating the seasonal performance of solar heating/desiccant-cooler systems at the five locations studied. The ability to perform a transient analysis is important because the effects of varying ambient conditions and solar energy input to a desiccant cooler cannot be detected in a limited number of steady-state analyses. The results from the TRNSYS simulations, the economic analyses, and the vapor-compression cooler simulation programs allow evaluation and comparison of the various systems.

As described in the previous sections, several solar heating/desiccant-cooling annual simulations were performed for five U.S. cities with diverse climatic conditions. Five conclusions regarding system performance were drawn from these simulations:

- Those climates that experience both high heating loads in the winter and high cooling loads in the summer are the most sultable candidates for solar heating and desiccant cooling. By having large heating and cooling loads, the solar system can be matched to the heating and cooling energy requirements without additional collector area beling required for the cooling season. The solar system can then be utilized year-round to the maximum extent.

- Washington, D.C., is the most promising of the five cities examined for the application of a solar heating and desiccant cooling system with a vapor-compression cooler backup. This results from the favorable climatic conditions, namely, the high heating and cooling loads and high relative humidity. Dodge City, Kans., shows promise for solar heating and desiccant cooling without vapor-compression cooler backup. Although the room conditions in a Dodge City home would occasionally leave the comfort zone during peak cooling loads, a reasonable degrec of comfort could be maintained during the summer months without auxiliary cooling. Other locations with similar climatic conditions have the same promise as these two cities.

- The desiccant cooler system which was modeled is preferentially a latent rather than sensible cooler. The steady-state simulations clearly showed that the potential latent cooling capacity is larger than the potential sensible capacity at a given desiccant regeneration temperature. Thus, the modeled desiccant cooler system would 
provide optimum cooling performance in humid climates such as Washington, D.C., and would perform less efficiently in dry climates with large sensible cooling loads, such as Phoenix, Ariz.

- The thermal performance of the desiccant cooler is best understood in terms of the interaction of the desiccant system with the solar collector/storage outlet (regeneration) temperature. Due to the cyclic nature of the solar input, the average regeneration temperature from the collectors is a major factor in the optimum coupling of solar collectors with desiccant coolers.

- For comblned solar space heating/desiccant-cooling systems, the optimum matches of system sizes and collector areas for Washington, $\mathrm{D}_{\dot{2}} \mathrm{C}$., (with auxiliary cooling) are a 4.5-kW desiccant cooler with 35$\mathrm{m}^{2}$ collector area and a $9.0-\mathrm{kW}$ desiccant cooler with $50-\mathrm{m}^{2}$ collector aiea. This selection $1 \mathrm{~s}$ based on the nhjective of maximiaing both cooling capacity and desiccant cooler off-time (that is, maximizing EER). These system sizes are smaller than those typically found in Washington, D.C., homes, so the vapor-compression backup would meet a portion of the cooling load. This strategy is preferable to large solar desiccant coolers that are sized to meet the full cooling load with no backup for two reasons: 1) solar desiccant coolers sized to meet peak cooling loads would be underutilized during a major portion of the cooling season; and 2) the collector area required for such a desiccant cooler would probably far exceed that required for heating, even if the heating and cooling loads were nearly equal, resulting in underutilization of the collectors during the heating season. Sizing desiccant coolers for peak cooling loads would tend to reduce the cost-effectiveness of the solar systems.

With the economics analysis program and cost assumptions described in Section 5.0 , the present worth of 20-year life-cycle costs was determined for each of the annual solar space heating/desiccant-cooler simulations (Section 3.7.3) and natural-gas-space-heating/vapor-compression-cooler simulations (Section 4.0). The percentage of fossil fuel displaced by the solar systems was also determined. Conclusions resulting from this analysis for combined heating and cooling systems (assuming a 1985 system installation) are as follows:

- Economic considerations indicate that humid climates with relatively high conventional fuel costs are the preferred conditions for the solar desiccant cooler modeled in this study.

- Analysis of life-cycle cost and fossil fuel displacement indicates that a $4.5-\mathrm{kW}$ desiccant cooler with a $35-\mathrm{m}^{2}$ collector area and auxillary vapor-compression cooling backup is the preferred configuration for Washington, D.C.; with no backup cooling, it is the preferred configuration for Dodge City.

- The solar heating/desiccant-cooling system with backup approaches cost competitiveness in Washington, D.C., at installed collector costs under $\$ 215 / \mathrm{m}^{2}$, but not in Dodge City (without backup), due to low costs for conventional fossil fuels in the latter location. 
- When a desiccant cooling system is added to a solar space heating system, a significant increase in displaced fossil fuel energy can be achieved. For the same cost/benefit ratio (cost-effectiveness) and collector cost per square meter, the addition of a desiccant cooler results in a larger economically allowable collector area and a slgnificant increase in fossil fuel displacement. Thus, if residential solar space heating can be justified (either economically or by fossil fuel conservation), then the addition of a desiccant cooler in certain climates can significantly increase fossil fuel displacement without affecting system cost-effectiveness.

Potential system configurations for climates not examined in detall in this study can be proposed. For the hot, dry climate of Phoenix, Ar1z., a system consisting of a relatively small solar-regenerated desiccant wheel and a large evaporative cooler could potentially provide the required degree of comfort. In such a dry climate, the large evaporative cooler should be able to provide the required sensible cooling. The addition of a desiccant wheel would maintain the relative humidity of the conditioned space within acceptable limits. For a warm, very humid climate such as Charleston, S.C., a large solar-regenerated desiccant wheel combined with a relatively small evaporative cooler should be the optimum system. A large destccant wheel is required to meet the large latent cooling load.

Thus, it should be possible to alter the cooling capacities of the individual components of a solar desiccant cooling system, namely, the desiccant wheel (latent) and evaporative cooler (sensible), in order to match the system to local climatic conditions. This is a distinct advantage over other cooler types for which the ratio of sensible to latent cooling output is fixed. System costs should be reduced by matching the sizes of the components with local requirements to minimize excessive latent or sensible capacities. However, for each case the total solar heating/desiccant-cooler system must be compared on a life-cycle basis to the conventional system employing energy from fossil fuels to determine if the solar desiccant cooler will be costeffective.

In spite of the apparent potential for solar space heating/desiccant-cooler systems in certain climatic conditions, additional work remains to be done to prepare solar desiccant cooler systems for residential application. The major areas of work include:

- selection of the optimum desiccant dehumidifier bed configuration (disc-type, as modeled in this study, or alternates, such as crosscooled 1sothermal beds or concentric drums);

- optimlzation of other desiccant cooler system components, such as the regenerative heat exchangers and evaporative coolers;

- construction and testing of prototype desiccant cooler systems;

- definition of expected desiccant cooler system capital costs and methods, if any, of cost reduction; 
- minimization of parasitic power required for desiccant coolers; and

- comparison of solar desiccant coolers with competing cooler types in terms of cost-effectiveness and fossil fuel displacement.

SERI and several other organizations under contract to the U.S. Department of Energy are continuing work in these areas in order to define the future role of solar desiccant cooling. The analysis techniques developed in this study should prove to be useful in comparing the performance of various cooling systems and in determining which system(s) should"ultimately be carried through the commercialization stage for the residential market. 
SECTION 7.0

REFERENCES

1. U.S. Federal Energy Administration. Project Independence Report. November 1974.

2. Stanford Research Institute. Patterns of Energy Consumption in the United States. Springfield, IL: National Technical Information Service; January $1972 ;$ PB -212776.

3. TRNSYS - A Transient Simulation Program Prepared by the Solar Energy Laboratory. Madison, WI: University of Wisconsin; February 1978; Report $38-9$.

4. Nelson, J. S. "An Investigation of Solar Powered Open Cycle Air Conditioners." M.S. Thesis in Mechanical Engineering. Madison, WI: University of Wisconsin; 1976.

5. Local Climatological Data: Annua1 Summaries for 1977. Asheville, NC: National Oceanic and Atmospheric Administration; 1978 .

6. ASHRAE Handbook \& Product Directory: 1977 Fundamentals. New York, NY: American Society of Heating, Refrigerating, and Air Conditioning Engineers, Inc.; 1977.

7. Boes, E. C.; et al. Availability of Direct, Tota1, and Diffuse Solar Radiation to Fixed and Tracking Collectors in the U.S.A. Albuquerque, NM: Sandia Labs.; August 1977; SAND 77-0885. Revised January 30, 1978.

8. Shelpuk, Benjamin. Proceedings of the Desiccant Cooling Conference of November 16, 1977. Golden, CO: Solar Energy Research Institute; April 1978; Report No. SERI-22.

9. Oonk, R. L.; Shaw, L. E.; Cash, M. Simulation of Air Based Solar Desiccant Cooling Systems. Denver, CO: Solaron Corporation; 1978.

10. Gunderson, M. E.; Hwang, K. C.; Railing, S. M. Technical Progress Report: Development of a Solar Desiccant Dehumidifier. Torrance, CA: Airesearch Manufacturing Company; March 31, 1978; Report No. 78-14957-1.

11. Illinois Institute of Technology. First Semi-annual Progress. Report (November - May 1978) on Development of a Solar Desiccant Dehumidifier. June 10, 1978.

12. Wurm, Jaroslav; We1l, S. A.; Wright, L. R. Solar-MEC Development Program: Project 9103 Semiannual Progress Report for the Period September 1, 1977 through February 28, 1978. Institute of Gas Technology; March 1978.

13. Hollands, K. G. T. "Analysis and Design of Evaporative Cooler Pads." Mechanical \& Chemical Engineering Transactions. pp. 55-61; November 1970. 
14. Maclaine-Cross, I. L.; Banks, P. J. "Coupled Heat and Mass Transfer in Regenerators:" An Analogy with Heat Transfer." International Journal of Heat and Mass Transfer. Vol. 15: pp. 1225-41; 1972.

15. Maclaine-Cross, I. L.; Banks, P. J.; Close, D. J. "Coupled Heat and Mass Transfer and Fluid Flow Through a Porous Medium: An Analogy with Heat Transfer." Heat Transfer. Vol. 11: paper CT 3.1; 1970.

16. Banks, P. J.; Close, D. J. "Coupled Equilibrium Heat and Single Adsorbate Transfer in Fluid Flow through a Porous Medium: Part II, Predictions for a Silica-Gel Air-Drier Using Characteristic Charts." Chemical Engineering Sclence. Vol. 27: pp. 1157-69; 1972.

17. Pawelski, M. J. "Development of Transfer Function Load Models and Their Use in Modeling the CSU Solar.House I." M.S. Thesis in Mechanical Engineering. Madison, WI: University of Wisconsin; 1976.

18. Solaron Corporation. Application Engineering Manual. Denver, CO;.June 1977.

19. Mitche11, John W. (University of Wisconsin - Madison). Letter to Ben Shelpuk (Solar Energy Research Institute). February 6, 1978.

20. Staats, William R.; Wurm, Jaroslav; Wright, L. R.; Kunc, V.; Banasiuk, H. A. Field Testing of Solar-MEC Systems: Final Report. Chicago: Institute of Gas Technology; July 1977.

21. Kays, William; London, A. L. Compact Heat Exchangers. New York: McGrawHill Book Co.; 1964 .

22. Industrial Ventilation: A Manual of Recommended Practice. 12 th edition. Lansing, MI: American Conference of Governmental Industrial Hygienists; 1972 .

23. Rask, D. R.; Mueller, L. J. Low-lost Solar Air Heater: Semiannual Progress Report. Minneapolis, MN: Honeywel1, Inc.; December 22, 1976; C00/2929-6.

24. Bird, R. Byron; Stewart; W. E.; Lightfoot; E. N. Transport Phenomena. New York: John Wiley \& Sons, Inc.; 1960.

25. Nelson, J. S.; Beckman, W. A.; Mitchell, J. W.; Close, D. J. "Simulation of the Performance of Open Cycle Desiccant Systems Using Solar Energy." Madison, WI: University of Wisconsin; n.d.

26. Solaron Corporation. Comparisons of Proposed Solaron-Heat Pump and Solaron-Desiccant Heating and Cooling Systems. Denver, C0; October 31, 1977.

27. Duffie, J. A. "Solar Heating in North America." Mechanical Engineering. pp. 36-45; November 1977. 
- 28. Threlkeld, James L. Thermal Environmental Engfneering. 2nd edition. Englewood Cliffs, NJ: Prentice Ha11, Inc.; 1970.

29. Grant, Eugene L.; Ireson, W. Grant. Principles of Engineering Economy. 5th edition. New York: The Ronald Press Co.; 1970. 


\section{SE尺І*}


APPENDIX A

SAMPLE RESULTS FROH SIMULATION OF ANNUAL SOLAR HRATING AND DESICCANT COOLING PERFORMANCE

$A-1$ 
SERI

A-2 


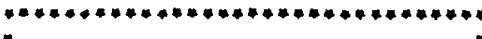

- oesiccant cooling simulation :

MASH2S

IUPIJT PARAMETERS

LOCATION : haSHINGTON, O.C. LATITUOE 138.83 OEgREES N

VEAP : 1959

honse DEscrictioin

THC STO $Y, 1 F 7.3$ M? FLCOR SPACE

179.6 YCे OUTS10E HALL SPACE

PITCH CF ROOF : JY. OEGREE

NORTH-SOUTH OPIENTATEON

$u=1.33$ JISEC-M2-S EHALLS + HINDOHSI

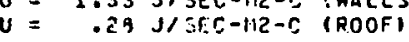

CCOLEF UNIT OESCRIPTION :

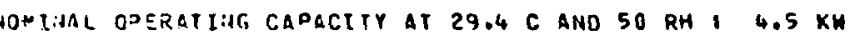

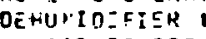

PAEKET BED

P:TIC:. SUPRACE AREA PER UNIT CEHUMIOIFIER VOLUME I 1573 M2/H

WHEEL DIAMETER

275 if

WHEEL ROH: .09180

SENSI DLE ANO LATENT QUXILIARY COOLING TO HOUSE

COLLECTOP

FLAT PLITE (ETR)

STORAGE I

PEable $3 E 0$
VOLUME I3.: H3 


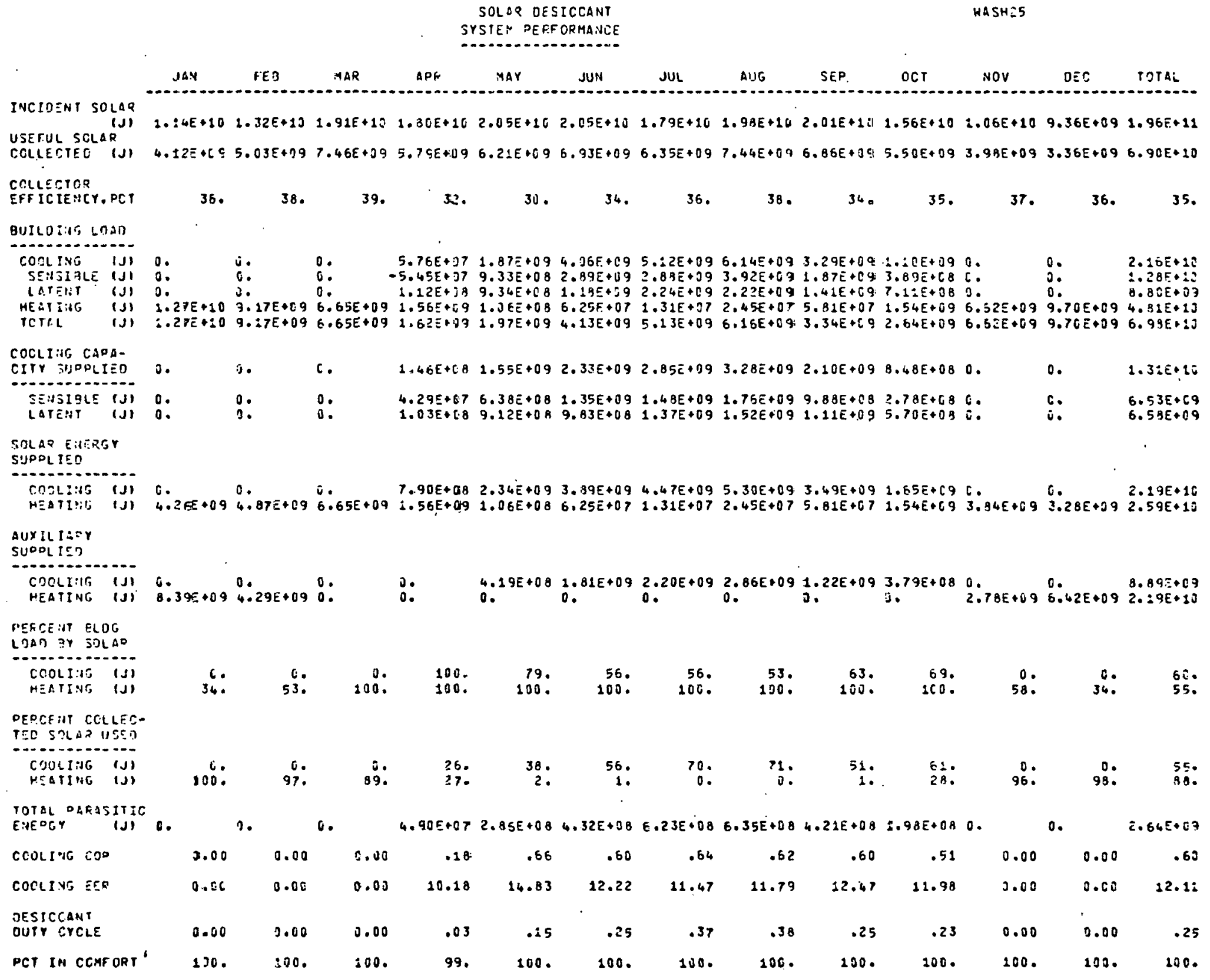




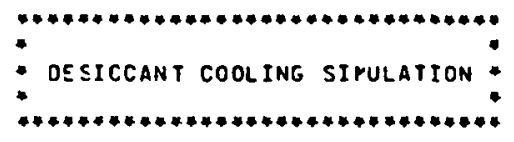

IHPUT DAFAYETEP.S

LOCATIO:1, PHED:JIX, ARIZONA LATITUOE 133.43 OEgREES N

$Y \leq A D, 13 E ?$

HOUSE DESCPIOTION:

FWo STOPY, IET.3 H2 FLCDE SPACE

D73.4 HE DUTSIOE UALL SPACE

PITCH CF UNCF I 33.L DEGEEES

ATRTH-SCUTH ORIEITATIGN

$U=1.33$ H SEC-HEC THALLS + HINOOHS

COOLER JIAT TESCRIPTIO:A,

NO:IIUL COFPATIH, CAPACIEY AT 29.4 C ANO 50 RH \& $4.5 \mathrm{KH}$

QCEHIMITIIF:

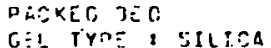

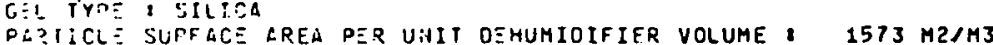

HHECL DIATEETEF

FLCA L.THGTH $1.0 .575 \%$

SENSI SLE AHC LGTENT AUXILIAFY COOLING TO HOUSE

COLLEETOP.

FLAT TLATE IAIRI
AREA

STORAGE ?

PEBBLE BEO

VOLUHE $13.1 \mathrm{H3}$ 


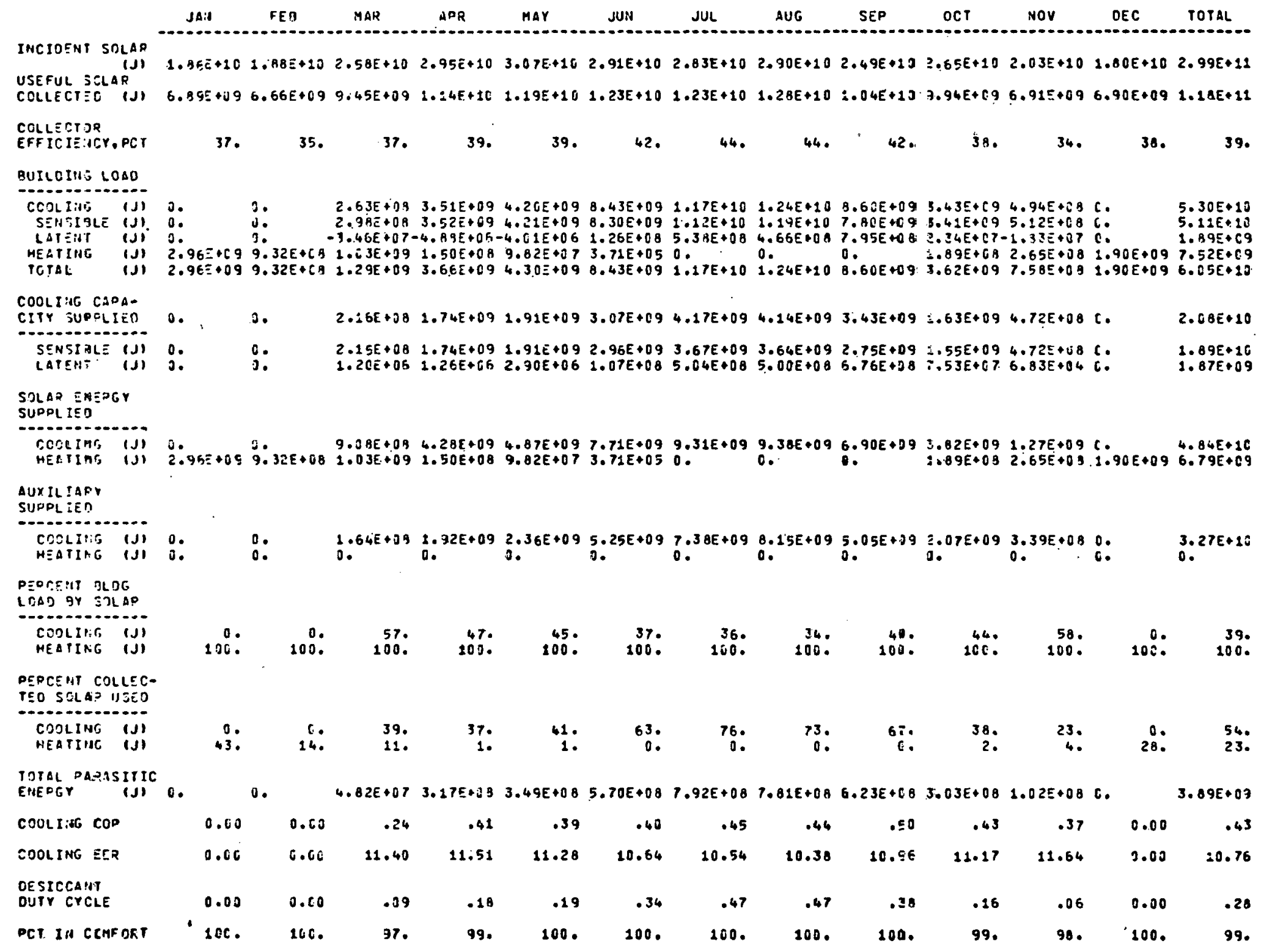




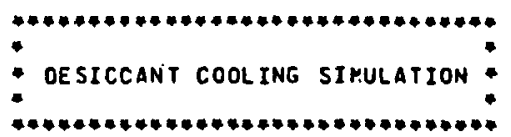

\section{INPUT PARAMETERS}

LCCATION: FOFT HOPTH, TEXAS LATITUOE, 32. BJ OEGREES N

YEAR : 960

HOUSE OESC?IPITIN

PWC STOFY, 167.3 HZ FLCOR SPACE

178.6 M2 OYTSIDE HALL SPACE

PITEH CF RJOF I 3?.G OEGREES

$U=1.33 \mathrm{~J} / \mathrm{SEC}-\mathrm{HZ}^{-C}$ (WALLS + WINOOWS

$u=.28 \mathrm{~J} / S E C-M Z-C$ (ROOF)

CCOLLEF UNIT OESEPIPIION :

NOMIUAL OPEPATING CAPACITY AT 29.4 C ANO 50 RH $4.5 \mathrm{KH}$

OERUTIDIFIER

DUEKEO SEC
GTL IYPE I SILICA

GTL IYPE I SILICA

WHEEL JIAMETEP: .97 A

FLOK LEIGTH :.J5275 H

SEHSIGLE AHC LATENT AUXILIARY COOLING TO HOUSE

COLLECTOR :

FLAT PLATE (AIR)

AREA I 35 1 M2

STOPAC.E,

PEBALE BEO

VOLUHE : $13.1 \mathrm{m3}$ 


\begin{tabular}{|c|c|c|c|c|c|c|c|c|c|c|c|c|c|}
\hline & JAN & FEB & MAR & $A P P$ & MAY & JUN & JUL & AUG & SEP & OCT & Nov & DEC & Total \\
\hline $\begin{array}{l}\text { IHCIDENT SOLAR } \\
\text { (J) } \\
\text { USEFUL SCLAR } \\
\text { COLLECTEC IJI }\end{array}$ & $\begin{array}{l}1.33 E+:= \\
4.92 E+09\end{array}$ & $\begin{array}{l}1.46 E+1= \\
5.44 E+69\end{array}$ & $\begin{array}{l}1.76 E+10 \\
6.12 E+09\end{array}$ & $\begin{array}{l}2.63 E+10 \\
6.70 E+09\end{array}$ & $\begin{array}{l}2.32 E+16 \\
7.81 E+09\end{array}$ & $\begin{array}{l}2.43 E+10 \\
9.26 E+09\end{array}$ & $\begin{array}{l}2.40 E+10 \\
9.43 E+09\end{array}$ & $\begin{array}{l}2.40 E+10 \\
9.40 E+09\end{array}$ & $\begin{array}{l}2.28 E+10 \\
8.69 E+09\end{array}$ & $\begin{array}{l}1.95 E+10 \\
6.93 E+0.9\end{array}$ & $\begin{array}{l}1.59 E+10 \\
5.81 E+09\end{array}$ & $\begin{array}{l}1.06 E+10 \\
3.77 E+09\end{array}$ & $\begin{array}{l}2.30 E+12 \\
8.43 E+10\end{array}$ \\
\hline $\begin{array}{l}\text { COLLECIOE } \\
\text { EFF ICIE:ICY, PCT }\end{array}$ & 37. & 37. & 35. & 33: & 34. & 38. & 39. & 39. & 38. & 36. & 37 . & 36. & 37. \\
\hline BUILOIHG LOAD & & & & & & & & & & & & & \\
\hline $\begin{array}{l}\text { COOLIAG } \\
\text { SENSIGLE (J) } \\
\text { LAIEITT } \\
\text { HEATING } \\
\text { TOTAL } \\
\text { TOTS } \\
\text { (J) }\end{array}$ & $\begin{array}{l}3 . \\
\text { c. } \\
\text { j.: } \\
\text { B.CEE+C } \\
\text { B.C } 6 E+69\end{array}$ & $\begin{array}{l}2 . \\
0: \\
3: \\
7.26 E+C 9 \\
7.26 E+09\end{array}$ & $\begin{array}{l}0 . \\
0 . \\
0 . \\
6.37 E+39 \\
6.07 E+09\end{array}$ & $\begin{array}{l}8.96 E+03 \\
1.49 E+08 \\
7.47 E+09 \\
1.83 E+68 \\
1.98 E+09\end{array}$ & $\begin{array}{l}2.67 E+09 \\
1.5 .0 E+09 \\
1.17 E+C 9 \\
6.75 E+07 \\
2.74 E+09\end{array}$ & $\begin{array}{l}7.03 E+0.9 \\
5.27 E+09 \\
1.75 E+69 \\
0.1 \\
7.03 E+09\end{array}$ & $\begin{array}{l}8.27 E+09 \\
5.93 E+09 \\
2.34 E+09 \\
0.0 \\
8.27 E+09\end{array}$ & $\begin{array}{l}8.22 E+C 9 \\
5.77 E+C 9 \\
2.46 E+C 9 \\
0.0 \\
8.22 E+C 9\end{array}$ & $\begin{array}{l}5.55 E+09 \\
4.29 E+09 \\
1.2 . E E+[.9 \\
6.27 E+07 \\
5.62 E+19\end{array}$ & $\begin{array}{l}2.23 E+09 \\
1.35 E+28 \\
1.46 E+29 \\
1.25 E+08 \\
2.36 E+C 9\end{array}$ & $\begin{array}{l}0 . \\
0 . \\
0 . \\
1.83 E+09 \\
1.33 E+09\end{array}$ & $\begin{array}{l}1 . \\
C . \\
C . \\
8.83 E+09 \\
8.03 E+09\end{array}$ & $\begin{array}{l}3.49 E+13 \\
2.37 E+10 \\
1.11 E+10 \\
3.25 E+10 \\
6.73 E+10\end{array}$ \\
\hline $\begin{array}{l}\text { COOLING CAOA- } \\
\text { CIIY SUBDLIEC }\end{array}$ & i. & $\therefore$ & c. & $1.69 E+69$ & $1.95 E+09$ & $3.74 E+09$ & $4.34 E+09$ & $4.26 E+09$ & $3.13 E+09$ & $1.97 E+09$ & 0. & 0. & $2.04 E+1 J$ \\
\hline $\begin{array}{l}\text { SENIIBLE (J) } \\
\text { LATENT (J) }\end{array}$ & $\begin{array}{l}u . \\
0 .\end{array}$ & $\begin{array}{l}0 . \\
0 .\end{array}$ & i: & $\begin{array}{l}3.08 E+08 \\
7.81 E+C B\end{array}$ & $\begin{array}{l}9.00 E+08 \\
1.0 .0 E+09\end{array}$ & $\begin{array}{l}2.27 E+09 \\
1.47 E+6.9\end{array}$ & $\begin{array}{l}2.42 \varepsilon+09 \\
1.92 \varepsilon+09\end{array}$ & $\begin{array}{l}2.37 E+09 \\
1.89 E+09\end{array}$ & $\begin{array}{l}1.89 E+09 \\
1.24 E+09\end{array}$ & $\begin{array}{l}6.31 E+C 8 \\
\vdots .33 E+09\end{array}$ & 0. & i. & $\begin{array}{l}1.68 \equiv+10 \\
9.63 E+09\end{array}$ \\
\hline
\end{tabular}

SOLAD ENERGY

SUPDL

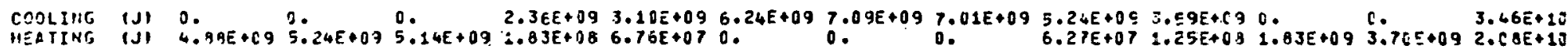
AUYILISTOP SUPDi IED

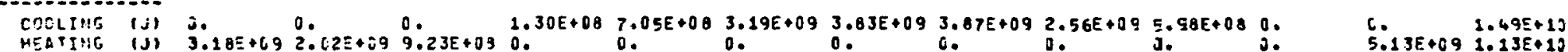

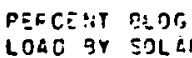

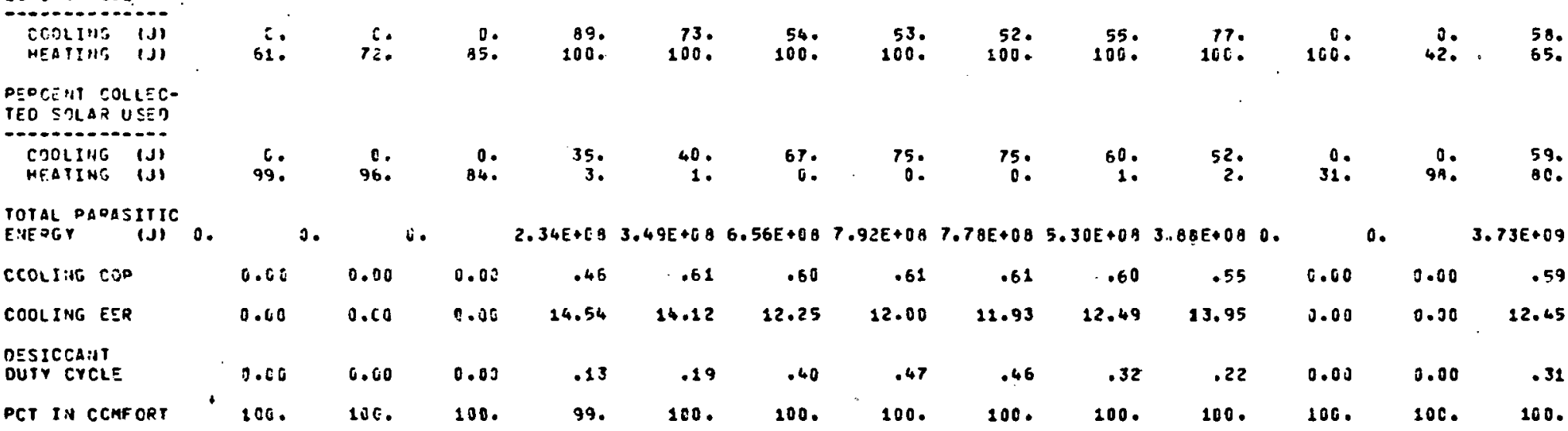




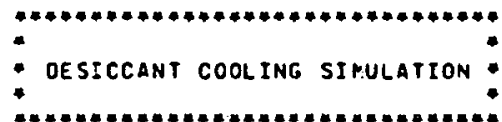

000012

INOUT PARAMETERS

LECATIO:I DOOGE CITY, KS LATITUDE I 37.7T DEGREES $N$

YEAO 1955

HOUSE DESCPIPTION,

THO STOFY, 1ET.3 M? FLCOP SPACE

179.4 ME OUTEIDE HALL SPACE

NORTH-SC.UTH ORIENTATION

$u=1.33 \mathrm{~J} / S E C-142-C$ IHALLS + MINDONSI

$u=$.CA JISEC-ML-C (ROOF)

CCOLER IJATI OESCRIPTIOA,

NOMINAL DOERATING CAPACITY AT 29.4 C ANO $50 \mathrm{RH}, 4.5 \mathrm{KM}$ DEFUMI DEFIER

GACXED TEO
GEL I SILICA

GEL YYDE 'STLICA

HHEEL OIAMETEP? AR?

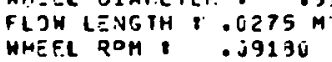

SENSI GLE AYC LATENT AUXILIAEY COOLING TO HOUSE

COLLECTOR I

FLAT PLATE (AIR)

AREA : 35.6 M2

STORAGE :

PEBQLE B.ED

VOLUME $323.1 \mathrm{MJ}$ 


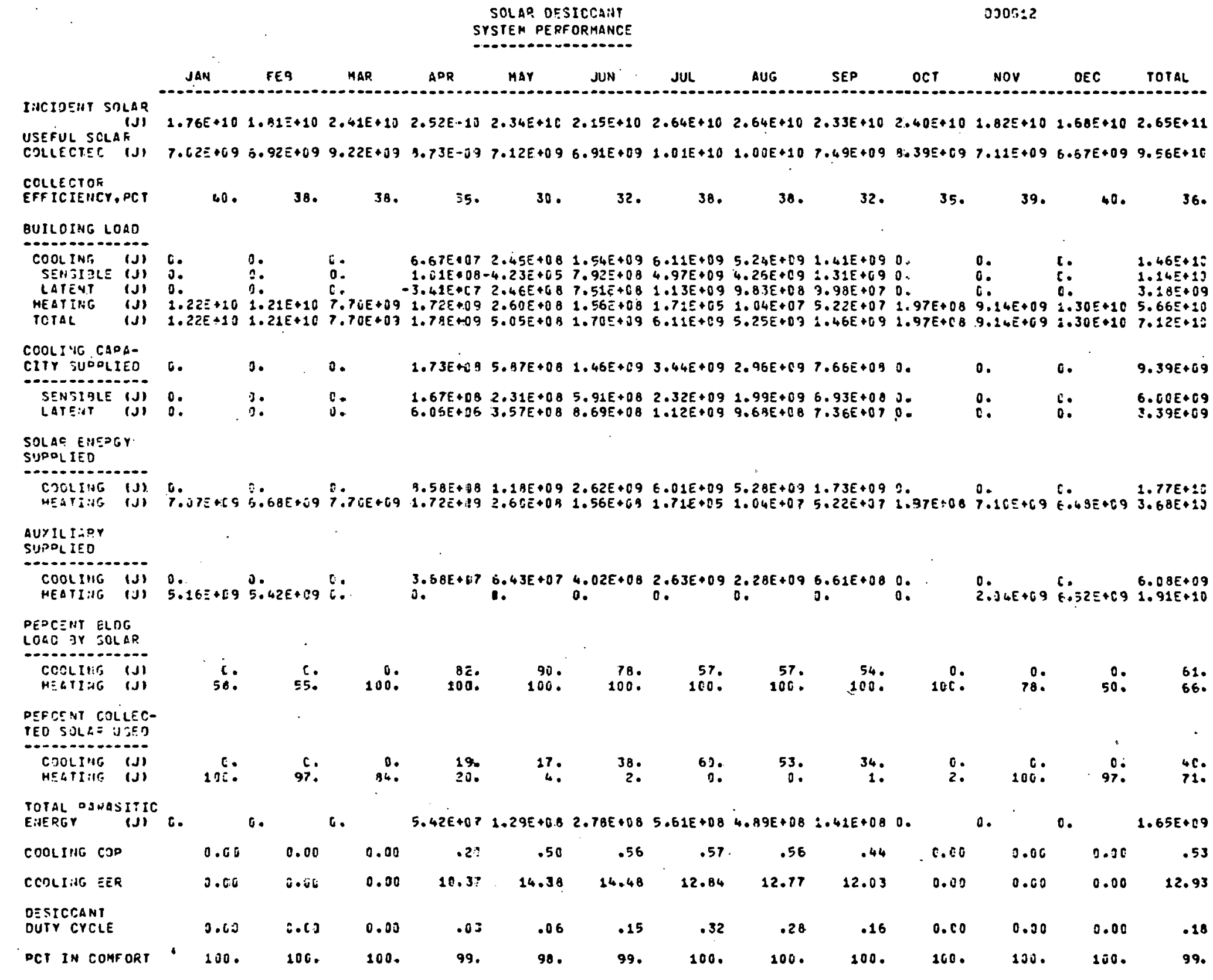




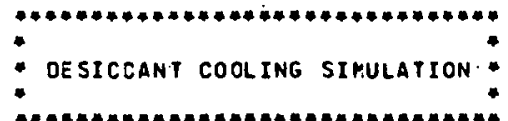

CHAR14

INPUT PAFAY ETEQS

LOCATION : Chapleston, SC LATITUDE 32.90 OEGREES N

VEAR : : 963

HOUSE OESCRIPTEON ,

TWC STOR Y. 167.3 H2 FLCOF SPACE

T.7A.4 ML OIITSIDE HALL SPACE

PITCH OF PJOF 33.0 DEGREES.

LS + MINDONSI

$U=.5$ JISEC-ME-C (ROOFI

CCOLEF UNIT OESCRIPTION

NOMINAL OPERATING CAPACITY AT 29.4 C ANO 50 RH $4.5 \mathrm{KH}$ DEHUMIDIFI PACKEC BE $D$

GFL IYPC SILICA

DADIIQE SUPFACE AQEA PEE UNIT OEHUHIOTFIER VOLUME 1573 H2/H3 WHEEL JIAMETER : .97 M

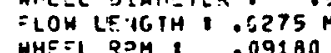

SENSIBLE AHD LATENT AUXILIARY COOLING TO HOUSE

COLLECTOP.

FLAT PLATE (AIP)

AREA I $35.0 \mathrm{ML}$

STORAGE :

PEEBLE BED

VOL HME \&. $13.1 \mathrm{H3}$ 


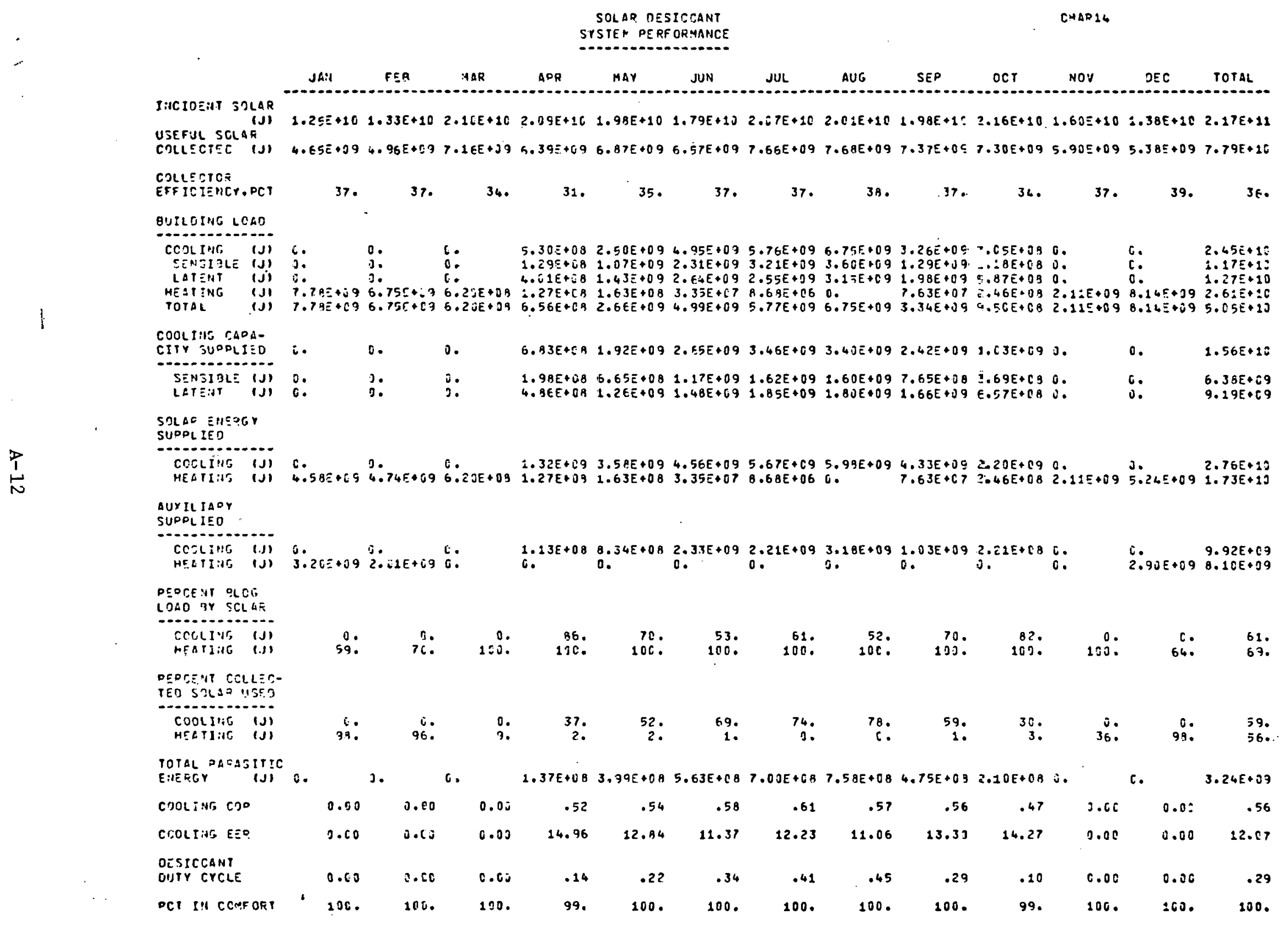


APPENDIX B

RESULTS FROM VAPOR-COMPRESSION COOLER SIMULATION

B-1 


\section{SENI*}

B-2 
Table B-1

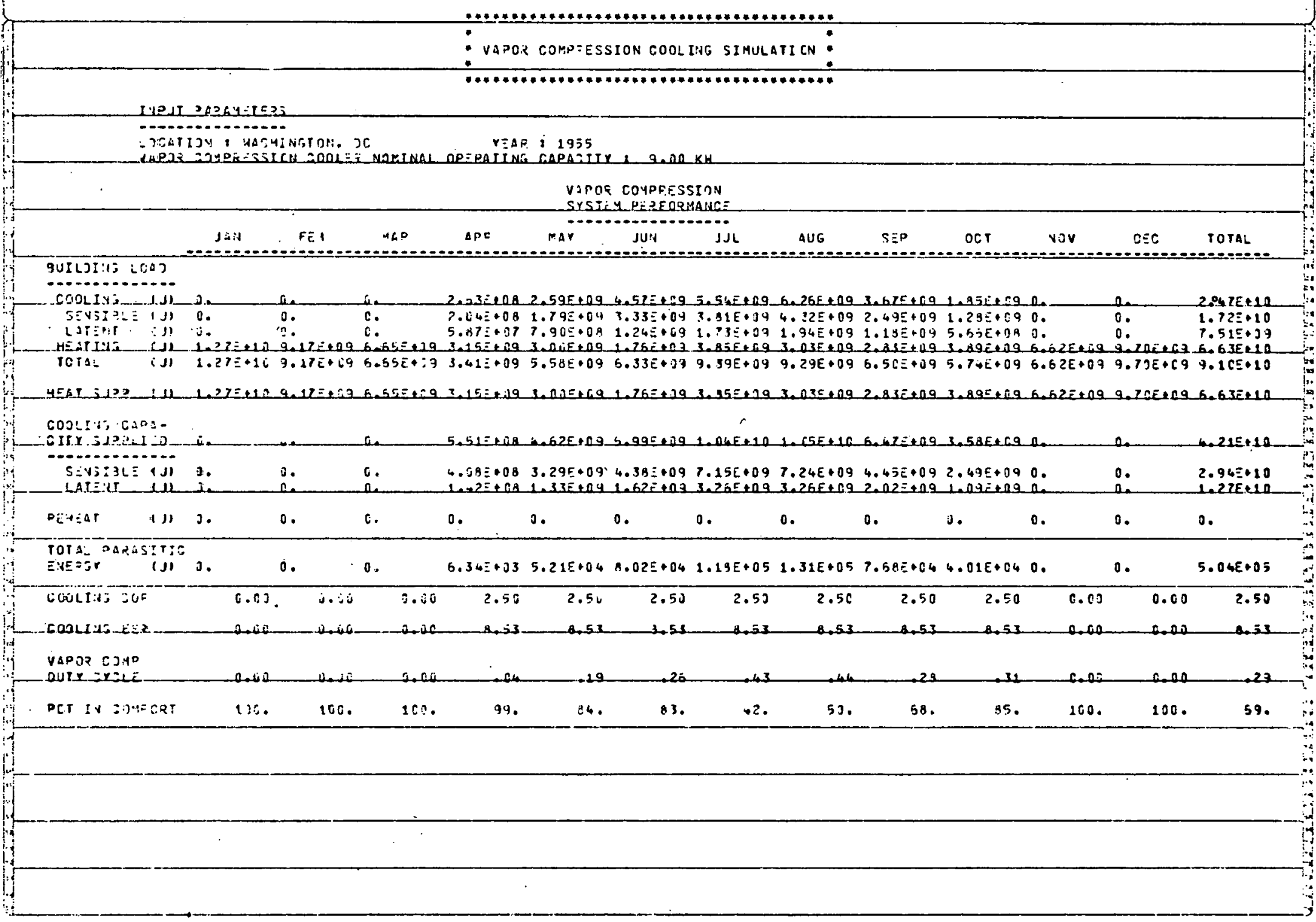




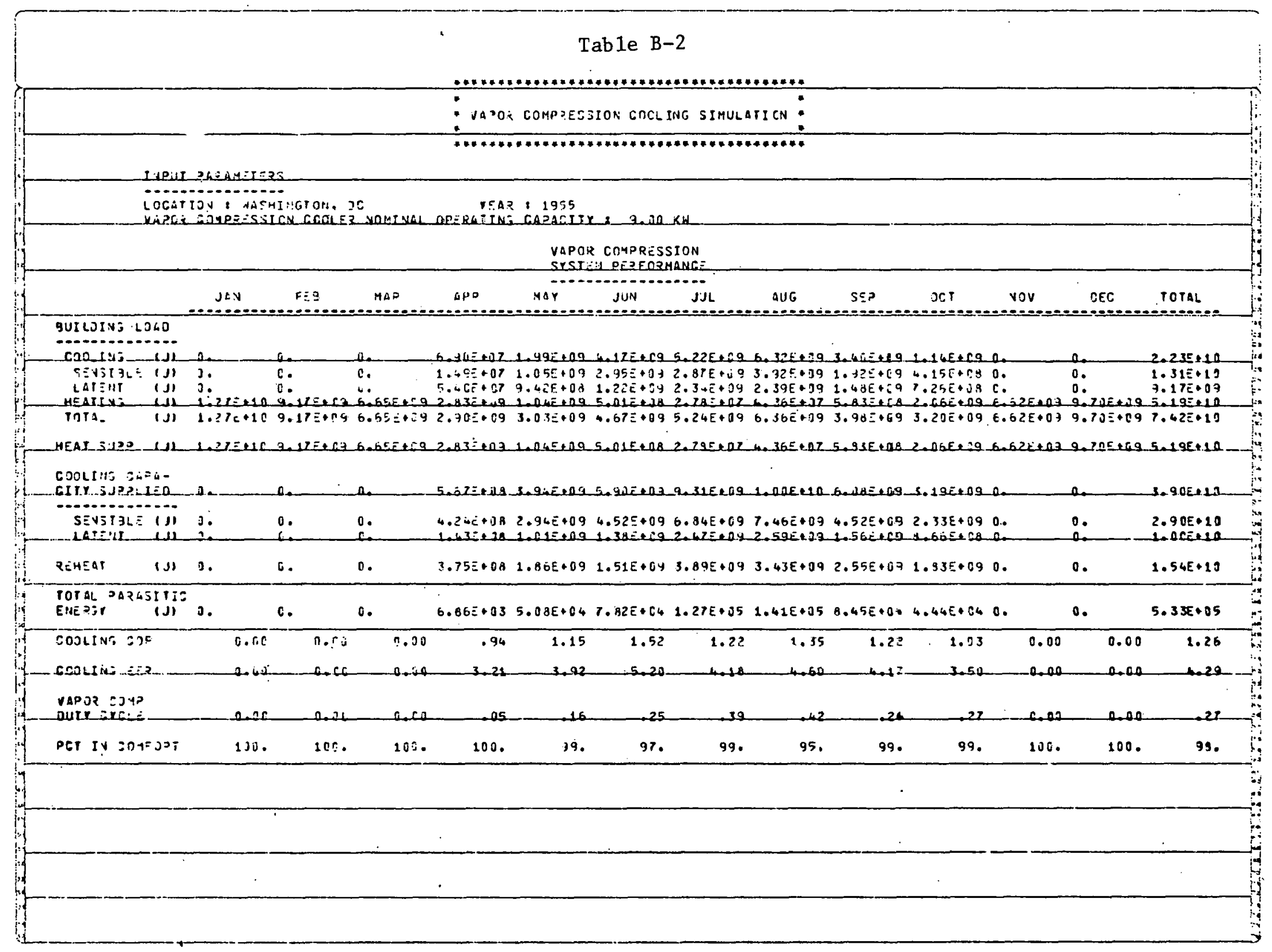


Table B-3

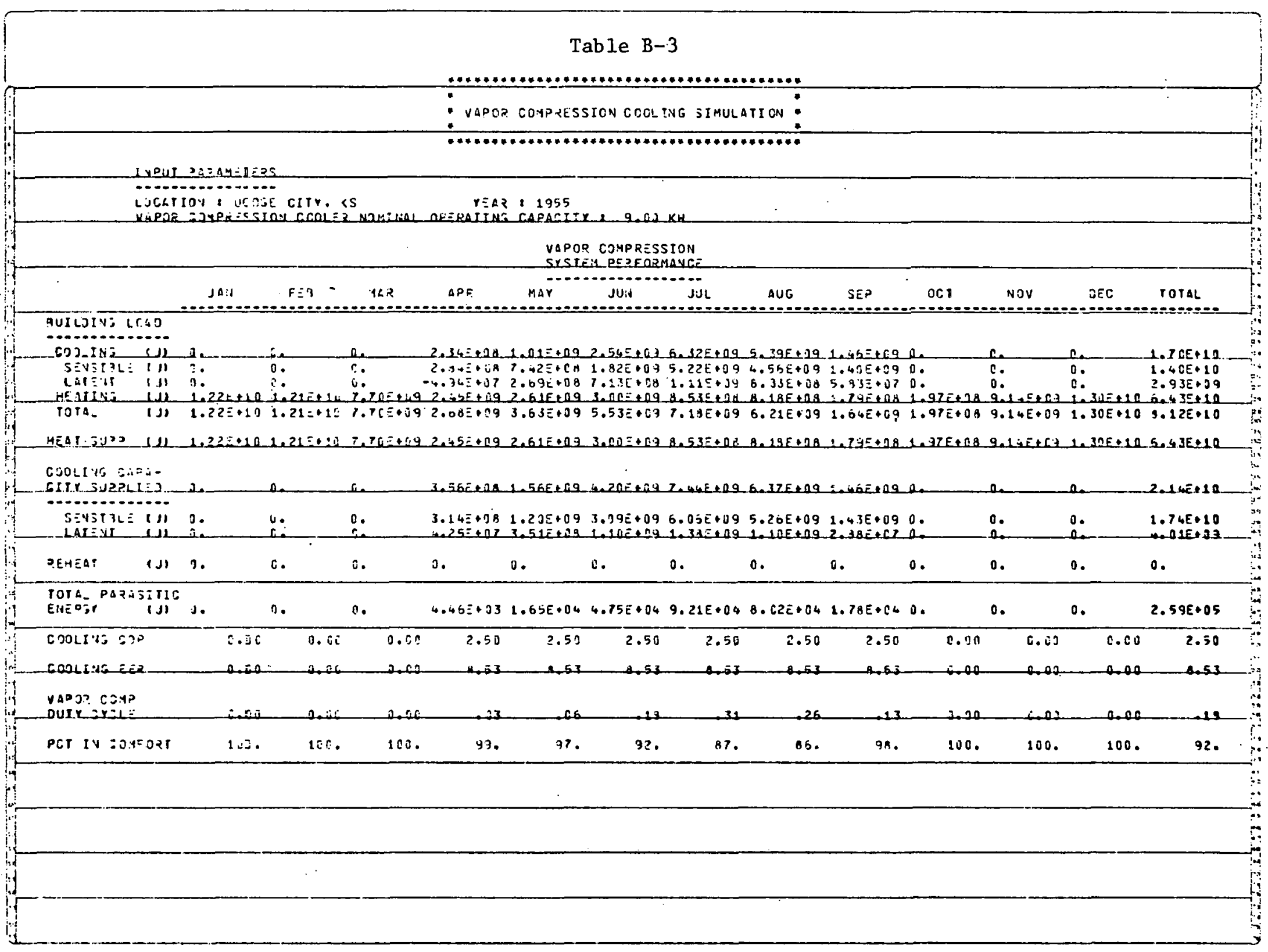


Table B-4

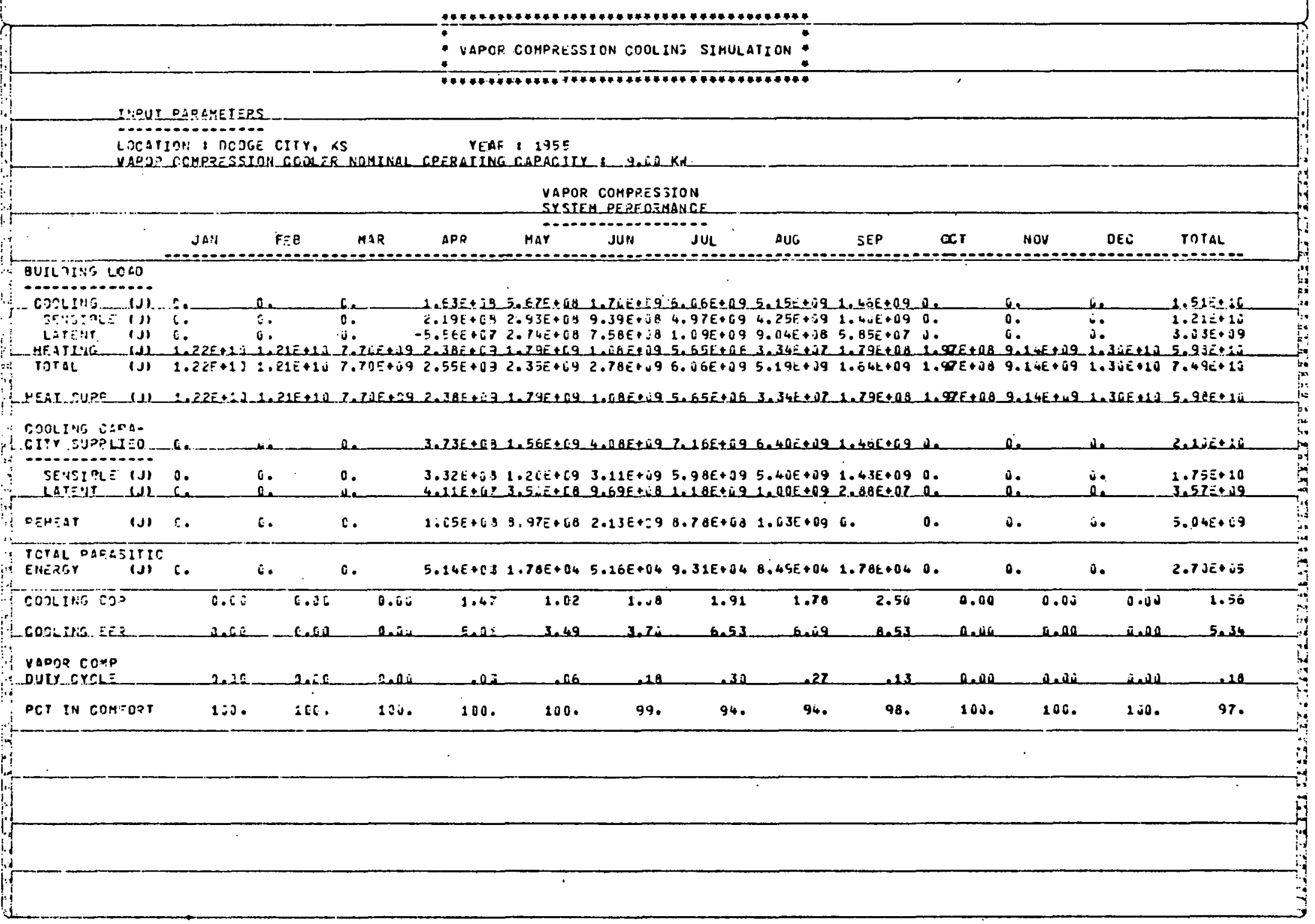


Table B-5

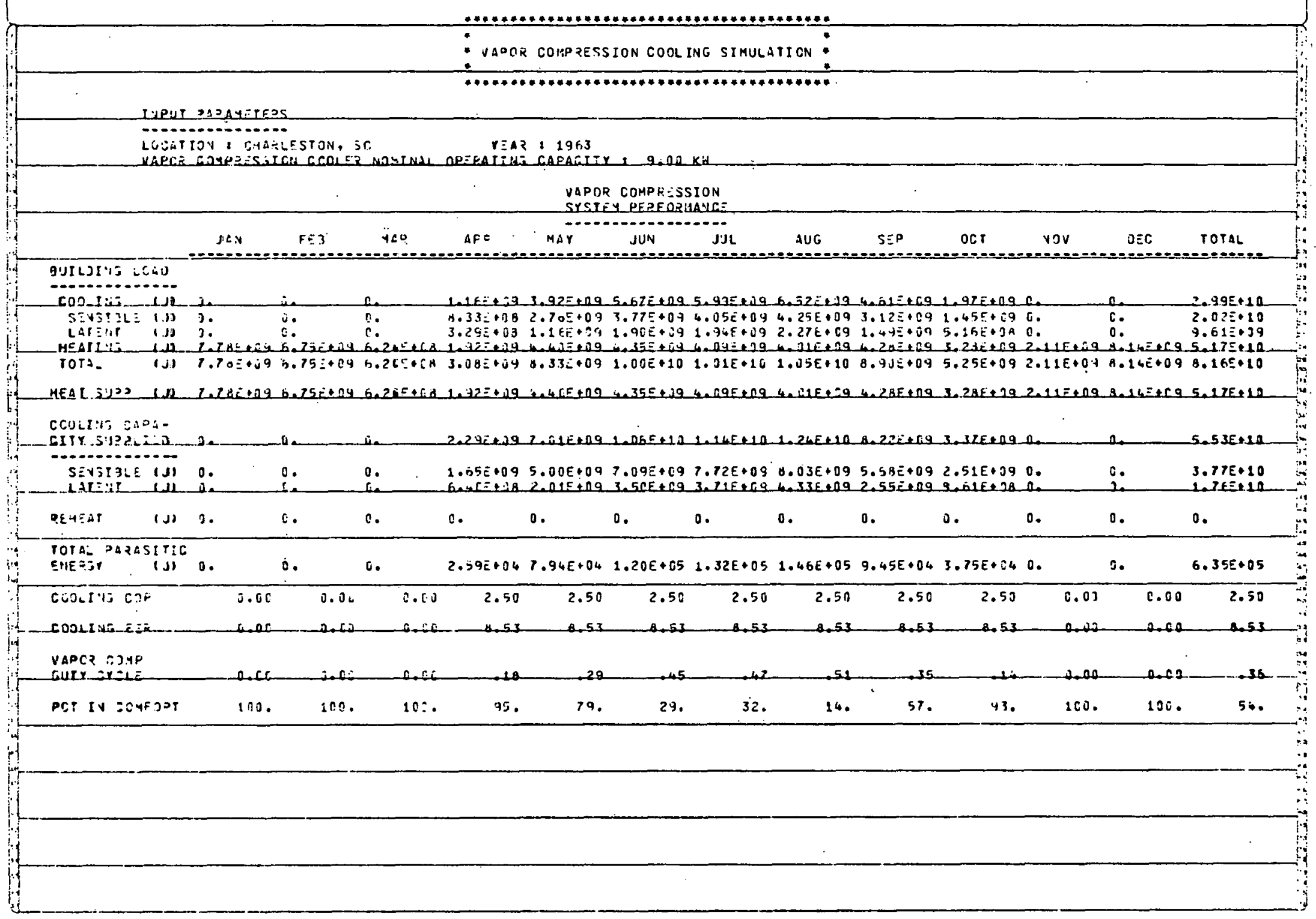




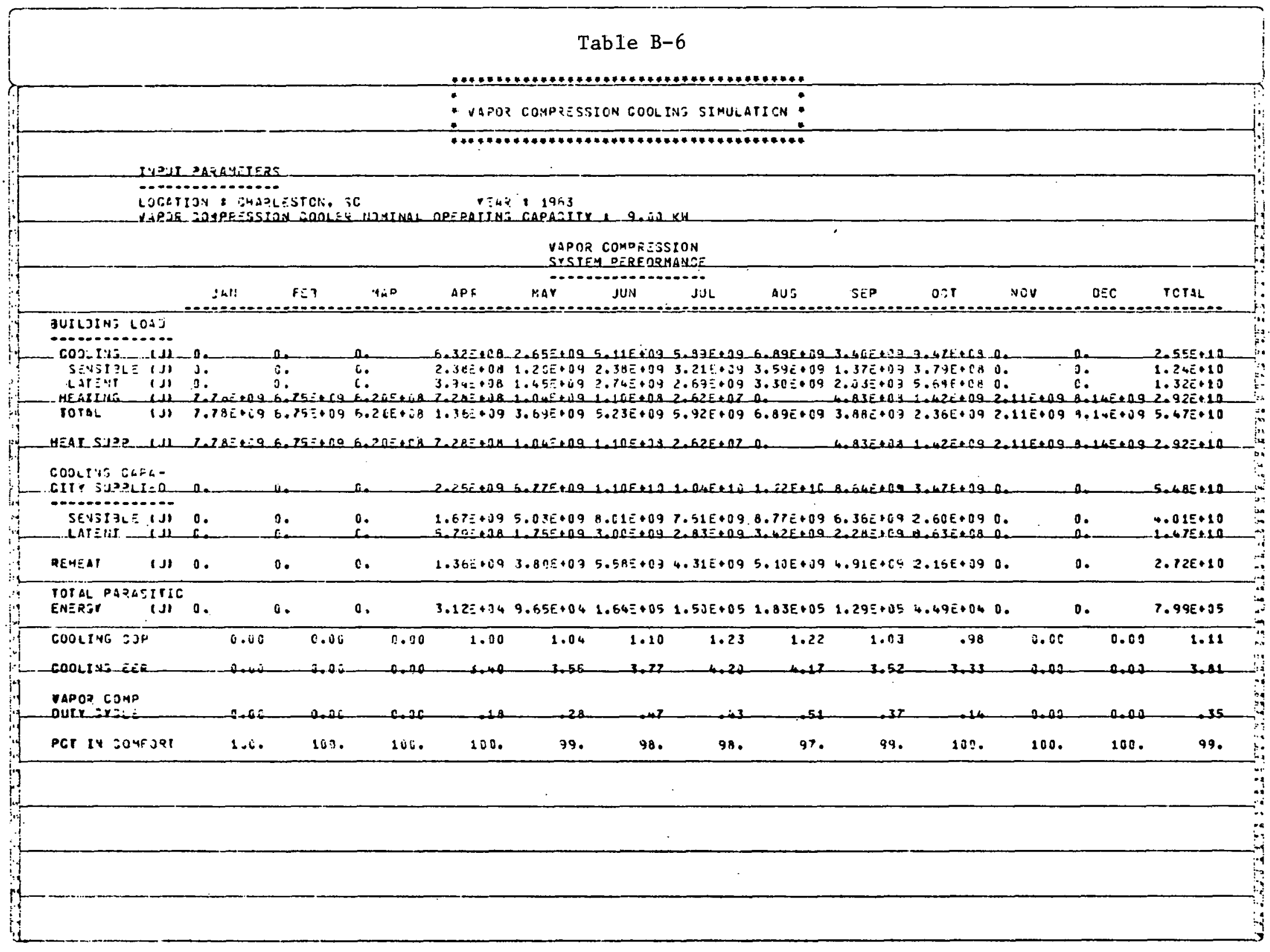


Table B-7

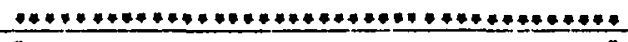

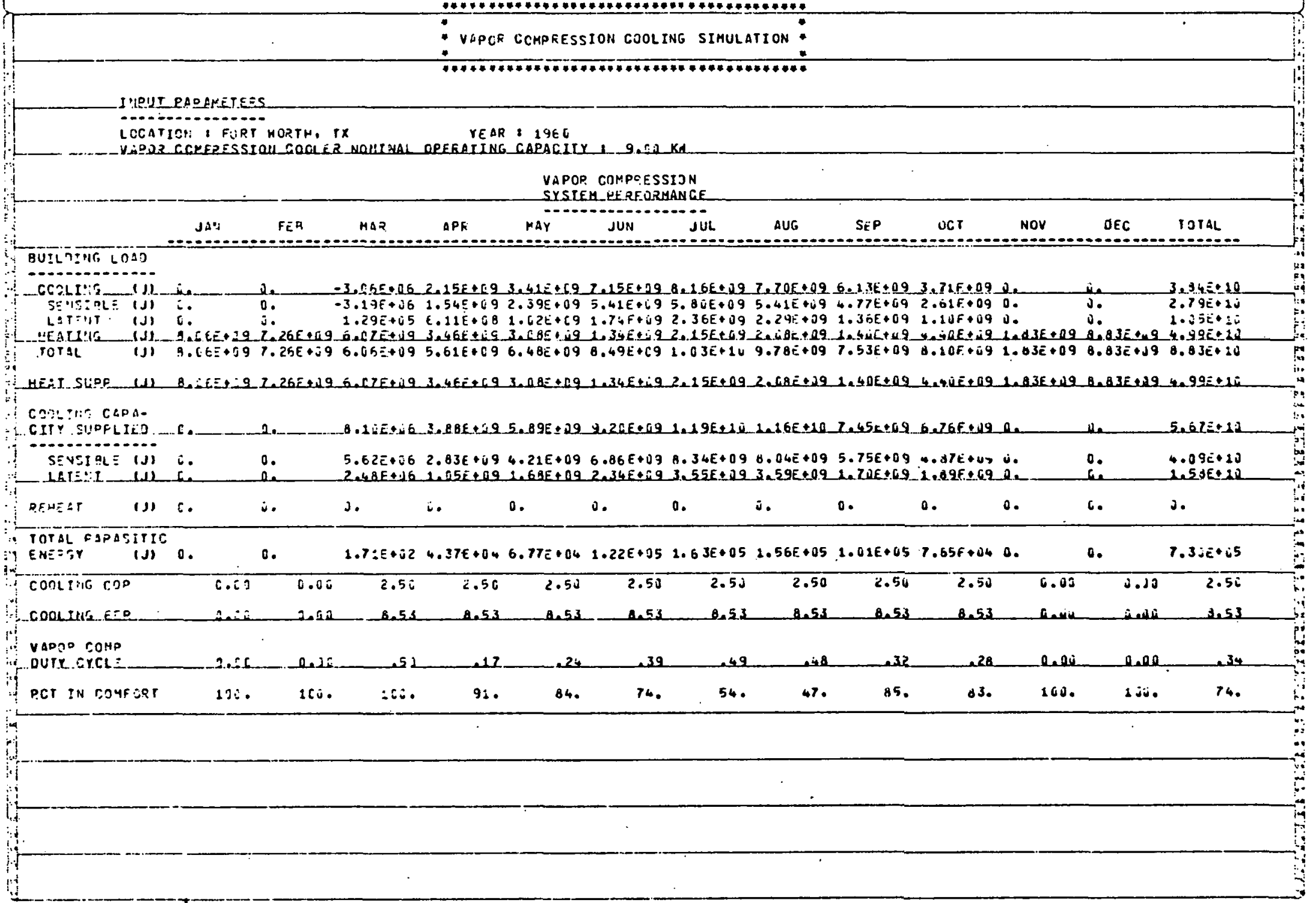


Table B-8

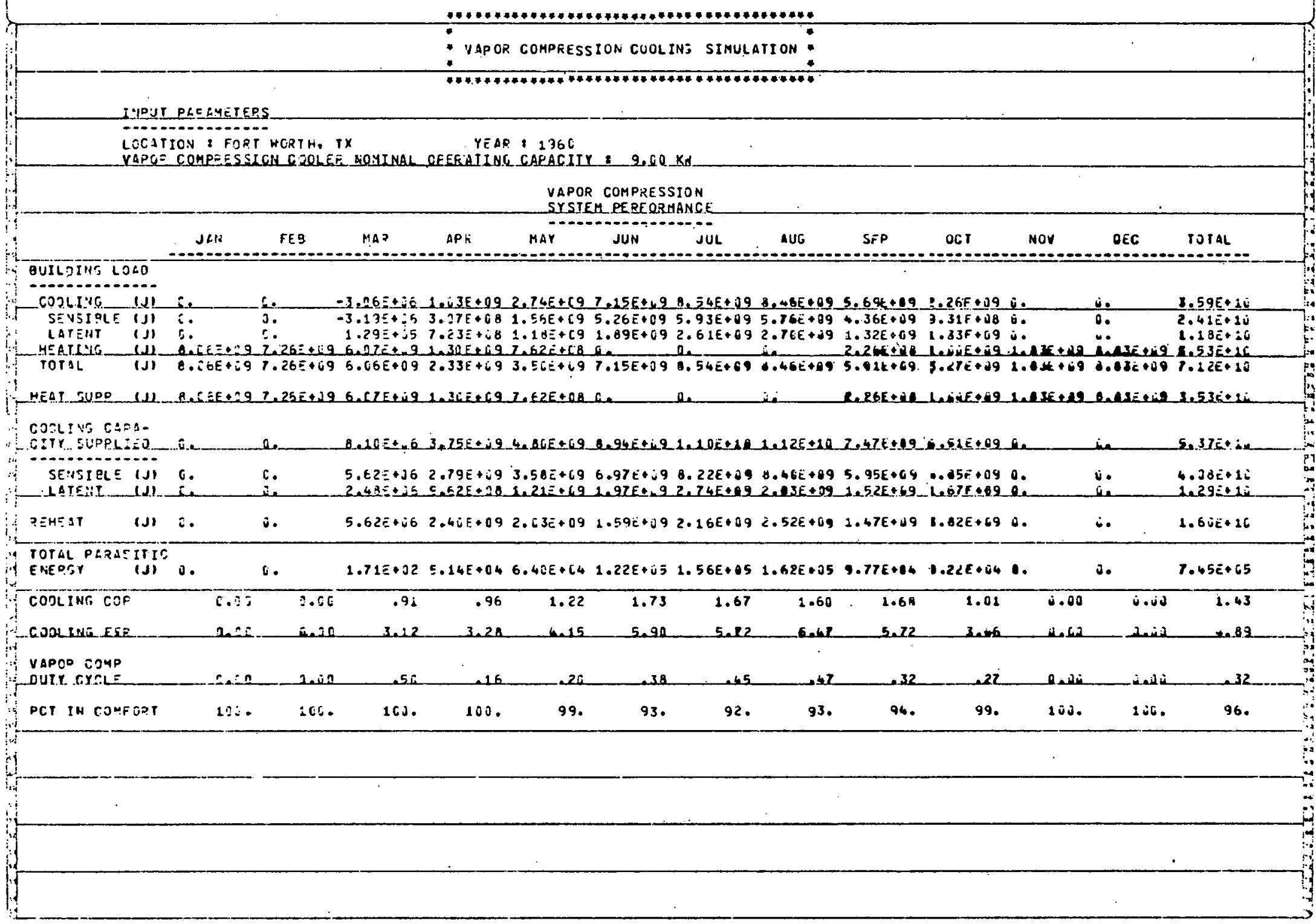




\section{Table B-9}

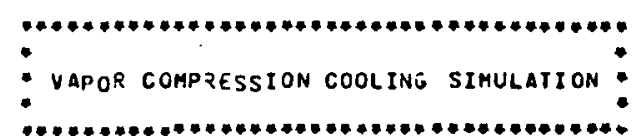

IHPUT PAFGMETERS

LOSATIOH: D DHOENIX, AT YTEAR 1962

VAPOE COMPRESSIOH COOLER NOHINAL OPERATING CAPACITY I 9. IJ KW

VAPOR COMPRESSIOM

SYSTEM PERFORMANCE

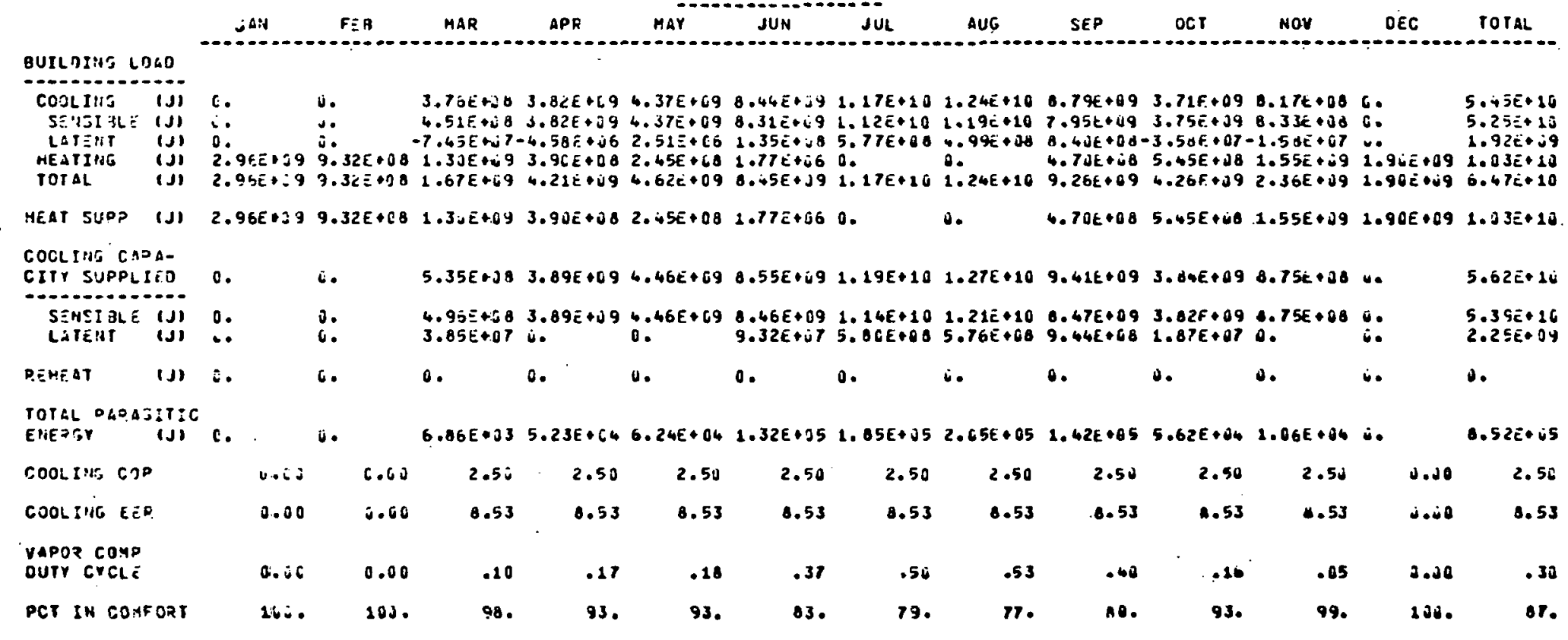


Table B-10

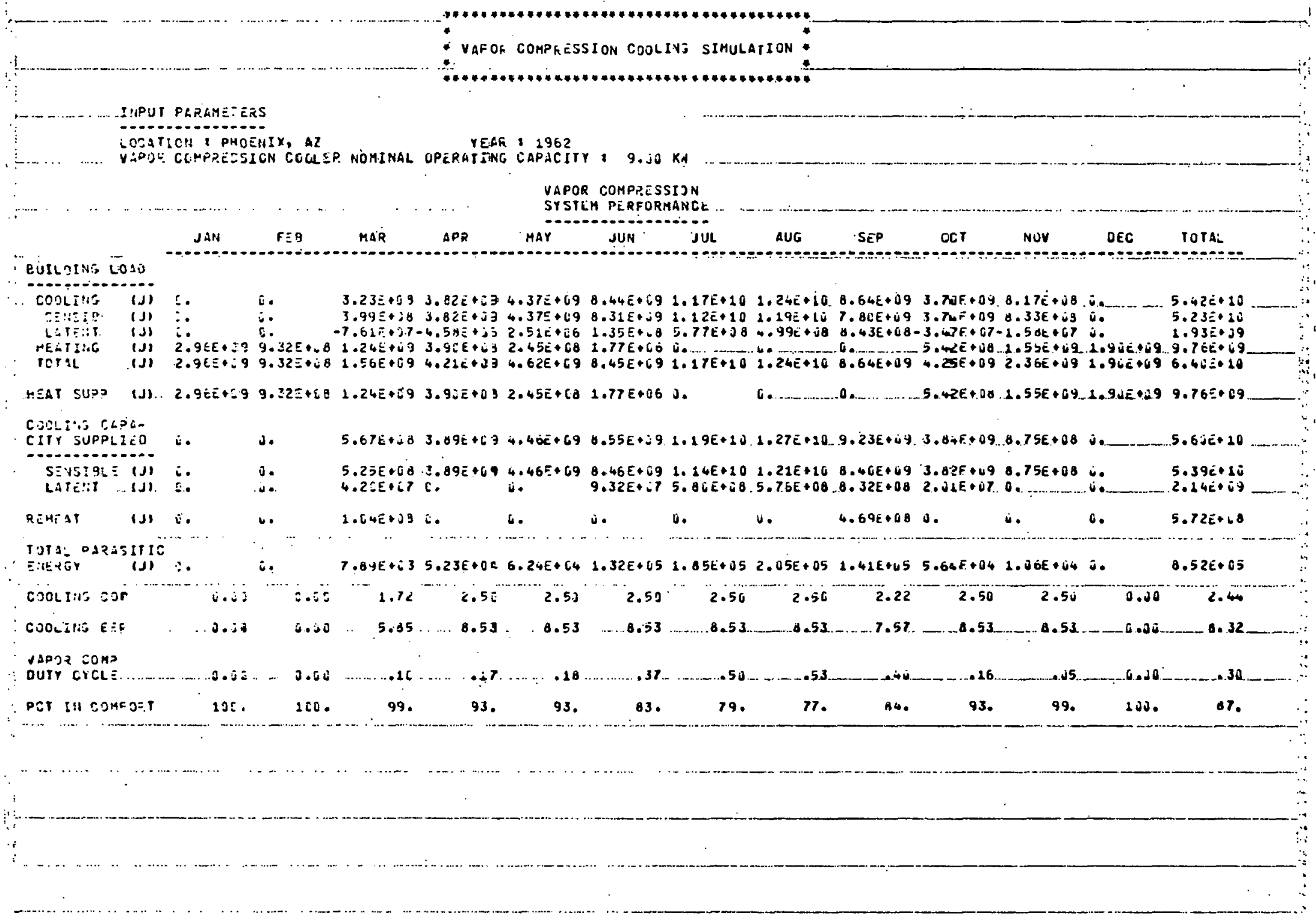


APPENDIX C

RESULTS OF COST/BENEFIT AKALYSIS

$$
c-1
$$




\section{SFRI}

$c-2$ 


\begin{tabular}{|c|c|c|c|c|c|c|c|}
\hline \multirow[b]{2}{*}{ Run 1} & \multirow[b]{2}{*}{$10 .^{a}$} & \multirow{2}{*}{$\begin{array}{c}\begin{array}{c}\text { Desiccant } \\
\text { Cooler Size }\end{array} \\
(\mathrm{kW})\end{array}$} & \multirow{2}{*}{$\begin{array}{l}\text { Collector } \\
\frac{\text { Area }}{\left(m^{2}\right)}\end{array}$} & \multicolumn{2}{|c|}{1985 Base Year } & \multicolumn{2}{|c|}{1990 Base Year } \\
\hline & & & & $\$ 107.65 / \mathrm{m}^{2}$ & $\$ 215.30 / \mathrm{m}^{2}$ & $\$ 107.65 / \mathrm{m}^{2}$ & $\$ 215.30 / \mathrm{m}^{2}$ \\
\hline WASH & 2 & 9.0 & 35 & 1.03 & 1.41 & 0.78 & 1.01 \\
\hline WASH & 4 & 4.5 & 35 & 0.95 & 1.33 & 0.73 & 0.96 \\
\hline WASH & 6 & 2.3 & 35 & 0.93 & 1.31 & 0.72 & 0.96 \\
\hline WASH & 8 & 9.0 & 50 & 1.13 & 1.67 & 0.81 & 1.14 \\
\hline WASH & 10 & 4.5 & 50 & 1.05 & 1.59 & 0.77 & 1.10 \\
\hline WASH & 12 & 2.3 & 50 & 1.03 & 1.57 & 0.76 & 1.09 \\
\hline WASH & 13 & 9.0 & 20 & 0.98 & 1.20 & 0.79 & 0.92 \\
\hline WASH & 14 & 4.5 & 20 & 0.88 & 1.10 & 0.73 & 0.86 \\
\hline WASH & 15 & 2.3 & 20 & 0.85 & 1.07 & 0.71 & 0.85 \\
\hline WASH & 16 & 9.0 & 42 & 1.08 & 1.53 & 0.79 & 1.07 \\
\hline WASH & 17 & 4.5 & 42 & 1.00 & 1.46 & 0.75 & 1.03 \\
\hline WASH & 18 & 2.3 & 42 & 0.98 & 1.43 & 0.74 & 1.02 \\
\hline WASH & 19 & 9.0 & 42 & 1.08 & 1.54 & 0.80 & 1.08 \\
\hline WASH & 20 & 9.0 & 20 & 1.01 & 1.22 & 0.82 & 0.95 \\
\hline WASH & 21 & 9.0 & 35 & 1.06 & 1.43 & 0.80 & 1.03 \\
\hline WASH & 22 & 9.0 & 50 & 1.13 & 1.67 & 0.81 & 1.14 \\
\hline WASH & 23 & 9.0 & 10 & 1.01 & 1.12 & 0.86 & 0.93 \\
\hline WASH & 24 & 4.5 & 10 & 0.89 & 1.00 & 0.78 & 0.85 \\
\hline WASH & 25 & 4.5 & 35 & 0.94 & 1.32 & 0.73 & 0.96 \\
\hline WASH & 26 & 4.5 & 50 & 1.05 & 1.59 & 0.77 & 1.10 \\
\hline WASH & 27 & 2.3 & 10 & 0.85 & 0.96 & 0.75 & 0.82 \\
\hline WASH & 28 & 2.3 & 35 & 0.93 & 1.31 & 0.73 & 0.96 \\
\hline WASH & 29 & 2.3 & 50 & 1.04 & 1.58 & 0.77 & 1.10 \\
\hline DODG & 1 & 9.0 & 35 & 1.54 & 2.28 & 1.10 & 1.57 \\
\hline DODG & 2 & 4.5 & 35. & 1.32 & 2.06 & 0.95 & 1.42 \\
\hline DODG & 3 & 4.5 & 35 & 1.62 & 2.37 & 1.22 & 1.69 \\
\hline DODG & 4 & 2.3 & 35 & 1.21 & 1.95 & 0.87 & 1.34 \\
\hline DODG & 5 & 2.3 & 35 & 1.58 & 2.33 & 1.21 & 1.68 \\
\hline DODG & 6 & 9.0 & 20 & 1.27 & 1.70 & 0.95 & 1.22 \\
\hline DODG & 7 & 4.5 & 20 & 1.07 & 1.49 & 0.81 & 1.08 \\
\hline DODG & 8 & 2.3 & 20 & 0.97 & 1.39 & 0.75 & 1.02 \\
\hline DODG & 9 & 9.0 & 42 & 1.64 & 2.53 & 1.14 & 1.70 \\
\hline DODG & 10 & 4.5 & 42 & 1.43 & 2.32 & 1.00 & 1.57 \\
\hline DODG & 11 & 2.3 & 42 & 1.33 & 2.22 & 0.93 & 1.50 \\
\hline DODG & 12 & 4.5 & 35 & 1.59 & 2.33 & 1.18 & 1.65 \\
\hline CHAR & 8 & 9.0 & 50 & 1.10 & 1.66 & 0.77 & 1.11 \\
\hline CHAR & 11 & 4.5 & 35 & 0.90 & 1.29 & 0.66 & 0.91 \\
\hline CHAR & 13 & 13.5 & 50 & 1.25 & 1.82 & 0.88 & 1.23 \\
\hline CHAR & 14 & 4.5 & 35 & 0.89 & 1.28 & 0.66 & 0.90 \\
\hline FTWR & 3 & 4.5 & 35 & 1.17 & 1.66 & 0.88 & 1.19 \\
\hline FTWR & 5 & 2.3 & 35 & 1.13 & 1.62 & 0.87 & 1.17 \\
\hline FTWR & 6 & 4.5 & 35 & 1.16 & 1.65 & 0.87 & 1.18 \\
\hline PHNX & 2 & 9.0 & 35 & 1.56 & 2.08 & 1.21 & 1.54 \\
\hline PHNX & 4 & 4.5 & 35 & 1.50 & 2.02 & 1.21 & 1.53 \\
\hline PHNX & 7 & 4.5 & 35 & 1.51 & 2.02 & 1.21 & 1.54 \\
\hline
\end{tabular}

2Gee Tablo 3-17 far type of auxlliary cooling (1f any) used with each run. 
SER

$$
c-4
$$


APPENULX̃ D

SAMIPLE OUTPUT FROM ECONOMICS AKALYSIS COMPUTER PROGRAM 
D-2 


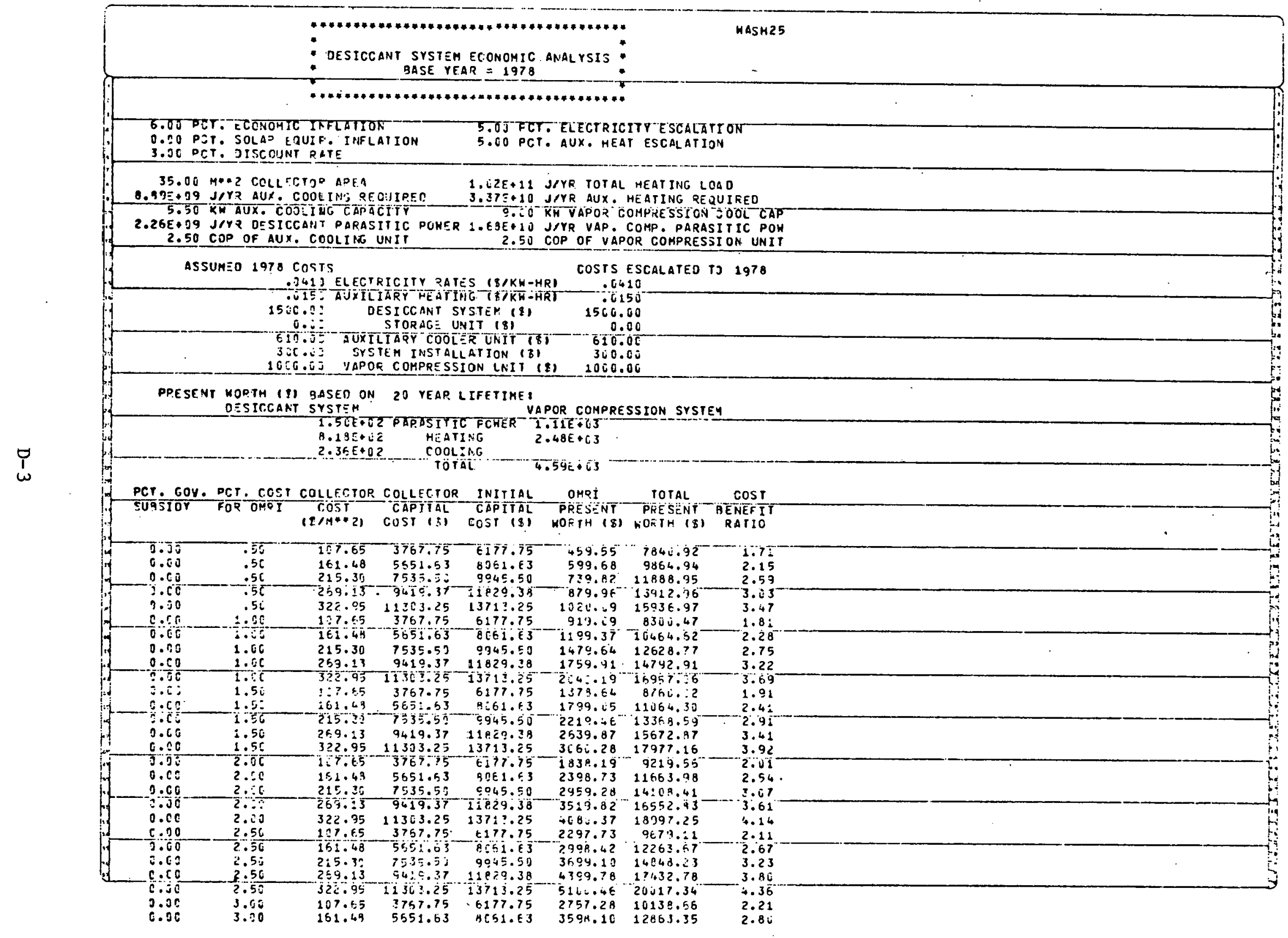




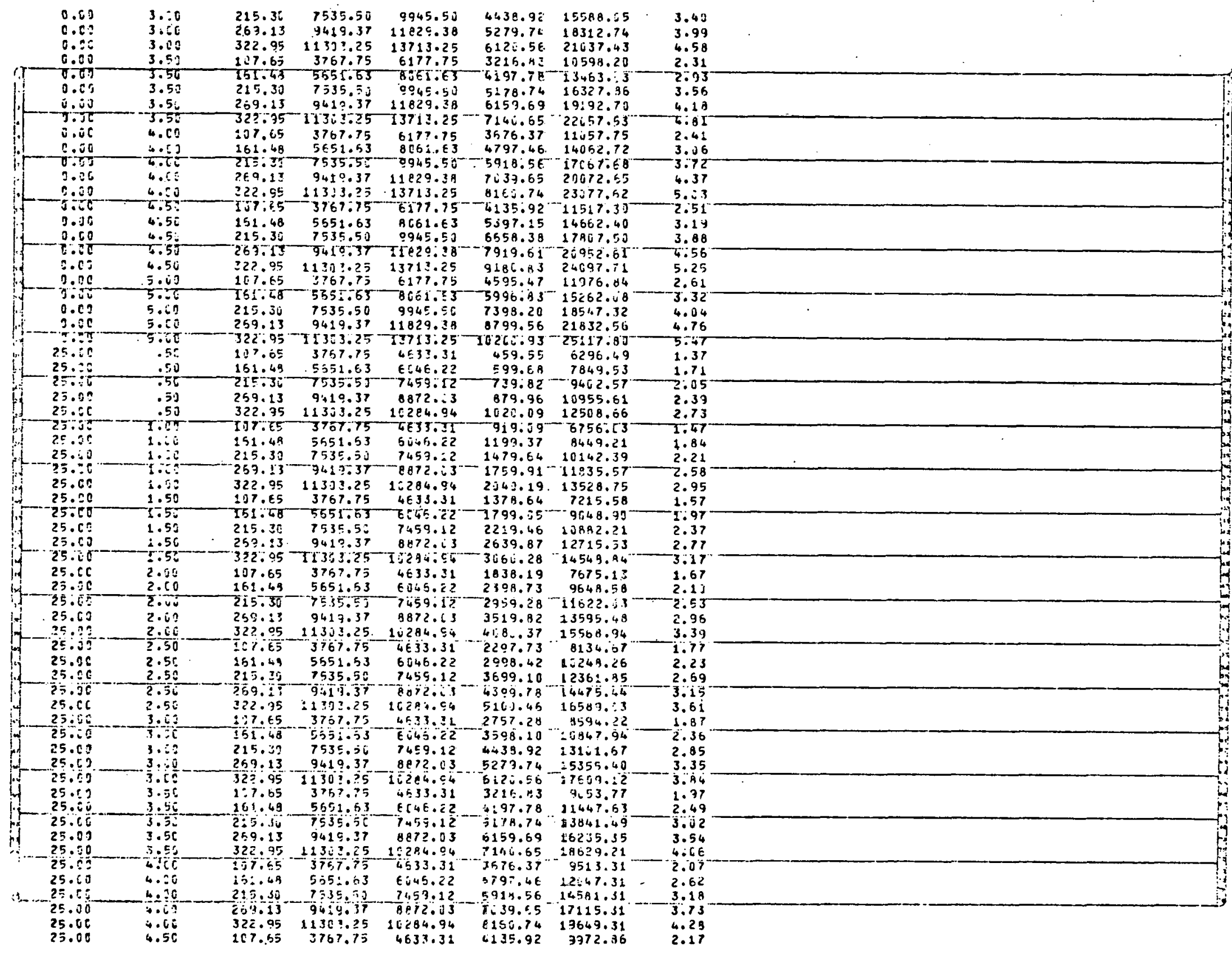




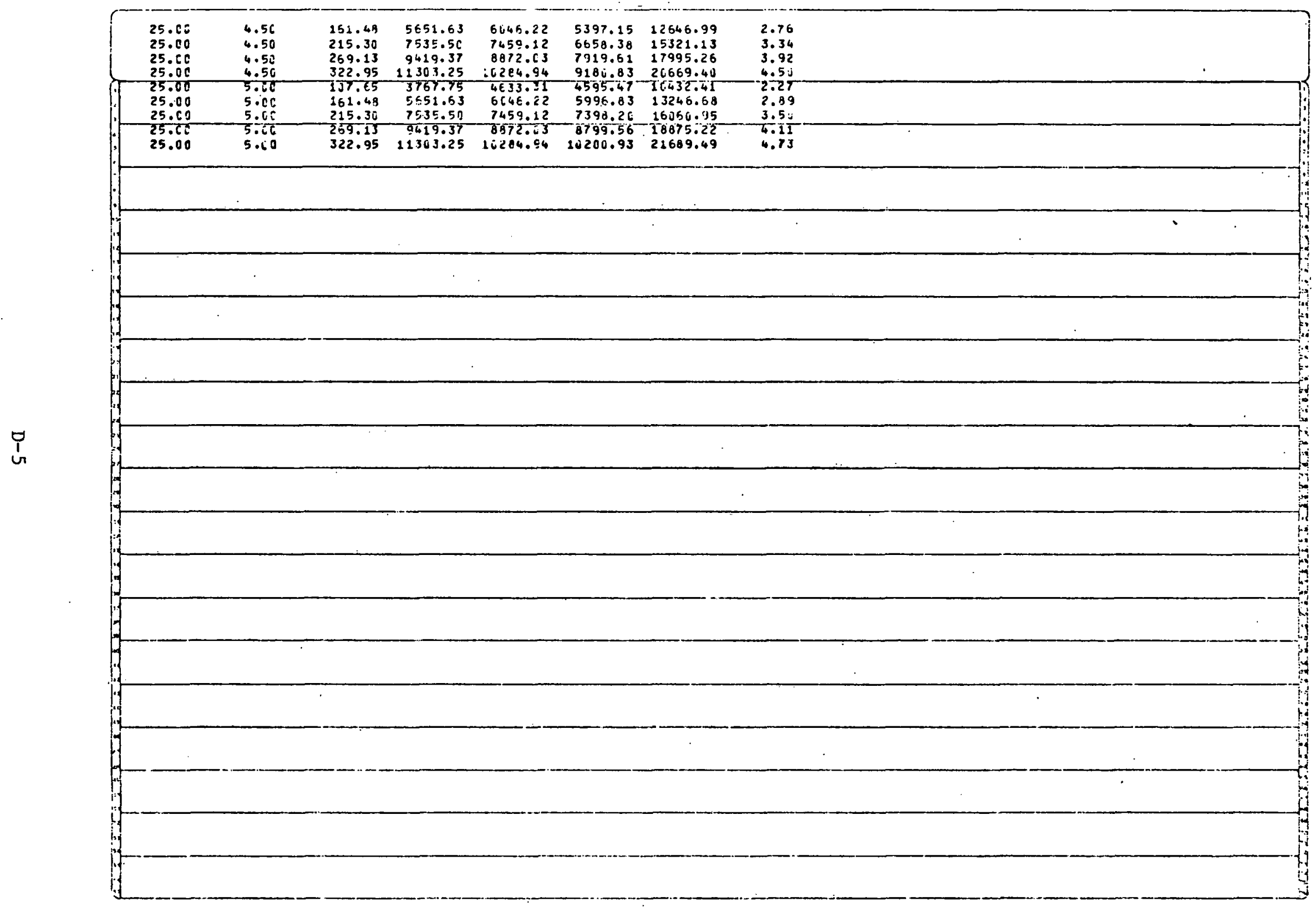




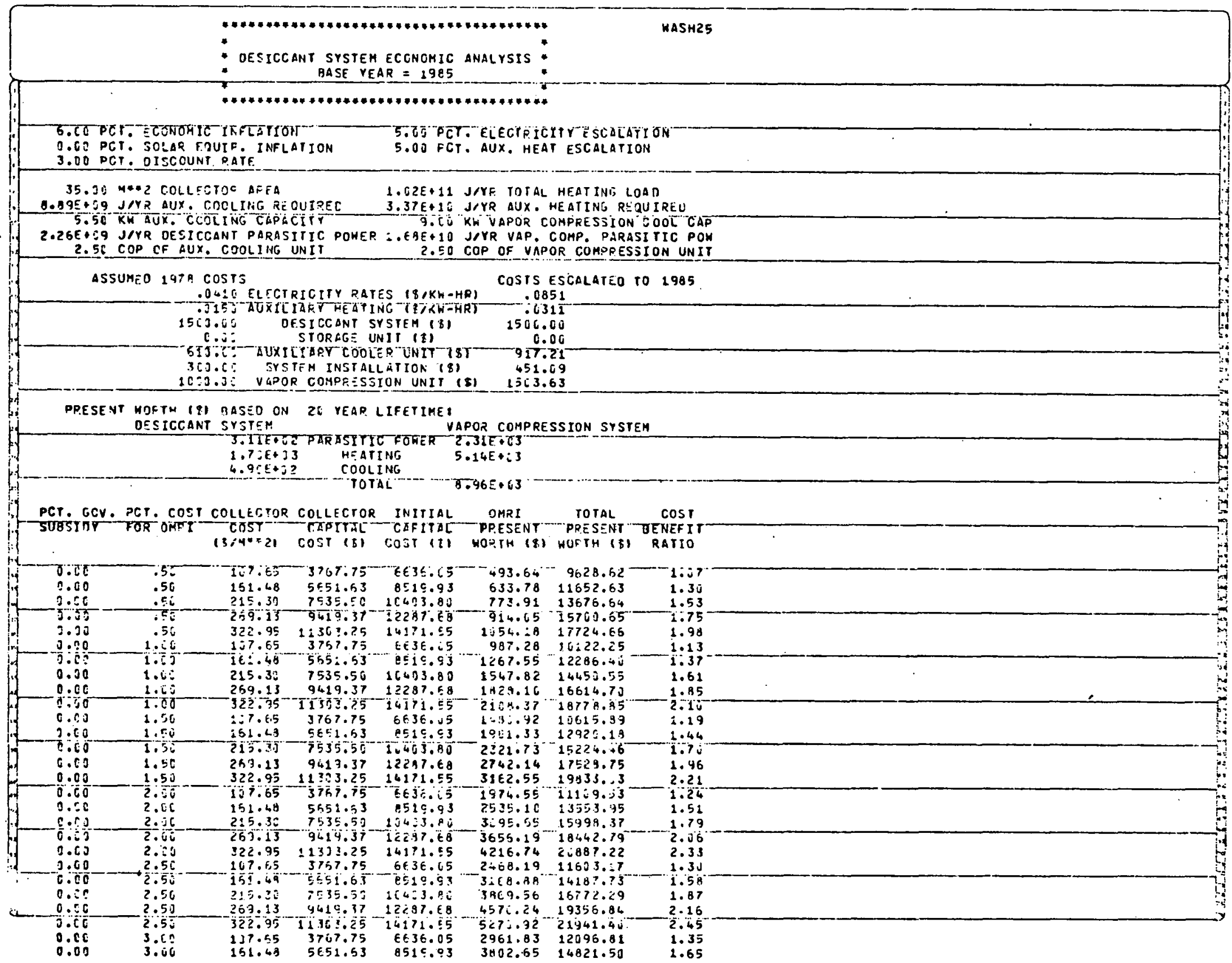




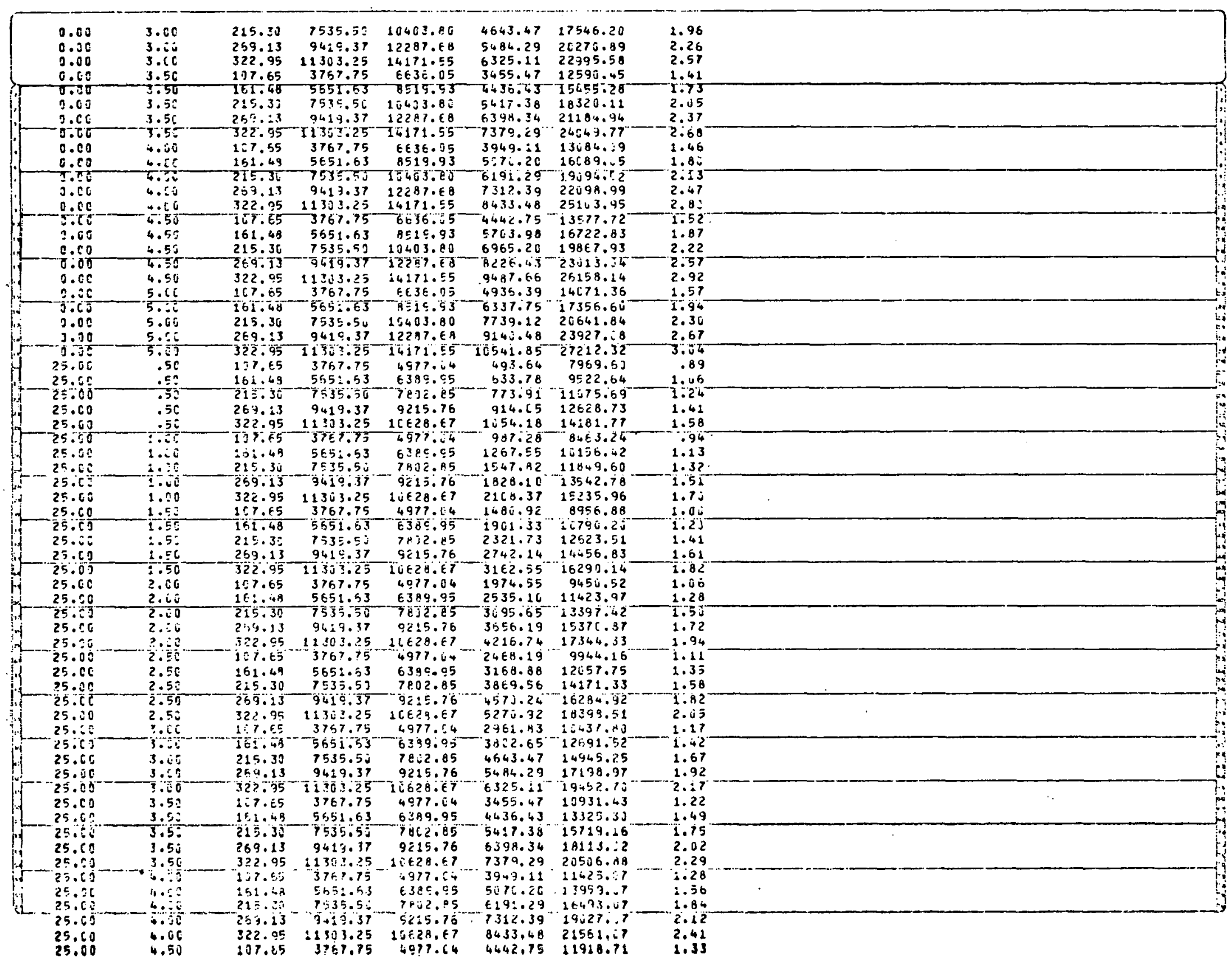




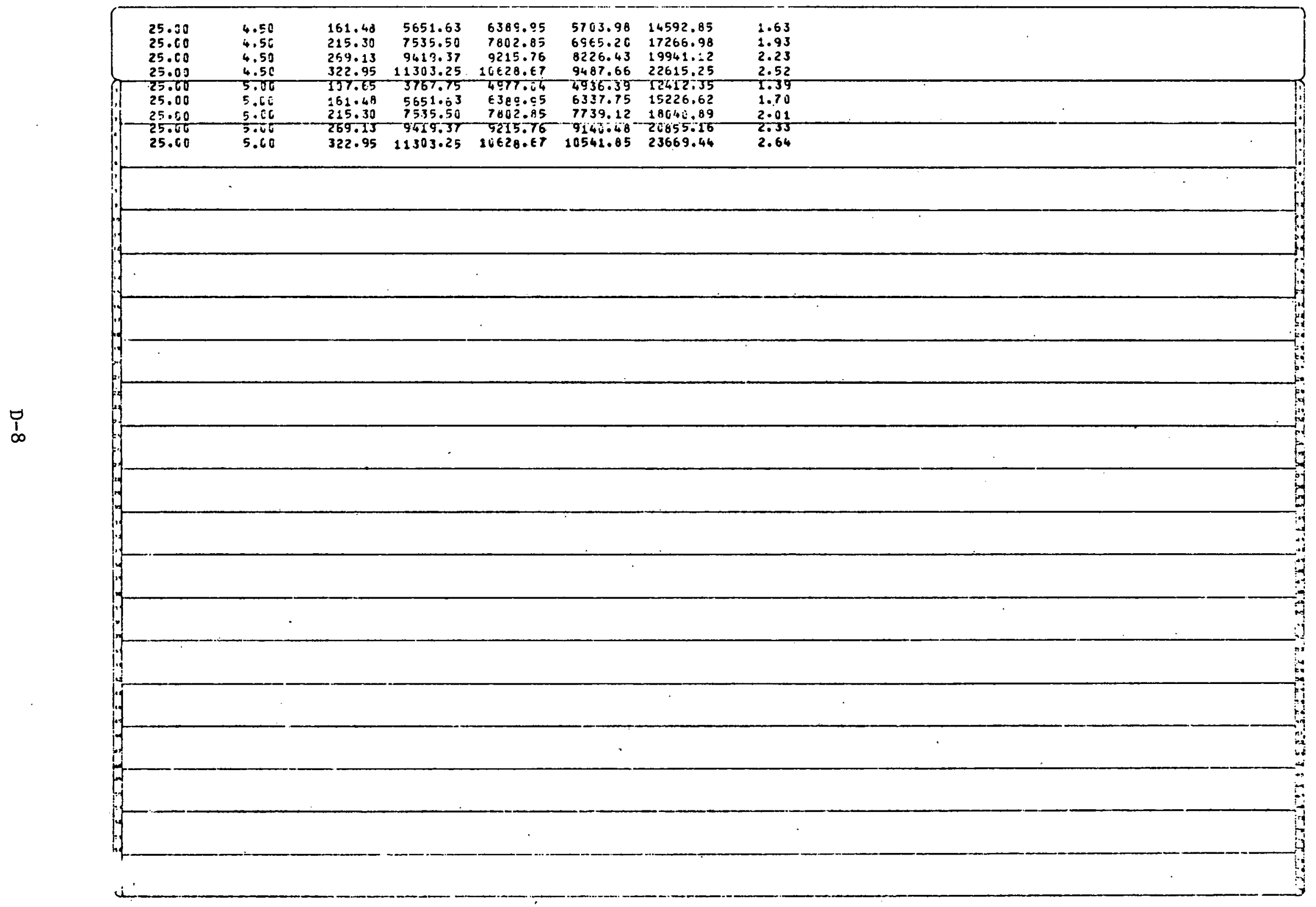




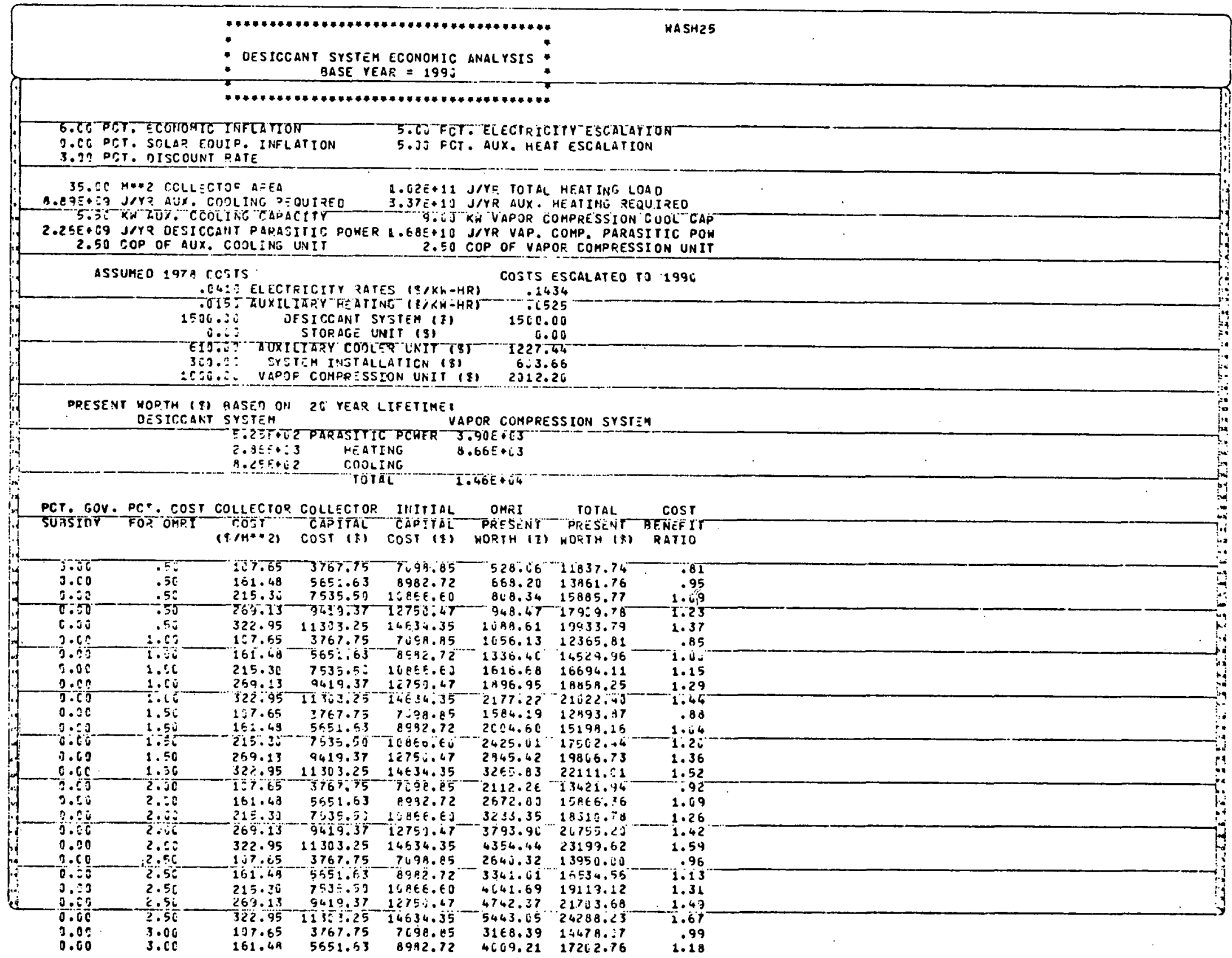




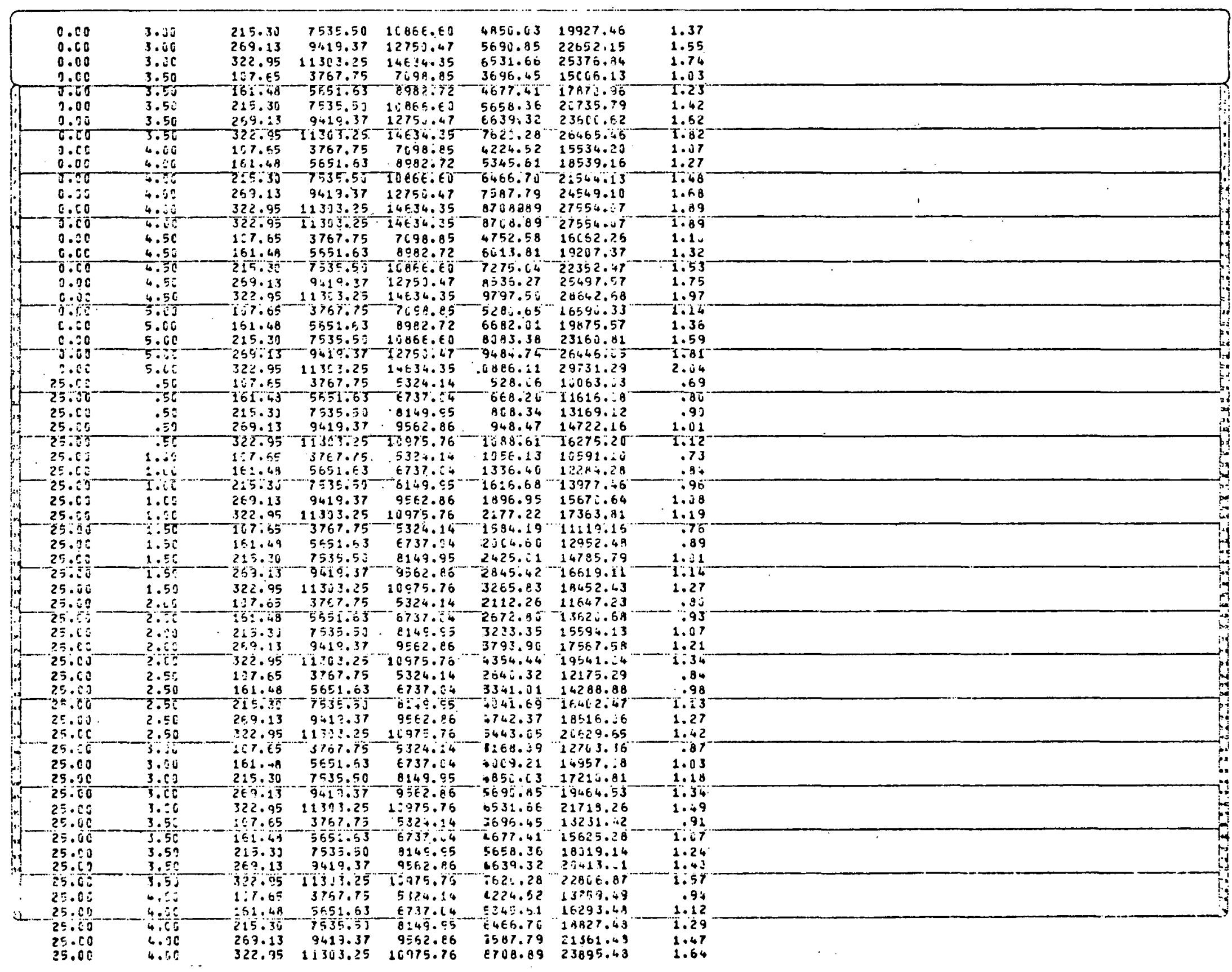




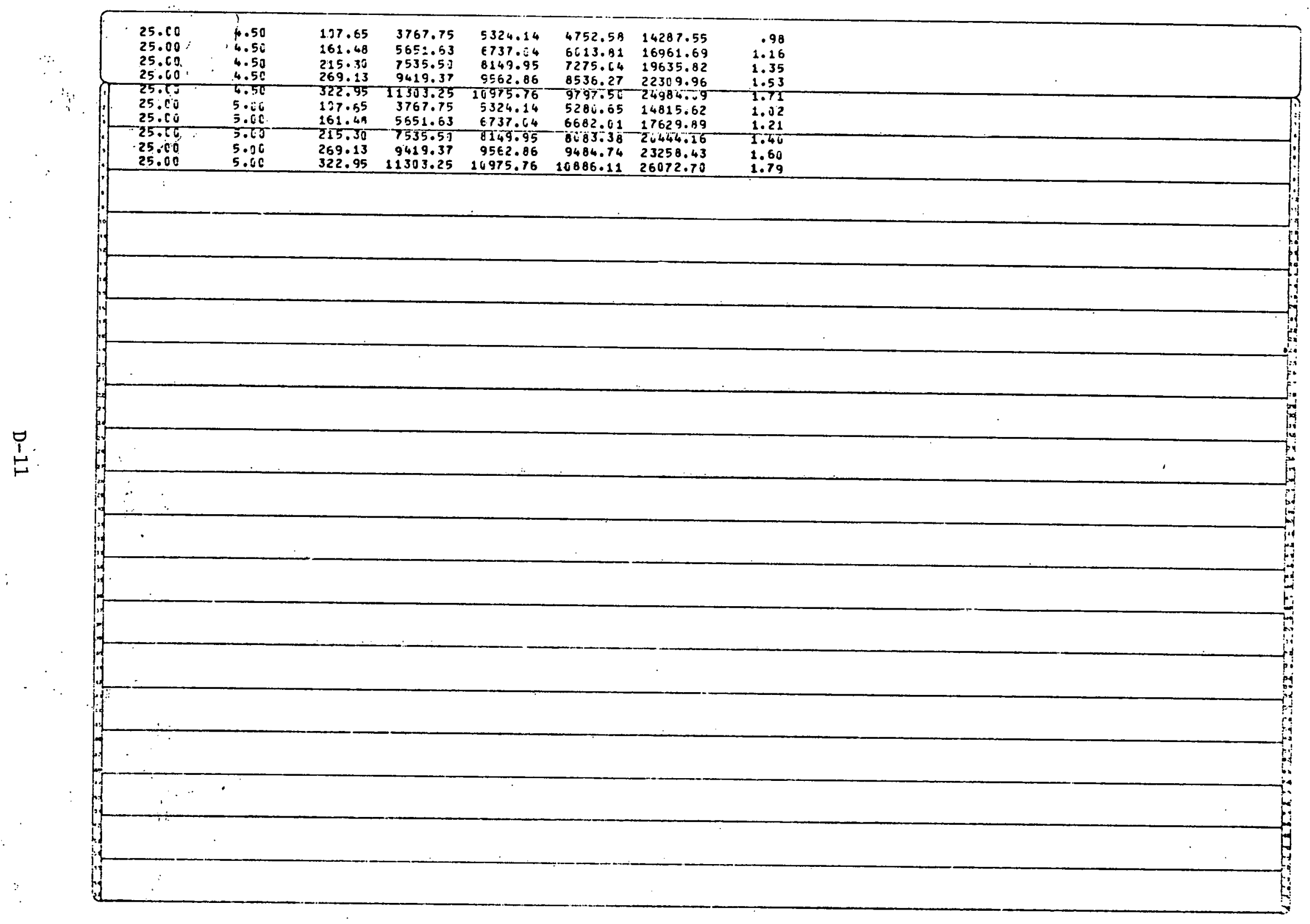




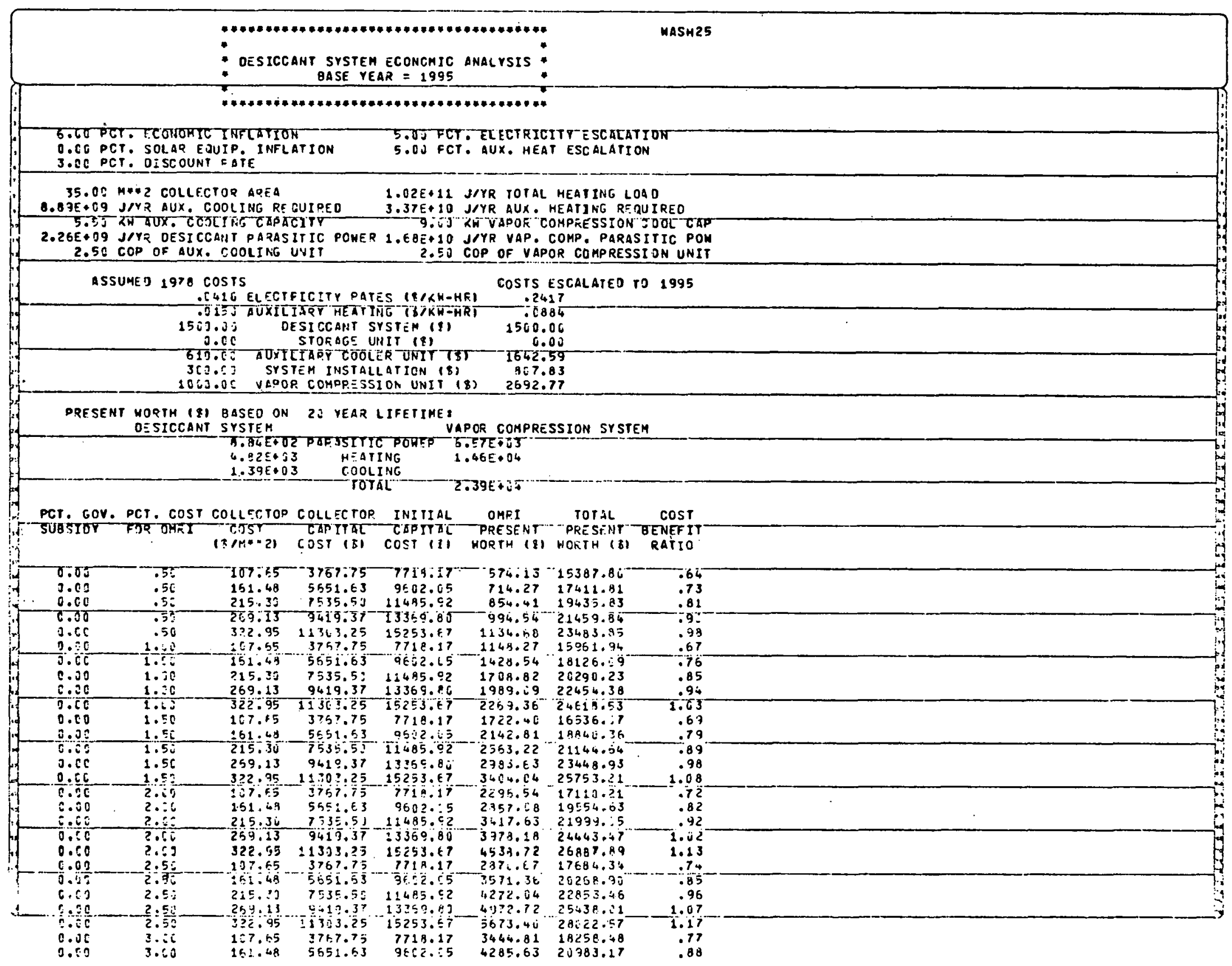




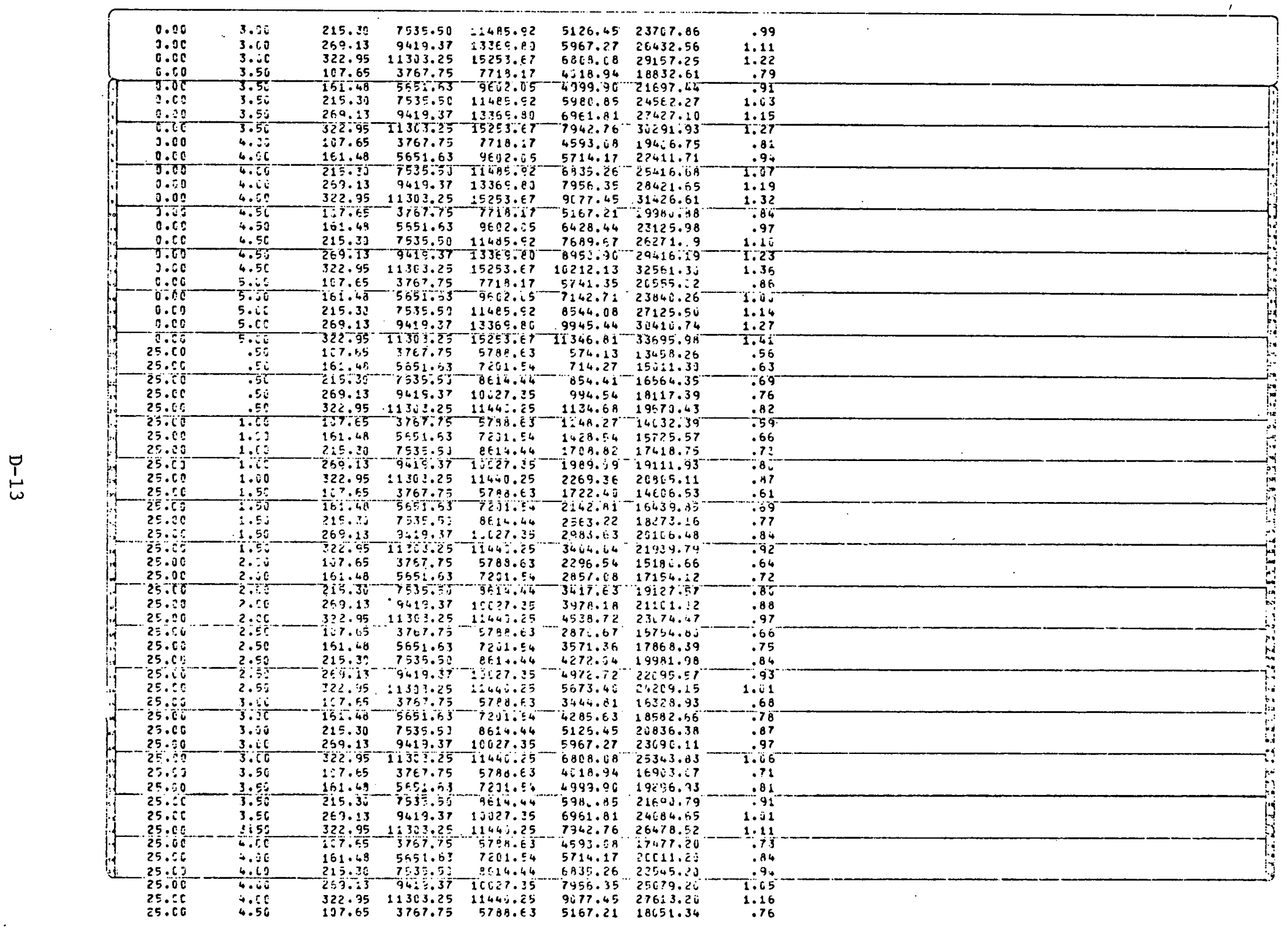




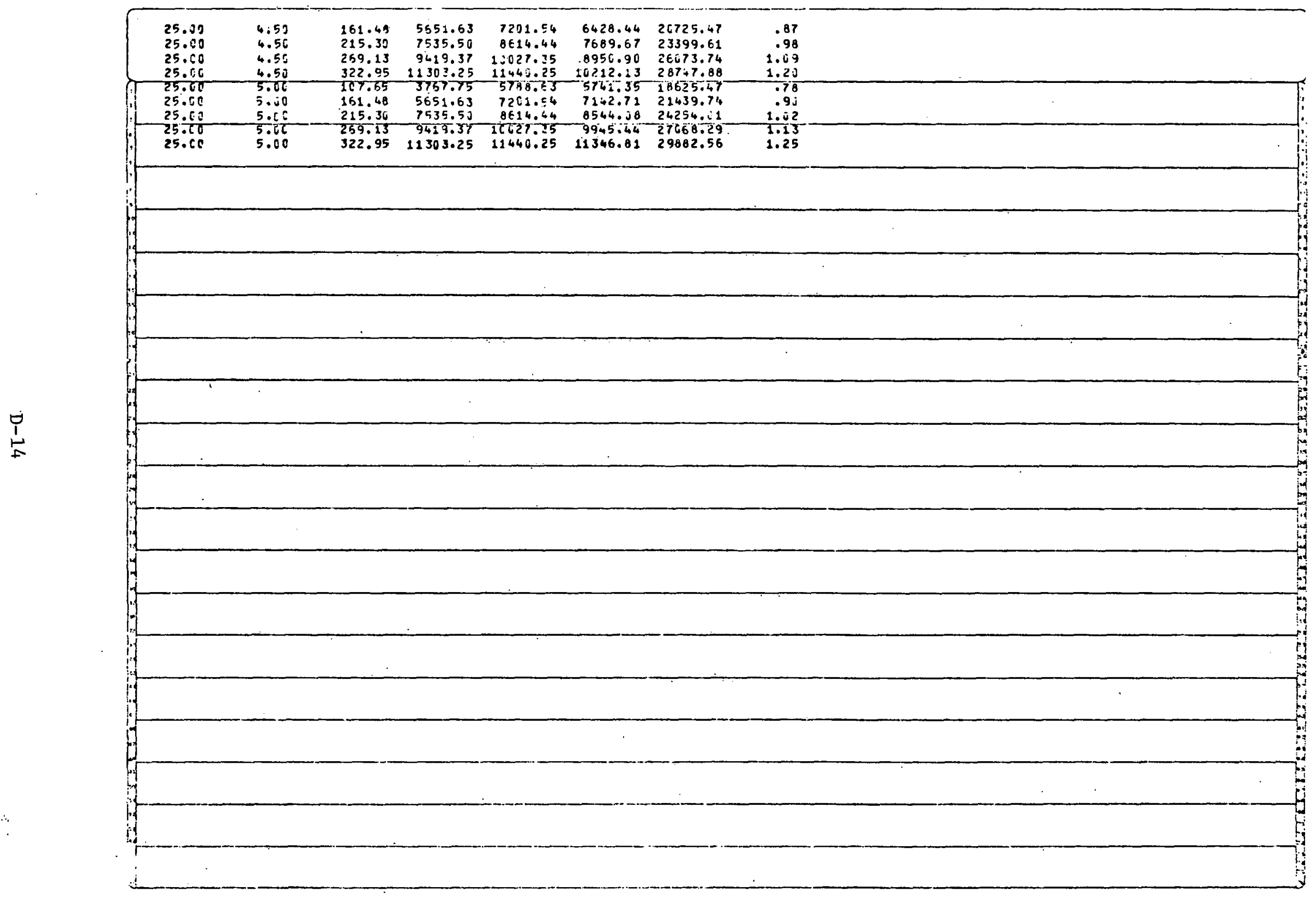




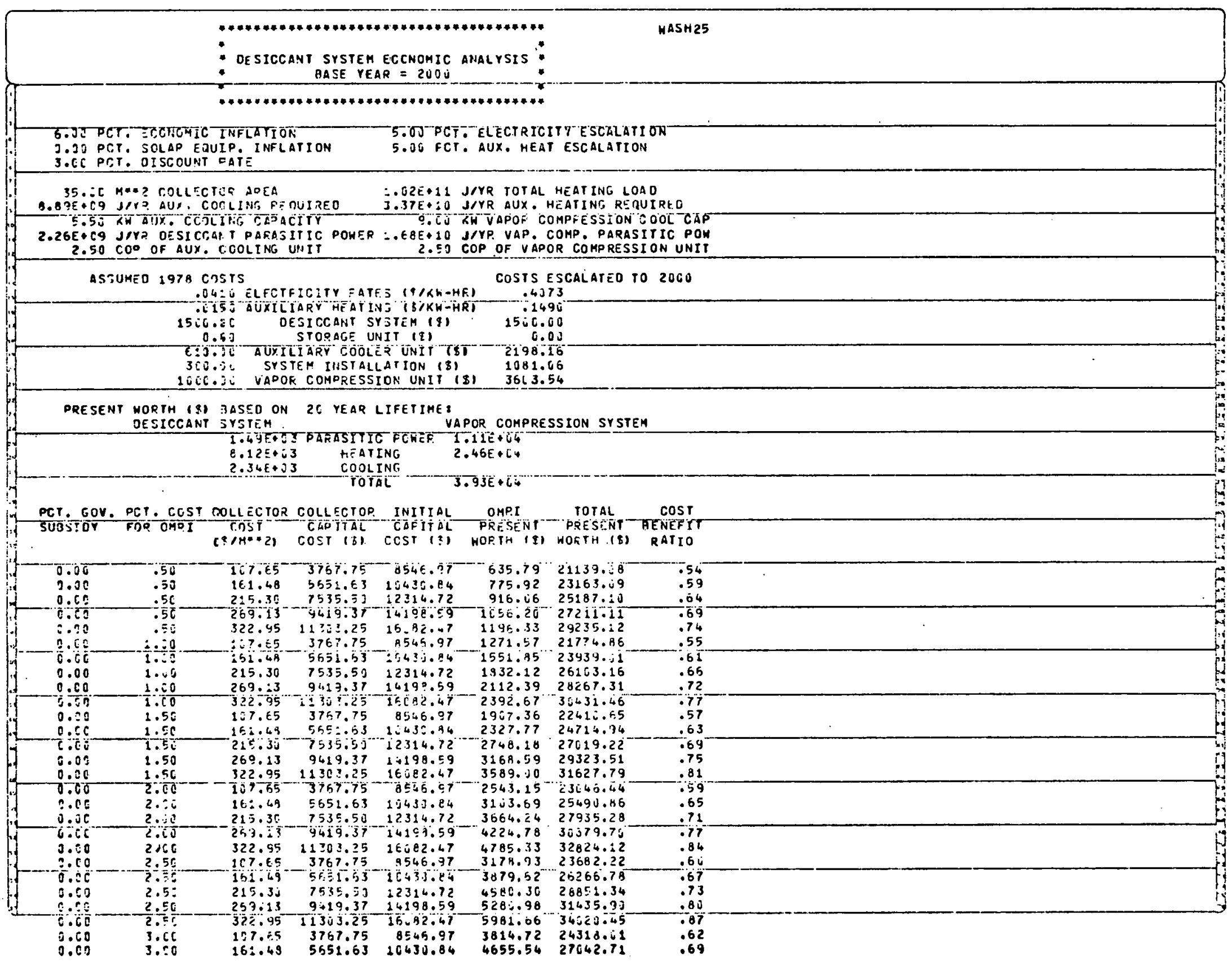




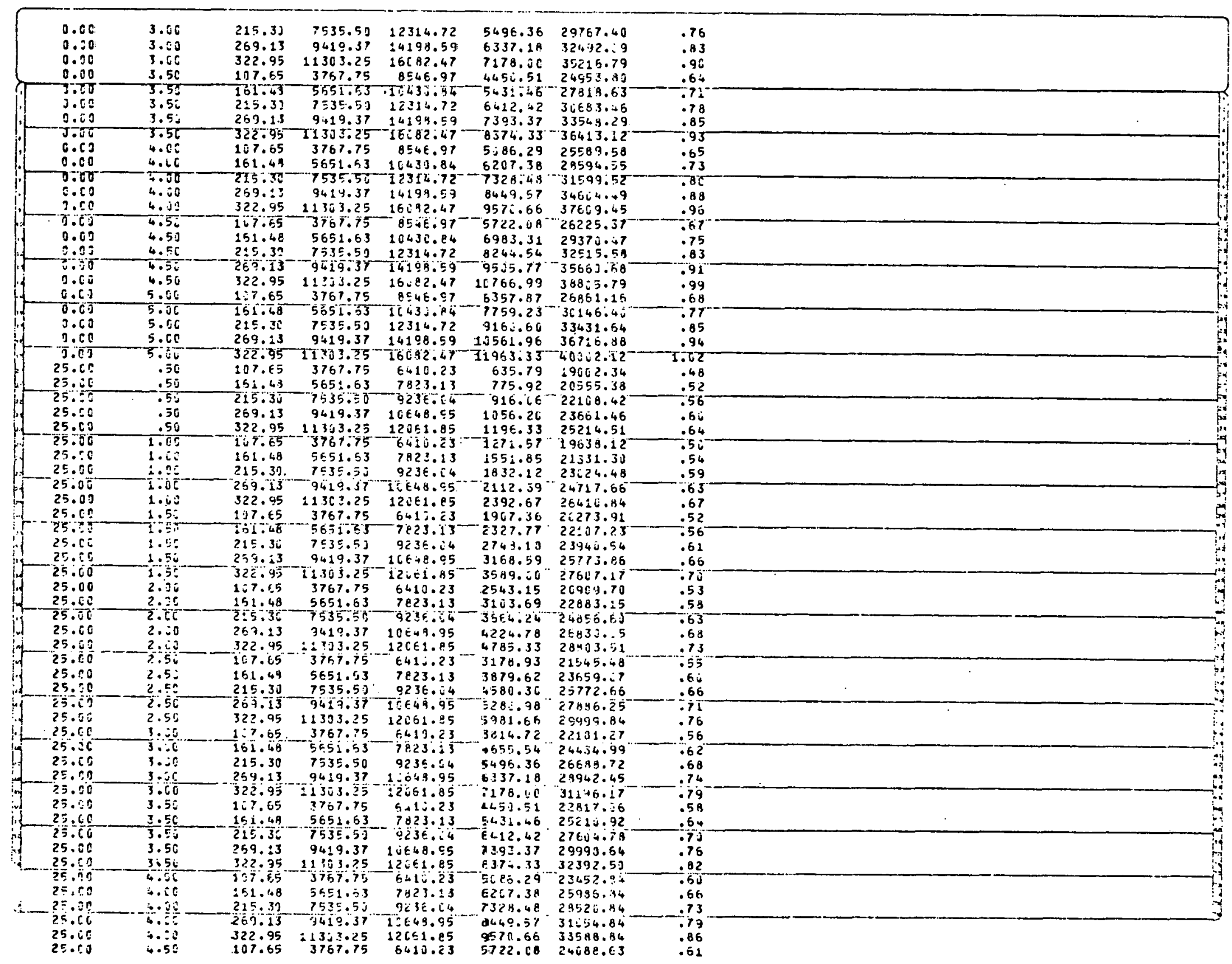




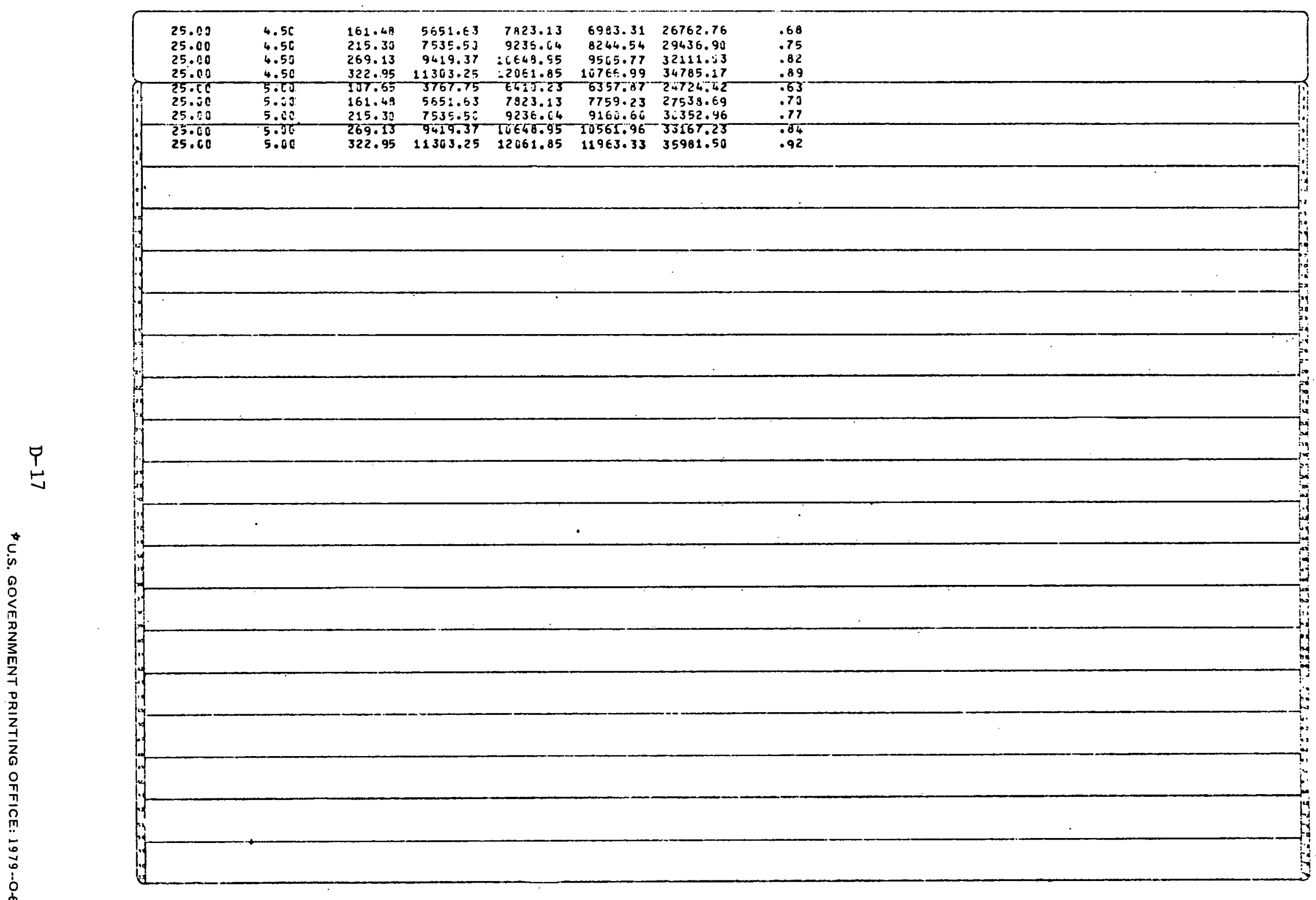

